\title{
Review and Analysis of the 1980-1989 Biomass Thermochemical Conversion Program
}

Don J. Stevens

Cascade Research, Inc.

National Renewable Energy Laboratory

1617 Cole Boulevard

Golden, Colorado 80401-3393

A national laboratory of the U.S. Department of Energy Managed by Midwest Research Institute

for the U.S. Department of Energy

Under Contract No. DE-AC36-83CH10093

Prepared under Subcontract Number AAE-3-13209-01

September 1994 
This publication was reproduced from the best available camera-ready copy submitted by the subcontractor and received no editorial review at NREL.

\section{NOTICE}

This report was prepared as an account of work sponsored by an agency of the United States government. Neither the United States government nor any agency thereof, nor any of their employees, makes any warranty, express or implied, or assumes any legal liability or responsibility for the accuracy, completeness, or usefulness of any information, apparatus, product, or process disclosed, or represents that its use would not infringe privately owned rights. Reference herein to any specific commercial product, process, or service by trade name, trademark, manufacturer, or otherwise does not necessarily constitute or imply its endorsement, recommendation, or favoring by the United States government or any agency thereof. The views and opinions of authors expressed herein do not necessarily state or reflect those of the United States government or any agency thereof.

Available to DOE and DOE contractors from:

Office of Scientific and Technical Information (OSTI)

P.O. Box 62

Oak Ridge, TN 37831

Prices available by calling (615) 576-8401

Available to the public from:

National Technical Information Service (NTIS)

U.S. Department of Commerce

5285 Port Royal Road

Springfield, VA 22161

(703) $487-4650$ 


\section{DISCLAIMER}

Portions of this document may be illegible in electronic image products. Images are produced from the best available original document. 


\section{ACKNOWLEDGEMENTS}

The author would like to acknowledge the significant contributions of Gary Schiefelbein at Battelle Pacific Northwest Laboratory who provided leadership for the Biomass Thermochemical Conversion Program through the 1980's. His assistance in preparing this document is sincerely appreciated. The help and assistance of Tom Milne at National Renewable Energy Laboratory in preparing and reviewing this document and the support of Ralph Overend is also gratefully acknowledged. 


\section{CONTENTS}

1.0 INTRODUCTION $\ldots \ldots \ldots \ldots \ldots \ldots \ldots \ldots \ldots \ldots \ldots$

1.1 OBJECTIVE AND SCOPE OF ANALYSIS PROJECT $\ldots \ldots \ldots \ldots 1$

1.2 BIOMASS AS AN ENERGY RESOURCE . . . . . . . . . 1

1.3 ORIGINS OF THE BIOMASS THERMOCHEMICAL

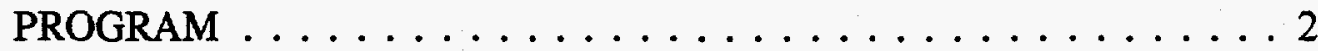

1.4 PROGRAM OBJECTIVE AND APPROACH $\ldots \ldots \ldots \ldots \ldots \ldots 3$

1.5 PROGRAM RATIONALE $\ldots \ldots \ldots \ldots \ldots \ldots \ldots$

1.6 PROGRAM HISTORY $\ldots \ldots \ldots \ldots \ldots \ldots \ldots \ldots \ldots$

1.7 PROGRAM PUBLICATIONS $\ldots \ldots \ldots \ldots \ldots \ldots$

1.8 RELATED BIOENERGY PROGRAMS $\ldots \ldots \ldots \ldots \ldots \ldots$

1.8.1 Other DOE-sponsored Programs . . . . . . . . . . 8

1.8.2 Other Federal Government Programs . . . . . . . . 10

1.8.3 State and Private Sector Programs . . . . . . . . . . 11

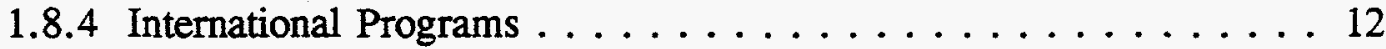

1.9 REFERENCES . . . . . . . . . . . . . 13

2.0 GASIFICATION RESEARCH $\ldots \ldots \ldots \ldots \ldots \ldots \ldots$

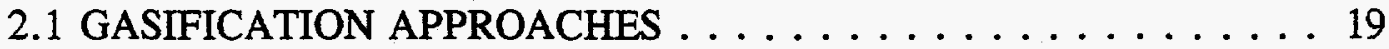

2.1.1 Low-Energy (Air-Blown) Gasification . . . . . . . . . 20

2.1.2 Medium-Energy Gasification . . . . . . . . . 20

2.1 .3 Gasifier Types . . . . . . . . . . . . . 21

2.2 GASIFICATION RESEARCH EMPHASIS . . . . . . . . 21

2.3 MEDIUM-ENERGY GASIFICATION RESEARCH $\ldots \ldots \ldots \ldots 22$

2.3.1 Larger Scale Medium Energy Biomass Gasifier Projects . . . 24

2.3.1.1 Circulating, Fluidized Bed Gasifier - Battelle Columbus Laboratory (BCL) . . . . . . . . . . . . 24

2.3.1.2 Fluidized Bed Gasifier with Internal Heat Exchangers University of Missouri-Rolla . . . . . 30

2.3.1.3 Pressurized Fluidized-Bed, Oxygen-Blown Gasifier Institute of Gas Technology (IGT) . . . . . . . . . 34

2.3.1.4 Down-Draft Oxygen-Blown Gasifier - National Renewable Energy Laboratory and SynGas Inc. . . . 39

2.3.2 Additional Indirectly-Heated, Medium-Energy

Gasification Projects . . . . . . . . . . . . . . . 43

2.3.2.1 Pulsed, Fluidized Bed Gasification - MTCI, Inc. . . 44

2.3.2.2 Ceramic Fire Tubes for Fluidized-Bed Gasifiers University of Nebraska . . . . . . . . . . . . 46

2.3.2.3 Pressurized Rotary Kiln Gasifier - Wright-Malta Corporation . . . . . . . . . . . . . 4 47 
2.3.2.4 Pyrolytic Gasification of Wastes - Garrett Energy Research and Engineering Co. (GERE) . . . . . . 50

2.3.3 Additional Oxygen-Blown, Medium-Energy Gasification Projects . . . . . . . . . . . . . . . . . 50

2.3.3.1 Oxygen-Blown Gasification Research - Texas Tech University . . . . . . . . . . . . . . . 51

2.3.3.2 Pressurized, Fixed-Bed Oxygen-Blown Gasification - NREL . . . . . . . . . . . 52

2.3.4 Alternative Medium-Energy Gasification Approaches . . . . 54

2.3.4.1 Gasification of High-Moisture Biomass Feedstocks - Pacific Northwest Laboratory (PNL). . 54

2.3.5 Biomass Research Related to Coal Gasification . . . . . . . 56

2.3.5.1 Gasifying Wood with Coal and Sewage Sludge Dynecology, Inc. . . . . . . . . . . . . 57

2.3.5.2 Survey of Coal Gasification Technologies Gorham International . . . . . . . . . . . . . . 58

2.4 LOW-ENERGY AIR-BLOWN BIOMASS GASIFICATION PROJECTS

2.4.1 Data Collection with Low-Energy Gasifiers . . . . . . . . 60

2.4.1.1 Coors Gasifier - University of Missouri Rolla . . . . 60

2.4.1.2 Data Collection on Gasifier Configurations Environmental Energy Engineering (EEE), Inc. . . 61

2.4.2 Use of Low-Energy Gases in Engines . . . . . . . . . . . . 63

2.4.2.1 Research on Gasifier/Engine Systems Cal Recovery Systems . . . . . . . . . . . . . . 63

2.4.2.2 Enhancement of Engine Performance University of Florida . . . . . . . . . . . . . 64

2.4.2.3 Field Testing of Small Gasifier Filter Systems Rocky Creek Gasogens, Inc. . . . . . . . . . . 65

2.5 ENVIRONMENTAL/END-USE ASPECTS OF BIOMASS GASIFICATION . . . . . . . . . . . . . 66

2.5.1 End-Use Applications . . . . . . . . . . . . 67

2.5.1.1 Catalysts for Synthesis Gas in an Indirectly Heated Fluidized-Bed Gasifier - Pacific Northwest Laboratory (PNL) . . . . . . . . . . . 67

2.5.1.2 Improved Catalysts for Mixed Alcohol

Production - Lehigh University . . . . . . . 71

2.5.2 Environmental Aspects of Gasification . . . . . . . . 72

2.5.2.1 Treatment of Wastewaters from Biomass

Gasification - Pacific Northwest Laboratory . . . . 72

2.5.2.2 Waste Disposal via Gasification - Georgia Tech Research Institute (GTRI) . . . . . . . . . 74

2.6 SUMMARY AND RECOMMENDATIONS - GASIFICATION $\ldots 75$

2.6.1 Summary of Gasification Accomplishments . . . . . . 75

2.6 .2 Recommendations . . . . . . . . . . . 78 
3.0 PYROLYSIS AND LIQUEFACTION RESEARCH . . . . . . . . . . . 79

3.1 LIQUEFACTION APPROACHES . . . . . . . . . . . 79

3.1.1 Pyrolysis and Upgrading Approaches . . . . . . . . . 80

3.1.2 Basic Pyrolysis Research . . . . . . . . . . . 81

3.1.3 Other Pyrolysis Research . . . . . . . . . . . . . 81

3.2 PYROLYSIS/LIQUEFACTION RESEARCH EMPHASIS . . . . . . 81

3.3 RESEARCH ON BIOMASS LIQUEFACTION PROCESSES . . . . . 82

3.3.1 High Pressure Liquefaction Projects . . . . . . . . . . 83

3.3.1.1 Albany, Oregon, Liquefication Test Facility -

Wheelabrator Cleanfuel Co. . . . . . . . . . . 83

3.3.1.2 Extruder Reactor System - University of Arizona . . . 87

3.3.1.3 Aqueous Slurry Process - Lawrence Berkeley

Laboratory (LBL) . . . . . . . . . . . . . . 90 90

3.3.1.4 Alternate Catalysts for High Pressure

Liquefaction - SRI International . . . . . . . . 92

3.3.1.5 Direct Liquefaction Studies - Pacific Northwest

Laboratory $(P N L) \ldots \ldots \ldots \ldots$. . . . . . 93

3.3.2 Rapid Pyrolysis Processes . . . . . . . . . . . . . . . 95

3.3.2.1 Ablative Reactor System - NREL . . . . . . . . . 96

3.3.2.2 Entrained Rapid Pyrolysis Reactor System -

Georgia Tech Research Institute (GTRI) . . . . . . 100

3.4 RESEARCH TO UPGRADE BIOMASS CRUDE OILS . . . . . . . 102

3.4.1 Upgrading of Biocrude Using Zeolite Catalysts . . . . . . 103

3.4.1.1 Zeolite Upgrading of Biocrude to High Octane

Gasoline - NREL . . . . . . . . . . . 103

3.4.2 Upgrading Using Hydrotreating Catalysts . . . . . . . 107

3.4.2.1. Catalytic Hydrotreating of Biocrude Oil -

Pacific Northwest Laboratory (PNL) . . . . . . 107

3.5 BASIC PYROLYSIS RESEARCH . . . . . . . . . . 110

3.5.1 Use of a Molecular Beam/Mass Spectrometer

(MBMS) System . . . . . . . . . . . . . . . . . 111

3.5.1.1 Fundamental Pyrolysis Studies - NREL . . . . . 111

3.5.1.2 Rapid Characterization of Biomass and

Biomass Oils . . . . . . . . . . . . . 115

3.5.2 Other Basic Pyrolysis Studies . . . . . . . . . . . 116

3.5.2.1 Pyrolysis in Hydrogen and Methane Atmospheres -

Brookhaven National Laboratory (BNL) . . . . . 116

3.5.2.2 Effects of Pressure on Pyrolysis - Princeton

University/University of Hawaii . . . . . . . . 119

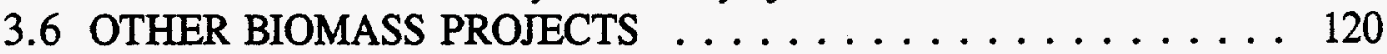

3.6.1 Other BTC Projects . . . . . . . . . . . . 120

3.6.1.1 Analysis and Comparison of Biomass

Pyrolysis/Gasification Condensates - Pacific

Northwest Laboratory (PNL) . . . . . . . . . . 120

3.6.1.2 Pyrolysis for Char Production - U. of Arkansas . . 122 
3.6.2 BTC Program Participation in Liquefaction/Pyrolysis Research Sponsored by the International Energy Agency (IEA). . . . . . . . . . . . . . . . . . . 123

3.6.2.1 IEA Biomass Liquefaction/Pyrolysis Project . . . . 123

3.7 SUMMARY AND RECOMMENDATIONS - PYROLYSIS AND LIQUEFACTION . . . . . . . . . . . . . . . . . 127

3.7.1 Summary of Pyrolysis/Liquefaction Accomplishments . . . . 127

3.7.2 Recommendations . . . . . . . . . . . . . . . . . . 129

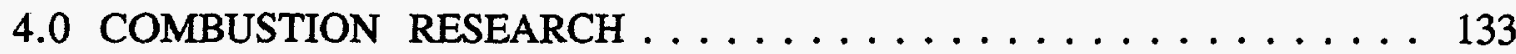

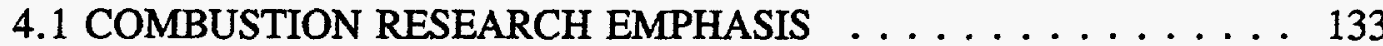

4.2 BIOMASS FUELED GAS TURBINE RESEARCH . . . . . . . . . . 133

4.2.1 Direct Combustion/Gas Turbine System - Aerospace

Research Corp. . . . . . . . . . . . . . . . . . . 134

4.2.2 Pyrolysis Oil Testing for Gas Turbines - Teledyne CAE . . . 139

4.3 OTHER COMBUSTION PROJECTS . . . . . . . . . . . . 140

4.3.1 Biomass Fueled Stirling Engine - United Stirling, Inc. . . . 140

4.3.2 Basic Studies of Biomass Combustion - Jet Propulsion Laboratory (JPL) . . . . . . . . . . . . . . . . 142

4.4 SUMMARY AND RECOMMENDATIONS - COMBUSTION . . . 143

4.4.1 Summary of Combustion Accomplishments . . . . . . . 144

4.4 .2 Recommendations . . . . . . . . . . . . . . . 145

5.0 TECHNOECONOMIC ANALYSIS/SYSTEM STUDIES $\ldots \ldots \ldots \ldots 147$

5.1 RESEARCH EMPHASIS . . . . . . . . . . . . . . 147

5.2 TECHNOECONOMIC ANALYSES . . . . . . . . . . . . 148

5.2.1 Technoeconomic Analysis of Advanced Biomass

Technologies Including Gasification, Liquefaction,

and Power Generation - SAIC International . . . . . . . 148

5.3 SYSTEMS STUDIES . . . . . . . . . . . . . . . . . . 153

5.3.1 Assessment Feedstock Availability - Pyros, Inc. . . . . . . 153

5.3.2 Solar Cost Data Bank - SRI International . . . . . . . . 155

5.3.3 Evaluation of Catalysis in Biomass and Coal Conversion -

Catalytica Associates, Inc. . . . . . . . . . . . . . 156

5.3.4 Research and Evaluation of Biomass Resources/

Conversion/Utilization Systems - Gilbert/Commonwealth

Associates, Inc. . . . . . . . . . . . . . . 156

5.4 RECOMMENDATIONS AND CONCLUSIONS . . . . . . 158

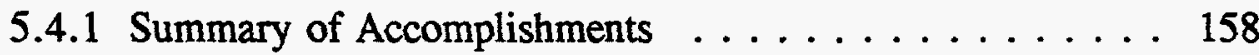

5.4 .2 Recommendations . . . . . . . . . . . . . . . 158

6.0 FEEDSTOCK CHARACTERIZATION AND OTHER BIOMASS

RESEARCH PROJECTS . . . . . . . . . . . . . . . . . . . . 161

6.1 FEEDSTOCK CHARACTERIZATION, AND INFLUENCES OF

FEEDSTOCK ON CONVERSION . . . . . . . . . . 161

6.1.1 Biomass Characterization/IEA Standards Activity - NREL . . 162 
6.1.2 The Effects of Biomass Properties on Conversion

Processes -Pacific Northwest Laboratory (PNL) . . . . . . 164

6.2 RESEARCH ON THE USE OF VEGETABLE OILS FOR FUELS . . . . . . . . . . . . . . . . . . 165

6.2.1 Oil Seeds as an Alternative Fuel Source - Tufts

University...

6.3 OTHER PARTICIPATION IN THE INTERNATIONAL ENERGY

AGENCY'S BIOENERGY AGREEMENT (IEA/BA) . . . . . . 167

6.3.1 IEA/BA Biomass Conversion Task - PNL . . . . . . . . 167

6.4 SUMMARY AND RECOMMENDATIONS - OTHER BIOMASS

RESEARCH . . . . . . . . . . . . . . . . . . . . . . 169

6.4.1 Summary of Accomplishments . . . . . . . . . . . . . 169

6.4.2 Recommendations . . . . . . . . . . . . . . . . . . . . . 169

7.0 OVERALL SUMMARY $\ldots \ldots \ldots \ldots \ldots \ldots \ldots \ldots \ldots$

7.1 TECHNICAL ACCOMPLISHMENTS . . . . . . . . . 171

7.1.1 Development of New Technologies . . . . . . . . . 171

7.1.2 Development of an Improved Basic Understanding of

Biomass Processes . . . . . . . . . . . . . . 172

7.2 INDUSTRIAL ACCEPTANCE OF BIOMASS THERMAL

CONVERSION TECHNOLOGIES . . . . . . . . . . 172

7.3 PROGRESS IN THE CONTEXT OF CHANGING

PROGRAM GOALS IN THE 1980'S . . . . . . . . . . . 173

7.4 ISSUES RELATING TO PUBLISHING DATA . . . . . . . . . 174 


\section{FIGURES}

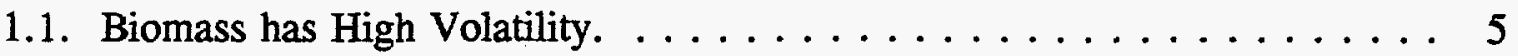

1.2. Biomass Chars are Highly Reactive. $\ldots \ldots \ldots \ldots \ldots \ldots \ldots \ldots$

2.1. Alternatives for Biomass Gasification. . . . . . . . . . . . . 19

2.2. Conceptual Diagram of the BCL Gasifier. . . . . . . . . 25

2.3. Product Gas Heating Value versus

Feedstock Moisture Content - BCL. . . . . . . . . . . . . 27

2.4. Schematic Diagram of the University of Missouri-Rolla Gasifier. . . . . . 31

2.5. Schematic Diagram of the IGT Oxygen-Blown Gasifier. . . . . . . 35

2.6. Representative Data from Char Gasification Studies. . . . . . . . . . . . 39

2.7. Schematic Diagram of Syngas/NREL Gasifier. . . . . . . . . . . 41

3.1. Comparison of Energy Densities of Various Fuels. . . . . . . . . . . . 79

3.2. Schematic Diagram of Albany, Oregon,

Liquefaction Test Facility (PERC Process). . . . . . . . . . . 85

3.3 Schematic Diagram of the University of Arizona

Extruder Liquefaction System. . . . . . . . . . . . . . . 88

3.4 Schematic Diagram of the NREL Ablative Pyrolysis Reactor. . . . . . . . . 97

3.5. Simplified Schematic of GTRI

Entrained Rapid Pyrolysis Reactor. . . . . . . . . . . . . . . 100

3.6. Schematic of NREL Zeolite Catalytic Reactor System. . . . . . . . . . 104

3.7. Schematic Diagram of the Pyrolysis MBMS System at NREL. . . . . . . 113

3.8. Representation of Typical Pyrolysis Reaction Pathways. . . . . . . . . . 114

3.9. Comparison of Mass Spectra Rapid Pyrolysis

and High Pressure Liquefaction Oils. . . . . . . . . . . . 116

3.10. Yields From Wood Pyrolysis in the Presence of Methane -

Brookhaven National Lab. . . . . . . . . . . . . . . . . . 118

4.1 Schematic Diagram of the Aerospace Combustion/Gas Turbine

Concept. . . . . . . . . . . . . . . . . . . . . . 135

\section{TABLES}

1.1. BTC Program Funding by Year. . . . . . . . . . . . . 7

2.1. Summary of Medium-Energy Gasification Projects

Funded by the BTC Program. . . . . . . . . . . . . 23

2.2. Typical BCL Product Gas Analysis (Dry Basis). . . . . . . . . . 27

2.3. Typical Gas Compositions and Heating Values for

Top- and Bottom-Fed Gasifier Operation, U. Missouri-Rolla

$\left(750{ }^{\circ} \mathrm{C}\right.$ inlet temperatures, test runs $\# 166$ and $\left.\# 211\right) \ldots \ldots \ldots 33$

2.4. Typical Gas Composition and Heating Value

for IGT Gasifier (Test Run GT-13, $825{ }^{\circ} \mathrm{C}$,

$20 \mathrm{~atm}, 0.23 \mathrm{~kg}$ Oxygen $/ \mathrm{kg}$ Feed) $\ldots \ldots \ldots \ldots \ldots \ldots . \ldots 37$

2.5. Typical Gas Compositions and Heating Values

for SynGas/NREL oxygen-blown gasifier 
(Test run $\# 5,650^{\circ} \mathrm{C}$ exit temperature,

$\mathrm{O}_{2}$ /wood ratio 0.25 , moisture ash-free basis).

2.6. Product Gas Compositions for Various Feedstocks

from the MTCI Gasifier.

2.7. Typical Product Gas Compositions from the

Wright-Malta Gasifier $\left(600{ }^{\circ} \mathrm{C}, 11 \mathrm{~atm}\right.$, dry basis). . . . . . . . . 49

2.8. Typical Gas Compositions from NREL Gasifier

(Pine feedstock, $0.43 \mathrm{~kg}$ oxygen $/ \mathrm{kg}$ feed).

2.9. Typical Gas Compositions from PNL High Moisture

Gasification Process $\left(450^{\circ} \mathrm{C}\right.$, Nickel Catalyst)

2.10. Summary of Low-Energy Gasification Projects

Funded by the BTC Program. . . . . . . . . . . . . . . . . 59

2.11. Typical Gas Compositions for the

University of Missouri Air-Blown Gasifier

(Test Run \#41, $775 \mathrm{C}$ )

2.12. Typical Product Gas Compositions

from the EEE Fluidized Bed Gasifier

(Pelletized oak hardwood, $790-815^{\circ} \mathrm{C}$ ). . . . . . . . . . . . 62

2.13. Summary of Environmental/End-Use Gasification Projects

Funded by the BTC Program. . . . . . . . . . . . . . . . . 67

2.14. Gas Compositions for Catalyzed Steam Gasification

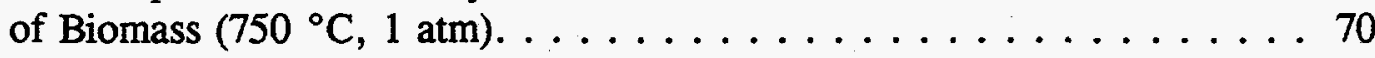

3.1. Summary of High Pressure and Rapid Pyrolysis Liquefaction

Projects Funded by the BTC Program. . . . . . . . . . . 83

3.2. Typical Yields and Characteristics of the Liquid

Products Produced at the Albany, Oregon, Test Facility. . . . . . . 86

3.3 Typical Characteristics of the Crude Product Oil

from University of Arizona. . . . . . . . . . . . . . . 8 89

3.4. Typical Characteristics of the Liquid Products

from the NREL Vortex Reactor.

3.5. Typical Yields and Characteristics

of the Liquid Products Produced at GTRI. . . . . . . . . . . . 101

3.6. Research Projects to Upgrade Biomass Crude Oils. . . . . . . . . . . 103

3.7. Yields of Products From the NREL Ablative Reactor/

Zeolite Upgrading System. (Run 95-B, Reaction Zone

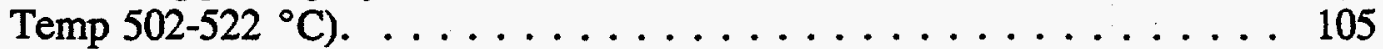

3.8. Comparison of Properties of Biocrude Oils and Hydrotreated Product. . . . 109

3.9. Basic Pyrolysis Research Projects. . . . . . . . . . . . . . . 111

3.10. Influence of Reaction Severity on Biomass Tar Composition. . . . . 121

4.1 Biomass Combustion Research Projects . . . . . . . . . . . . . . . 134

5.1 Technoeconomic Analysis and Systems Studies Projects. . . . . . . . . 148

5.2 Summary of Capital and Electricity Production Costs. . . . . . . . . 152

6.1 Other Research Projects Sponsored by the BTC Program. . . . . . . . . 161 


\subsection{INTRODUCTION}

\subsection{OBJECTIVE AND SCOPE OF ANALYSIS PROJECT}

In the period between 1980 and 1989, the U. S. Department of Energy (DOE) sponsored research and development projects through its Biomass Thermochemical Conversion (BTC) Program. Thermochemical conversion technologies use elevated temperatures to convert biomass into more useful forms of energy such as fuel gases or transportation fuels. The BTC Program included a wide range of biomass conversion projects in the areas of gasification, pyrolysis, liquefaction, and combustion. This work formed the basis of the present DOE research and development efforts on advanced liquid fuel and power generation systems. At the beginning of Fiscal Year 1989, the management of the BTC Program was transferred from Pacific Northwest Laboratory (PNL) to National Renewable Energy Laboratory (NREL, formerly Solar Energy Research Institute).

This document presents a summary of the research which was performed under the BTC Program during the 1981-1989 time frame. The document consists of an analysis of the research projects which were funded by the BTC Program and a bibliography of published documents. This work will help ensure that information from PNL's BTC Program is available to those interested in biomass conversion technologies.

The background of the BTC Program is discussed in the first chapter of this report. In addition, a brief summary of other related biomass research and development programs funded by the U.S. Department of Energy and others is presented with references where additional information can be found. The remaining chapters of the report present a detailed summary of the research projects which were funded by the BTC Program. The progress which was made on each project is summarized, the overall impact on biomass conversion is discussed, and selected references are provided.

\subsection{BIOMASS AS AN ENERGY RESOURCE}

Biomass is an important energy resource, both at present and from an historical perspective. Biomass is broadly defined as trees and other plants which have stored chemical energy from sunlight through the process of photosynthesis. Until the discovery of large quantities of petroleum and natural gas in the early 1900's, wood supplied a significant portion of the United States' energy requirements for heat and power. Combustion of wood in boilers produced steam to heat buildings, power industrial machinery and fuel ships, trains, and farm machinery. In less-developed countries throughout the world, biomass is still the primary energy resource. 
In the United States, biomass continues to provide large amounts of energy. In 1981, for example, it is estimated that biomass provided about $2.8 \mathrm{EJ}$ (1 ExaJoule $=10^{18} \mathrm{Joule}$ $=0.95$ quadrillion Btu or 0.95 "Quads") or about $3.6 \%$ of the annual U.S. energy demand. By 1990, the contribution from biomass was estimated to be about $3.5 \mathrm{EJ}$ or nearly $4 \%$ of total energy demand. ${ }^{2}$

More than $95 \%$ of this biomass energy is produced by combusting wood, wood wastes, and farm residues to provide heat and electricity. Currently, the U.S. electrical generating capacity from biomass is approximately $8,000 \mathrm{MW} .{ }^{3}$ Farm crops, primarily com, are also biochemically converted to ethanol for transportation purposes. Approximately 3 billion liters of ethanol are produced annually $y^{4}$, which accounts for 0.07 EJ or about $0.1 \%$ of the U.S. annual energy demand. In other developed countries with large forest reserves, biomass contributes an even greater percentage of the annual energy demand. For example, Sweden produces about $15 \%$ of its energy using biomass. ${ }^{5}$

The use of biomass as an energy resource is expected to increase in the future due to a number of factors. Biomass is renewable, and with appropriate management, can be grown at the same rate it is consumed. The carbon dioxide which is released when the biomass is burned will be recaptured by new biomass as it is regrown. As a result, biomass can potentially be used as an energy resource without net emissions of carbon dioxide to the atmosphere. In addition, most biomass resources naturally have low sulfur content and therefore emit little sulfur dioxide when burned.

Biomass has other social and economic benefits which increase its attractiveness. As a domestic resource, biomass can provide a stable energy supply which is not susceptible to international disruption. Since biomass is grown relatively near energy conversion facilities, it can provide local employment opportunities. The use of biomass also allows agricultural and energy policies to be coordinated for maximum benefit.

With appropriate resource development and improved conversion technologies, it has been estimated that biomass can supply approximately $20 \mathrm{EJ}$ of energy per year by the year $2030^{2}$. The contribution of biomass to the annual energy supply would rise from approximately $4 \%$ at present to about $13 \%$ at that time. For biomass use to increase this much, new production and conversion technologies will be needed.

\subsection{ORIGINS OF THE BIOMASS THERMOCHEMICAL PROGRAM}

To meet demand for petroleum in the 1960's and early 1970's, the U.S. increased its importation of inexpensive oil from countries in the Persian Gulf, Africa, and South America. In the late 1970's, the Organization of Petroleum Exporting Countries (OPEC) restricted oil production and implemented temporary oil embargoes in an effort to manipulate prices. These actions resulted in unprecedented increases in petroleum costs and raised serious questions about national security and long-term petroleum availability. 
As a result of these changes, the U.S. Department of Energy (DOE, formerly the Energy Research and Development Administration), began a series of programs to increase the use of domestic energy resources including biomass. Biomass materials such as wood, wood wastes, energy crops, and farm residues were domestically produced, and energy from these sources was independent of foreign influence. The wood products industries already used biomass wastes to produce heat and electricity, but the potential for producing gaseous and liquid fuels from biomass could only be realized if new technologies were developed. Better methods were needed to increase the rate of biomass production and to reduce feedstock costs. Improved conversion technologies were also needed to produce a variety of gaseous and liquid fuels at competitive costs. To meet these needs, DOE sponsored research and development efforts aimed at bringing new biomass energy technologies to the marketplace.

The Biomass Thermochemical Conversion (BTC) Program was a major part of this effort. Thermochemical conversion processes utilize heat and chemistry to convert biomass into a variety of liquid or gaseous fuels. Battelle Pacific Northwest Laboratory provided technical assistance and field management of the BTC Program from 1980 through 1989. During this period, research and development efforts resulted in improved technologies for producing fuel gases, liquid fuels, and electric power. In 1989, the BTC Program was consolidated with other DOE biomass programs at the National Renewable Energy Laboratory.

\subsection{PROGRAM OBJECTIVE AND APPROACH}

The objective of the BTC Program was to generate a base of scientific and engineering data which would lead to the establishment of cost-effective processes for converting biomass into clean fuels. The three primary areas of interest under the program were:

- Gasification technologies to produce fuel gases which could provide substitutes for natural gas and synthesis gases which could be used for the manufacture of methanol and other fuels and chemicals.

- $\quad$ Liquid fuels technologies which could produce hydrocarbon fuels substitutes using advanced pyrolytic concepts.

- Innovative combustion technologies which could expand the use of biomass in non-traditional applications such as gas turbines for power generation.

These three technology areas were identified by DOE as having highest priority. Individual process concepts in all three areas were in an early stage of development, and the financial and technical risks were too high for independent private sector development of the technologies. The purpose of DOE's R\&D effort was to generate the necessary data to allow transfer of new technologies to the private sector for commercialization.

To accomplish this objective, the BTC Program funded a variety of scientific and engineering research projects aimed at developing new thermal conversion technologies. 
These projects included basic studies to establish fundamental parameters such as reaction rates and decomposition mechanisms. Applied research projects included the operation of bench-scale reactors to test conversion concepts under continuous, steady-state conditions. Engineering development research was conducted for selected conversion processes which were successful at the small scale. These development projects were funded to determine process feasibility at reasonable scale, typically 1-10 tons of feedstock per day. Through this process, the program continually evaluated individual projects and selected the most promising technologies from the numerous ideas which had originally been promoted.

\subsection{PROGRAM RATIONALE}

The R\&D efforts of the BTC Program were focused on exploiting the unique characteristics of biomass to their maximum extent. Compared with other solid fuels such as coal, biomass has unique properties that offer potential advantages for thermal conversion processes. These properties include:

- High Reactivity - Biomass is more reactive than other solid fuels such as coal or peat. Biomass feedstocks contain a high fraction, typically $70-90 \%$, of material which can be volatilized when heated. This means that a large portion of biomass can be volatilized rapidly at relatively low temperatures. Figure 1.1 presents $^{6} \mathrm{a}$ comparison of the volatility differences between hardwood and a typical coal.

Following devolatilization, the remaining biomass char is also highly reactive. Biomass chars gasify rapidly in the presence of steam, again at relatively low temperatures. The gasification of biomass chars does not require the presence of oxygen or air to attain reasonable rates. This property is illustrated in Figure 1.2 , which compares the reactivity of biomass, coal, and peat chars.

Because biomass is highly reactive, the rates of conversion are limited primarily by the rate of heat transfer in the conversion unit rather than the rate of the biomass decomposition itself. Exploitation of this property is crucial for biomass technologies to achieve high feedstock throughputs and to reduce unit capital costs.

- Low sulfur and ash content - Typical wood feedstocks contain less than $0.2 \%$ sulfur. The low sulfur content reduces gas clean-up costs and allows biomass to be reacted in the presence of most catalysts without sulfur poisoning problems. Wood and most biomass also has low ash content, typically around $3 \%$ by weight (a few biomass feedstock such as straw have $10 \%$ or more ash). The ash handling and disposal requirements for many systems are low in cost. 


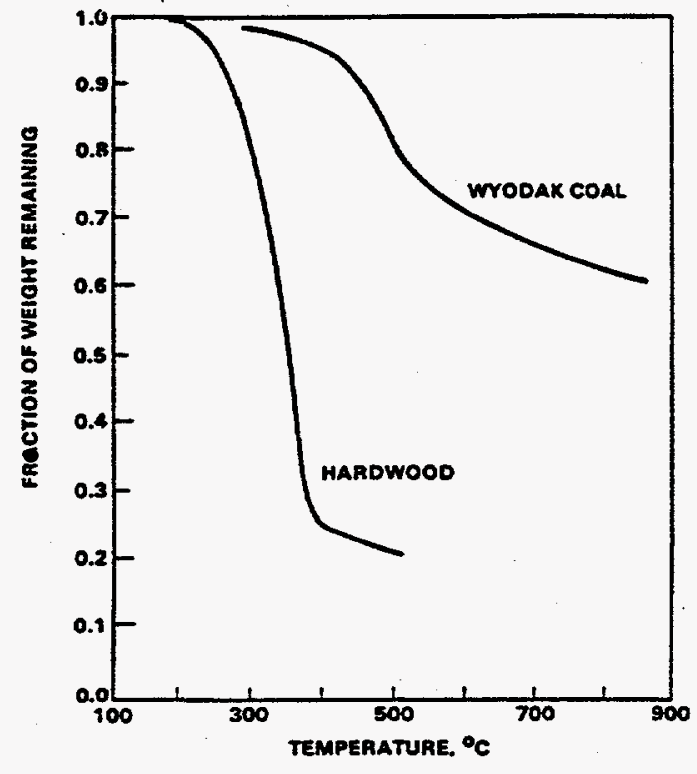

Figure 1.1. Biomass has High Volatility.

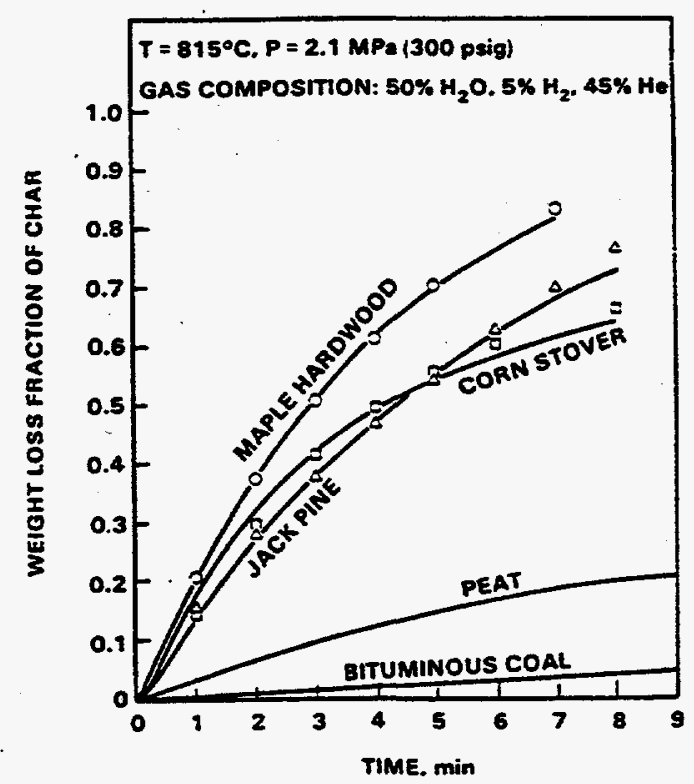

Figure 1.2. Biomass Chars are Highly Reactive.

The BTC Program recognized that exploitation of these unique properties of biomass was necessary if economical conversion technologies were to be developed. Biomass is a distributed resource which can be transported only moderate distances to conversion facilities. The maximum size of a biomass facility is probably no greater than 5,000 10,000 tons of biomass feedstock per day, and most will be much smaller. When compared with coal, the biomass conversion technologies are limited to smaller scale. By designing biomass reactors specifically to exploit the reactivity of biomass, it is possible to achieve high conversion rates with low capital costs in relatively small reactors. The low sulfur and ash contents of the feedstock also reduce conversion and cleanup capital costs. By carefully exploiting the characteristics of the feedstock, it is possible to compete at a small scale with conversion of other solid fuels on a larger scale.

\subsection{PROGRAM HISTORY}

Program Management - The BTC Program started in 1976 as part of the Fuels from Biomass program operated by DOE's predecessor, Energy Research and Development Administration (ERDA). The Fuels from Biomass Program evolved into the Biomass Energy Technology Development (BETD) Program and included research on the production of woody, herbaceous, and aquatic crops; bioconversion of biomass through anaerobic digestion and fermentation; and thermochemical conversion. Initially, the BTC Program was managed and operated by DOE from its Washington D.C. Headquarters. Project selection and subcontracting functions were performed by DOE with support from its field offices. 
As the BTC Program grew rapidly in scope and size, DOE utilized the resources of its national laboratory system to help provide technical expertise and subcontracting support for the program. Pacific Northwest Laboratory (PNL), operated by Battelle Memorial Institute, began assisting DOE in the management of the BTC Program in 1978. This role was expanded in 1980 when PNL was named as the Field Management Laboratory for the BTC Program. As the Field Management Laboratory, PNL provided overall technical direction for the program and issued subcontracts for research projects at a variety of universities, national laboratories, and private industries.

In 1985, the thermal conversion portion of DOE's Alcohol Fuels Program was merged into the BTC Program managed by PNL. This research focused on the production of methanol for transportation uses and included gasification research at NREL. The Alcohol Fuels Program is referenced later in this chapter, and the thermal conversion projects in this area are discussed in the gasification section of this report.

Due to low funding levels and the desire to consolidate bioenergy programs, DOE moved the BTC Program to NREL in Golden, Colorado in October, 1988. The work at PNL was phased out over the following year as subcontractors prepared final reports.

Program Funding - The annual funding for the BTC Program and the overall Biomass Energy Technology Division is shown in Table 1.1. The budget for the BTC Program varied between $\$ 8.7 \mathrm{MM}$ in 1980 and $\$ 1.3 \mathrm{MM}$ in 1988 . In total, approximately $\$ 44$ MM was spent between 1980 and 1989.

Historical Program Emphasis - The increase in petroleum prices and the interruptions of supply in the late 1970's suggested that new, biomass-based technologies were needed as rapidly as possible. In addition, pricing regulations on domestic supplies were inhibiting the production of natural gas and increasing its cost. Biomass gasification technologies offered the potential to provide substitutes for natural gas in many fuel applications. In addition, these products could also potentially be used as synthesis gases to generate a wide range of substitutes for petrochemicals such as methanol. As a result of these influences, the primary focus of the Program was initially on biomass gasification and the rapid development of new technologies.

In the early 1980's, the BTC Program on gasification emphasized larger scale development projects aimed at rapidly developing new conversion technologies. The BTC Program sponsored research on several gasification concepts with research units ranging in scale from approximately 1 to 20 tons/day of feedstock conversion. Several concepts for producing a medium-Btu gas product from biomass were successfully tested. These concepts formed the basis of DOE's present work to develop advanced gasifier/gas-turbine technologies for improved power generation and sungas for transportation fuels. In addition, the BTC Program sponsored basic and applied research to support the gasification program. By providing detailed data on biomass reactivity mechanisms and rates, the conversion processes were improved. The area of biomass gasification is described in greater detail in Chapter 2.0 of this report. 
Table 1.1. BTC Program Funding by Year.

\begin{tabular}{||c|c|c|c||}
\hline \multicolumn{4}{|c|}{ Biomass Thermochemical Conversion Program } \\
Funding History (\$1000's) \\
$\begin{array}{c}\text { Fiscal } \\
\text { Year }\end{array}$ & $\begin{array}{c}\text { Total } \\
\text { Funding for } \\
\text { BETD } \\
\text { Division }\end{array}$ & $\begin{array}{c}\text { Funding for } \\
\text { BTC } \\
\text { Program }\end{array}$ & $\begin{array}{c}\text { Percent } \\
\text { of Total }\end{array}$ \\
\hline FY 1980 & 33,000 & 8,799 & $27 \%$ \\
\hline FY 1981 & 27,200 & 7,806 & $29 \%$ \\
\hline FY 1982 & 20,500 & 6,250 & $31 \%$ \\
\hline FY 1983 & 16,500 & 3,126 & $20 \%$ \\
\hline FY 1984 & 28,500 & 5,430 & $19 \%$ \\
\hline FY 1985 & 29,000 & 5,500 & $19 \%$ \\
\hline FY 1986 & 28,400 & 2,600 & $9 \%$ \\
\hline FY 1987 & 24,200 & 2,985 & $12 \%$ \\
\hline FY 1988 & 17,065 & 1,290 & $8 \%$ \\
\hline
\end{tabular}

The second major area of program interest was biomass liquefaction. The research on liquid fuels initially focused on high pressure processes to produce a substitute for fuel oils. Consistent with the philosophy of the early 1980 's, the program funded a 1 ton/day development facility located in Albany, Oregon. While this facility was operated successfully, it also showed the need to develop a better understanding of biomass liquefaction processes.

Through the mid-1980's, the program funded additional basic and applied research to improve liquefaction technologies. Improved liquefaction methods using fast pyrolysis were conceived, and catalytic techniques to upgrade the bio-crude oils into hydrocarbon fuels for transportation fuels were developed. Technology developed by this part of the program is now being commercialized for mixed production of energy and chemicals. The individual liquefaction projects are discussed in Chapter 3.0 of this report. 
The BTC Program also sponsored research on innovative combustion technologies. This area of research was funded at a lower overall level than gasification or liquefaction. Research included projects designed to increase the use of biomass in non-traditional applications such as gas turbines or Stirling engines for power generation. This work has important implications for the current DOE programs that deal with gasifier/gas-turbine systems. Chapter 4.0 describes the research on combustion.

Finally, the BTC Program sponsored ongoing research dealing with systems analyses, feedstock supply availability, and similar issues. These projects are described in Chapters 5.0 and 6.0 of this report.

\subsection{PROGRAM PUBLICATIONS}

The BTC Program produced numerous documents including annual reports, published proceedings of annual review meetings, and others. Representative program publications ${ }^{7-20}$ are listed at the end of this chapter, and selected references for the individual technical projects are provided in the following chapters. These publications provide more detailed information about the BTC Program and the research projects which were funded.

\subsection{RELATED BIOENERGY PROGRAMS}

In addition to the BTC Program, many other bioenergy programs were funded by various groups during the late 1970's and throughout the 1980's. These included other programs within DOE, programs funded by other U.S. government agencies, and programs funded by other countries. The BTC Program worked closely with many of these programs to ensure that new technologies would be developed effectively. While it not the purpose of this report to describe these other programs in detail, it is important to recognize that a broad range of bioenergy R\&D activities were being funded. Brief descriptions of many of these bioenergy programs are provided below. This list is not intended to be a complete listing of all bioenergy programs during the 1980's but identifies the main programs with which the BTC Program interacted. Selected references to additional information on these programs are provided.

\subsubsection{Other DOE-sponsored Programs}

The Department of Energy sponsored several different bioenergy programs throughout the 1980's. These include the following:

DOE's Biomass Energy Technology Division (BETD) - This was the major bioenergy program sponsored by DOE; the Biomass Thermochemical Conversion Program at PNL was one element of this larger effort. The BETD program included work on production of woody and herbaceous biomass managed by Oak Ridge National Laboratory and 
production of aquatic species managed by NREL. Biochemical conversion projects in the areas of anaerobic digestion and fermentation were also managed by NREL.

The BETD program evolved over time from loosely coordinated programs within several different DOE divisions. The thermochemical conversion work was originally part of the Fuels from Biomass Program. Research on the production of ethanol and methanol in the early 1980's was initially funded by DOE's Office of Alcohol Fuels, and other groups also provided funding for some projects. The consolidation of these various programs into the BETD began in the early 1980's and was complete by 1985 . In 1986, the program expanded to include research on conversion of municipal solid waste (MSW), and was renamed the Energy from Biomass and Municipal Wastes Program. Argonne National Laboratory initially provided management for the work on MSW, and this was later consolidated at NREL. When DOE reorganized in 1990, the program was split into three elements corresponding to the formation of three new Offices. Research and development on power generation systems was placed in the Office of Utility Technologies, work on fuels was placed in the Office of Transportation Technologies, and research on MSW in the Office of Industrial Technologies. Selected technical references for the projects funded by the BTC Program are listed in this document, and other documents describing the larger program are also available ${ }^{21-23}$.

Office of Alcohol Fuels Program - In the late 1970's and early 1980's, this DOE program provided funds for research on the production of ethanol and methanol fuels from biomass. The program funded research on biochemical conversion of woody biomass to ethanol, primarily at NREL, and funded research on the fuel utilization in vehicles. Thermochemical gasification research on methanol ${ }^{24}$ at NREL and some Universities was also funded.

The largest amount of funding from this program was used to provide loan guarantees that spurred private companies to build facilities for converting corn and other crops to ethanol. Authorized by Public Law PL96-126, this program expanded U.S. ethanol production capacity. The Alcohol Fuels Program was discontinued in 1985, and the biochemical conversion research became part of the BETD Program. Work on alternative fuels in vehicles is presently funded through DOE's Office of Transportation Technologies. The thermal conversion research projects were transferred to the BTC Program and are described in greater detail in Chapter 2.

DOE Regional Programs - Department of Energy established a regional bioenergy program encompassing the Pacific Northwest and Alaska in 1979. At the request of Congress, DOE expanded the program to stimulate the development of biomass energy in other regions in 1983. Programs were established in the Northeast, Southeast, and Great Lakes regions at that time, and a program in the Western region was started in 1987.

These regional programs emphasize shorter-term research projects to help establish and expand the use of biomass in the regions. Examples of typical projects include assessments of regional biomass resources, measurements of wood stove efficiencies, and funding for businesses which install new biomass conversion technologies. The program 
encourages the participation of state energy agencies and local industries and leverages DOE funds through the requirement of extensive cost-sharing of its projects ${ }^{25-2}$.

NREL Universities Grant Program - From 1979 through 1983, NREL (SERI at that time) provided grants to a half-dozen universities to conduct research on biomass conversion. Funding was provided in part by the Fuels from Biomass Program and part by DOE's Office of Energy Research. The grants were awarded to study mechanistic and kinetic aspects of biomass pyrolysis, to establish a fundamental data base for pyrolysis reactions, and to study devolatilization of solid biomass in reactive environments. The program provided useful basic information which helped in the development of an improved understanding of biomass pyrolysis processes. Several technical papers were published as a result of this work ${ }^{23-30}$.

Basic Energy Sciences - This DOE organization provided funding for basic research on wide range of energy topics. Most of the funds were used to support research efforts at DOE Laboratories. While the program had no specific biomass component, several projects dealing with the mechanisms of cellulose thermal decomposition were funded ${ }^{31-32}$ throughout the 1980's.

Municipal Solid Waste Programs - Very little work on MSW conversion was funded by the BTC Program. In limited cases, MSW was used as a feedstock in the biomass gasification and combustion units being funded by the BTC Program, and those efforts are described in more detail in the following chapters of this report. However, DOE had separate programs on MSW conversion throughout the period that the BTC Program was active. In the early 1980's, Argonne National Lab provided field management for most of the work, particularly that dealing with thermal conversion. The National Bureau of Standards also participated in the thermal conversion work. NREL participated actively in the MSW research, particularly in the bioconversion areas. The funding for this work was provided by DOE's Energy from Municipal Wastes Division through 1985. In 1986, the MSW research was integrated into the Biomass and Municipal Waste Technology Division, and by 1988 the field management function has been transferred to NREL. In 1990 , consistent with the reorganization of DOE, the MSW program was placed in the Office of Industrial Technologies, and the management functions remain at NREL ${ }^{33-34}$.

DOE Conservation Programs - DOE funded other biomass research through its energy conservation programs. This included research on biomass gasification followed by synthesis of diesel-like hydrocarbon fuels. ${ }^{35}$

\subsubsection{Other Federal Government Programs}

U.S. Department of Agriculture (USDA) Programs - USDA sponsored approximately fifty research projects on biomass and solar energy in agriculture through its Southern Agricultural Energy Center from 1980 through 1985. The Program investigated a variety of biomass conversion technologies, including the thermochemical production of hydrocarbon fuels via gasification/synthesis gas routes. Research also examined the production of vegetable oils for use as diesel substitutes (biodiesel) and methods to 
improve anaerobic digestion. Some funding was also used to support research on ethanol production at a Tennessee Valley Authority (TVA) research facility. More information is available from the proceedings of annual meetings organized by this program ${ }^{36}$.

National Science Foundation (NSF) - NSF provided funding for very fundamental research on the thermal decomposition of biomass as early as 1976 through its Research Applied to National Needs Program. An expanded program of research on fundamental reaction pathways and innovative processing concepts was continued by NSF's Chemical and Biochemical Processing Division through the mid-1980's. The work of this period is well summarized in the proceedings of a meeting held in Hawaii in June $1984^{37}$.

Tennessee Valley Authority (TVA) - TVA sponsored research which focused on the production of ethanol. Research focused on the use of dilute and concentrated acid hydrolysis processes as a means to convert the cellulose from woody biomass into fermentable sugars. USDA also provided funding support for this research. The TVA program also funded research on selected environmental issues and on screening of biomass energy crops $^{3240}$.

\subsubsection{State and Private Sector Programs}

State Programs - In the early 1980's, most states established agencies to deal with energy issues. In a few cases, active bioenergy programs were started to help industry and to increase job opportunities. Particularly active programs were established in California, New York and Hawaii.

The California Energy Commission made funds available to industries which would install state-of-the-art biomass conversion equipment in their facilities. The purpose of this funding was to reduce the risk to the private sector for converting to biomass technologies. If the technologies were successful in reducing costs for the industrial partner, that partner paid part or all of the funding back to CEC, allowing continuation of the program. CEC also funded assessments and analyses as needed to gather information about feedstock supply and other topics. The CEC is still active in Califormia ${ }^{41}$.

The New York State Energy Research and Development Administration (NYSERDA) also established an active bioenergy program. Funding was made available on a cost-shared basis to support the development of innovative, near-commercial bioenergy technologies. NYSERDA also funded selected analyses and resource assessments to aid the development of bioenergy in New York and remains active at present ${ }^{42}$.

The state of Hawaii has also been actively involved in promoting the development of bioenergy. Through its Hawaii Natural Energy Institute (HNEI) at the University of Hawaii, the state has funded an extensive research program on bioenergy. The research has included biomass resource studies, projects to increase biomass production, and projects on conversion technologies suitable for Hawaii ${ }^{43}$. On many projects, HNEI has 
coordinated its work closely with DOE. The state is also currently providing substantial cost-sharing for a biomass gasifier scale-up project, which is partially funded by DOE. This project is described in more detail in Chapter 2.0.

Private Sector Programs - Several of the institutes associated with the natural gas and electric power industry established continuing research programs in the area of bioenergy. Electric Power Research Institute (EPRI) has funded ${ }^{44}$ numerous projects to evaluate and help implement biomass technologies for power generation. EPRI has current interest in innovative biomass combustion and gasifier/gas-turbine technologies which would produce electricity.

Gas Research Institute (GRI) funded extensive work ${ }^{4546}$ on bioconversion of biomass throughout the 1980's. GRI's primary interest was in the area of anaerobic digestion of biomass and wastes to methane. GRI funded or co-funded work at a facility at Walt Disney World in Florida and developed methods to enrich the methane content of fuel gas from these reactors.

Institute of Gas Technology (IGT) participated in biomass gasification research for more than ten years and is involved in a gasifier scale-up project in Hawaii. The work at IGT which was sponsored by the BTC Program is described in Chapter 2. IGT also organized annual bioenergy conferences through most of the 1980's. The proceedings of these meetings provide excellent documentation ${ }^{47.53}$ of research projects funded by many different programs over the years.

\subsubsection{International Programs}

The interest in bioenergy was world-wide throughout much of the 1980's. Most developed countries funded R\&D programs dealing with biomass production and conversion. The BTC Program interacted with many of these countries' programs through the International Energy Agency's Bioenergy Agreement. In addition, the BTC Program interacted closely with the national programs sponsored by Canada. It should be noted that there were many other active programs such as that of the European Economic Community, but the interactions of the BTC Program with those efforts were either limited or through the IEA.

International Energy Agency (IEA) - The United States and fourteen other countries joined the IEA's Bioenergy Agreement which started in the late 1970's and is continuing at present. The Bioenergy Agreement provides for coordination of ongoing national programs in the areas of biomass production, harvesting, and conversion. The BTC Program lead the work on biomass conversion. Conversion projects included the areas of thermochemical conversion, biochemical conversion, and specialized topics such as the preparation of a directory of world-wide thermal conversion projects and the establishment of biomass reference standards at National Institute of Standards and Technology (NIST). The thermal conversion work is described more in later chapters of this report, and additional information on the overall IEA program is available ${ }^{5457}$. 
Canadian National Programs - The Canadian federal government funded a major bioenergy program which began in the late 1970's and has continued through the present. Through organizations such as Energy, Mines, and Resources (EMR), Forestry Canada, and the National Research Council, Canada sponsored a wide range of basic and applied research on biomass production and conversion. In the thermal conversion area, the Canadian research included both thermal liquefaction and gasification. The BTC Program in the U.S. interacted closely with the Canadian programs to ensure effective communication. The Canadian programs held periodic review meetings and published detailed proceedings which give a good overview of the work which was funded ${ }^{50-60}$.

U.S. Agency for International Development (AID) - Biomass is a major energy resource in third-world and under-developed countries. In the mid-1980's, the U.S. AID coordinated efforts to improve biomass technologies in Asia and Latin America. Much of the effort was focused on development of low-Btu gasification technologies. The BETD Program was not actively involved in this work but followed its progress.

\subsection{REFERENCES}

1. Haggin, J., and J.H. Kriegr. March 14, 1984. Chem. and Eng. News, p. 28.

2. Idaho National Engineering Laboratory, et.al. 1990. The Potential of Renewable Energy. An Interlaboratory White Paper. National Renewable Energy Laboratory, Golden, CO. SERI/TP-260-3674.

3. Klass, D.L. 1990. "The U.S. Biofuels Industry." Proceedings of the Energy From Biomass and Wastes XIII Conference, pp. 1-46. Institute of Gas Technology, Chicago, Illinois.

4. Wyman, C.E., R.L. Bain, N.D. Himan, and D.J. Stevens. 1993. "Ethanol and Methanol From Cellulosic Biomass." Renewable Energy Sources for Fuels and Electricity, T.B. Johansson, et. al., eds. Island Press, Washington, D.C.

5. Statens Energiverk, 1990. Energy in Sweden. National Energy Administration, Stockholm.

6. Antal, M.J. 1978. "Biomass Energy Enhancement." A Report to the President's Council on Environmental Quality. Princeton University, Princeton, NJ.

7. Solar Energy Research Institute. 1988. Thermochemcial Conversion Program Annual Meeting, June 21-22, 1988. SERI/CP-231-3355, National Renewable Energy Laboratory, Golden, Colorado.

8. Pacific Northwest Laboratory. 1987. Proceedings of the 1987 Biomass Thermochemical Conversion Contractors' Review Meeting, Atlanta, Georgia, May 
20-21, 1987. CONF-8705212, Pacific Northwest Laboratory, Richland, Washington.

9. Pacific Northwest Laboratory. 1986. Proceedings of the 1986 Biomass Thermochemical Conversion Contractors' Meeting, Minneapolis, Minnesota, October 15-16, 1985. CONF-8510167, Pacific Northwest Laboratory, Richland, Washington.

10. Pacific Northwest Laboratory. 1984. Proceedings of the 16th Biomass Thermochemical Conversion Contractors' Meeting, Portland, Oregon, May 8-9, 1984. CONF-8405157, Pacific Northwest Laboratory, Richland, Washington.

11. Pacific Northwest Laboratory. 1983. Proceedings of the 15th Biomass Thermochemical Conversion Contractor's Meeting, Atlanta, Georgia, March 1617, 1983. CONF-830323, Pacific Northwest Laboratory, Richland, Washington.

12. Pacific Northwest Laboratory. 1982. Proceedings of the 14th Biomass Thermochemical Conversion Contractor's Meeting, Arlington, Virginia, June 2324, 1982. CONF-820685, Pacific Northwest Laboratory, Richland, Washington.

13. Pacific Northwest Laboratory. 1981. Proceedings of the 13th Biomass Thermochemical Conversion Contractor's Meeting, Arlington, Virginia, October 27-29, 1981. CONF-8110115, Pacific Northwest Laboratory, Richland, Washington.

14. Schiefelbein, G.F., D.J. Stevens, and M.A. Gerber. 1988. Biomass Thermochemical Conversion Program 1987 Annual Report. PNL-6614, Pacific Northwest Laboratory, Richland, Washington.

15. Schiefelbein, G.F., D.J. Stevens, and M.A. Gerber. 1987. Biomass Thermochemical Conversion Program 1986 Annual Report. PNL-6282, Pacific Northwest Laboratory, Richland, Washington.

16. Schiefelbein, G.F., D.J. Stevens, and M.A. Gerber. 1986. Biomass Thermochemical Conversion Program 1985 Annual Report. PNL-5801, Pacific Northwest Laboratory, Richland, Washington.

17. Schiefelbein, G.F., D.J. Stevens, and M.A. Gerber. 1985. Biomass Thermochemical Conversion Program 1984 Annual Report. PNL-5442, Pacific Northwest Laboratory, Richland, Washington.

18. Schiefelbein, G.F., D.J. Stevens, and M.A. Gerber. 1984. Biomass Thermochemical Conversion Program 1983 Annual Report. PNL-5096, Pacific Northwest Laboratory, Richland, Washington. 
19. Schiefelbein, G.F., D.J. Stevens, and M.A. Gerber. 1983. Biomass Thermochemical Conversion Program 1982 Annual Report. PNL-4779, Pacific Northwest Laboratory, Richland, Washington.

20. Schiefelbein, G.F. 1989. "Biomass Thermal Gasification Research: Recent Results from the United States DOE's Research Program." Biomass 19, pp. 145159.

21. Biofuels and Municipal Waste Technology Program. 1988. Five Year Research Plan 1988-1991 Biofuels: Renewable Fuels for the Future. DOE/CH10093-25, U.S. Department of Energy, Washington, D.C.

22. Walter, D.K. 1989. "Biofuels and Municipal Waste Research Program of the U.S. Department of Energy." Proceedings of the Energy from Biomass and Wastes XII Conference, p. 1, ed. Klass, D.L. Institute of Gas Technology, Chicago, Illinois.

23. Science Applications International Corporation. 1991. Conservation and Renewable Technologies U.S. Department of Energy Biofuels Program Summary FY 1990. U.S. Department of Energy, Washington, D.C.

24. Reed, T.B. and M. Grabowski. 1982. Biomass to Methanol Specialists Workshop Proceedings. SERI/CP/234-1590, National Renewable Enmergy Laboratory, Golden, Colorado.

25. Lusk, P. 1993. Review Report of the Regional Biomass Energy Program Technical Projects. Report submitted under subcontract CAE-3-13383-01 to National Renewable Energy Laboratory, Golden, Colorado.

26. U.S. Government Interagency Program. 1991. Pacific Northwest and Alaska Regional Bioenergy Program. DOE/BP 1487, U.S. Department of Energy and Bonneville Power Administration, Washington, D.C.

27. Coalition of Northeastern Governors Policy Research Center, Inc. 1991. Northeast Regional Biomass Program Mission, Accomplishments, Prospects: 1991. CONEG Policy Research Center, Inc., Washington, D.C.

28. Krieger, B.B., W. Chun, and R. Chan. 1982. "Analysis of Chemcial and Physical Processes During Devolatilization of a Single, Large Particle of Wood." Chemical Reaction Engineering, ACS Symp. Series 196, p. 479, Boston.

29. Hajaligol, M.R., J.B. Howard, J.P. Longwell, and W.A. Peters. 1982. "Product Compositions and Kinetics for Rapid Pyrolysis of Cellulose." Ind. Eng. Chem. Process Design Develop., 21, pp. 457-465. 
30. Thornton, M.M. and P.C. Malte. 1985. "Analysis of Condensate and Gases Formed in Combusion of Model Wood Volatile Compounds." Fundamentals of Thermochemical Biomass Conversion, ed. R.P. Overend, p. 811. Elsevier Applied Science Publishers, London.

31. Nelson, D.A., P.M. Molton, J.A. Russell, and R.T. Hallen. 1983. "Application of Direct Thermochemical Liquefaction for the Conversion of Cellulosic Biomass." Ind. \& Eng. Chem. Prod. Res. Dev., 23, p. 471.

32. Donovan, J.M., P.M. Molton, and T.F. Demmitt. 1981. "Effects of Pressure, Temperature, $\mathrm{pH}$, and Carbon Monoxide on Oil Yields from Cellulose Liquefaction." Fuel, 60, pp. 898-902.

33. Office of Industrial Technologies. 1992. Energy from Municipal Waste Program Program Plan. U.S. Department of Energy, Washington, D.C.

34. Brooks, C., ed. 1987. Municipal Waste to Energy: An Annotated Bibliography of the U.S. Department of Energy's Contractors Reports. ANL CNSV-TN-183, Argonne National Laboratory, Argonne, Illinois.

35. Proceedings of the Sixth Annual Solar and Biomass Energy Workshop. 1986. February 23-27, Altlanta, GA. Available from Southern Agricultural Energy Center, Tifton, GA

36. Proceedings of the Fifth Annual Solar and Biomass Energy Workshop. 1985. April 23-25, Altlanta, GA. Available from Southern Agricultural Energy Center, Tifton, GA

37. Antal, M.J., ed. 1984. Biomass Engineering: Thermochemical Conversion Research Needs. Report of the Kona Workshop, June 1984. Available from University of Hawaii, Honolulu, Hawaii.

38. TVA Office of Agriculture and Chemical Development. 1985. Renewable Energy Alternative: TVA's Biomass Program. TVA Z-189, TVA Office of Agriculture and Chemical Development, Muscle Shoals, Alabama.

39. Roetheli, J.C., et al. 1982. Programmatic Environmental Overview: TVA's Biomass Fuels Program. TVA Z-136, TVA Office of Agriculture and Chemical Development, Muscle Shoals, Alabama.

40. Badger, P.C., et al. 1982. Integrated On-Farm Alcohol Production: Progress Report. TVA Z-134, TVA Office of Agriculture and Chemical Development, Muscle Shoals, Alabama.

41. For additional information, contact California Energy Commission, 1516 9th Street, Sacramento, California. 
42. Mathusa, P.D. 1989. "The New York Sate Energy Research and Development Authority's RD\&D Program in Biomass and Municipal Wastes." Proceedings of the Energy from Biomass and Wastes XII Conference, pp. 15-32, ed. Klass, D.L. Institute of Gas Technology, Chicago, lllinois. (For additional information, contact NYSERDA, 2 Rockefeller Plaza, Albany, New York.)

43. Phillips, V. 1990. "Hawaii Integrated Biofuels Research Report." Submitted under Subcontract XK-9-18000-1 to National Renewable Energy Laboratory, Golden CO. (For additional information, contact HNEI, University of Hawaii, 2540 Dole St., Honolulu, HA).

44. A list of approximately 25 biomass energy reports prepared by Electric Power Research Institute are available from Innovative Communications, P.O. Box 23025, Pleasant Hill, CA 94523.

45. LeGrand, R., T.M. Master, C.S. Warren, and T.D. Hayes. 1989. "Analysis of Biological Gasification of Terrestrial Biomass Using the ECSA Model." Proceedings of the Energy from Biomass and Wastes XII Conference, pp. 925964, ed. Klass, D.L. Institute of Gas Technology, Chicago, Illinois.

46. Chynoweth, D.P., et al. 1989. "Use of Biotechnology for Evaluation of Bacterial Populations in Anaerobic Digestion." Proceedings of the Energy from Biomass and Wastes XII Conference, pp. 963-1000, ed. Klass, D.L. Institute of Gas Technology, Chicago, Illinois.

47. Klass, D., ed. 1989. Proceedings of the Energy from Biomass and Wastes XII Conference. Institute of Gas Technology, 3424 S. State Street, Chicago, Illinois.

48. Klass, D., ed. 1987. Proceedings of the Energy from Biomass and Wastes $X$ Conference. Institute of Gas Technology, 3424 S. State Street, Chicago, Illinois.

49. Klass, D., ed. 1985. Proceedings of the Energy from Biomass and Wastes IX Conference. Institute of Gas Technology, 3424 S. State Street, Chicago, Illinois.

50. Klass, D., ed. 1983. Proceedings of the Energy from Biomass and Wastes VII Conference. Institute of Gas Technology, 3424 S. State Street, Chicago, Illinois,

51. Klass, D., ed. 1982. Proceedings of the Energy from Biomass and Wastes VI Conference. Institute of Gas Technology, 3424 S. State Street, Chicago, Illinois.

52. Klass, D., ed. 1981. Proceedings of the Energy from Biomass and Wastes $V$ Conference. Institute of Gas Technology, 3424 S. State Street, Chicago, Illinois.

53. Klass, D., ed. 1980. Proceedings of the Energy from Biomass and Wastes IV Conference. Institute of Gas Technology, 3424 S. State Street, Chicago, Illinois. 
54. IEA Bioenergy Annual Report. 1993. NUTEK, S-117 86 Stockholm, Sweden.

55. IEA Bioenergy Annual Report. 1992. NUTEK, S-117 86 Stockholm, Sweden.

56. Mitchell, C.P., L Zsuffa, S. Andersson, and D. J. Stevens. 1990. Forestry, Forest Biomass, and Biomass Conversion. The IEA Bioenergy Agreement (19861989) Summary Reports. Elsevier Applied Science, London.

57. Mitchell, C.P., L. Zsuffa, and D.J. Stevens, Guest Eds. 1992. Biomass \& Bioenergy - International Energy Agency Bioenergy Agreement, Progress and Achievements 1989-1991. Pergamon Press, Oxford.

58. Hogan, E. 1989. Proceedings of the Seventh Canadian Bioenergy $R \& D$ Seminar. NRCC 30688. National Resaerch Council of Canada, Ottawa, Ontario, Canada.

59. Granger, C. 1988. Proceedings of the Sixth Canadian Bioenergy R\&D Seminar. Elsevier Applied Science, New York.

60. Hasnain, S. 1984. Proceedings of the Fifth Canadian Bioenergy R\&D Seminar. Elsevier Applied Science, New York. 


\subsection{GASIFICATION RESEARCH}

In general terms, gasification involves the thermal breakdown of organic material from biomass into combustible gases, which can be used as fuel gases in a variety of applications such as boilers and turbines. Depending on the technology used, the gasification products can also be used as synthesis gases to produce liquid fuels such as methanol. Gasification research was the largest component of the Biomass Thermochemical Conversion (BTC) Program between 1980 and 1989. The gasification research projects funded by the BTC Program are described in this chapter.

\subsection{GASIFICATION APPROACHES}

Thermal gasification processes use heat to convert biomass into a mixture of combustible gases including hydrogen, carbon monoxide, methane, and others. The heating value of the gas and its potential uses depend on how the gas is made, as shown in Figure 2.1. Air-blown gasification, for instance, leads to a low-energy product which can be used in many applications but may require derating of equipment such as boilers. Other types of gasification approaches produce medium-energy gases which can either be used as fuel gases to replace natural gas or as synthesis gases which can be used to produce liquid fuels such as methanol. These options are discussed below.

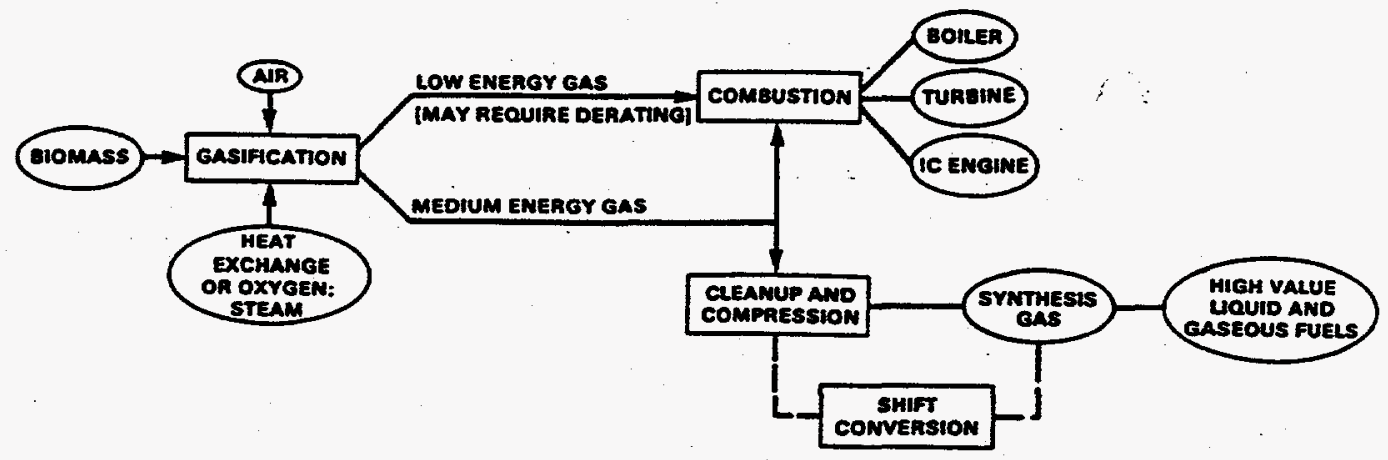

Figure 2.1. Alternatives for Biomass Gasification. 


\subsubsection{Low-Energy (Air-Blown) Gasification}

Low-energy gases, sometimes called producer gases, are generated by partially combusting the biomass feedstock with air. The partial oxidation process produces a mixture composed primarily of carbon dioxide, hydrogen, and nitrogen, as shown in simplified form below:

$$
\text { Biomass }+\mathrm{O}_{2}+\mathrm{N}_{2} \text { (Air) } \rightarrow \mathrm{CO}+\mathrm{H}_{2}+\mathrm{N}_{2}+\text { heat (partial oxidation) }
$$

The reaction with oxygen produces heat to drive the chemical reactions which break apart the solid biomass. In addition to the $\mathrm{CO}$ and $\mathrm{H}_{2}$ products, the process also generates smaller amounts of water, carbon dioxide, methane, ethane, and similar products.

Air contains about $80 \%$ nitrogen, and this nitrogen dilutes the product gas. For this reason, air-blown gasification processes generate fuels with energy contents of about 3.57.8 MJ/NM ${ }^{3}(80-200 \mathrm{Btu} / \mathrm{SCF})$. This product can be used for a variety of uses, but the energy content is low enough that systems such as boilers must frequently be derated. The gasifiers must also be closely coupled with the end-use to avoid loss of the heat in the gas. The dilution by nitrogen also makes these gases unsuitable for synthesis gas use with current catalysts. Low-energy gasifiers were used extensively in World War II to provide an emergency source of fuel for approximately one million vehicles, primarily in Europe.

\subsubsection{Medium-Energy Gasification}

By eliminating the inert nitrogen from the product, medium-energy gases containing 11$20 \mathrm{MJ} / \mathrm{NM}^{3}$ (250-500 Btu/SCF) can be produced. The higher energy density of these products allows them to be used in most retrofit situations without derating problems. The flame temperature of medium-energy gases is higher than that for low-energy products, making them suitable for processes where this is a critical factor. The gases can also be cooled and transported by pipeline for moderate distances, allowing more versatility. With appropriate cleaning and conditioning, the medium-energy gases can also be used for the synthesis of liquid fuels such as methanol or synthetic gasoline. Medium-energy gases therefore offer potential advantages over low-energy gases, but the technologies for producing them tend to be more complex.

Medium-energy gases can be produced from biomass using either oxygen-blown partial oxidation or pyrolytic approaches, shown in simplified form below:

$$
\begin{gathered}
\text { Biomass }+\mathrm{O}_{2} \rightarrow \mathrm{CO}+\mathrm{H}_{2}+\text { heat (partial oxidation) } \\
\text { Biomass }+\mathrm{Heat}+\mathrm{Steam} \rightarrow \mathrm{CO}+\mathrm{H}_{2} \text { (pyrolysis) }
\end{gathered}
$$

The oxygen-blown, partial oxidation pathway is similar to air-blown gasification except that air is replaced by oxygen. The partial oxidation with $\mathrm{O}_{2}$ provides heat to drive the gasification reactions. Nitrogen is eliminated from the product and the energy density 
of the gas is higher. However, oxygen must be provided using processes such as cryogenic separation that increase process cost as compared to air-blown systems.

Because of its high reactivity, biomass can also be gasified using the pyrolytic reaction pathway shown above. The pyrolysis step is endothermic, and heat to decompose the solid biomass feedstock must be supplied from an outside source. This requires special reactor design to provide for heat transfer, but eliminates the expense of purchasing or producing oxygen. In addition to the carbon monoxide and hydrogen products, some of these steam gasification systems also produce significant amounts of methane. Methane will tend to increase the heating value of fuel gases but is undesirable for the synthesis of liquid fuels. The pyrolytic gasification approach works well with biomass but generally cannot be used with other solid fuels such as coal because they are not sufficiently reactive.

\subsubsection{Gasifier Types}

A wide range of gasifier designs are available for producing either low- or mediumenergy gases from biomass. Most of these fall into the two major categories of fixed-bed and moving-bed types. Examples of fixed-bed gasifiers include up-draft and down-draft reactors with fixed metal grates. Moving-bed gasifiers include fluidized bed, entrained bed, and other types of reactors. All must include basic features such as an effective feed system, a method to inject air, oxygen, or heat, a means to remove and clean the gas, and a way to remove ash and unreacted char.

Each gasifier type has specific advantages and limitations which have direct implications for its performance characteristics. Gasifiers which are well suited for some applications may be unsuited for others. Fixed-bed downdraft gasifiers, for example, are simple to design and operate but will generally be limited to small or medium scale applications. Fluidized bed gasifiers are appropriate for medium or large scale applications but are best suited to situations where there is a relatively constant demand for gas. No single type of gasifier is appropriate for all applications, and gasifier selection will depend on the specific application in which it will be used. The BTC Program sponsored research on several gasifier types which are described in this chapter.

\subsection{GASIFICATION RESEARCH EMPHASIS}

The BTC Program focused primarily on the development of medium-energy gasification technologies. As indicated, the medium-energy gasifiers can not only produce high quality fuel gases but also can produce gases for the synthesis of transportation fuels. This versatility was viewed as being very important in the late 1970's when the program was started. At that time, shortages of domestic natural gas supplies and interruptions in petroleum from the OPEC nations spurred efforts to find replacements for these energy products. Medium-energy gasification of biomass was largely at the conceptual stage, and the BTC Program was seen as a means to speed the development of this technology. 
The goals of the BTC Program were to determine the feasibility of a variety of approaches to producing medium-energy gases and to better understand the basics of the gasification process. Gasification approaches of interest included indirectly heated gasifiers such as those at the University of Missouri or Battelle Columbus Laboratory and oxygen-blown reactors such as those at NREL or at the Institute of Gas Technology. The objective of the gasification research was to determine the feasibility of these approaches under continuous, steady-state conditions. The indirectly-heated gasifiers had not been studied in detail previously and offered a unique opportunity to improve biomass gasification. While extensive work on the oxygen-blown gasification of coal had been conducted elsewhere, very little work on biomass had been completed. The BTC Program provided the opportunity to collect data on both types of systems and to compare the performance of each.

In the early stages of the program, experimental research was conducted on several different medium energy gasifier concepts of both the indirectly heated and oxygen blown varieties. Most of the early work was conducted in laboratory scale reactors or small scale semi-continuous gasifiers. Based on results from the initial research, four gasifiers were subsequently tested at larger scales in the 10-20 tpd range. The experimental results from the operation of the four larger scale gasifiers are described in Section 2.3.1 of this report. The research in smaller gasifiers and the additional support research which was conducted to better understand the gasification process itself is described in Section 2.3.2 of this report.

Between 1980 and 1989, the BTC Program also funded limited research on low-energy gasification processes. Low-energy gasification technologies had advanced to the commercial and near-commercial stages of development. Air-blown gasifiers, for example, had been used throughout Europe in World War II as emergency sources of fuel for transportation vehicles. DOE did not want to compete with the private sector in this area, and the BTC Program funded a few projects to collect data which would help in the overall development of the technology. Rate and kinetic data were collected in selected gasifiers to better understand low-energy gasification processes. In addition, the BTC Program funded research on the use of low-energy gas as fuel for internal combustion engines. This effort is described in Section 2.4 of this report.

The BTC Program also funded generic research on the environmental aspects of biomass gasification. This research included studies of gasifier wastewaters and their clean-up, waste disposal via gasification, and catalytic studies focused on the clean-up and conditioning of the gas products. This work is described in Section 2.5.

\subsection{MEDIUM-ENERGY GASIFICATION RESEARCH}

Medium energy gasification projects sponsored by the BTC included both indirectly heated and oxygen blown reactors. The gasification efforts can be grouped in several main categories. Table 2.1. presents a summary of these medium energy gasification projects, which are described in greater detail below. 
Table 2.1. Summary of Medium-Energy Gasification Projects

Funded by the BTC Program.

\begin{tabular}{|c|c|}
\hline TECHNOLOGY AREA & INSTITUTION \\
\hline \multicolumn{2}{|l|}{ Larger Scale Gasifier Projects: } \\
\hline \multicolumn{2}{|l|}{ Indirectly Heated Gasifiers } \\
\hline $\begin{array}{l}\text { Circulating, Fluidized/Entrained Bed } \\
\text { Gasifier }\end{array}$ & Battelle Columbus Laboratory \\
\hline $\begin{array}{l}\text { Fluidized Bed Gasifier with Internal Fire } \\
\text { Tubes }\end{array}$ & $\begin{array}{l}\text { University of Missouri - } \\
\text { Rolla }\end{array}$ \\
\hline \multicolumn{2}{|l|}{ Oxygen-Blown Gasifiers } \\
\hline Pressurized, $\mathrm{O}_{2}$-Blown Gasifier & Institute of Gas Technology \\
\hline Atmospheric, $\mathrm{O}_{2}$-Blown Gasifier & NREL/SynGas, Inc. \\
\hline \multicolumn{2}{|l|}{ Additional Indirectly Heated Gasifier Projects } \\
\hline Pulsed, Fluidized Bed Gasification & MTCI, Inc. \\
\hline Heat Transfer in Fluidized Bed Gasifiers & University of Nebraska \\
\hline Rotary Kiln Gasification & Wright-Malta Corp. \\
\hline Pyrolytic Gasification of Wastes & Garrett Energy and Eng. Co. \\
\hline \multicolumn{2}{|l|}{ Additional Oxygen-Blown Gasifier Projects } \\
\hline $\mathrm{O}_{2}$-Blown Gasification Research & $\begin{array}{l}\text { National Renewable Energy } \\
\text { Lab. }\end{array}$ \\
\hline Synthesis Gas from Alternate Feedstocks & Texas Tech University \\
\hline \multicolumn{2}{|l|}{ Alternative Approaches } \\
\hline Gasification of High-Moisture Feedstocks & Pacific Northwest Laboratory \\
\hline \multicolumn{2}{|l|}{ Biomass Research Related to Coal Gasification } \\
\hline $\begin{array}{l}\text { Gasification of Coal/Wood/Sewage Sludge } \\
\text { Mixtures }\end{array}$ & Dynecology, Inc. \\
\hline Survey of Coal Gasification Technology & Gorham International \\
\hline
\end{tabular}

In the first group, there are four demonstration scale gasifiers (10-20 tpd). These gasifiers were constructed and operated to provide steady-state data which would be 
representative of commercial scale units. Two of these units were indirectly heated gasifiers and two were oxygen-blown units.

In the second group of projects, there are smaller scale gasifiers and laboratory scale studies which supported the development of the concept of indirectly heated gasification. The third group contains projects which supported the development of oxygen-blown gasification. A fourth group consists of research on a low-temperature concept suitable for producing medium-energy gases from high-moisture biomass feedstocks. Finally, limited biomass research was performed as it relates to coal gasification.

\subsubsection{Larger Scale Medium Energy Biomass Gasifier Projects}

The BTC Program funded the operation of four project development unit (PDU) biomass gasifiers with capacities ranging from 10 to 20 tpd of biomass feedstock. These gasifiers included two indirectly heated and two oxygen blown concepts. The indirectly heated gasifiers included a circulating bed reactor at Battelle Columbus Laboratory and a fluidized bed reactor with internal heat exchangers at University of Missouri-Rolla. The oxygen blown concepts included a fluidized bed, pressurized reactor at Institute of Gas Technology and fixed bed reactor based on a concept developed at NREL.

Research sponsored by the BTC Program in the early 1980's had shown that each of these concepts had potential for success. However, the operability and reliability of the concepts under more realistic operating conditions had not been determined. The objective of the work with the larger gasifiers was to gather experimental date under steady state conditions. All four gasifiers were successfully operated for extended periods of up to about 120 hours of continuous operation. The results of this research are described below.

Based upon the success of the gasifiers at this scale, the U.S. Congress appropriated funds in 1985 to construct and operate a near-commercial scale gasifier demonstration facility with a capacity of about 100 tons/day of biomass. The congressional funding stipulated that substantial cost sharing by industry of approximately $50 \%$ would be required. After some delays, and following a competitive solicitation, the project was initiated in 1991. Pacific International Center for High Technology Research (PICHTR) in Hawaii was awarded the contract, and a pressurized gasifier based upon the IGT concept is being built. The gasifier will be capable of operating either in an air- or oxygen-blown mode. In early 1994, the gasifier vessel had been installed at the site, and work to complete the overall system was progressing. Since the main part of this project is occurring well past the time period covered in this report, it will not be discussed in detail here. However, additional details are available through the National Renewable Energy Laboratory in Golden, Colorado. 
Principal Investigators: Mark A. Paisley, Herman Feldmann

Project Objective: Battelle Columbus proposed an indirectly-heated gasifier concept based on a circulating fluidized bed reactor system. The concept offered the potential for high biomass throughput and a relatively high energy content product. BCL conducted research to collect data on the concept. The research consisted of construction and operation of a process development unit (PDU) with the capacity of gasifying up to about 20 tons/day of biomass.

Summary of Research Program: Battelle Columbus Laboratory conducted research on the production of medium-energy gases using a two-vessel, entrained bed gasifier concept. The gasifier is an indirectly heated reactor in which biomass is pyrolytically converted to gases. Biomass is gasified by contacting the feedstock with the hot, entrained bed material (sand). Unreacted biomass char plus the cooled sand is transferred to a separate, fluidized bed combustor where the char is burned. The heated sand is then recirculated back to the gasifier to provide heat for gasification. The hot sand serves as both a heat transfer medium and as the entraining medium for the gasifier. The reactor operates at atmospheric pressure. A conceptual diagram of the $B C L$ process is shown in Figure 2.2.

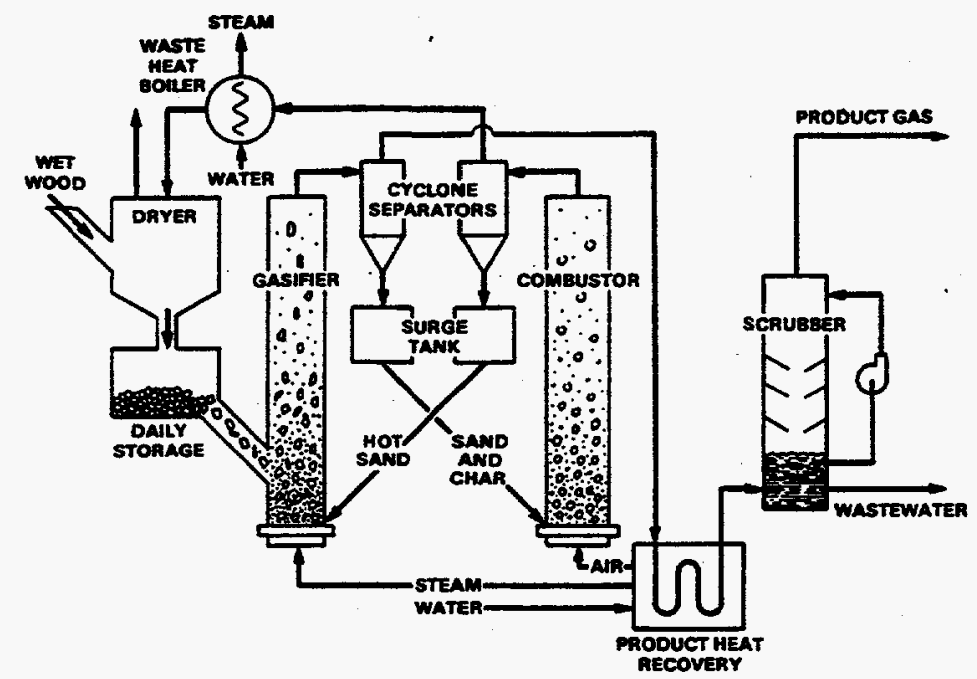

Figure 2.2. Conceptual Diagram of the BCL Gasifier.

The research program was conducted in two phases. Initially, a $15 \mathrm{~cm}$ ID entrained bed gasifier with a manually operated feed system was used. Internal baffles were installed in the head of the reactor in some test runs to increase the biomass residence time. The baffles were found to increase carbon conversion efficiencies, but similar results could be obtained by varying other reaction parameters. In the second phase of work, the original reactor was replaced with a $25 \mathrm{~cm} \mathrm{ID} \mathrm{gasifier} \mathrm{and} \mathrm{an} \mathrm{automated} \mathrm{feed} \mathrm{system.}$ The $25 \mathrm{~cm}$ gasifier had an active length of $6.9 \mathrm{~m}$ and was capable of gasifying approximately 20 tpd of biomass. Internal baffles were used in a few experimental tests but were found to have no effect on carbon conversion. The feed system consisted of multiple screw feeders. The initial feed screw delivered biomass at a measured rate to 
a second screw auger which rapidly injected the feed into the gasifier. Both the large and small gasifiers were outfitted with numerous temperature and pressure sensors, and both systems were coupled with a bubbling bed combustor. The combustor was fueled with both the unreacted char from the gasifier and natural gas to allow flexibility in the experimental unit.

The gasifier system was operated to determine the overall feasibility of the BCL concept. The objectives of the experimental program were to:

- Determine product yields and compositions

- Determine the effects of using various types and sizes of biomass feedstocks

- Identify parameters controlling gasification and determine gasifier performance

- Demonstrate overall process feasibility under steady-state conditions.

Typical gasifier experiments were conducted in single, 10-hour shifts with data collection over a 4- to 7-hour period. The gasifier PDU was specifically designed with features to allow reaction temperatures to be changed rapidly. For instance, the gasifier was surrounded by electrical heaters and insulation to balance heat losses, and the fluidized bed combustor could burn supplemental natural gas to increase the temperature of the bed material. These types of features are commonly used in experimental facilities to help speed data collection but would not be part of commercial units. In addition to the typical 10-hour experiments, BCL operated the PRU for two test periods of 120 hours of continuous operation to evaluate longer term gasifier stability.

\section{Summary of Experimental Results:}

Biomass Feedstocks - A variety of woody biomass feedstocks were tested in the gasifier as listed below:

- $\quad$ Mixed hardwood chips

- $\quad$ Mixed oak, birch, maple chips

- Hardwood bark

- Red oak chips

- Swamp oak chips

- Whole tree hogged fuel
- Cherry chips

- Pine chips

- Pine sawdust

- Birch and maple chips

- Gum chips

- $\quad$ Shredded stumps

In addition, refuse-derived fuel (RDF) was used as a feedstock in selected experimental tests. All feedstocks gasified as expected, and no feedstock related problems were encountered. The feeder system successfully handled all materials, including fibrous bark. Even in the smaller $15 \mathrm{~cm}$ gasifier, bark strands as long as $30 \mathrm{~cm}$ were fed and gasified without problem.

Product Yields and Composition - The composition of the product gas from the BCL gasifier is shown in Table 2.2. The gas has a relatively high heating value, measured to be in the range of $16.7-18.5 \mathrm{MJ} / \mathrm{NM}^{3}(450-500 \mathrm{Btu} / \mathrm{SCF})$ in most experimental test runs. 
The heating value of the product gas is largely independent of the moisture content of the wood feedstock, as shown in Figure 2.3. This result is in contrast to oxygen- or airblown gasifiers where the gas heating value is dependent on the feedstock moisture. In both cases, increases in moisture content will increase the amount of heat required for gasification. In the BCL gasifier, the higher moisture feedstocks are not gasified as completely, and the resulting char is transferred to the combustor to be burned. In effect, the additional heat required to gasify higher moisture biomass is provided by burning additional feedstock in the BCL concept. As a result, the quantity of product gas is reduced when moist feedstocks are gasified, but the heating value of the gas remains constant.

Table 2.2. Typical BCL Product Gas Analysis (Dry Basis).

\begin{tabular}{|l|r|c|}
\hline \hline Product & $\%$ Volume & $\begin{array}{c}\text { Heating Value } \\
\text { (MJ/NM? }\end{array}$ \\
\hline Hydrogen & 17.5 & 2.1 \\
\hline Carbon monoxide & 50.4 & 6.0 \\
\hline Carbon dioxide & 9.4 & $-\ldots$ \\
\hline Methane & 15.5 & 5.8 \\
\hline $\mathrm{C}_{2} \mathrm{H}_{4}$ & 6.1 & 3.6 \\
\hline $\mathrm{C}_{2} \mathrm{H}_{6}$ & 1.1 & 0.7 \\
\hline $\begin{array}{l}\text { Heating Value: } 18.4 \mathrm{MJ} / \mathrm{NM}^{3}(493 \mathrm{Btu} / \mathrm{SCF}), \text { ASTM } \\
\text { Method D3588 }\end{array}$ \\
\hline
\end{tabular}

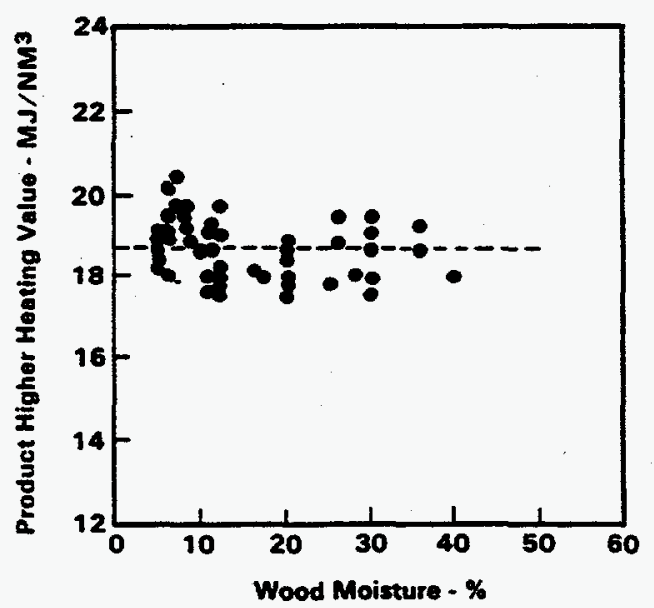

Figure 2.3. Product Gas Heating Value versus Feedstock Moisture Content - BCL. 
Char from the entrained gasifier was transferred to the bubbling bed combustor and burned to provide heat. Combustion was essentially complete, and no char could be recovered for analysis.

In addition to the product gas and char, the product gas stream also contained organic tars in small amounts, typically $0.5-1.0 \%$ by of the dry feed by weight. The yield of tar was independent of gasifier temperature over a range from $700-1000{ }^{\circ} \mathrm{C}$. The tars were analyzed by PNL (discussed in Chapter 3) and consisted of highly condensed aromatics with a general absence of functional groups such as hydroxyls. The tars were water insoluble with the following general characteristics:

Tar Physical Properties:

$\begin{array}{ll}\text { Viscosity } & 9800 \mathrm{cP} \mathrm{@} \mathrm{51}{ }^{\circ} \mathrm{C} \\ \text { Density } & 1.14 \mathrm{~g} / \mathrm{ml} @ 22^{\circ} \mathrm{C} \\ \text { HHV (wet) } & 23.2 \mathrm{MJ} / \mathrm{kg}(10,000 \mathrm{Btu} / \mathrm{lb})\end{array}$

In the experimental test program, the tars were collected from the product gas stream but were not re-injected into the combustor. In a commercial system, the tars would be injected into the combustor, which would significantly reduce or eliminate the amount of tar produced.

Gasifier Performance - Gasifier performance in the 15 and $25 \mathrm{~cm}$ reactors was measured as a function of design and operating parameters. Carbon conversions, gas yield and composition, and gasifier throughput were measured as a function of the following independent parameters:

- Wood feed rate

- Biomass type and composition

- $\quad$ Feed gas flow rate and composition

- Sand circulation rate

- Combustor temperature.

In the $15 \mathrm{~cm}$ reactor, the gasifier temperature was the main parameter which affected gasifier performance. Carbon conversions ranged from approximately $30 \%$ at temperatures of $720^{\circ} \mathrm{C}$ to approximately $75 \%$ at temperatures between $820-930{ }^{\circ} \mathrm{C}$ in the smaller gasifier. Char which was burned in the fluidized bed combustor was not included in these figures, so the overall carbon conversion for the integrated system was higher. In some test runs, internal baffles were installed in the $15 \mathrm{~cm}$ gasifier to increase the contact between the bed material and the biomass feedstock. While the baffles increased the carbon conversion, it was found that identical results could be obtained by optimizing factors such as the amount of bed material being fed to the reactor. For this reason, most of the experimental data was obtained without the use of internal baffles.

Carbon conversions in the $15 \mathrm{~cm}$ gasifier were generally insensitive to the type of feedstock used but were slightly higher for bark and sawdust than for chips. It is not clear whether the reactivity differences arose from differences in the particle size distributions or the reactivity of the feedstock, but the differences were slight in any case. 
Carbon conversions were also independent of either gasifier gas velocity (from 3$12 \mathrm{~m} / \mathrm{sec}$ ) or biomass feed rate over the range of 16 to $160 \mathrm{~kg} / \mathrm{hr}$ of biomass. Feedstock throughput in the $15 \mathrm{~cm}$ gasifier was limited by the ability to manually load the feedstock into the feed hopper, but feedstock rates as high as $160 \mathrm{~kg} / \mathrm{hr}$ were obtained, resulting in a cross-sectional throughput of about $8800 \mathrm{~kg} / \mathrm{hr}-\mathrm{m}^{2}\left(1800 \mathrm{lb} / \mathrm{hr}-\mathrm{ft}^{2}\right)$. This cross sectional throughput does not include the area of the combustor.

In the second phase of work, the original gasifier was replaced with a $25 \mathrm{~cm}$ reactor to test the scalability of the concept. The feed system for the gasifier was also modified to allow automated feeding of biomass from 2 to 20 tons/day of feedstock. Modifications to the combustor were also made to increase heat output. The results with the $25 \mathrm{~cm}$ reactor were consistent with the smaller gasifier.

In the $25 \mathrm{~cm}$ unit, temperature was again the only parameter having measurable effect on carbon conversion. Carbon conversions ranged from $30 \%$ at $650{ }^{\circ} \mathrm{C}$ to $95 \%$ at $980{ }^{\circ} \mathrm{C}$. (In commercial systems, carbon conversions above about $70 \%$ would not be desirable because the unreacted char is required for heat production). Internal baffles in the $25 \mathrm{~cm}$ reactor were determined to have no effect on gasifier performance and were not subsequently used. Gasifier performance was also unaffected by the biomass feed rate. Because of the larger feedstock requirements, the effects of various biomass feedstocks were not examined in detail. Throughputs of approximately $16,600 \mathrm{~kg} / \mathrm{hr}-\mathrm{m}^{2}$ $\left(3400 \mathrm{lb} / \mathrm{hr}-\mathrm{ft}^{2}\right)$ were obtained in the gasifier while maintaining carbon conversions sufficient for thermally balanced operation.

Although the gasifier was typically operated for single-shift periods, limited expanded tests were also performed. In the longest of these tests, the gasifier was operated continuously for five 24-hour periods with wood feeding for 80 hours. Continuous operation was achieved for 72 hours, with one stop to repair a weld. The system operation was stable throughout the period, and no unexpected or non-equilibrium situations were encountered.

In addition to operation with wood, the BCL gasifier was also operated using RDF as a fuel. The results were very similar to those using woody biomass. Product gases of 18$20 \mathrm{MJ} / \mathrm{NM}^{3}$ were generated with high throughputs of approximately $9800 \mathrm{~kg} / \mathrm{hr}-\mathrm{m}^{2}(2000$ $\left.\mathrm{lb} / \mathrm{hr}-\mathrm{ft}^{2}\right)$. No unexpected operational problems were encountered, and the emissions when using the RDF were similar to those using wood.

Combustor Performance - While the gasifier is the primary reactor in the BCL system, the closely coupled combustor is also an important part of the system. In the experimental tests of the gasifier, a bubbling bed combustor was used to provide heat. BCL also conducted limited research using a multi-solids fluidized bed combustor to support the gasification research. The tests were conducted in a $15 \mathrm{~cm} \mathrm{ID} \mathrm{circulating}$ fluidized bed reactor. The combustor was operated in both fluidized- and entrained-bed modes using wood-derived charcoal as a replacement for gasifier char in experimental tests. Carbon conversions were dependent on temperature but were $95-100 \%$ at $980{ }^{\circ} \mathrm{C}$. Wood ash added at concentrations as high as $20 \%$ of the charcoal elutriated quickly from the bed, and no problems of ash agglomeration were encountered. Carbon monoxide 
emissions from the combustor were typically $9-90 \mathrm{~g} / \mathrm{M} \mathrm{kJ}(0.02-0.2 \mathrm{lb} / \mathrm{M} \mathrm{Btu})$ and were independent of combustor temperature or excess oxygen level. Nitrogen oxide emissions were typically $9-14 \mathrm{~g} / \mathrm{M} \mathrm{kJ}(0.2-0.3 \mathrm{lb} / \mathrm{M} \mathrm{Btu})$, or less than half the New Source Performance Standards for stationary sources.

Burner tests of the tars from the gasifier were also performed. Combustion gases from these tests were passed through a modified EPA Method 5 train, and the extracts were analyzed for various PAH constituents. The tests showed the tars would burn as cleanly as natural gas with respect to PAH formation.

Current Status: With DOE funding provided through NREL, the experimental PRU at $\mathrm{BCL}$ is currently being operated to determine the feasibility of using this gasifier with a gas turbine for electric power generation and to provide a clean synthesis gas for transportation fuels products. Initial experiments have tested catalysts to condition the hot gas from the unit. The catalysts would both crack tars and also steam reform part of the methane. A $200 \mathrm{~kW}$ gas turbine is being added to the gasifier system in 1994 . The turbine, contributed by Solar, will be operated on the product gas of the gasifier. Initially, the gasifier product will simply be scrubbed and then be burned in the turbine. Depending on results of these tests, additional hot gas conditioning steps may be tested.

$\mathrm{BCL}$ is also in the planning stage for constructing a 200 tpd "proof of concept" gasifier at the McNeil power facility in Burlington, Vermont. The gasifier would be operated at the existing facility to determine overall feasibility and system reliability at a nearcommercial scale. It is currently envisioned that a combination of private and federal funds would be used to build and operate the facility.

\section{Selected References:}

Feldman, M.F., M.A. Paisley, H.R. Appelbaum, and D.R. Taylor. 1988. Conversion of Forest Residues to a Methane-Rich Gas in a High-Throughput Gasifier. PNL-6570, Pacific Northwest Laboratory, Richland, Washington.

Feldman, M.F. and M.A. Paisley. 1988. "Conversion of RDF to Medium-Btu Gas." In Thermochemical Conversion Program Annual Meeting, pp. 101-111, SERI/CP-231-3355, National Renewable Energy Laboratory, Golden, Colorado.

\subsubsection{Fluidized Bed Gasifier with Internal Heat Exchangers - University of Missouri-Rolla}

Principal Investigator: Virgil J. Flanigan

Project Objective: The university proposed a medium-energy gasification concept where the heat for biomass gasification was to be provided to a fluidized bed reactor using a fire-tube heat exchanger located inside the reactor. The purpose of the research was to determine the feasibility of using fire tubes as internal heat exchangers. The research consisted of the construction and operation of a $50 \mathrm{~cm}$ gasifier with a capacity of up to 
approximately 9 tons/day of biomass. Additional research performed by the University on low-energy gas production is discussed in Section 2.4 of this report. The low energy research used a gasifier donated by the Adolph Coors Company.

Summary of Research Program: The University of Missouri-Rolla conducted research on the production of medium-energy gases using an indirectly-heated, fluidized bed gasifier. Heat for the gasification reaction was supplied by passing hot combustion gases through a heat exchanger placed inside the fluidized bed reactor. The heat exchanger consisted of a bundle of U-tubes oriented vertically in the reactor, as shown in Figure 2.4.

Indirectly Fired Wood Gasifier

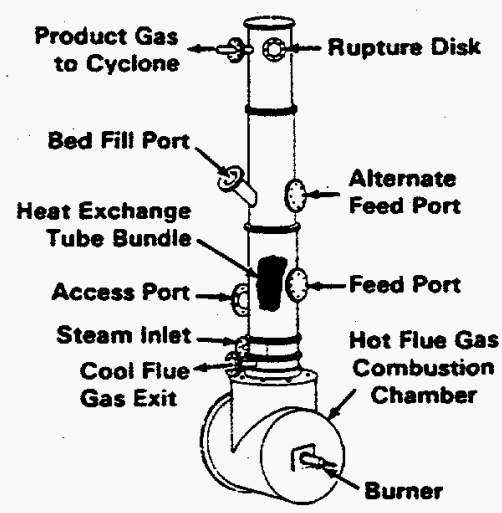

\section{Gasifier Internal Heat Exchanger}

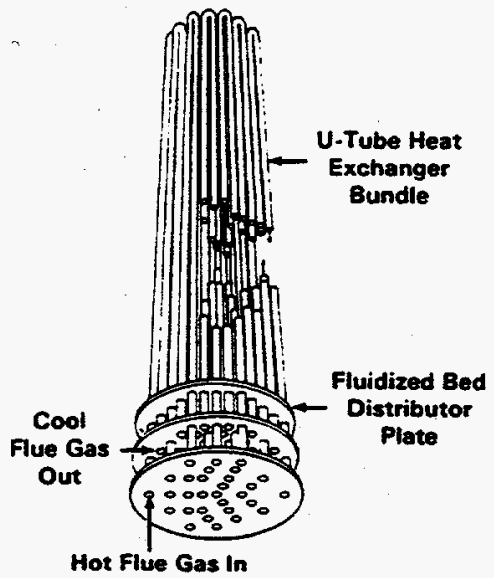

Figure 2.4. Schematic Diagram of the University of Missouri-Rolla Gasifier.

The gasifier system consisted of three major components including the gasifier vessel, the U-tube heat exchanger, and a combustor to provide heat to the tube bundle. The fluidized bed gasifier vessel consisted of a stainless steel cylinder measuring $64 \mathrm{~cm} \mathrm{ID}$ by $5.2 \mathrm{~m}$ long. Various ports along the vessel supported instrumentation and feeding systems. The bed material was fluidized using steam from a low pressure boiler. Two different feeder systems were tested on the gasifier. Initially, a simple $15 \mathrm{~cm}$ auger was used to meter biomass into the reactor at the bottom of the fluidized bed. Later, a livebottom feeder was added to feed biomass into the reactor at the top of the tube bundle. Twin metering screws delivered a controlled amount of wood to an injection auger, which then rapidly transferred the feed to the gasifier. The rapid injection reduced the tendency for the biomass to partially react before entering the gasifier. The gasifier could be operated with either or both feeders, and feedstock rates could be varied from .5 to 9 tons/day.

The heat exchange tube bundle used $30 \mathrm{U}$-tubes with a $2.5 \mathrm{~cm}$ OD. Hot combustion gases entered the tube bundle through a lower tube plate, then passed upward through both an upper tube plate and a distributor plate into the gasifier. The exhaust end of the tubes were welded to an upper tube plate. Initially, ceramic tubes were used in the inlet section to protect the bundle from high temperatures. Ceramic tubes were inserted into stainless steel sleeves on the upper and lower tube plates. After several runs, the ceramic cracked, and the tubes between the upper and lower plates were replaced with 
RA-330 steel. The inlet section beneath the lower tube plate was replaced with a wetmold ceramic, which hardened with the initial startup.

The gasifier system used a propane combustor to provide heat to the U-tube heat exchanger. The system consisted of two burners capable of producing a total of $2.1 \mathrm{MM} \mathrm{kJ} / \mathrm{hr}$. Hot combustion gases exited the gasifier through the U-tube heat exchanger bundle. In some tests, additional heat was extracted from the flue gas to increase steam temperatures. Propane was chosen as a fuel to simplify operation of this research unit. In a commercial gasifier, heat for the tube bundle could be provided either by burning part of the medium-energy fuel gas from the gasifier or by burning lowenergy gas from a separate gasifier.

The gasifier was operated to determine the feasibility of this concept and to ensure that the heat transfer was sufficient to drive the pyrolytic reactions which occur in the indirectly heated gasifiers. In conducting this research, the relationships between process variables such as reaction temperature on gasifier performance were determined. Most experimental test runs were performed for a few hours following gasifier start-up and temperature equilibration. Limited longer-duration tests of up to 5 days of continuous operation were also successfully completed. In total, the gasifier unit was operated for over 4000 hours.

\section{Summary of Experimental Results:}

Biomass Feedstocks - The main feedstock used in the research effort was hardwood sawdust, primarily oak. The effects of feedstock difference on gasification were not examined.

Product Yields and Composition - As indicated previously, wood could be fed to the gasifier either at the top or the bottom of the fluidized bed. The location of the feeder affected the product gas composition. Typical product gas compositions for the top and bottom feeding positions are shown in Table 2.3. The higher heating value of the gas ranged from 14 to $20 \mathrm{MJ} / \mathrm{NM}^{3}$ (375 to $550 \mathrm{Btu} / \mathrm{SCF}$ ).

When the feedstock entered at the bottom of the fluidized bed, the lomger residence time of the material was sufficient that secondary reactions increased the relative amounts of hydrogen as compared to carbon monoxide, due to the water gas shift reaction. When fed from the top, the shorter residence times of the material lead to lower hydrogen concentrations in the product gas.

In addition to the product gas, the gasifier also produced tars and char. Tar formation was related to bed temperature and ranged from about $10 \%$ at $620{ }^{\circ} \mathrm{C}$ to about $6 \%$ at $790{ }^{\circ} \mathrm{C}$. Elemental analysis indicated the tars contained about $69 \%$ carbon, $7 \%$ hydrogen, $22 \%$ oxygen, and $1.8 \%$ ash. Detailed analysis of the tars was not reported by University of Missouri but the tars were analyzed by PNL, as reported in Chapter 3. The high tar formation caused some operating problems at the lowest temperatures, but the amounts of tar would be greatly reduced in a commercial unit which would operate at about $875{ }^{\circ} \mathrm{C}$. Char formation is related to gasifier efficiency.and is discussed below. 
Table 2.3. Typical Gas Compositions and Heating Values for Top- and Bottom-Fed Gasifier Operation, U. Missouri-Rolla ( $750{ }^{\circ} \mathrm{C}$ inlet temperatures, test runs $\# 166$ and $\# 211$ ).

\begin{tabular}{|l|c|c|}
\hline Product & $\begin{array}{c}\text { Volume \% } \\
\text { Top Feed }\end{array}$ & $\begin{array}{c}\text { Volume \% } \\
\text { Bottom Feed }\end{array}$ \\
\hline Hydrogen & 21.3 & 31.4 \\
\hline Carbon Monoxide & 44.1 & 34.6 \\
\hline Carbon Dioxide & 12.8 & 15.6 \\
\hline Methane & 13.2 & 12.0 \\
\hline $\mathrm{C}_{2} \mathrm{H}_{4}$ & 4.0 & 3.1 \\
\hline $\mathrm{C}_{2} \mathrm{H}_{6}$ & 0.1 & 0.7 \\
\hline $\mathrm{C}_{3}+$ & 3.3 & 1.5 \\
\hline Nitrogen & 0.3 & 0.9 \\
\hline $\begin{array}{l}\text { Higher Heating Value, } \\
\text { MJ/NM }\end{array}$ & 19.7 & 16.9 \\
\hline Gas Yield, NM ${ }^{3} / \mathrm{kg}$ feed & 0.80 & 0.74 \\
\hline
\end{tabular}

Gasifier Performance - The gasifier system allowed the effects of three main parameters to be studied. These include temperatures ranging from $560-800{ }^{\circ} \mathrm{C}$, wood feed rates from 45 to $180 \mathrm{~kg} / \mathrm{hr}$, and steam rates from 78 to $270 \mathrm{~kg} / \mathrm{hr}$. As indicated. the location of the feeder system also influenced performance.

Temperature, as expected, was shown to have the greatest impact on gasifier performance. The amount of product gas increased from about 0.030 to about $.045 \mathrm{~kg}$-mole $/ \mathrm{kg}$ wood over the range from $620-790^{\circ} \mathrm{C}$. Likewise, gasification thermal efficiencies increased from about $60 \%$ to about $80 \%$ over the same temperature range.

The temperature effects were also influenced by the location of the feed inlet into the gasifier. When fed from the top, the gasifier was approximately $10 \%$ more efficient than when bottom fed. When top-fed, the higher heating values of the gas increased from about 18.6 to $20.8 \mathrm{MJ} / \mathrm{NM}^{3}$ as temperature increased from $650-790{ }^{\circ} \mathrm{C}$. By comparison. the higher heating values of the product gas from the bottom-fed configuration remained approximately constant at about $16.8 \mathrm{MJ} / \mathrm{NM}^{3}$ over the same temperature range.

The amount of steam added to the gasifier, as measured by the steam-to-wood ratio, had a much smaller effect on gasifier performance. The gasification test runs were divided into three groups including those with low (less than 1.2), medium (between 1.2 and 2.0) 
and high (greater than 2.0) steam/wood ratios. Because of considerable scatter in the data, only general trends can be noted. Tar yields appear to be largely independent of the steam/wood ratio over a wide temperature range. On the average, gasification efficiencies tend to be about $5 \%$ greater when the high rather than low steam/wood rations were used. Sufficient steam is needed to ensure adequate fluidization of the bed, but excess steam adds process costs. In the experimental unit, steam/wood ratios of about 1.5 appeared to be optimum. Gasifier performance was largely independent of feed rates over the range 45 to $180 \mathrm{~kg} / \mathrm{hr}$.

The experimental test runs also provided information on overall heat transfer coefficients in the reactor. With indirectly heated gasifier concepts, the ability to transfer heat efficiently is crucial to successful operation. Overall heat transfer coefficients for the reactor varied from $80-230 \mathrm{~kJ} / \mathrm{hr}-\mathrm{m}^{2}-{ }^{\circ} \mathrm{C}\left(4.3-12.0 \mathrm{Btu} / \mathrm{hr}-\mathrm{ft}^{2}-{ }^{\circ} \mathrm{F}\right)$, with typical figures from 155 to $195 \mathrm{~kJ} / \mathrm{hr}-\mathrm{m}^{2}-^{\circ} \mathrm{C}\left(8.0\right.$ to $\left.10.0 \mathrm{Btu} / \mathrm{hr}-\mathrm{ft}^{2}-^{\circ} \mathrm{F}\right)$ in later runs. As evidenced by the insensitivity to biomass feed rates, these heat transfer rates appear to be satisfactory.

Current Status: The University of Missouri is currently developing a pyrolyzer concept based on the internally heated gasifier. The pyrolyser will be used to dispose of waste tires. In early 1994, a facility to dispose of 7 million tires per year was being built in China. The research team also is interested in using the gasifier concept in gas turbine applications for power generation.

Selected References:

Flanigan, V.J., O.C. Sitton, and W.E. Huang. 1988. The Development of a 20-Inch Indirect Fired Fluidized Bed Gasifier. PNL-6520, Pacific Northwest Laboratory, Richland, Washington.

Flanigan, V.J., A. Punyakumleard, and O.C. Sitton. 1984. "Steam Gasification of Wood by Indirect Fired Internal Heating." In Proceedings of the 6th Symposium of Biotechnology for Fuels and Chemicals, C.D. Scott, ed., Symposium No. 14, pp. 3-14, John Wiley \& Sons, New York, New York.

\subsubsection{Pressurized Fluidized-Bed, Oxygen-Blown Gasifier - Institute of Gas Technology (IGT)}

Principal Investigator: Suresh Babu

Project Objective: The research at IGT centered on an oxygen-blown gasifier capable of operating at pressures up to about $35 \mathrm{~atm}$. The ability to generate a pressurized gas product is a potential advantage for many applications, such as methanol production and gas turbine operation. IGT conducted research to test the feasibility of using a fluidizedbed, oxygen-blown gasifier to produce medium-energy gas from biomass. The research consisted of the construction and operation of a research gasifier with a nominal feedstock capacity of about 12 tons/day of biomass. In addition, bench-scale and coldflow fluidization tests were performed to support the gasifier development. 
Summary of Research Program: Institute of Gas Technology conducted research on an oxygen-blown, pressurized fluidized bed gasifier. The IGT gasifier used partial combustion of biomass with oxygen to provide heat for gasification. This approach was significantly different than the indirectly-heated gasifier concepts tested at Battelle Columbus Laboratory and at the University of Missouri-Rolla. The IGT gasifier was also capable of operating at pressures up to about $35 \mathrm{~atm}$. In applications such as methanol synthesis or for powering gas turbines, the product gas must be pressurized prior to use. Gasifying the biomass at pressure generally costs less than mechanically compressing the product gas. Pressurized fluidized bed combustors are used successfully in many commercial applications, and the IGT gasifier is based on this type of technology.

The IGT gasifier consisted of an $29 \mathrm{~cm}$ ID Incoloy reactor surrounded by a $1 \mathrm{~m}$ OD carbon-steel pressure vessel. Thermal protection for the outer pressure vessel was provided with fiber insulation and by nitrogen flowing between the two reactor vessels. The reactor was $6.4 \mathrm{~m} \mathrm{ft}$ long, including a $2.1 \mathrm{~m}$ reaction zone and a $2.3 \mathrm{~m}$ disengagement zone that had a larger $46 \mathrm{~cm}$ ID. The surrounding pressure vessel had a total length of $7.3 \mathrm{~m}$. The gasifier was operated at pressures of 6 to $23 \mathrm{~atm}$ and had a design capability of $35 \mathrm{~atm}$ ( $500 \mathrm{psig}$ ). The bed material consisted of small alumina spheres and was fluidized with oxygen and, in most runs, steam. The gases exiting from the reactor were cleaned in a cyclone and then flared. The IGT gasifier is shown schematically in Figure 2.5.

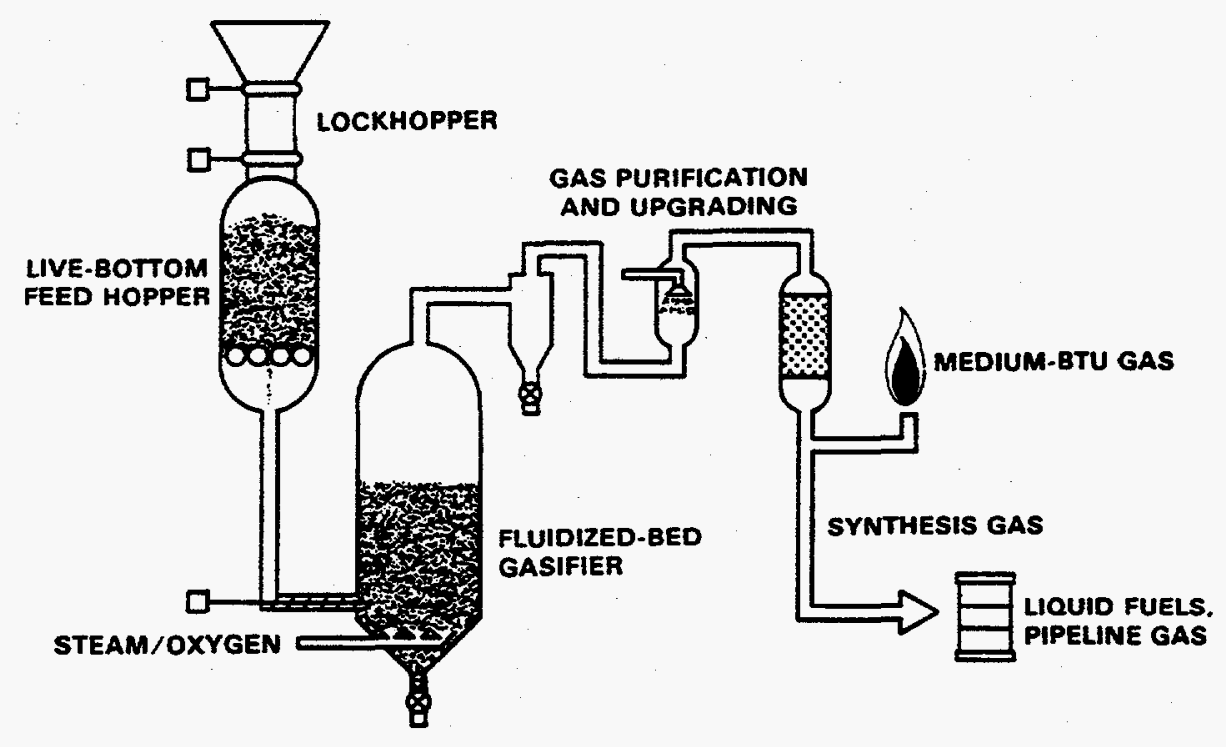

Figure 2.5. Schematic Diagram of the IGT Oxygen-Blown Gasifier.

Biomass was fed to the gasifier by a multiple-screw feed auger system from a pressurized feed hopper. This system was capable of feeding wood chips of up to $3.8 \mathrm{~cm}$ Biomass entered the feed hopper through a pressure lock hopper with sliding gate valves at each end. Biomass at ambient pressure entered the lock hopper, and the upper gate valve was 
then closed. After the hopper was pressurized, the bottom valve was opened and the biomass moved into the pressurized feed hopper where it was then fed into the gasifier. Continued cyclic operation of the gate valves kept the feed hopper full. Although the operational problems were initially encountered with the gate valves, IGT and engineering consultant Tom Miles effected innovative design changes which resulted in trouble-free operation. These changes included, among others, the addition of hydraulic lifters to help the valve seal against pressure. As a result of this work, the gate valves offered a simple and effective means of feeding pressurized biomass reactors.

The gasifier was operated to determine overall system performance and to perform parametric studies including determination of oxygen requirements. Experimental data was typically collected over 4- to 8-hour periods of steady-state performance following startup. The startup and cooling down procedures took approximately 8 hours each before and after the data collection periods. Limited longer-duration test runs up to 3 days in length were also performed, and the data from the longer operation matched that of the shorter test runs.

\section{Summary of Experimental Results:}

Biomass Feedstocks - Gasification tests were performed with three wood feedstocks including maple chips, whole tree chips containing over $90 \%$ red oak, and mixed whole tree chips which consisted of about one third oak, one third maple, and the remaining third a mixture of birch, pine, and brush. Gasifier performance was relatively insensitive to differences in these feedstocks. Oxygen demand as a function of temperature was unchanged for either maple or whole tree mixed chips. Gasification of the mixed chips resulted in approximately $5 \%$ greater carbon conversion than for the maple chips over the temperature range $760-925^{\circ} \mathrm{C}$, but the differences appear to arise primarily from different moisture contents in the two feedstocks.

Product Yields and Composition - Typical compositions of the medium-energy gas produced by IGT are shown in Table 2.4. The composition corresponds to an average fluidized bed temperature of $825^{\circ} \mathrm{C}$ and a pressure of about $20 \mathrm{~atm}$.

As indicated above, nitrogen was used between the reactor vessel to provide thermal protection for the pressure vessel. In the operation of the gasifier, some of the nitrogen routinely passed into the product stream. The raw product gas therefore contained 15$20 \%$ nitrogen by volume. In a commercial reactor, the gasifier would be refractory lined, eliminating the need for nitrogen. The gas composition values in Table 2.4 have been adjusted to a dry, nitrogen-free basis to more accurately reflect the composition of the gas product from a commercial unit.

In addition to the gases, small amounts of tars and char were also formed. Tar yields were typically $1.5-3.5 \%$ of the weight of the feed and were largely insensitive to gasifier temperature. Analysis showed the tars to be composed of several major fractions including a small aqueous fraction, more than two-thirds light oils, plus small amounts of phenols and poly-aromatic hydrocarbons. Tar yields appeared to decrease at higher 
pressures and at higher steam rates. Char formation is related to gasifier efficiency and is discussed below.

Table 2.4. Typical Gas Composition and Heating Value for IGT Gasifier (Test Run GT-13, $825^{\circ} \mathrm{C}$, $20 \mathrm{~atm}, 0.23 \mathrm{~kg}$ Oxygen $/ \mathrm{kg}$ Feed).

\begin{tabular}{||l|c|}
\hline Product & Volume \% \\
\hline Hydrogen & 30.3 \\
\hline Carbon Monoxide & 15.5 \\
\hline Carbon Dioxide & 37.8 \\
\hline Methane & 14.9 \\
\hline $\mathrm{C}_{2} \mathrm{H}_{4}$ & 0.02 \\
\hline $\mathrm{C}_{2} \mathrm{H}_{6}$ & 1.12 \\
\hline $\mathrm{C}_{3}+$ & 0.31 \\
\hline Higher Heating Value, $\mathrm{MJ} / \mathrm{NM}^{3}$ & 12.3 \\
\hline Gas Yield, $\mathrm{NM}^{3} / \mathrm{kg}$ feed & 1.03 \\
\hline
\end{tabular}

Gasifier Performance - Gasifier performance was measured as a function of the following parameters:

- Temperature and oxygen requirements

- Steam feed rate

- Operating pressure

- Feed rate

- Bed height

- $\quad$ Feedstock moisture content.

The temperature in the oxygen-blown gasifier is dependent upon the amount of oxygen added. For feedstock at $10 \%$ moisture content, the oxygen requirement varied from $0.17 \mathrm{~kg} / \mathrm{kg}$ wood at $755^{\circ} \mathrm{C}$ to $0.31 \mathrm{~kg} / \mathrm{kg}$ wood at $980^{\circ} \mathrm{C}$. At $815^{\circ} \mathrm{C}$, the typical oxygen requirement was about $0.23 \mathrm{~kg} / \mathrm{kg}$ wood. As expected, higher bed temperatures increase carbon conversion in the gasifier. Carbon conversion to gases ranged from about $85 \%$ at $760{ }^{\circ} \mathrm{C}$ to over $96 \%$ at $900{ }^{\circ} \mathrm{C}$. At $815^{\circ} \mathrm{C}$, typical carbon conversions to gas were approximately $93 \%$, and this figure could potentially be increased by reinjecting liquid products into the gasifier.

The effects of pressure were examined by conducting test runs at about 6 and 20 atm. In the low pressure tests, the feedstock throughput rate was about $50 \%$ of that at higher 
pressure in order to maintain appropriate superficial gas velocities. Under these conditions, the total carbon conversions were insensitive to pressure, but the composition of the gases showed some pressure dependence. The concentrations of hydrogen and methane increased at higher pressure while the concentrations of carbon monoxide decreased. These shifts caused the higher heating value of the gas to be 1.5 to 2.0 $\mathrm{MJ} / \mathrm{NM}^{3}$ higher for the gases produced at low pressure.

The moisture content of the feedstock was varied from about 5 to $27 \mathrm{wt} \%$. The primary effect of increasing feedstock moisture was an accompanying increase in oxygen demand to maintain gasifier temperature. The compositions of the gases were also affected, with increases in $\mathrm{CO}$ and $\mathrm{CO}_{2}$ as feedstock moisture increased.

The performance of the gasifier was relatively insensitive to feedstock throughputs ranging from $160-470 \mathrm{~kg} / \mathrm{hr}$ (wet), and to bed height. Performance was also largely insensitive to the steam feed rate over the measured range from 0.50 to $0.86 \mathrm{~kg} / \mathrm{kg}$ wood.

Other Support Research: In addition to the construction and operation of the PDU, IGT conducted research to support the development of the PDU. A major portion of this work consisted of bench-scale experiments to characterize the devolatilization of biomass and the gasification of the resulting biomass chars. A $5 \mathrm{~cm} \mathrm{ID} \mathrm{laminar} \mathrm{flow} \mathrm{reactor}$ capable of feeding up to $1 \mathrm{~g} / \mathrm{min}$ of feedstock was constructed for this work. Biomass entrained in an inert gas flowed through the reactor, which was heated with external electric heaters. The length of the reactor could be adjusted to allow free-fall distances of $30-120 \mathrm{~cm}$, giving average residence times of about 1-4 sec. Extensive data dealing with the devolatilization as a function of temperature were collected, and the data helped with reactor design.

Char gasification studies were also conducted using a thermobalance reactor where the weight of a sample is continuously monitored as the sample is gasified. Data was collected for feedstocks such as pine, maple, and corn stover. Representative data is shown in Figure 2.6.

IGT also conducted cold-flow fluidization model tests to help determine the effects of gas densities on fluidization behavior. Tests were conducted in a $29 \mathrm{~cm}$ ID Plexiglas fluidized bed enclosed in a $1 \mathrm{~m}$ OD steel pressure vessel. Compressed gases Here pumped in a continuous loop through the bed, two cyclones, and a filter before reentering the compressor. The apparatus was operated at $27{ }^{\circ} \mathrm{C}$ and 6 atm to simulate the same gas densities which would be experienced from operating at $815^{\circ} \mathrm{C}$ and $20 \mathrm{~atm}$. The data was used to help with the design of the PDU. 


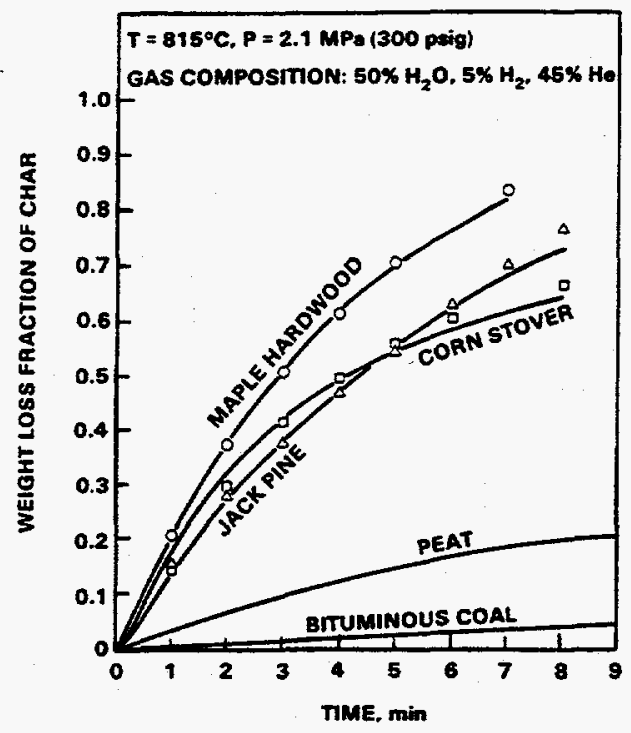

Figure 2.6. Representative Data from Char Gasification Studies.

Current Status: IGT is currently a participant in a project to construct and operate a demonstration-scale gasifier in Hawaii with a feedstock capacity of about 100 tons/day. The project is co-funded by DOE, the State of Hawaii, and others. In early 1994, the gasifier was under construction. IGT also maintains its PDU gasifier in Chicago and has operated it for various clients. The DOE biomass power program is now using the IGT gasifier and Westinghouse filter technology to clean the gas for turbine operation.

\section{Selected References:}

Evans, R.J., R.A. Knight, M. Onischak, and S.P. Babu. 1988. Development of Biomass Gasification to Produce Substitute Fuels. PNL-6518, Pacific Northwest Laboratory, Richland, Washington.

Evans, R.J., et al. 1987. "Process Performance and Environmental Assessment of Renugas Process. In Proceedings of Energy From Biomass and Waste X, D.L. Klass, ed., pp. 677-696. Institute of Gas Technology, Chicago, Illinois.

\subsubsection{Down-Draft Oxygen-Blown Gasifier - National Renewable Energy Laboratory and SynGas Inc.}

Principal Investigators: Thomas B. Reed, Michael S. Grabowski (currently Colorado School of Mines)

Project Objective: The concept proposed by NREL and SynGas Inc, was based on a fixed bed, oxygen blown downdraft gasifier. Fixed bed systems are relatively simple to design and operate and could potentially offer advantages for use in many applications. The BTC Program funded research to develop and test a fixed-bed, oxygen blown gasifier to produce medium-energy gases. The research consisted of the construction and testing of a 20 ton/day gasifier. 
Summary of Research Program: In the early 1980's, Dr. Thomas Reed of NREL developed the concept of a stratified, down-draft, oxygen-blown gasifier to produce a medium-energy fuel. This work was partly based on results and calculations of $R$. Bailie at EEE Engineering which showed that the temperature of oxygen-blown gasification was only $50{ }^{\circ} \mathrm{C}$ higher than that for air gasification, and that special high temperature materials would not be required for the gasifier. As the work progressed, a "stratified down-draft gasifier" evolved in which air or oxugen passed uniformly down through the bed, rather than being injected by nozzles at the side of the reactor. The concept offered the potential to scale fixed-bed gasifiers to a relatively large scale. Dr. Michael Grabowski, a co-investigator in this work, acquired the patent rights to the NREL technology in the early 1980's and subsequently assigned them to SynGas, Inc. SynGas constructed a 20 ton/day pilot facility to test a gasifier design which would incorporate many features of the NREL technology in a commercially suitable unit. Funding for the initial NREL work was provided primarily by DOE's Office of Alcohol Fuels, and the SynGas facility was constructed largely with private funding.

The Syngas gasifier had originally been designed for operation in an air-blown mode to produce a low-energy fuel product. With minor modifications, the Syngas gasifier could be operated with oxygen to produce a medium-energy product. In 1985, the BTC Program funded NREL and SynGas, Inc. to modify the gasifier and to collect data on medium-energy gas production.

The Syngas gasifier was a fixed bed, downdraft design which operated at slightly above ambient pressure, typically about $1.3 \mathrm{~atm}$ absolute. The gasifier consisted of a carbon steel cylinder approximately $75 \mathrm{~cm} \mathrm{ID} \mathrm{by} 4.0 \mathrm{~m}$ long. Wood was top-fed into the reactor using a live-bottom feeder, and feed rates up to $900 \mathrm{~kg} / \mathrm{hr}$ were achieved. The SynGas/NREL gasifier is shown schematically in Figure 2.7.

Oxygen was also injected from the top of the reactor through a 316 stainless steel injector nozzle, creating a hot zone at the top of the reactor. Wood entering the system was rapidly devolatilized, and the volatiles were burned in the freeboard region of the gasifier, where temperatures reached approximately $1200^{\circ} \mathrm{C}$. The resulting char formed the bed of the gasifier and was maintained at a height of $30-90 \mathrm{~cm}$ during operation. Char gasification took place primarily in the upper portions of the bed. The char bed rested upon a proprietary grate which both provided agitation for the bed and allowed ash removal. The grate system also allowed some regulation of the system pressure.

The modifications to the gasifier to allow oxygen-blown, rather than air-blown, operation were relatively minor. For instance, the size of the oxygen injector port was modified to reduce turbulence in the freeboard space. Operational procedures also had to be changed slightly to reduce air infiltration, to provide additional cooling for certain components, and to address similar differences between the use of air and oxygen, but no major problems were encountered.

The gasifier was operated to determine the feasibility of using this concept for producing medium-energy gases and to collect data on the effects of varying operating parameters. Typical test runs were approximately 6 hours in length, with the gasifier being started 
up in the air-blown mode and then switched to oxygen. One extended test run of about 55 hours with the gasifier operating in the oxygen-blown mode was successfully completed to demonstrate the feasibility of longer-term operation.

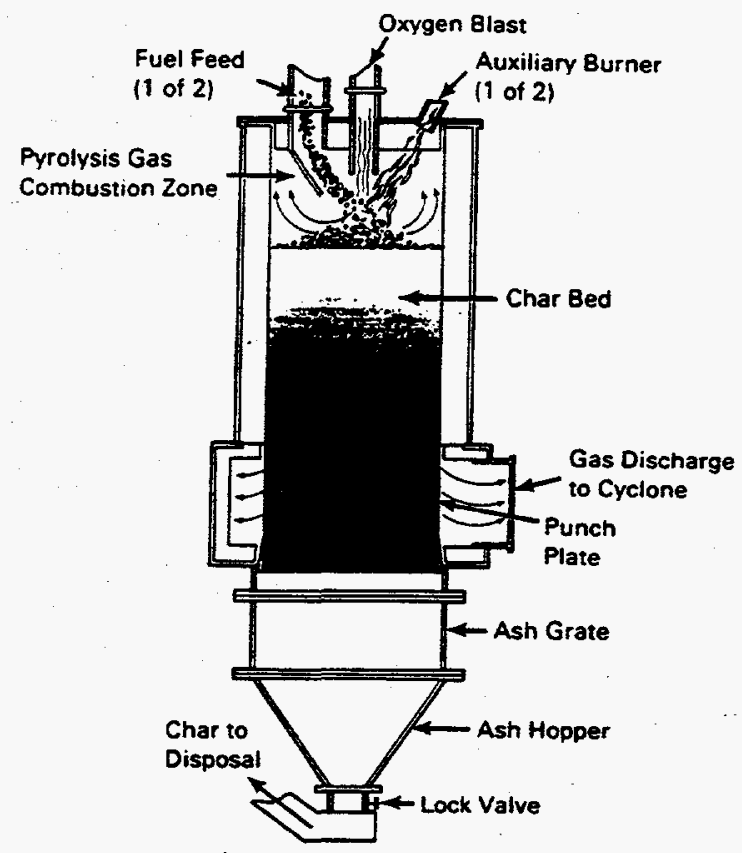

Figure 2.7. Schematic Diagram of Syngas/NREL Gasifier.

\section{Summary of Experimental Results:}

Biomass Feedstocks - The gasifier was operated primarily with cedar and pine feedstocks with moisture contents typically ranging from 5 to $10 \%$ moisture. Pine feedstocks with moisture contents of up to $25 \%$ were also successfully gasified. The material was received as $2.5 \mathrm{~cm}$ chips with variable amounts of fines, which were sometimes reduced by screening. No noticeable differences were noted in the gasification of these feedstocks. SynGas also gasified samples of MSW for a private client.

Product Yields and Composition - The typical gas composition for the SynGas/NREL gasification work is shown in Table 2.5. The results are for pine feedstock with $12.8 \%$ moisture content with a $650{ }^{\circ} \mathrm{C}$ exit temperature from the gasifier. Typically more than $90 \%$ of the biomass was converted to products other than char. In addition to the gas product, the gasifier produced tars ranging from 0.7 to $2.5 \%$ by weight of the gas. Tar production was independent of feedstock moisture content but was a inversely related to gas exit temperature. At exit temperatures greater than $670{ }^{\circ} \mathrm{C}$, the content was less that $1 \%$ by weight of the gas, but increased to over $2 \%$ as the temperature decreased to $575{ }^{\circ} \mathrm{C}$. The tars from the SynGas gasifier were not analyzed in detail. The gasifier produced large amounts of char, most of which was gasified during its residence in the bed. In typical operation, char was removed through 
the grate at the rate of about 25 to $65 \mathrm{~kg} / \mathrm{hr}$, which corresponded to between 5 and $12 \%$ of the weight of the incoming feedstock.

Table 2.5. Typical Gas Compositions and Heating Values for SynGas/NREL oxygen-blown gasifier

(Test run $\# 5,650^{\circ} \mathrm{C}$ exit temperature, $\mathrm{O}_{2}$ /wood ratio 0.25 , moisture ash-free basis).

\begin{tabular}{|l|c|}
\hline Product & Volume \% \\
\hline Hydrogen & 25.0 \\
\hline Carbon Monoxide & 38.4 \\
\hline Carbon Dioxide & 28.4 \\
\hline Methane & 5.6 \\
\hline $\mathrm{C}_{2} \mathrm{H}_{4}$ & 1.42 \\
\hline $\mathrm{C}_{2} \mathrm{H}_{6}$ & 0.32 \\
\hline $\mathrm{C}_{3}+$ & 0.39 \\
\hline Higher Heating Value, $\mathrm{MJ} / \mathrm{NM}^{3}$ & 11.4 \\
\hline
\end{tabular}

Gasifier Performance - Gasifier performance was determined by varying the following operating parameters:

- Wood feed rate

- Wood moisture content

- Oxygen demand

Gasifier performance was relatively insensitive to differences in feed rates varying from 400 to $900 \mathrm{~kg} / \mathrm{hr}$. Both the gas composition and its heating value remained approximately the same over this range of feed rates. The upper limit of $900 \mathrm{~kg} / \mathrm{hr}$ results from the design of the feeder system, but the gasifier itself may be able to exceed this value. In all cases, the ratio of the feed rate to the rate of carbon extraction required to maintain the bed at a consistent level remained about the same.

The moisture content of the feedstock affected both the oxygen demand and the product gas composition. The oxygen demand increased from 0.23 to $0.25 \mathrm{wt} \mathrm{O}_{2} / \mathrm{wt}$ wood when the moisture content of the wood increased from $12.8 \%$ to $22.8 \%$. In addition, the hydrogen/carbon monoxide ratio of the product gas increased from about 0.48 to 0.65 by changing from the lower to the higher moisture feedstock.

The oxygen requirements varied from 0.16 to $0.33 \mathrm{~kg} / \mathrm{kg}$ wood, depending on the conditions used. Heating values of the products gases varied inversely with the amount 
of oxygen used, ranging from over $12.1 \mathrm{MJ} / \mathrm{NM}^{3}$ at the lower oxygen/wood ratios to about $9.3 \mathrm{MJ} / \mathrm{NM}^{3}$ at the highest. It should be noted that ungasified char amounting to $5-12 \%$ of the feedstock was removed from the system in all test runs. If higher carbon conversions were desired, then additional oxygen would have to be used, and the freeboard temperatures in the gasifier would be higher. In the design of the SynGas gasifier, char is viewed as a valuable byproduct which would be sold.

Current Status: Further development of the SynGas air-blown gasifier continued through the late 1980's. Work on the development and testing of a gasifier to supply a 10-MW power generation facility in Long Island, New York was conducted, and a 75 ton/day testy facility operated successfully operated for three months. The test facility was heavily damaged by high winds from a hurricane, and the project was terminated. No work is currently planned for oxygen-blown applications of this technology.

\section{Selected References:}

Reed, T.B., B. Levie, and M.S. Graboski. 1988. Fundamentals, Development and Scaleup of the Air-Oxygen Stratified Downdraft Gasifier. PNL-6600, Pacific Northwest Laboratory, Richland, Washington.

Reed, T.B., B. Levie, J. Scahill, R. Evans, and T. Milne. 1986. "Moving-Bed Air and Oxygen Biomass Gasification." In Proceedings of the 1985 Biomass Thermochemical Conversion Contractors' Meeting, Minneapolis, Minnesota, October 15-16, 1985, p. 29. PNL-SA-13571, Pacific Northwest Laboratory, Richland, Washington.

\subsubsection{Additional Indirectly-Heated, Medium-Energy Gasification Projects}

As indicated previously, the BTC Program sponsored extensive research on the development of indirectly heated biomass gasification technologies. These technologies offered potential advantages for biomass and had not been explored in detail previously. In addition to the larger scale gasifiers at Battelle-Columbus and at IGT, the Program sponsored work to better understand the gasification process and to test various concepts in bench-scale or small research-scale gasifiers. This work is described in the following section of this report.

With indirectly heated gasifiers, heat must be provided to drive the pyrolytic biomass gasification reactions. The BTC Program focused primarily on research which could lead to better methods for providing effective heat transfer to indirectly heated gasifiers. In addition to the research on heat transfer, the BTC Program sponsored research to better understand the pyrolytic gasification reactions which occur in indirectly heated biomass gasifiers. Projects which explored methods to improve heat transfer included:

- $\quad$ MTCI - Pulsed, fluidized-bed gasifier

- University of Nebraska - Ceramic tube heat exchangers

- Wright-Malta Corp. - Pressurized rotary kiln gasifier

- Garrett Energy - Pyrolytic gasifier for animal wastes. 


\subsubsection{Pulsed, Fluidized Bed Gasification-MTCI, Inc.}

Principal Investigator: M. N. Mansour

Project Objective: MTCI, Inc. conducted research on the use of a pulsed, fluidized-bed gasifier to improve heat transfer into the reactor. The MTCI gasifier had heat exchange tubes located in a fluidized bed gasifier. Part of the biomass was burned in an external combustor to provide heat for the gasifier, similar in concept to the University of Missouri-Rolla gasifier. Rather than using a conventional combustor to provide heat for the system, however, MTCI used a pulsed combustor. The pulsing action of the combustor provided for greater turbulence of the hot combustion gases at the surface of the heat exchange tubes. As a result, higher heat transfer rates to the gasifier were possible than with conventional combustors.

The MTCI gasifier was also constructed specifically to handle a variety of biomass and waste feedstocks including wood, black liquor from paper production, MSW, waste hydrocarbons, and others. The purpose of the research was to verify the gasification concept on a variety of feedstocks. Funding for this work was provided by several sources including the BTC Program, California Energy Commission, and Weyerhauser Company. MTCI had earlier obtained funding for the development of the concept through DOE's Small Business Innovative Research Program.

Summary of Research Project and Results: MTCI constructed and operated a fluidized bed gasifier with a feedstock capacity of about $90 \mathrm{~kg} / \mathrm{hr}$. The reactor consisted of a steel cylinder with a $46 \mathrm{~cm}$ diameter and approximately $3.7 \mathrm{~m}$ long. Eight U-tube heat exchangers entered the fluidized bed from the bottom of the reactor, extended through the fluidized bed, and then exited at the reactor bottom. Various feeders were used depending on the feedstock.

Heat was provided to the U-tubes by a resonance pulsed combustor. The pulsed combustor cycle proceeds in four steps. First, air and fuel enters the combustion chamber and spontaneously ignites as it encounters the hot combustion gases from the previous cycle. Next, the ignition causes the gases to expand and move outward into the fire tube. The inertia of the moving gases causes the pressure in the combustor to drop below atmospheric. In the third part of the cycle, fresh air and fuel are drawn into the combustion chamber because of the low pressure, and the hot combustion gases also flow back toward the chamber. Finally, the momentum of the hot combustion gases compresses and heats the new air/fuel charge so that it once again ignites. The pulsed combustion system offered the potential of higher heat transfer rates and more uniform tube temperatures than conventional combustors, and the resonance vibration also helped clean tube surfaces.

MTCI gasified a variety of biomass-based feedstocks including wood chips, black liquor, nut shells, fiber waste, rice hulls, urban wood waste, an orchard prunings/bagasse blend, and recycled paper with plastic. The product gas from each was characterized by relatively high hydrogen compositions ranging from 32 to $66 \mathrm{vol} \%$, methane levels 
ranging from 2 to $12 \%$, and higher hydrocarbons from 1 to $5 \%$. Typical gas compositions for selected feedstocks are shown in Table 2.6.

Table 2.6. Product Gas Compositions for Various Feedstocks from the MTCI Gasifier.

\begin{tabular}{|c|c|c|c|c|}
\hline & $\begin{array}{c}\text { Wood } \\
\text { Chips }\end{array}$ & $\begin{array}{c}\text { Black } \\
\text { Liquor }\end{array}$ & $\begin{array}{c}\text { Rice } \\
\text { Hulls }\end{array}$ & $\begin{array}{c}\text { Pistachio } \\
\text { Shells }\end{array}$ \\
\hline Gas Composition, vol\% & & & & \\
\hline $\mathrm{H}_{2}$ & 48.1 & 64.8 & 42.8 & 35.0 \\
\hline $\mathrm{CO}$ & 22.9 & 3.1 & 19.7 & 23.4 \\
\hline $\mathrm{CO}_{2}$ & 20.2 & 29.2 & 24.4 & 25.2 \\
\hline $\mathrm{CH}_{4}$ & 8.3 & 2.4 & 11.6 & 11.3 \\
\hline $\mathrm{C}_{2}+$ & 0.4 & 0.5 & 1.6 & 2.9 \\
\hline $\begin{array}{l}\text { Higher Heating Value, } \\
\text { MJ/NM }\end{array}$ & 12.2 & 9.4 & 13.6 & 15.1 \\
\hline Gasifier Temp., ${ }^{\circ} \mathrm{C}$ & 695 & 605 & 720 & 660 \\
\hline
\end{tabular}

The black liquor gasification tests used a smaller gasifier with a capacity of about $11 \mathrm{~kg} / \mathrm{hr}$. The black liquor was injected into the gasifier in a slurry containing about $67 \%$ solids. Black liquor contains significant quantities of sulfur, and hydrogen sulfide was identified qualitatively in the product gas. In a commercial process, the hydrogen sulfide would be scrubbed for the product stream. It is interesting to note the high hydrogen concentrations in the product gas from black liquor.

The MTCI gasifier also achieve high heat transfer rates using the pulsed combustion system. Typical heat transfer coefficients to the gasifier were found to be approximately $580 \mathrm{~kJ} / \mathrm{m}^{2}-\mathrm{hr}-{ }^{\circ} \mathrm{C}\left(30 \mathrm{Btu} / \mathrm{ft}^{2}-\mathrm{hr}-{ }^{\circ} \mathrm{F}\right)$. By comparison, typical heat transfer rates in the University of Missouri gasifier were about $175 \mathrm{~kJ} / \mathrm{m}^{2}-\mathrm{hr}-{ }^{\circ} \mathrm{C}$. The measured heat transfer rate in the MTCI gasifier also exceeded the theoretical rate calculated for this unit assuming that a conventional combustor was substituted for the pulsed one. Higher heat transfer rates should allow higher cross-sectional throughputs of biomass in the gasifier.

Current Status: MTCI has continued its development and commercialization of its gasifier concept. A larger scale demonstration unit was operated using residual fiber waste from paper processing. In early 1994, MTCI was involved in a project with a large wood products company to build and operate a commercial 100 tpd gasifier to convert wood and paper wastes. MTCI has also conducted limited experiments for the current DOE program. 
Selected Reference:

Manufacturing and Technology Conversion International Incorporated. 1990. Testing of an Advanced Thermochemical Conversion Reactor System. PNL-7245, Pacific Northwest Laboratory, Richland, Washington.

\subsubsection{Ceramic Fire Tubes for Fluidized-Bed Gasifiers - University of Nebraska}

\section{Principal Investigator: L. Davis Clements}

Project Objective: The BTC Program sponsored research on gasifier concepts such as University of Missouri-Rolla and MTCI which used fire tube heat exchangers in fluidized beds to provide heat for gasification. These gasifiers used metal heat exchangers because they were reliable and relatively easy to construct. The research at University of Nebraska examined the potential for using ceramic rather than metal heat tubes in the fluidized bed. The ceramic tubes had two potential advantages. First, they could be operated at higher temperatures which would allow more conductive and convective heat transfer to the gasifier. In addition, the ceramic tubes at higher temperatures could also potentially transfer radiant energy from the "glowing" tubes to the reactor. The combination of radiant heat transfer plus higher operating temperatures offered the potential to improve gasifier performance.

Summary of Research Program and Results: The University of Nebraska conducted modeling studies of heat transfer and collected supporting data in various bench-scale reactors. Initially, research was conducted to determine the effect of radiant heating on the gasification of biomass. This research used a thermogravimetric analyzer to measure the rate of biomass volatilization as biomass was subjected to radiant energy. The experimental system consisted of an electrobalance housed inside a radiant furnace. Biomass samples were prepared by compacting cellulose samples into dowels which were $0.5 \mathrm{~cm}$ diameter by $2 \mathrm{~cm}$ in length. The samples were placed in the electrobalance, and the weight loss of the sample was measured as the temperature was increased. Nitrogen flowed over the samples as they were heated, so the studies were primarily concerned with the pyrolysis of the sample. The temperature in the reactor rose from 100 to $500{ }^{\circ} \mathrm{C}$ in approximately two minutes.

Research in this unit showed that the adsorption of radiant energy increased with temperature but reached a plateau at about $500^{\circ} \mathrm{C}$. At the time (1982), this result was somewhat surprising. Some researchers had predicted that the adsorption of radiant energy would be linear with temperature. This result would correspond to a situation where the biomass would heat and react at the surface, with the reactive front passing uniformly through the particle. In fact, there are no clear boundaries between char, partially reacted material, and unreacted material. Researchers such as Krieger-Brockett at other organizations have since shown the pyrolysis occurs initially at the surface with the pyrolysis front subsequently moving through the sample. As the internal material heats, the volatiles must move through hot char material at the surface, where they undergo further reaction. This process is limited by the rate of heat conduction through 
the biomass sample. Thus, while radiative heat transfer is important in some situations, the effect is more limited at higher temperatures for single particles.

In a complex gasifier system where there are many biomass particles plus bed material, the potential for radiant heat transfer to affect reactions rates is more complex. The University of Nebraska also conducted research in a bench-scale fluidized bed reactor to examine the influence of radiant energy in a simulated gasifier. The reactor consisted of a heated stainless steel vessel which was first loaded with finely ground biomass or char and a bed material, alumina. Hot gases were then passed through the reactor to fluidize the contents, and electric heaters provided black body temperatures up to about $700^{\circ} \mathrm{C}$. Data on heat fluxes at various places in the system was measured with thermocouples. The data showed conceptually that both convective and radiative effects were important in the reactor, but the data could not resolve quantitatively the relative importance of each. The University of Nebraska also conducted limited cold-model tests of the effects that different ceramic tube configurations would have on reactor performance. The results suggested that a horizontal placement might be optimal.

As this work was proceeding, results from other projects sponsored both by the BTC and other programs showed that biomass is highly reactive, and that special measures to increase radiant heat transfer would be unnecessary in most instances. In addition, ceramic fire tubes are fragile and would potentially be subject to operational problems in commercial gasifiers. Based on these results, the concept of ceramic fire tube heat exchangers was not pursued further.

\section{Selected References:}

Clements, L.D., C.H. Cho, H.Y. Fang, and L.L. Ginn. 1984. "Development of an Indirectly Heated Fire Tube Biomass Pyrolysis Reactor." In Proceedings of the 16th Biomass Thermochemical Conversion Contractors' Meeting, Portland, Oregon, May 8-9, 1984, p. 129. CONF-8405157, Pacific Northwest Laboratory, Richland, Washington.

Clements, L.D., et al. 1983. Development of an Indirectly Heated Biomass Pyrolysis Reactor, Final Report. Texas Tech University, Lubbock, Texas and $\mathrm{Q}^{2}$ Corporation, Oxnard, California.

\subsubsection{Pressurized Rotary Kiln Gasifier - Wright-Malta Corporation}

\section{Principal Investigator: John A. Coffman and Rodger H. Hooverman}

Purpose: While much of the BTC Program research on indirectly-heated gasifiers focused on the use of fluidized or entrained bed technologies, the program also funded research on other reactor concepts. Among these was the rotary kiln process being developed by Wright-Malta Corporation. In the kiln, biomass was gasified in the presence of steam at pressures of about $20 \mathrm{~atm}$. An alkali catalyst was sometimes added to the biomass prior to reaction. Wright-Malta proposed that much of the heat for the reactor could be provided by careful recovery of exothermic heat of pyrolysis from the 
initial reaction of the biomass plus waste heat from the eventual gasification of the resulting char.

The work on the Wright-Malta concept started well before the BTC Program. Initial funding was provided in 1975 by a group of New York state utilities, with subsequent funding form Environmental Protection Agency, NYSERDA, and finally DOE. The BTC Program funded research on the third phase of this project which consisted of the construction and operation of a process development gasifier unit capable of gasifying up to 6 tpd.

Summary of Research Program and Results: The Wright-Malta gasifier was a horizontal cylinder of about $60 \mathrm{~cm}$ diameter and $30 \mathrm{~m}$ long. The vessel was constructed of $1.9 \mathrm{~cm}$ thick stainless steel and was capable of operating at pressures up to about $20 \mathrm{~atm}$. An auger which ran the length of the cylinder rotated at a few rounds per minute to both agitate the biomass and to transport the biomass and char through the reactor. Hot product gases at about $620^{\circ} \mathrm{C}$ from the reactor entered heat exchanger coils which were wrapped around the outside of the steel cylinder. The hot gases flowed back toward the end of the reactor where biomass was fed to the reactor and provided heat for the gasification reaction. In the start-up mode, steam was used to provide heat, and both could be used if necessary. The residence time of the gases in the reactor was a few minutes, and the solids took up to about an hour to fully react.

In this system, biomass was fed into the cooler end of the reactor by a hydraulic ram. As the biomass moved down the reactor, it encountered increasing temperatures and began devolatilizing. The auger continued to push the biomass and the resulting char down the reactor to the hottest portions of the reactor where the char was gasified. Wright-Maita proposed that most of the heat for the reaction could be provided by careful recovery of exothermic heat of pyrolysis of the biomass. This heat would be recovered from the product gas through the coiled heat exchanger on the outside of the vessel. The existence of the exotherm was based on the simplified reaction:

$$
\begin{aligned}
& 8 \mathrm{C}_{6} \mathrm{H}_{9} \mathrm{O}_{4}+58 \mathrm{H}_{2} \mathrm{O} \Rightarrow 2 \mathrm{C}+2 \mathrm{CH}_{4}+12 \mathrm{H}_{2}+4 \mathrm{CO}+22 \mathrm{CO}_{2}+42 \mathrm{H}_{2} \mathrm{O} \\
& \text { Exotherm }=980 \mathrm{~kJ} / \mathrm{kg}
\end{aligned}
$$

If the calculated exotherm in fact existed and could be recovered, the process would need little additional heat and would have a high efficiency. Since heat could be added to the reactor by various methods, the reactor was not particularly dependent on the exotherm for successful operation, although it could help improve system efficiency. Due to operational problems with the auger, only a limited number of experimental test runs were performed, and neither the presence of the exotherm nor the ability to fully recover it was confirmed.

Typical gas compositions from the Wright-Malta gasifier are shown in Table 2.7. 
Table 2.7. Typical Product Gas Compositions from the Wright-Malta Gasifier $\left(600{ }^{\circ} \mathrm{C}, 11 \mathrm{~atm}\right.$, dry basis).

\begin{tabular}{||l|c|}
\hline Product & Volume \% \\
\hline Hydrogen & 28 \\
\hline Carbon Monoxide & 5 \\
\hline Carbon Dioxide & 41 \\
\hline Methane & 22 \\
\hline Ethane & 4 \\
\hline Higher Heating Value, $\mathrm{MJ} / \mathrm{NM}^{3}$ & 14.4 \\
\hline
\end{tabular}

As indicated, the reactor encountered serious operational problems with the auger. As biomass slowly pyrolyzed after entering the reactor, tars were formed, and the biomass stuck to the flights in the auger. The partially reacted clumps of biomass continued to accumulate additional biomass which slowly reacted, and the space between the auger blades could become totally plugged. During a test run in 1981, the plugging became severe enough that the auger acted essentially as an extruder, and the stresses broke the auger flights. Based upon its performance in the test runs, the auger stirrer was felt to be inadequate for the gasifier, even if it could have been fixed. Wright-Malta proposed major modifications to the reactor design that could potentially have solved some of the problems. However, the modifications were not funded due to changes in program priorities at the time. Wright-Malta has done additional development work on the concept over the past decade, but no additional gasifier construction or operation has been completed.

\section{Selected References:}

Coffman, J.A. 1982. "Steam Gasification of Biomass." In Proceedings of the 14th Biomass Thermochemical Conversion Contractors' Meeting, pp 32-45. CONF-820685, National Technical Information Service, Springfield, Virginia.

Coffman, J.A. 1981. "Steam Gasification of Biomass." In Proceedings of the 13th Biomass Thermochemical Conversion Contractors' Meeting, pp. 274-296. CONF-81110115, National Technical Information Service, Springfield, Virginia.

Hooverman, R.H. 1979. Catalyzed Steam Gasification of Biomass Phase II, Final Report. COO/4736-1,2,\&3. Wright-Malta Corporation, Ballson Spa, New York. 

Engineering Co. (GERE)

\section{Principal Investigator: D. Garrett}

Project Objective: GERE proposed to dispose of moist farm wastes, primarily bovine manure, by gasifying it to form a medium-energy gas. This project was funded by DOE prior to the start of the BTC Program, and was essentially over when the BTC began in 1980.

Summary of Research Project and Results: GERE operated a process development gasifier with a design capacity of about 6 tpd. The gasifier consisted of a multi-hearth furnace system where wet animal wastes were fed to be pyrolysed. A heated screw feeder preheated the solids which were then fed to the upper hearth of the furnace where they were dried by contact with air and hot pyrolysis gases. The dried solids were then transported to a pyrolysis hearth, which had a design temperature of about $800{ }^{\circ} \mathrm{C}$. Part of the solids were bumed to provide heat for the pyrolysis hearth. The projected heating value of the product gas was about $11.1 \mathrm{MJ} / \mathrm{NM}^{3}$

In actual operation, the gasifier experienced many problems. The screw feeder was subject to plugging, and the manure feedstock was of low quality with high levels of soil. The product gas had a heating value of about $6.3 \mathrm{MJ} / \mathrm{NM}^{3}$, more characteristic of a lowenergy product. This result probably arose from extensive air leaks in the gasifier unit. Due to these and other problems, research with this unit was not funded past 1979.

Selected References:

Garrett, D.E. 1979. "Thermal Conversion of Biomass into Medium Btu Gas in a Multiple Hearth Type Furnace." In Proceedings of the Eighth Biomass Thermochemical Conversion Contractors' Meeting, July 31 - August 1, 1979, Seattle, Washington.

\subsubsection{Additional Oxygen-Blown, Medium-Energy Gasification Projects}

In addition to the work on two large-scale gasifiers at IGT and Syngas/NREL, the BTC Program sponsored limited research on other oxygen-blown gasifiers. Oxygen blown gasifiers had been used with coal, but their use with biomass was limited. Research was conducted to attempt to reduce oxygen demand in the gasifiers and to optimize these systems for biomass use.

The BTC Program sponsored one project at Texas Tech University which focused on the production of medium-energy gas from manure. The work at DOE's Office of Alcohol Fuels also sponsored extensive research on oxygen-blown gasification at NREL. Although it was not part of the BTC Program, the work at NREL is summarized briefly for the sake of completeness. Prior to the BTC Program, DOE had funded work at Gilbert/Commonwealth Associates, which subcontracted to Environmental Energy Engineering (EEE), Inc. to provide gasification data for biomass. Most of this work was 
air-blown, but limited tests in an oxygen-blown mode were also made. Because the research was primarily on air-blown gasification, this project is discussed in Section 2.4 of this report.

\subsubsection{Oxygen-Blown Gasification Research - Texas Tech University}

Principal Investigator: Steven R. Beck

Project Objective: Prior to the start of the BTC Program, Texas Tech University had conducted research on the production of low-energy gases from a variety of biomass feedstocks. In late 1979, DOE funded Texas Tech to convert its research gasifier to an oxygen-blown mode and to conduct gasification research on wood. Because of the program emphasis at the time, the work was mainly on production of synthesis gases.

Summary of Research Project and Results: Texas Tech used a fluidized bed research gasifier which had a $15 \mathrm{~cm}$ diameter and was approximately $2.4 \mathrm{~m}$ high. Biomass entered the reactor from the top, and steam/oxygen mixtures were fed from the bottom to provide fluidization. The reaction of oxygen with the biomass provided heat for the gasification. The product gas exited from the top of the reactor and was cleaned in cyclones. Unreacted char was removed from the reactor by an air-driven ram. The gasifier was typically operated at about $11 \mathrm{~kg} / \mathrm{hr}$ of biomass feedstock and at a pressure of 5-15 psig. In these tests, air-dried oak sawdust with a moisture content of about $15 \%$ was used. Typical residence times of the solids ranged from 1 to 50 minutes in the bed. Data was collected in experimental test runs of approximately 4 hours in duration.

Texas Tech conducted experimental tests to determine the effects of operational parameters on gasification results. These tests investigated the effects of temperature, oxygen demand, and steam rates on gas yields and compositions. Temperatures were varied over the range of $640-820^{\circ} \mathrm{C}$, oxygen/feed ratios from 0.104 to $0.522 \mathrm{~kg} / \mathrm{kg}$, and steam $/$ feed ratios between 0.298 and $1.54 \mathrm{~kg} / \mathrm{kg}$.

As expected, increasing temperature resulted in higher gas yields. The yield of gases increased from about $0.8 \mathrm{NM}^{3} / \mathrm{kg}$ feed at $640{ }^{\circ} \mathrm{C}$ to about $1.12 \mathrm{NM}^{3} / \mathrm{kg}$ at $820^{\circ} \mathrm{C}$. Total carbon conversions ranges from $60 \%$ to about $85 \%$, with a large amount of scatter in the data and weak correlation with temperature. Temperature also affected the product gas composition. The yields hydrogen tripled from 0.12 to $0.36 \mathrm{NM}^{3} / \mathrm{kg}$ feed over the range of 640 to $820^{\circ} \mathrm{C}$. Carbon dioxide also increased from about 0.19 to nearly $0.5 \mathrm{NM}^{3} / \mathrm{kg}$ feed over the same range. The mole ratio of hydrogen to carbon monoxide increased from about 0.4 at $640{ }^{\circ} \mathrm{C}$ to about 1.1 at $820^{\circ} \mathrm{C}$. Extrapolation of the data suggested that an appropriate synthesis gas with a hydrogen/carbon monoxide ratio of $2: 1$ could be obtained in a non-catalytic reactor at about $1000{ }^{\circ} \mathrm{C}$. The yields of carbon monoxide, methane, and ethane remained approximately constant over this temperature range.

The primary effect of added oxygen was a higher reactor temperature. As a result, the product gas yield increased about $20 \%$ as oxygen increased from 0.1 to $0.5 \mathrm{~kg} / \mathrm{kg}$ feed. The total product gas yields were independent of steam rates, and the relative 
compositions of the gas components varied only slightly. Higher steam rates favored greater hydrogen formation while reducing carbon monoxide concentrations.

Texas Tech also conducted some of the earliest research on the analysis of the tars and wastewaters. The work identified the presence of various organics in the wastewaters including methanol, ethanol, and acetone, as well as formic, acetic, and propionic acids. Analysis showed that the tars from oxygen-blown tests also contained polynuclear aromatics such as benzo[a]pyrene. Total PAH concentrations were found to be about $30 \mu \mathrm{g} / \mathrm{g}$ tar, an amount which was less than $1 \%$ of the quantities found in similar airblown tests.

Current Status: The biomass gasification research at Texas Tech was largely discontinued in the mid-1980's.

Selected Reference:

Beck, S.R., R.A. Bartsch, and U. Mann. 1982. Application of SGFM Technology to Alternate Feedstocks, Phase 3. DOE/ET-20041T3, Texas Tech University, Lubbock, Texas.

\subsubsection{Pressurized, Fixed -Bed Oxygen-Blown Gasification - NREL}

Principal Investigator: Thomas B. Reed

Project Objective: The BTC Program funded the large-scale Syngas/NREL gasifier project which was described in Section 2.3.1 of this report. The research in a smaller investigation which led up to this project was funded by DOE's Office of Alcohol Fuels and was not officially part of the BTC Program. However, because this research is so closely related to the BTC program, a brief summary of the work is included here, and additional information is available elsewhere.

Summary of Research Project and Results: NREL constructed and operated a research gasifier with a design capacity of about 1 ton/day of biomass. The gasifier was a fixedbed, down-draft unit capable of operating at pressures up to about $10 \mathrm{~atm}$. The gasifier consisted of a cylinder approximately $30 \mathrm{~cm}$ in diameter and about $1.5 \mathrm{~m}$ long. The reactor was lined with a $7.5 \mathrm{~cm}$ layer of cast alumina refractory. Biomass was fed to the pressurized reactor through a rotating star valve. Oxygen was added at the top of the reactor, and additional oxygen could be added through ports along the length of the gasifier. In most test runs, an internal stirrer was used to agitate the bed. The stirrer consisted of a rotating shaft which entered from the bottom of the gasifier. Although this type of stirrer may not be appropriate for large scale gasifiers, other types of moving grates such as that on the Syngas/NREL gasifier can effectively provide agitation of the fixed bed.

Biomass entering from the top of the reactor immediately began reacting with oxygen in a "flaming pyrolysis zone." As the biomass encountered the top of the bed, the pyrolysis 
reactions were completed, and the volatiles flowed downward into the char bed. The volatiles were cracked to simple molecules in the hot char bed, and additional char was gasified. Fine char particles reaching the bottom of the reactor were continuously removed to prevent a pressure buildup.

The NREL gasifier was operated both at ambient pressure and at elevated pressures up to about $10 \mathrm{~atm}$ with oxygen feeds of about $0.43 \mathrm{~kg} / \mathrm{kg}$ wood. Under both sets of operating conditions, the product gas was reasonably suitable for synthesis use and contained low levels of methane, typically under $4 \%$. Typical gas compositions for the atmospheric and pressurized operations using pine sawdust as a feedstock are shown in Table 2.8. It should be noted that during the high pressure tests, leaks in the feeding system resulted in nitrogen entering the system, and the product gas contained $15-30 \%$ nitrogen. The gas compositions listed below are adjusted to a dry, nitrogen free basis.

Table 2.8. Typical Gas Compositions from NREL Gasifier (Pine feedstock, $0.43 \mathrm{~kg}$ oxygen $/ \mathrm{kg}$ feed).

\begin{tabular}{|c|c|c|}
\hline $\begin{array}{l}\text { \% Gas Composition (Dry, } \\
\text { nitrogen-free basis) }\end{array}$ & $\begin{array}{c}\text { Atmospheric } \\
\text { Pressure }\end{array}$ & $\begin{array}{c}\text { High } \\
\text { Pressure } \\
\text { (700 kPa) }\end{array}$ \\
\hline $\mathrm{H}_{2}$ & 33.3 & 22.0 \\
\hline $\mathrm{CO}$ & 42.8 & 51.5 \\
\hline $\mathrm{CO}_{2}$ & 19.8 & 22.8 \\
\hline $\mathrm{CH}_{4}$ & 3.9 & 3.7 \\
\hline
\end{tabular}

Although the ratio of hydrogen to carbon monoxide is much lower than would be desirable for methanol synthesis gas, the product gas could be reformed for this purpose. NREL shipped 10 cylinders of compressed product gas to Chem Systems, Inc., and the gas was converted to methanol in a test apparatus. This became the first actual biomassbased methanol produced from biomass gasification.

Current Status: The NREL research gasifier has been dismantled. NREL continues to lead DOE's program on thermal gasification, which is largely tied to gasifier scale-up and to hot gas cleaning.

\section{Selected References:}

Reed, T.B., B. Levie, and M.S. Graboski. 1988. Fundamentals, Development and Scaleup of the Air-Oxygen Stratified Downdraft Gasifier. PNL-6600, Pacific Northwest Laboratory, Richland, Washington.

Reed, T.B., M. Graboski, and M. Markson. 1982. Synthesis Gas from Biomass: Operating Data on a 1-Ton/Day Oxygen Gasifier. Presented at the Biomass-to-Methanol 
Specialists Workshop, Tamarron, Colorado, March 3-5, 1982. SERI/TP-234-1455, Solar Energy Research Institute, Golden, Colorado.

Reed, T.B. 1984. Evaluation of Downdraft Gasification for MSW Conversion. Presented at the Energy From Municipal Waste Research Workshop, Kissimmee, Florida, February 22-24, 1984. SERI/TP-234-2243, Solar Energy Research Institute, Golden, Colorado.

\subsubsection{Alternative Medium-Energy Gasification Approaches}

In addition to the indirectly-heated and oxygen-blown gasification concepts described above, the BTC Program also sponsored research at PNL on a concept which would be appropriate for use with high moisture biomass feedstocks. The typical medium-energy gasifiers require that biomass be dried to $10-15 \%$ moisture prior to conversion, and feedstocks such as wood can readily be dried to that level using waste process heat. Many other types of feedstocks, however, contain high moisture contents and are difficult to dry. Examples include grasses, farm crops such as sorghum, spent grain from ethanol production, or food wastes. The ability to efficiently gasify high moisture feedstocks provides additional opportunities to generate energy from biomass. The work at PNL is summarized below.

\subsubsection{Gasification of High-Moisture Biomass Feedstocks - Pacific Northwest Laboratory (PNL).}

Principal Investigators: L. J. Sealock, R. S. Butner, and D. C. Elliott

Project Objective: PNL conducted research on a concept to gasify high moisture biomass feedstocks. In this concept, aqueous biomass slurries (1-20\% solids) were heated in the presence of a nickel catalyst to about $350{ }^{\circ} \mathrm{C}$ at pressures of $135-270 \mathrm{~atm}$ (2000$4000 \mathrm{psi})$. The biomass reacted to form a medium energy gas composed primarily of methane and carbon dioxide. The gas closely resembled the product from an anaerobic digester, but the reaction rate was several hundred times more rapid. The objective of this work was to first collect data on the process in a batch reactor and then to operate a small continuous reactor system.

Summary of Research Project and Results: PNL examined the gasification of more than a dozen different types of biomass including:

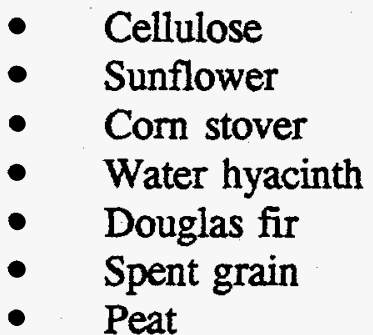

$\begin{array}{ll}\text { - } & \text { Sorghum } \\ \text { - } & \text { Napier grass } \\ \text { - } & \text { Kelp } \\ \text { - } & \text { Grape Pomace } \\ \text { - } & \text { Potato waste } \\ & \text { Black liquor }\end{array}$


Detailed characterization of each feedstock was completed including determination of carbon, hydrogen, nitrogen, and oxygen contents as well as analysis of trace metal content.

PNL conducted most of the research on this concept with a bench-scale, autoclave-based reactor system. A 1-liter stirred autoclave was loaded with an aqueous slurry containing catalyst and approximately $10 \%$ biomass solid. The catalyst consisted of alkali salts plus finely ground nickel/alumina (Harshaw 1404) methanation catalyst. The reactor was sealed, and the temperature raised to 400 or $450{ }^{\circ} \mathrm{C}$ over for approximately 90 minutes and allowed to remain at temperature an additional 45 minutes. Gas samples were removed during the course of the reaction, and the remaining slurry was analyzed at the end of the reaction period.

From these feedstocks, a product gas was obtained which typically contained high yields of methane and carbon dioxide, as shown in Table 2.9. The higher heating value of the raw gas product varied with feedstock, with typical values of about $11.1 \mathrm{MJ} / \mathrm{NM}^{3}$.

Table 2.9. Typical Gas Compositions from PNL High Moisture Gasification Process $\left(450^{\circ} \mathrm{C}\right.$, Nickel Catalyst)

\begin{tabular}{|c|c|}
\hline Gas Composition (Dry, ash free basis) & Mole \% \\
\hline $\mathrm{H}_{2}$ & 4.7 \\
\hline $\mathrm{CO}$ & 0.1 \\
\hline $\mathrm{CO}_{2}$ & 40.1 \\
\hline $\mathrm{CH}_{4}$ & 52.5 \\
\hline $\mathrm{C}_{2}+$ & 0.8 \\
\hline
\end{tabular}

The rates of reaction were dependent on temperature, catalyst loading, and the nature of the feedstock. Biomass feedstocks with large quantities of cellulose and hemicellulose reacted quickly, while those with high lignin reacted slowly. At $450^{\circ} \mathrm{C}$, for instance, carbon conversions of sorghum to gas were about $98 \%$, while conversions of digester wastes were about $60 \%$. For most feedstocks at the non-optimized catalyst loadings used $\left(.17 \mathrm{~g}\right.$ catalyst/g feed), the carbon conversions at $400{ }^{\circ} \mathrm{C}$ were approximately half those at $450{ }^{\circ} \mathrm{C}$. Increasing catalyst from 0.17 to $1.1 \mathrm{~g} / \mathrm{g}$ biomass increased the carbon conversions and allowed reactions to be conducted at temperatures as low as $380^{\circ} \mathrm{C}$.

In addition to the batch autoclave work, PNL constructed and operated a research reactor capable of continuous, steady state operation. The continuous reactor consisted of a 1-liter stirred autoclave modified to accept biomass slurry from a metering pump. Catalyst was held in a basket suspended in the reaction vessel. The reactor was heated to near the desired temperature with water, and then the biomass slurry was pumped to the reactor after it was at temperature. Effluent from the reactor passed to an external 
cooler and was collected for analysis. Depending on the pumping rate, the residence time of solids could be varied from about 5 to over 60 minutes. Results from work from the continuous unit confirmed the data from the batch reactor and showed that reactive feedstocks such as sorghum could be converted ( $98 \%$ carbon conversion) in about 11 minutes.

The high methane content of the product gas from this process was very different than those from the other gasifiers described above. However, the methane formation appeared to occur by a combination of the same basic steps which occur in higher temperature systems, including pyrolysis, gasification, and gas reforming steps. In the PNL system, biomass first pyrolyzed to form a complex mixture of gaseous and aqueous phase products. These materials were catalytically gasified to produce simple molecules, and the concentrations of the gases changed as the system reached equilibrium. The major difference was the presence of the catalysts and the high concentrations of water. Although the roles of the alkali and nickel catalysts are not entirely clear, the alkali appears to catalyze the water gas shift reaction which produces $\mathrm{CO}_{2}$ and hydrogen from water and carbon monoxide. The nickel catalyst appears to aid in methane formation. With alkali catalysts alone, gas production is substantially reduced, and the formation of liquid products is enhanced. The nickel catalyst is essential for high gas yields.

Current Status: PNL has applied for patents on this gasification process and has entered into a proprietary arrangement with industry to commercialize the concept. The concept is being investigated as a means to dispose of many types of aqueous organic wastes. Additional funding from DOE's Office of Industrial Technologies has allowed a mobile test unit to be assembled. PNL anticipates conducting tests at industrial sites on a variety of feedstocks.

\section{Selected References:}

Elliot, D.C., et al. 1989. Low-Temperature Conversion of High-Moisture Biomass Continuous Reactor System Results. PNL-7126, Pacific Northwest Laboratory, Richland, Washington.

Sealock, L.J. Jr., D.C. Elliot, R.S. Butner, and G.G. Neuenschwander. 1988. LowTemperature Conversoin of High-Moisture Biomass. PNL-6726, Pacific Northwest Laboratory, Richland, Washington.

Baker, E.G., et al. 1989. Thermocatalytic Conversion of Food Processing Wastes. PNL-6784, Pacific Northwest Laboratory, Richland, Washington.

\subsubsection{Biomass Research Related to Coal Gasification}

The BTC Program also sponsored very limited research on biomass gasification as it related to coal gasification. This included a project at Dynecology, Inc., to investigate gasification of mixed coal/sewage sludge/wood briquettes, and a review of coal gasification technology by Gorham, International. These projects are discussed below. 
It is important to note that coal is a very different feedstock than biomass and that those differences have very significant impacts on the gasification process. Coal is much less reactive than biomass, and gasification occurs at much higher temperatures under more severe reaction conditions. The reaction mechanisms are also substantially different due to the differences in the feedstocks. While there is general information from coal gasification which will be useful, it is clear that biomass gasification processes must be designed to exploit the characteristics of the feedstock. Processes which fail to account for the unique characteristics of biomass will be less efficient and less economically competitive that those which do.

\subsubsection{Gasifying Wood with Coal and Sewage Sludge - Dynecology, Inc.}

\section{Principal Investigator: Helmut Schultz}

Project Objective: With co-funding from DOE's municipal waste and fossil programs, the BTC Program sponsored research to gasify mixtures of slagging coal, wood, and sewage sludge. The gasification of slagging coals was often accompanied by caking of the coal/slag mixture, which caused plugging in the gasifier. The addition of wood could potentially reduce plugging. Gasifying coal/wood mixtures with sewage sludge also offered a potential means to dispose of unwanted sludges and to use tipping fees to help support process economics. Dynecology performed research on the gasification of briquettes of these mixed feedstocks. The research included tests to determine appropriate briquette formulations as well as gasification tests in an oxygen-blown gasifier at Columbia University in New York City.

Summary of Research Project and Results: Dynecology conducted its gasification tests with briquetted feedstocks consisting of mixtures of coal, biomass, and sewage sludge. The pellets included both $5.7 \mathrm{~cm}$ square "pillow" briquettes and cylindrical pellets $3 \mathrm{~cm}$ in diameter by $2.5 \mathrm{~cm}$ long. Tests were performed to determine the desired pellet formulation. Dewatered sewage sludge was dried in a rotary kiln to about $15 \%$ moisture, and briquettes were formed at pressures of 300 to $1000 \mathrm{~atm}$ in a Carver press similar to commercial briquetting devices. Stable briquettes could be formed without binder when sewage sludge or wood was added.

Approximately $1350 \mathrm{~kg}$ of briquettes were produced and gasified in a $5 \mathrm{tpd}$ updraft gasifier at Columbia University. The gasifier was an oxygen-blown, fixed bed unit. Oxygen and steam were added at the bottom of the reactor, and the product gases flowed through the bed of briquetted feedstock. The hearth temperature of the gasifier was maintained at $1550-1600{ }^{\circ} \mathrm{C}$.

The gasification tests showed that wood or sewage sludge could reduce the caking tendencies of the coal. Wood at concentrations as low as about $4 \%$ eliminated caking of the briquettes, while concentrations of sewage sludge at about $33 \%$ accomplished the same. Gasification of coal/sewage sludge mixtures as high as $1: 2$ were successfully completed. The slagged ash from the gasifier was found to contain heavy metals, but acid leaching tests showed that the levels in the leachate were less than those allowed by 
EPA. Analysis of the product gases was limited to determination of hydrogen (34\%), carbon monoxide (51\%), methane $(3 \%)$ and carbon dioxide $(12 \%)$. No detailed analysis of volatile metals or sulfur in the product gases was performed. The primary influence of biomass was to reduce caking in the reactor, and this could be accomplished with a very small amount of biomass.

Current Status: The research at Dynecology ended in 1984. Since that time, there has been interest in co-firing biomass and coal in combustion systems to reduce sulfur emissions from coal. However there has been little or no activity in gasifying these mixtures.

\section{Selected References:}

Dynecology Incorporated. 1984. "Clean Energy from Coal, Forest Pulp, and Sewage Sludge." In Proceedings of the 16th Biomass Thermochemical Conversion Contractors' Meeting, pp. 193-210. CONF-8405157, National Technical Information Service, Springfield, Virginia.

Dynecology Incorporated. 1984. Development of a Process for Producing Clean Energy from Coal, Forest Pulp and Sewage Sludge. Final Report submitted under subcontract B-F0440-A-Q, Pacific Northwest Laboratory, Richland, Washington.

\subsubsection{Survey of Coal Gasification Technologies - Gorhan International}

\section{Principal Investigator: Andrew Nyce}

Project Objective: In the late 1970's, DOE funded Gorham International to review the literature relating to coal gasification and to analyze the applicability of using coal technologies for gasifying biomass. The project ended in 1980 and was not actually par of the BTC Program, but is summarized briefly here for the sake of completeness.

Summary of Research Project and Results: Gorham International completed the first phase of their work and produced a list of coal gasification references from the 1970 's. However, no analysis of the material from the search was made, and the information was not useful in guiding the BTC Program. In retrospect, the knowledge gained over the past decade and a half have shown the importance of exploiting the reacuive characteristics of biomass in thermal conversion processes including gasification. Processes which do not account for the reactive characteristics of the biomass are unlikely to be commercially competitive with biomass technologies which do.

Current Status: The work at Gorham International ended in 1980.

Selected References: 
Keene, A.G. and A.C. Nyce. 1979. "Coal Gasification Technology: Wood Feedstock Retrofit Potential." In Proceedings of the Eighth Biomass Thermochemical Conversion Contractors' Meeting, July 31 - August 1, 1979, Seattle, Washington.

Nyce, A. and A. Keene. 1979. "An Assessment of the Technical and Economic Feasibility of Converting Wood Residues to Liquid and Gaseous Fuel Products Using State-Of-The-Art and Advanced Coal Conversion Technology." In Proceedings of the Seventh Biomass Thermochemical Conversion Contractors' Meeting, April 24-25, Roanoke, Virginia.

\subsection{LOW-ENERGY AIR-BLOWN BIOMASS GASIFICATION PROJECTS}

In addition to the research on medium-energy gasification processes, the BTC Program sponsored limited work on the production of low-energy gases from air-blown gasifiers. Air-blown biomass gasifiers had been used in World War II to provide fuel for various uses, and the technology was available from the private sector, although the reliability of many commercial products at that time was questionable. The BTC Program funded research in two areas, including the operation of selected gasifiers in the very early 1980 's in order to collect data on low-energy systems. In the mid-1980's, the BTC Program sponsored research to collect data on the use of low-energy gases in engine systems. These projects are shown in Table 2.10.

Table 2.10. Summary of Low-Energy Gasification Projects Funded by the BTC Program.

\begin{tabular}{||l|l||}
\hline \hline TECHNOLOGY AREA & INSTITUTION \\
\hline Low-Energy Gasification & \\
\hline $\begin{array}{l}\text { Data Collection with Low-Energy Gasifiers } \\
\text { Coors Gasifier }\end{array}$ & $\begin{array}{l}\text { University of Missouri - } \\
\text { Rolla }\end{array}$ \\
Data Collection on Gasifier Configurations & $\begin{array}{l}\text { Environmental Energy Eng., } \\
\text { Inc. }\end{array}$ \\
Use of Low-Energy Gases in Engines & \\
Research on Gasifier/Engine Systems & Cal Recovery Systems \\
Enhancing Engine Performance & University of Florida \\
Field Testing Small Gasifier Filter Systems & Rocky Creek Farm Gasogens, \\
& Inc. \\
\hline \hline
\end{tabular}




\subsubsection{Data Collection with Low-Energy Gasifiers}

The BTC Program sponsored research on two low-energy gasifiers, including those at the University of Missouri-Rolla and EEE, Inc. These projects are described below.

\subsubsection{Coors Gasifier - University of Missouri Rolla}

Principal Investigators: V. Flanigan, Y. Omurtag

Project Objective: In 1978, the Adolph Coors company donated a $100 \mathrm{~cm}$ fluidized bed, air-blown gasifier to the University of Missouri-Rolla. The gasifier was operated in order to collect data on low-energy gasification processes. The unit helped the university to develop expertise in medium-energy gasification, as previously described in Section 2.3 of this report.

Summary of Research Project and Results: The gasifier at the university consisted of a $100 \mathrm{~cm}$ ID fluidized bed reactor. Biomass could be fed into the bed either from the top or bottom of the reactor, but gas production was insensitive to feed location. The gasifier operated at a slight positive pressure of about $0.5 \mathrm{~atm}$. Biomass feed rates could be varied from about 90 to $1000 \mathrm{~kg} / \mathrm{hr}$ of wood with moisture contents from 6 to $52 \%$. Air to feed ratios could be varied from 1.0 to $4.5 \mathrm{~kg}$ air $/ \mathrm{kg}$ wet wood. In addition to the large gasifier, a small $10 \mathrm{~cm}$ ID research gasifier was also constructed at the site.

Because air rather than oxygen is used to partially combust the biomass, the product gas from air-blown gasifiers contains large amounts of nitrogen which reduce its heating value. Typical gas compositions from the university gasifier are shown in Table 2.11. The heating values of the gases varied significantly depending on feedstock moisture content, reaction temperature, and other variables. Typical higher heating values were in the range of 5.6 to $7.1 \mathrm{MJ} / \mathrm{NM}^{3}$, with values as high as $8.9 \mathrm{MJ} / \mathrm{NM}^{3}$ being obtained. As expected, the research showed that carbon conversions increased at higher bed temperatures.

The university also proposed that the heating value of the product could potentially be increased by replacing part of the air with recycled product gas. Efforts to adapt the gasifier to operate on recycled gas were attempted, but no data was reported for this concept.

As a result of the research completed with this reactor, the university then proposed and successfully demonstrated the internal fire-tube concept for producing medium-energy gas which is described in Section 2.3. 
Table 2.11. Typical Gas Compositions for the

University of Missouri Air-Blown Gasifier

(Test Run \#41, 775 C)

\begin{tabular}{|c|c|}
\hline Gas Composition (Dry basis) & Volume \% \\
\hline $\mathrm{H}_{2}$ & 6.7 \\
\hline $\mathrm{CO}$ & 20.5 \\
\hline $\mathrm{CO}_{2}$ & 16.5 \\
\hline $\mathrm{CH}_{4}$ & 4.9 \\
\hline $\mathrm{C}_{2}+$ & 2.3 \\
\hline $\mathrm{N}_{2}$ & 48.3 \\
\hline Higher Heating Value, $\mathrm{MJ} / \mathrm{NM}^{3}$ & 7.0 \\
\hline
\end{tabular}

\section{Selected Reference:}

V. Flanigan, et al. 1981. Gasification Research on Wood (Grow) Low Energy Gas, Production-Phase I Results. DOE/ET/23029-T6, Available from NTIS, Springfield, VA.

\subsubsection{Data Collection on Gasifier Configurations - Environmental Energy Engineering (EEE), Inc.}

Principal Investigator: R. Bailie

Project Objective: In the late 1970's, DOE funded Gilbert/Commonwealth Associates to prepare an evaluation of biomass resource/conversion/utilization systems. As part of this work, Gilbert/Commonwealth entered into a subcontract with EEE, Inc. to provide gasification data for the systems study. The work consisted primarily of the operation of a research gasifier in fluidized and fixed bed modes to compare air-blown gasification in different types of gasifiers and several types of biomass. In a few tests, medium energy gases were produced by replacing air with an oxygen/steam mixture.

Summary of Research Project and Results: The fluidized bed gasifier consisted of a cylinder approximately $5.2 \mathrm{~m}$ long with a $46 \mathrm{~cm}$ ID diameter. The reactor was placed inside an older gasifier at the site, and the auxiliary systems from the older gasifier were used with minor modification. Air or oxygen/steam mixtures were added from the bottom of the reactor to provide fluidization of the bed. Feedstock could be gasified at rates from about $18-110 \mathrm{~kg} / \mathrm{hr}$. Operating temperatures were varied from about 760 
$850^{\circ} \mathrm{C}$. Typical test runs were conducted over 2 -hr periods of steady-state operation, and limited tests of about 7 hours of duration were also made.

Several types of pelletized biomass were gasified including hardwood, woodex, peanut hulls, corn fodder, and peat. All feedstocks were gasified in the fluidized bed gasifier without major operational problems. Results were obtained with fluidization provided by air, and in some cases by a $10 \%$ oxygen $/ 90 \%$ steam mixture Limited runs with a $15 \%$ oxygen $/ 90 \%$ steam mixture were completed, but the material balances on these were not complete. Representative data for pelletized oak feedstock is shown in Table 2.12. Under air-blown conditions, the heating values of feedstocks such as corn fodder and peanut shells were much lower than for woody biomass, with values ranging from about 3.2 to $4.8 \mathrm{MJ} / \mathrm{NM}^{3}$

Table 2.12. Typical Product Gas Compositions from the EEE Fluidized Bed Gasifier (Pelletized oak hardwood, $790-815^{\circ} \mathrm{C}$ ).

\begin{tabular}{|c|c|c|}
\hline \% Gas Composition (Dry basis) & $\begin{array}{c}\text { Air- } \\
\text { Blown }\end{array}$ & $\begin{array}{c}\mathbf{1 0 \%} \mathbf{O}_{\mathbf{2}} \\
\mathbf{9 0 \%} \text { Steam }\end{array}$ \\
\hline $\mathrm{H}_{2}$ & 20.6 & 25.4 \\
\hline $\mathrm{CO}$ & 16.9 & 19.5 \\
\hline $\mathrm{CO}_{2}$ & 16.9 & 31.8 \\
\hline $\mathrm{CH}_{4}$ & 5.4 & 13.6 \\
\hline $\mathrm{N}_{2}$ & 39.6 & trace \\
\hline $\begin{array}{l}\mathrm{Higher} \text { Heating Value, dry basis, } \\
\mathrm{MJ} / \mathrm{NM}^{3}\end{array}$ & 6.4 & 10.6 \\
\hline
\end{tabular}

EEE also conducted tests where part of the air was replaced with recycled product gas. In all cases, however, the heating value of the product was under $3.7 \mathrm{MJ} / \mathrm{NM}^{3}$, making the gas difficult to use and uneconomical in most situations.

In other tests, catalysts including calcium oxide, silica gel, and iron oxide were added to the air-blown fluidized bed reactor continuously with the feedstock. The low-energy gasification process was insensitive to these catalysts.

EEE also performed some tests by operating the reactor as an updraft, fixed bed reactor. Coarse sand was placed at the bottom of the reactor, and the feedstock was loaded on top of the sand. Air was fed in a stream upward through the bed, and biomass was fed by gravity from the top of the reactor. In this configuration, extensive plugging and bridging in the gasifier caused significant operational problems. Feedstocks such as wood plugged near the top of the reactor because tars from the gasifier would condense 
on the cool particles and cause them to stick. Plugging from ash fusion also occurred in the middle and bottom of the gasifier when feedstocks such as corn stover were used. Although biomass feedstocks have been successfully gasified in updraft gasifiers, these results demonstrate the importance of careful reactor design and feedstock selection.

Dr. Bailie also conducted research at the University of West Virginia to determine reactivity differences between several types of biomass. Thermogravimetric procedures were used to determine the weight loss of biomass over time as samples were heated. The rates of heating were slow, approximately $40^{\circ} \mathrm{C} / \mathrm{min}$. Data from this work, however, does not appear to have been published in either the report prepared for Gilbert/Commonwealth or in the final report for this work.

\section{Selected Reference:}

Environmental Energy Engineering, Inc. 1980. Biomass PDU Gasification Studies, Volume IV, Research and Evaluation of Biomass Resources/Conversion/Utilization Systems. Final Report to Gilbert/Commonwealth under DOE contract DE-AC02$78 \mathrm{ET} 20611$.

\subsubsection{Use of Low-Energy Gases in Engines}

In the early 1980's, there was widespread interest in using low-energy gasifiers to power internal combustion engines. This interest arose not only from potential developers of the technology but also from political interests in the U.S. Congress who saw the possibility for exporting the technology to other countries. As a result of this interest. the BTC Program sponsored limited work on methods to improve low-energy gases for engine use. The primary goal of the BTC Program was to demonstrate that low-energy gases could be used in internal combustion engines in emergency situations where conventional fuels were not available.

Gasifiers had been used in Europe during the 1940's to provide an emergency source of fuel for transportation fuels. Engines typically ran successfully on the low-energy gas for short periods, but the tars and particulates in the gases tended to cause premature engine failure. The BTC Program research examined methods to provide a higher quality fuel gas from these gasifiers. Projects at three locations were funded including $\mathrm{Cal}$ Recovery Systems, University of Florida, and Rocky Creek Gasogens.

\subsubsection{Research on Gasifier/Engine Systems - Cal Recovery Systems}

\section{Principal Investigator: G. M. Savage}

Project Objective: Cal Recovery conducted research to identify areas where the operation and performance of gasifier/gas cleanup/engine systems could be improved. The gas from a small gasifier was cleaned and fed to a stationary diesel engine, and the 
system was examined to determine what modifications could be made to improve engine behavior.

Summary of Research Project and Results: The project consisted of the operation of a diesel engine fueled by cleaned gas from a gasifier. The fixed bed gasifier consisted of a 55-gal drum lined with refractory. Wood or charcoal (approx $0.1 \mathrm{~m}^{3}$ ) was loaded batchwise into the gasifier, ignited, and gasified with air. The product gases contained 2.2-5.6 MJ/NM .

The raw product gases then passed through a cooling and cleaning train consisting of an integral wet scrubber/sieve plate unit and then a cloth filter. The gas cleanup train was designed to be simple but to effectively cool the gas and to remove as much tar and particulate as possible. The system worked effectively through the tests, and no engine problems attributable to gas quality were encountered. While it was appropriate for the research conducted, this approach may be less suitable for commercial applications since it produces large quantities of aqueous waste and has a relatively low energy efficiency.

The fuel gas was then used to fuel an industry standard Cooperative Fuel Research (CFR) diesel engine with a $4.5 \mathrm{~kW}$ output. The diesel engine was operated on a mixture of diesel and low-energy gas where the biomass product supplies from $20-80 \%$ of the input energy for the engine. The use of the low-energy gas reduces power in engines. When low-energy gas supplied $30 \%$ of the energy in the fuel mixture, the power of the engine was about $25 \%$ less than when running on diesel alone. The dual-fueled engine also exhibited a tendency to "knock" much like an internal combustion engine. This could be controlled by lowering the compression ratio of the engine and by reducing the load, but that further lowered engine performance.

Cal Recovery suggested modifications to the diesel engine to partially offset the power loss from using biomass gas, but the modification studies were not funded.

\section{Selected Reference:}

Cal Recovery Systems, Inc. 1984. "Research and Development on Biomass Gasifier/ Engine Systems." In Proceedings of the 16th Biomass Thermochemical Conversion Contractors' Meeting, Portland, Oregon, May 8-9, 1984, pp. 231-244. CONF-8405157, Pacific Northwest Laboratory, Richland, Washington.

\subsubsection{Enhancement of Engine Performance - University of Florida}

\section{Principal Investigator: L. N. Shaw}

Project Objective: The University of Florida conducted research to improve the performance of engines using low-energy gas through the use of turbo and superchargers. Research was conducted on both spark-ignition and diesel engines. 
Summary of Research Project and Results: The university conducted its research using a system which included a gasifier, and gas clean-up train, and test engines. The gasifier was a downdraft design with a rotating hearth. The gasifier was loaded batchwise with about 3001 of fuel, closed, and gasification was started. The gas had composition typical of low-energy gasifiers with a heating value of about $5.1 \mathrm{MJ} / \mathrm{NM}^{3}$. The cleanup train consisted of a cyclone cleaner and two fiber filters capable of removing $98 \%$ of particulates greater than 3 microns.

The gasifier could be coupled with either a combustion ignition (diesel) or a spark ignition engine. For the spark ignition engine, tests were made using both normally aspirated and turbocharged modes. The turbocharger was oriented so that it compressed only clean air and did not compress additional producer gas. The power of the normally aspirated spark ignition engine operating on producer gas $(2000 \mathrm{rpm})$ was found to be only $57 \%$ of that when operated with gasoline. Turbocharging the engine when using producer gas increased the power to $65 \%$ of the normally aspirated engine operating on gasoline, but this level was also felt to be unacceptably low.

With the combustion ignition engine, a dual-fuel fueling system was developed. The dual fuel allowed $0-20 \%$ diesel to be added to the biomass gas and was actuated by an oxygen sensor in the engine exhaust. Using this system, the engine performance was within $80 \%$ of the maximum performance that would be expected on diesel alone. Supercharging the engine had no measurable effect when biomass gas was used. This work suggests that with further development, the dual fuel system could potentially be used in some combustion ignition engines.

\section{Selected References:}

University of Florida. 1986. "Performance Enhancement of Engines Fueled on Producer Gas." In Proceedings of the 1985 Biomass Thermochemical Conversion Contractors' Meeting, pp. 257-262. CONF 8405157, National Technical Information Service, Springfield, Virginia.

Shaw, L.N. 1986. Performance Enhancement of Engines Fueled with Producer Gas. Final Report submitted under subcontract B-F0462-A-Q, Pacific Northwest Laboratory, Richland, Washington.

\subsubsection{Field Testing of Small Gasifier Filter Systems - Rocky Creek Gasogens, Inc.}

Principal Investigator: R. H. Hargrave

Project Objective: In the early 1980's, several individuals and firms had small gasifier units coupled to various vehicles. Rocky Creek Gasogens operated both a truck and a field tractor on low-energy gas from biomass. The BTC Program funded Rocky Creek Gasogens in conjunction with the University of Florida to evaluate filter systems which might be appropriate for such applications. 
Summary of Research Project and Results: The research consisted of three tasks. First, a small gasifier was installed on a field tractor, and four filter systems were designed. The tractor was taken to the University of Florida where measurements of the tars and particulates which passed through the filter were made. The filter systems were then tested for reliability under real-life conditions on a farm.

The gasifier was a simple fixed-bed, down-draft design, and a cyclone filter was attached for primary filtration. Four secondary filters were tested. These included two configurations of fiberglass filters, a baghouse filter, and an oil-bath cleaner. Testing at the University of Florida showed that the primary cyclone filter removed only coarse material but passed almost all material in the 1-100 micron size range. Of the secondary filters, the oil bath cleaner was least effective, removing only about $8 \%$ of the tars in the 10-100 micron range and removing almost none of the material under 10 microns. The baghouse and fiberglass batt filters could be configured to remove essentially all of the material above 10 microns and up to about $80 \%$ of the tar below 10 microns. These configurations were deemed acceptable to meet engine specifications. Tests at the engine exhaust showed that most of the tar below 10 microns in size which entered the engine was burned.

Field testing showed that the engine would operate satisfactorily with the baghouse or fiberglass batt filters for moderate periods of time. After about 20 hours, however, 5$15 \mathrm{~mm}$ pieces of charcoal would break through the filters. The filters required servicing at least once per day and were messy to deal with. While gasifier technologies can potentially be used to fuel mobile internal combustion engines in emergency situations, the combination leads to many problems.

\section{Selected References:}

Hargrave, R. H. 1984. "Field Testing Small Gasiifer Filter Systems." In Proceedings of the 16th Biomass Thermochemcical Conversion Contractors' Meeting, pp. 223-230. CONF-8405157, National Technical Information Service, Springfield, Virginia.

Hargrave, R.H. 1984. Final Report for Field Testing Small Gasifier Filter Systems. Submitted under subcontract B-F0463-A-Q, Pacific Northwest Laboratory, Richland, Washington.

\subsection{ENVIRONMENTAL/END-USE ASPECTS OF BIOMASS GASIFICATION}

In addition to the research on producing medium- and low-energy gases from biomass, the BTC Program sponsored research on several environmental and end-use issues associated with biomass gasification. In the end-use area, the program sponsored research to develop improved catalysts for converting medium-energy biomass synthesis gases and to mixed alcohol fuels. In the environmental area, the program sponsored research on gasifier wastewaters and on methods to dispose of biomass tars. These projects are shown in Table 2.13. The program also conducted research to characterize 
the tars from various biomass gasification and pyrolysis units. This work is discussed in Chapter 3 of this report, with the pyrolysis projects.

Table 2.13. Summary of Environmental/End-Use Gasification Projects Funded by the BTC Program.

\begin{tabular}{||l|l|}
\hline TECHNOLOGY AREA & INSTITUTION \\
\hline Environmental/End-Use Aspects of Gasification & \\
\hline End-Use Applications & \\
$\quad \begin{array}{l}\text { Catalysts for Producing Synthesis Gas in } \\
\text { Indirectly-Heated Gasifiers }\end{array}$ & Pacific Northwest Lab \\
& \\
$\quad$ Improved Catalysts for Mixed Alcohol & Lehigh University \\
Production & \\
Environmental Aspects of Gasification & \\
& \\
Treatment of Wastewaters from Biomass & Pacific Northwest Laboratory \\
Wasification & \\
& Georgia Tech Research \\
\hline
\end{tabular}

\subsubsection{End-Use Applications}

This research included work with bench- and research-scale gasifiers at Pacific Northwest Laboratory to develop information on catalysts for upgrading the medium-energy product gas, and work at Lehigh University on catalysts to produce mixed alcohol fuels. These projects are discussed below.

\subsubsection{Catalysts for Synthesis Gas in an Indirectly Heated Fluidized-Bed Gasifier - Pacific Northwest Laboratory (PNL)}

Principal Investigators: Lyle K. Mudge, Ed G. Baker

Project Objective: Battelle PNL conducted extensive research on indirectly heated biomass gasification systems in the early 1980's. This work was aimed at producing medium-energy gases suitable for use in the synthesis of methanol. Due to shortages of petroleum in the 1970's, the production of biomass based methanol was viewed as an important alternative for liquid transportation fuels.

The work at PNL focused on the use of catalysts to upgrade the medium-energy product gas so that it would be suitable for synthesis use. The ideal methanol synthesis gas 
contains primarily hydrogen and carbon monoxide in a 2:1 molecular ratio. The raw product from most biomass gasifiers not only has the incorrect ratio of hydrogen to carbon monoxide, but also has significant quantities of carbon dioxide, hydrocarbons such as methane or ethane, tars, and particulates, all of which are undesirable in methanol synthesis. PNL explored the use of catalysts which could be used directly in the gasifier to both crack hydrocarbons and to shift the ratio of hydrogen to carbon monoxide. By producing a more suitable product gas directly in the gasifier, the cost of methanol could potentially be lowered.

In most of the work, the catalysts were placed directly in the gasifiers. The pyrolytic reactions occurring in the indirectly heated reactors create a reducing atmosphere which is suitable for many types of metallic catalysts. By comparison, the oxidizing atmosphere of air- or oxygen-blown gasifiers would be detrimental to many catalysts.

It should also be noted that Mudge conducted extensive basic gasification studies at PNL in the late 1970's prior to the start of the BTC Program. Detailed discussions of this research are available elsewhere (i.e., "Investigations on Catalyzed Steam Gasification of Biomass," PNL Report PNL-3695, Mudge, et al., 1981).

Summary of Research Project and Results: The PNL catalytic gasification research was conducted in both laboratory and research-scale gasifiers. The research gasifier was a fluidized bed type with heat for the gasification reaction supplied by electrical heaters. In this configuration, the research reactor closely matched the characteristics of larger scale units such as University of Missouri gasifier, where heat is provided to a fluidized bed through a fire tube heat exchanger. While electric heaters would not be used in commercial gasifiers, they provided a simple and effective method to control the temperature in the PNL research unit.

The research gasifier consisted of a steel cylinder $0.61 \mathrm{~m}$ in diameter by $3 \mathrm{~m}$ long located inside a steel pressure vessel. The gasifier was operated at pressures up to $10 \mathrm{~atm}$. Heat was provided by electric heaters suspended both inside the fluidized bed and wrapped around the exterior of the gasifier vessel. The bed was fluidized with preheated steam, which also reacted with the biomass chars. The product gas could also be stored and recycled back to the reactor to reduce steam requirements. In addition, a bench scale reactor was used for catalyst screening studies. The laboratory scale gasifier was a quartz vessel surrounded by electric heaters and operated at ambient pressure.

In an indirectly heated gasifier, three types of primary biomass reactions occur. These include the pyrolytic reactions which produce volatiles and char as the biomass is initially heated, the subsequent steam gasification of char, and the further reforming and condensation of the volatile products. In the PNL work, alkali carbonates, termed primary catalysts, were used to enhance the reaction of char with steam. Supportod metal catalysts, termed secondary catalysts, were used to catalyze gas phase reforming and condensation reactions.

Alkali catalysts including $\mathrm{K}_{2} \mathrm{CO}_{3}, \mathrm{Na}_{2} \mathrm{CO}_{3}$, trona, and borax were added to biomass in concentrations ranging from .003 to $.0003 \mathrm{~g}$-moles $/ \mathrm{g}$ wood and reacted at temperatures 
from $500-750{ }^{\circ} \mathrm{C}$. Research showed that alkali catalysts were effective in increasing the yields of gases in both the laboratory and research gasifiers. The alkali catalysts increased the yield of gases by reducing the amount of tars formed. The char remaining after the initial volatilization was more reactive with the alkali catalysts, and the rate of the steam gasification of the char increased. The increase probably occured because the alkali increased the carbon surface area available for reaction. More than $80 \%$ of the alkali catalysts could be recovered from the ash using a water wash.

Secondary catalysts were also tested to allow production of specific synthesis gases for processes such as methanol production, ammonia production, or hydrogen production. The catalysts included the following types:

\begin{tabular}{|c|c|}
\hline Metal: & Support: \\
\hline $\mathrm{Ni}$ & $\begin{array}{l}\text { Alumina, refractory, others (Harshaw, } \\
\text { Gerdler, Grace, and others) }\end{array}$ \\
\hline Ni-Cu-Mo & $\begin{array}{l}\text { Alumina and silica (Harshaw, Grace, } \\
\text { others) }\end{array}$ \\
\hline $\mathrm{Cu}-\mathrm{Zn}$ & NA \\
\hline $\mathrm{Fe}_{2} \mathrm{O}_{3}$ & NA \\
\hline Co-Mo & Alumina (Harshaw) \\
\hline Molecular sieves & Mordenite \\
\hline
\end{tabular}

The most active of these were the $\mathrm{Ni}$ and $\mathrm{Ni}-\mathrm{Co}-\mathrm{Mo}$ catalysts, while the copper, iron oxide, and molecular sieves were not active. Typical gas compositions for these catalysts are shown in Table 2.14 .

Additional studies with wood in the laboratory reactor showed that the compositions of the gas could be varied substantially by selecting appropriate catalysts and reaction temperatures. By reducing temperatures to about $550^{\circ} \mathrm{C}$, a methane-rich gas $(25.4 \%$ by volume) can be produced using a nickel catalyst. A hydrogen rich gas is produced by increasing reaction temperatures to $750{ }^{\circ} \mathrm{C}$ in the presence of a Co-Mo catalyst. At least at this scale, it is possible to produce a product gas custom tailored to the endproduct needs. Extensive studies with bagasse were also made with similar results. Bagasse contains more sulfur than most wood, and catalyst lifetimes were sometimes shortened by its presence.

Catalyst lifetimes were determined in both the laboratory and the research gasifier. In the laboratory reactor, certain of the Ni-Co-Mo catalysts maintained high activity for the duration of the 1470 hours that testing occurred. In the research gasifier, however, catalyst lifetimes were much shorter, with major deterioration in less than 24 hours. The loss of activity appeared to come primarily from carbon build-up on the catalyst surface, but losses to attrition in the turbulence of the fluidized bed also occurred. From these results, it appears that it will be difficult to achieve long catalyst lifetimes when the catalysts are placed directly in the gasifier. Since that time, PNL has developed a proprietary method for using catalysts in a second reactor immediately downstream from the gasifier. In this concept, the tri-metallic catalysts still shift and reform the product 
gas as they did in the gasifier. However, the separate reactor allows the catalysts to be isolated from the turbulence of the fluidized bed. The process also involved proprietary methods to regenerate the catalyst by removing deposited carbon. This work suggests that catalysts can be effective in cleaning and conditioning the raw gas from biomass gasifiers, but that systems must be designed specifically to allow long catalyst lifetimes.

Table 2.14. Gas Compositions for Catalyzed Steam Gasification of Biomass $\left(750^{\circ} \mathrm{C}, 1 \mathrm{~atm}\right)$.

\begin{tabular}{|c|c|c|}
\hline & $\begin{array}{c}\text { Ni/Ceramic } \\
\text { Catalyst }\end{array}$ & $\begin{array}{c}\text { Ni-Co-Mo } \\
\text { Catalyst on } \\
\text { Silica/Alumina }\end{array}$ \\
\hline Gas Composition, vol \% & & \\
\hline $\mathrm{H}_{2}$ & 53.0 & 50.0 \\
\hline $\mathrm{CO}_{2}$ & 21.3 & 19.2 \\
\hline $\mathrm{CH}_{4}$ & 5.5 & 5.8 \\
\hline $\mathrm{CO}$ & 19.7 & 24.7 \\
\hline $\mathrm{C}_{2}+$ & 0.6 & 0.3 \\
\hline Carbon Conversion, wt\% & & \\
\hline To gases & 93 & 93 \\
\hline To char & 7 & 7 \\
\hline To liquids & - & - \\
\hline Syn Gas Yield, $\mathbf{m}^{3} / \mathrm{kg}$ feed & 1.27 & 1.26 \\
\hline
\end{tabular}

Current Status: PNL completed additional work on their proprietary catalyst upgrading system in the early 1990's. No publicly available reports have been issued on the proprietary system.

\section{Selected References:}

Baker, E.G. and L.K. Mudge. 1984. Catalysis in Biomass Gasification. PNL-5030, Pacific Northwest Laboratory, Richland, Washington.

Baker, E.G., M.D. Brown, and R.J. Robertus. 1985. Catalytic Gasification of Bagasse for the Production of Methanol. PNL-5100, Pacific Northwest Laboratory, Richland, Washington. 
Mudge, L.K., et al. 1983. Catalytic Gasification Studies in a Pressurized Fluid Bed Unit. PNL-4594, Pacific Northwest Laboratory, Richland, Washington.

\subsubsection{Improved Catalysts for Mixed Alcohol Production - Lehigh University}

\section{Principal Investigator: K. Klier}

Project Objective: The cleaned and conditioned medium-energy gases from biomass can be reacted with catalysts to form alcohol fuels. The process is essentially the same as commercial processes for producing methanol from natural gas. In the commercial process, natural gas is first reacted to form $\mathrm{CO}$ and $\mathrm{H}_{2}$ and then reacted to produce methanol. Over the years, the catalysts have been improved to be very specific for methanol production while practically eliminating the simultaneous production of other alcohols such as ethanol or propanol.

The BTC Program sponsored research on catalysts which would provide a mixed-alcohol product consisting of not only methanol but higher alcohols as well. The mixed alcohol fuel would have a higher heating value than methanol alone and would have other potential operational advantages as well. In addition, the amounts of $\mathrm{CO}_{2}$ in biomass gases can be relatively high, which can affect the synthesis catalysts. Lehigh University conducted research to better understanding the influence of carbon dioxide on typical copper/zinc catalysts for methanol production and to examine other types of catalysts for producing mixed alcohols.

Summary of Research Project and Results: The effects of carbon dioxide on copper/zinc catalysts for methanol production were studied by converting mixtures of $\mathrm{CO}, \mathrm{H}_{2}$, and $\mathrm{CO}_{2}$ to methanol in a laboratory reactor system at about $75 \mathrm{~atm}$. The mixtures contained from 0 to $10 \% \mathrm{CO}_{2}$ with the remainder being $70 \% \mathrm{H}_{2}$ and $30 \% \mathrm{CO}$. Conversion temperatures ranged between $225-250{ }^{\circ} \mathrm{C}$. The highest methanol yields were found with $\mathrm{CO}_{2}$ concentrations of about $2 \%$, while at either higher or lower concentrations, the yields of methanol declined. Carbon dioxide appears to play two opposing roles in the reaction by both bringing the catalyst to its active state via its oxidizing power and retarding synthesis through high adsorption onto the catalyst. These results suggest that the synthesis gases from biomass would have to be scrubbed of $\mathrm{CO}_{2}$ or that catalyst modifications would be required.

Lehigh University also examined rhodium catalysts for producing mixed alcohols from biomass synthesis gases. Rhodium catalysts were known to cause ethanol formation. Several rhodium-based catalysts were prepared including $\mathrm{Rh} / \mathrm{Cu} / \mathrm{ZnO}, \mathrm{Rh} / \mathrm{TiO}_{2}$, and others. Rhodium at about 1 mole\% on the copper/zinc support produced about $95 \%$ methanol, $2 \%$ methane, $1.3 \%$ ethanol and $1 \%$ other alcohols and ethers at $250{ }^{\circ} \mathrm{C}$ and $75 \mathrm{~atm}$. Although the catalysts are still highly preferential toward methanol, a wider range of products can be produced. The research suggested that higher rhodium contents in the catalyst could increase yields and that other catalysts could potentially be used. Due to changing national priorities in the early 1980's, the production of mixed alcohol fuels became a low priority, and the BTC program discontinued this research. 
Selected Reference:

Klier, K. and R.G. Herman. 1981. "Catalysts for Alcohols From Biomass." In Proceedings of the 12th Biomass Thermochemical Conversion Contractors' Meeting, Washington, D.C., March 18-19, 1981.

\subsubsection{Environmental Aspects of Gasification}

The BTC conducted research to identify and solve potential environmental concerns about gasification processes. Work on a concept to re-inject liquid wastes from biomass gasification into the gasifier and work on the treatment of biomass gasification wastewaters is described below. In addition to these projects, the BTC Program sponsored research at PNL to characterize the tar and liquid products from a number of gasifiers and pyrolysis reactors. That work is described in Chapter 3 of this report.

\subsubsection{Treatment of Wastewaters from Biomass Gasification - Pacific Northwest Laboratory (PNL).}

Principal Investigator: S. E. Petty, J. V. Maxham

Project Objective: PNL conducted research to determine if typical methods for treating process wastewater would be effective in with aqueous wastes from biomass gasifiers. These tests included both physical/chemical techniques as well as biological approaches. When this work was done in late 1980, the number of medium-energy gasifiers which were in operation was limited, and in most cases, operation had not been optimized with respect to major operational variables such as temperature. The BTC Program recognized that aqueous samples from any of the gasifiers were not necessarily representative of those which would eventually be obtained from commercial units. However, the research was conducted to provide a preliminary idea of what possible treatment options might be.

Summary of Research Project and Results: PNL obtained aqueous effluent samples from the gasifier at Texas Tech University, as described in Section 2.3.2 of this report. These effluents were produced during wood gasification tests. COD values for the samples ranged from 30,000 to $70,000 \mathrm{mg} / \mathrm{l}$, roughly 100 times greater than municipal sewage. Analysis at Texas Tech had indicated that the primary components of the samples were carboxylic acids, and PNL confirmed the presence of acetic and propionic acids. PNL analyzed trace metals in the solutions, but detailed identification of organic species was not performed. PNL examined both biological and physical/chemical methods of treating the wastewaters. 
Three physical/chemical wastewater treatment techniques were examined including wet air oxidation, solvent extraction, and reverse osmosis. Wet air oxidation (WAO) experiments were conducted in a stirred autoclave reactor. Aqueous effluents were added to the reactor which was sealed and heated, and pressurized air flowed through the vessel. Temperatures were varied from $150-300^{\circ} \mathrm{C}$ and reaction times ranged from 20 $180 \mathrm{~min}$. Following reaction, the remaining effluent was analyzed for color and COD.

The COD removal was strongly dependent of the severity of the treatment which includes both temperature and residence time. At $300^{\circ} \mathrm{C}$, approximately $80 \%$ of the COD was removed in $20 \mathrm{~min}$, while almost no reaction occurred at the lowest temperatures and shortest residence times. The components causing coloration of the samples were removed more rapidly, with $98 \%$ color reduction at $300^{\circ} \mathrm{C}$ in 20 minutes.

Solvent extraction of the organic components of the aqueous waste was also attempted. Ten different solvents were tested for effectiveness by placing them in a separatory funnel, adding wastewater samples, shaking, and analyzing the extract. The ten solvents included methyl-isobutyl ketone, various butanols and acetates, tri-n-octyl phosphine oxide in kerosene, kerosene, toluene, and others. None of these solvents was particularly effective at extracting the organic material from the wastewaters. The best solvent was n-butanol, which had a distribution coefficient (concentration of waste organics in extracted solvent divided by the concentration in the aqueous phase) of 1.28 , which is still insufficient.

PNL also applied reverse osmosis techniques to the wastewaters. Wastewaters pressurized to 700-800 psi were passed over a semipermeable membrane, and the effluent was analyzed. The process was successful in removing $90-100 \%$ of the COD from the waste stream, but the costs for such a process were expected to be high.

PNL also applied biological aerobic and anaerobic digestion techniques to treat the wastewaters. The research was conducted in small laboratory reactors constructed for this purpose. In the aerobic situation, full strength biomass wastewaters were fed to a system configured to simulate a high rate fixed film activated sludge treatment process. Inorganic nutrients including phosphate, magnesium, and calcium were also added, and air was pumped through the system. The COD of the wastewater was typically lowered to $15-30 \%$ of its original value with liquid residence times of about 15 days and solids residence times of about 25 days.

Anaerobic digestion was also tested in a reactor simulating an upflow sludge blanket treatment process. The anaerobic digestion process was unable to digest full strength gasification wastewaters, although samples diluted by $50: 1,25: 1$, and 10:1 ratios could be treated. However, even in the diluted samples, the rates of reaction were slow, and methane production was significantly impaired. Total COD reductions were only about $7 \%$. The use of anaerobic digestion to clean the effluent from the aerobic process was also only marginally useful. It appears that many of the components of the gasification wastewater are toxic to the anaerobic microbes, and that the wastewaters also inhibit methane production. 
Current Status: The research showed that there are combinations of biological and physical/chemical methods which can potentially be used to treat the wastewaters. However, even if a $90 \%$ reduction in the COD level were obtained, it would leave the waste stream with an organic content several times that of municipal sewage. Organics in the waste stream not only represent a potential cost burden for cleanup but also lower the overall gasification process efficiency. As a result of these considerations, gasifier development in the 1990's is pursuing various means to minimize or eliminate waste streams. By carefully engineering the various process streams and by using or reinjecting various components, the amount of waste can be reduced or possibly eliminated. The fact that wastes could represent a problem has spurred efforts to greatly reduce the amount of waste that will be produced.

Selected Reference:

Pacific Northwest Laboratory. 1981. "Treatment of Biomass Gasification Wastewaters Using Wet Air Oxidation, Sovent Extraction, and Reverse Osmosis." In Proceedings of the 13th Biomass Thermochemical Conversion Contractors' Meeting, Arlington, Virginina, October 27-29, 1981, pp. 718-747. CONF-8110115, Pacific Northwest Laboratory, Richland, Washington.

\subsubsection{Waste Disposal via Gasification - Georgia Tech Research Institute (GTRI)}

\section{Principal Investigator: T. F. McGowan}

Project Objective: GTRI conducted research on a concept to use tars produced during the gasification process. In this concept, the tars produced from gasification would be burned to form water and carbon dioxide. The $\mathrm{H}_{2} \mathrm{O}$ and $\mathrm{CO}_{2}$, would then be reinjected back into the gasifier. The higher concentrations of these products in the gasifier would theoretically promote reactions to increase the amounts of $\mathrm{H}_{2}$ and $\mathrm{CO}$ in the product gas. The process could potentially reduce tars while improving the product gas quality.

Summary of Research Project and Results: The research at GTRI consisted the design and construction of a test facility for the concept. The facility was to include a lowenergy gasifier, an external burner to destroy the tar, and an injection system. Over a two-year period in 1983 and 1984, the project experienced many delays, and meaningful results were not obtained before the project was discontinued.

\section{Selected References:}

McGowan, T.F., A.D. Jape, and J.L. Walsh. 1984. "Utilization of Tar and Aqueous Effluents from Biomass Gasification Systems." In Proceedings of the 16th Biomass Thermochemical Conversion Contractors' Meeting, Portland, Oregon, May 8-9, 1984, pp. 177-191. CONF-8405157, Pacific Northwest Laboratory, Richland, Washington.

McGowan, T.F., A.D. Jape, and J.L. Walsh. 1983. "Utilization of Waste Streams in Biomass Gasifiers." In Proceedings of the 15th Biomass Thermochemical Conversion 
Contractors' Meeting, pp. 223-235. CONF-830323, National Technical Information Service, Springfield, Virginia.

McGowan, T.F. 1981. "Wood Gasification Research for Textile Industry Applications." In Proceedings of the 13th Biomass Thermochemical Conversion Contractors' Meeting, Arlington, Virginina, October 27-29, 1981, pp. 685-696. CONF-8110115, Pacific Northwest Laboratory, Richland, Washington.

\subsection{SUMMARY AND RECOMMENDATIONS - GASIFICATION}

\subsubsection{Summary of Gasification Accomplishments}

The BTC Program was successful both in developing new technologies for producing medium-energy gases from biomass and in helping to improve the basic understanding of biomass gasification processes. A summary of major accomplishments is listed below:

- The BTC Program successfully developed and demonstrated several concepts for producing medium-energy gases from biomass.

The BTC Program demonstrated that medium-energy gases could be successfully produced using either directly or indirectly heated gasifier concepts. Indirectly heated gasifier concepts included fluidized bed designs with internal heat exchangers typified by the University of Missouri-Rolla and MTCI, Inc., and a dual bed design at Battelle Columbus Laboratory. Directly heated, oxygen blown technologies were successfully demonstrated in fluidized and fixed bed reactors by Institute of Gas Technology and Syngas/NREL, respectively. The medium energy gasifiers capable of processing 10-20 tons/day of biomass were successfully operated for continuous periods of $70-120$ hours.

The development of several different gasifier concepts by the program will allow prospective users to choose a technology which is best suited for their specific use. For example, the fixed bed technology may be well suited for small scale application, while moving bed technologies may be better suited for large scale applications. Several gasifiers performed well at the process development unit scale. From the research performed, it is not possible to identify a single concept as being the overall best or lowest cost method for producing medium-energy gas. The choice of gasifier will depend very much on the project-specific criteria such as the nature of the feedstock, the scale of operation, and the product gas use. The ability of industry to select a technology suitable for its needs is very important in the future development of biomass gasification. Had the BTC Program concentrated development on a single gasifier, the prospect for commercial application of a single technology would be significantly less than it is at present with more choices available. 
- The technologies developed by the BTC Program are being scaled up and commercialized by industry.

Several of the gasifier concepts developed by the BTC Program are currently being scaled to commercial or near-commercial size. MTCI is constructing a large (approximately $100 \mathrm{tpd}$ ) commercial gasifier for Weyerhauser in North Carolina, and IGT is constructing a similar sized demonstration gasifier with cofunding from DOE and various Hawaiian interests. Battelle-Columbus is in the design stage for a scale-up version of its reactor, and the University of MissouriRolla is constructing a tire pyrolysis unit based on its gasification technology. Because the cost of natural gas has remained low, the initial uses of these technologies will likely involve the conversion of wastes which would otherwise have resulted in disposal costs. The MTCI gasifier being built for Weyerhauser is an example.

- The gasification technologies developed by the BTC Program appear to have significant potential for use in advanced power generation systems.

The high energy content of the product gas makes the medium-energy gases potentially suitable for use in advanced gasifier/gas turbine systems for power generation. These systems offer higher power generation efficiencies than conventional biomass combustion/steam turbine systems. Battelle-Columbus is currently testing a small turbine system connected to its gasifier, and the DOE/PICHTR scale-up activity based on the IGT technology will also conduct gas turbine tests in the future.

Gas turbines require very clean fuel gases, and the inorganic material in the raw biomass gas will have to be removed. Current research in hot gas cleanup is addressing this potential problem. The medium-energy technologies developed by this program will compete with low-energy, air blown technologies for powering gas turbines, but final selection of appropriate systems will be made only after several technical and economic issues are resolved.

- The BTC Program demonstrated that methanol synthesis gas could successfully be produced from biomass.

While most of the near-term interest in biomass gasification is presently in producing a fuel gas, a major concern in the early 1980's was the production of methanol which could serve as a liquid transportation fuel. The BTC Program successfully demonstrated that raw product gases suitable for methanol synthesis could be made, and small amounts of methanol from biomass synthesis gases were produced. Research with catalysts showed that the raw product gases could be conditioned to produce appropriate $\mathrm{H}_{2}$ to $\mathrm{CO}$ ratios to improve the synthesis process. The synthesis gases could potentially be tailored for other needs such as Fisher-Tropsch synthesis of diesel-like fuels. 
With low natural gas prices, the production cost of methanol from biomass remains higher than from natural gas. At the present, there is little interest in producing methanol from biomass. It should be noted, however, that NREL has estimated that the costs of producing methanol thermochemically from biomass are approximately the same, on an energy basis, as producing ethanol biochemically from woody biomass.

- The BTC Program developed methods to effectively gasify biomass feedstocks with high moisture contents.

The program conducted research on a concept at PNL which can gasify biomass feedstocks with high moisture contents. This concept allows more biomass feedstocks to potentially be used for energy. In addition, the concept appears to have potential for disposing of many types of organic waste streams.

- The research of the BTC Program and other programs at the time helped create a much better understanding of basic reaction behavior of biomass as it gasifies.

Through the combined research of the BTC Program, the National Science Foundation, and others, a much better understanding of the basis of biomass gasification has been developed. The research was successful in describing how biomass reacts and in determining the detailed chemical reactions which occur under various conditions. The role of pyrolytic reactions in the gasification process are now well understood, and detailed models of biomass gasification can be developed to accurately predict behavior of specific gasifier configurations. It should be noted that this basic knowledge has been accumulated over time in many references and in many locations. It may be useful to produce a reference volume where much of this information could be gathered.

- The BTC Program conducted some of the first research on environmental effects of biomass gasification including gasification tars and wastewaters.

The BTC Program conducted research on the characterization and treatment of tars and aqueous wastes from biomass gasification. The results showed that unoptimized systems can produce fairly large streams of organic materials. Aqueous wastes can be treated with some conventional technologies, but the costs will be high if waste streams are not minimized. The tars may contain undesirable components, and it is desirable to reduce or eliminate them.

It must be strongly noted that the tars and aqueous wastes used in this research were not from optimized systems and were not necessarily representative of material which would be obtained from the commercial scale version of the same or different concepts. The results therefore must be considered carefully. Detailed analysis of the wastes from each commercial scale gasifier will have to be made. The information, however, does clearly show the need to minimize waste streams both to reduce treatment costs and to improve overall conversion 
efficiencies. In the large scale gasifiers currently being designed and built, techniques to minimize wastes are being incorporated.

\subsubsection{Recommendations}

- For advanced applications such as gas turbines, the product gases from biomass gasifiers must be very clean. Inorganic particulates from the ash in biomass are of particular concern. Continued research on gas clean-up and conditioning methods is needed if the gasifiers are to be successfully used in these systems.

- The development of medium-energy biomass gasification systems has progressed to the point where commercial systems can successfully be built. While new systems would still entail risk to investors, additional research to develop new gasifiers is not needed once the current round of scale-up and demonstration projects is complete.

- Low-energy air-blown gasifiers are commercially available. Several have been built and successfully operated over the past decade, but they have been unable to compete with low cost fuels such as natural gas. Since these systems are commercially available, additional research should be limited to gas cleanup. The use of low-energy gases to power automotive type internal combustion engines appears to have little potential except perhaps in emergency situations.

- Biomass gasification mechanisms are well understood, and this information can be used to successfully create predictive models of gasification behavior in most systems. The basic data, however, is scattered and not readily referenceable. It would be useful to collect and summarize the basic data in one location such as a dedicated reference volume.

- It appears that national energy and environmental policy will be the major determinants regarding future commercial implementation of biomass gasification technologies. As long as the prices of natural gas and petroleum fuels are at present levels, the biomass technologies will have relatively little impact. Certain of these technologies, such as MTCI's, will solve waste disposal problems. Those applications will be the first developed and may serve as the base of the longer-term development effort with biomass. DOE should take positive steps to more closely coordinate its energy and waste disposal efforts so that appropriate technologies are available regardless of the feedstock used. 


\subsection{PYROLYSIS AND LIQUEFACTION RESEARCH}

The BTC Program conducted research on a variety of pyrolytic approaches to produce liquid fuels from biomass. In these direct liquefaction processes, biomass was heated at moderate temperatures $\left(300-600^{\circ} \mathrm{C}\right)$ with the goal of making a product consisting primarily of liquid material. The so-called "biocrude" material was then upgraded into a hydrocarbon fuel, which was equivalent to gasoline from petroleum. Because the liquefaction process was pyrolytic in nature, the BTC Program also sponsored research to better understand the ways in which biomass reacts as it pyrolyzes. Between 1980 and 1989, pyrolysis/liquefaction research was the second largest component of the program. The pyrolysis and liquefaction research projects funded by the BTC Program are described in this chapter.

\subsection{LIQUEFACTION APPROACHES}

Interruptions in the supply of petroleum and the resulting price fluctuations in the late 1970's resulted in strong interest in producing liquid transportation fuels from domestic resources. The production of a hydrocarbon fuel which could directly substitute for gasoline was seen as an important goal. As shown in Figure 3.1, gasoline has more than 10 times the energy density by volume of wood, and has a density higher than alcohol fuels. As the BTC Program started its research, a major national concern was to ensure that sufficient fuels were available for transportation needs. Hydrocarbon fuels could be used without modification in existing distribution systems and vehicles. A direct substitute for existing fuels which did not require other system changes was viewed as an important possibility. In this chapter, the research in the direct liquefaction of biomass and the ungrading of the intermediate products to hydrocarbon fuels is described.

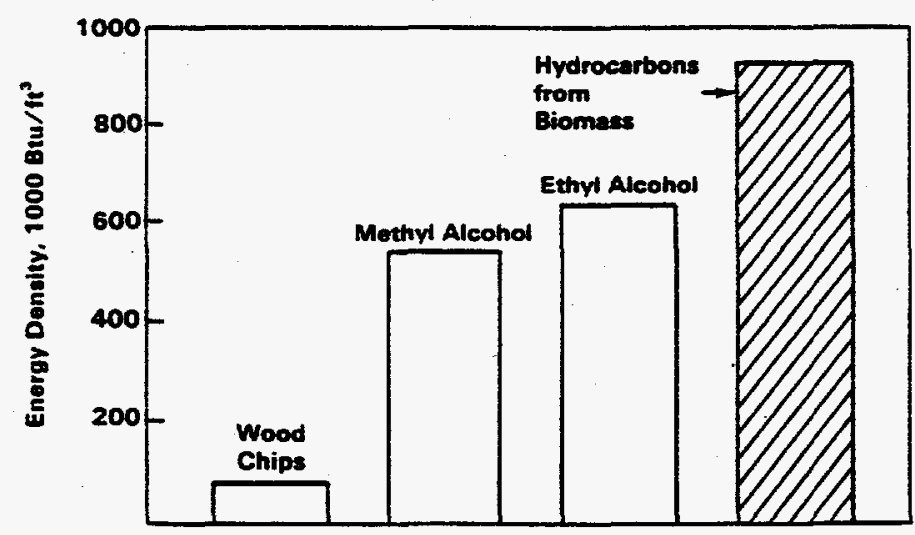

Figure 3.1. Comparison of Energy Densities of Various Fuels. 
The thermochemical conversion of biomass to liquids can be accomplished by either direct or indirect approaches. With direct liquefaction processes, biomass is converted directly to a "biocrude" liquid that can either be used as a substitute for low quality fuel oil or subsequently upgraded to a hydrocarbon fuel suitable for transportation uses. While the crude material is substantially different chemically than petroleum crude, the hydrocarbon product would be virtually indistinguishable from gasoline from petroleum sources. With indirect liquefaction approaches, biomass is first gasified, and the resulting synthesis gas is then converted to fuels such as methanol, as described in Chapter 2.

Since biomass direct liquefaction occurs in the absence of $\mathrm{O}_{2}$, the process is pyrolytic in nature. Pyrolysis has been used for centuries as a method to produce charcoal, along with small amounts of liquid products. Through the 1970's and 1980's, research showed that by varying the reaction conditions, the products from biomass pyrolysis could be altered substantially. As biomass is heated, a complex mixture of volatile products is given off. These products include primary components such as levoglucosan, or phenolics, plus premanent gases such as carbon monoxide and others. If the primary volatile materials are removed rapidly from the reactive zone, they can be condensed as liquids. By comparison, the volatiles will tend to recombine and further react when they remain at moderate temperatures for longer periods, leading to additional char formation. In gasification systems where the reaction conditions are more severe, the volatiles will tend to crack into lighter molecular weight molecules.

By varying the reaction temperatures and the residence times, up to approximately $65 \mathrm{wt} \%$ of the biomass could be converted to liquids, while the amount of char was reduced to less than $10 \%$. Likewise, under more severe conditions, pyrolytic processes could be used for biomass gasification, as described in Chapter 2. It is important, therefore, to note that pyrolysis is the complex set of reactions which occurs when biomass is heated rather than a single process to produce charcoal. The research sponsored by the BTC Program contributed significantly to the basic understanding of biomass pyrolysis and how pyrolysis could be used in advanced conversion systems.

\subsubsection{Pyrolysis and Upgrading Approaches}

The research sponsored by the BTC Program focused on two basic direct liquefaction approaches for producing a biocrude product from wood. The first of these were high pressure processes where biomass was heated for approximately 20 minutes at about $350{ }^{\circ} \mathrm{C}$ in the presence of a hydrogen/carbon monoxide-reducing gas. The reaction occurred under pressures of about $200 \mathrm{~atm}$. Catalysts such as sodium carbonate were sometimes used in the reaction process. The product oil was a viscous material with about $10-15 \%$ oxygen content and had a higher heating value of approximately 34,900 $\mathrm{kJ} / \mathrm{kg}(15000 \mathrm{Btu} / \mathrm{lb})$. The product oil superficially resembled heavy petroleum fuel oil in its physical properties, but it is very different chemically. Yields of the product from the high pressure processes were up to about $53 \mathrm{wt} \%$ of the feedstock on a dry basis. 
A second approach to producing liquids was based on fast pyrolysis at ambient pressures. By reducing the residence time of the pyrolysis products to a few seconds, higher yields up to about $65 \mathrm{wt} \%$ (dry basis) of the feedstock of a different type of liquid could be formed. In the fast pyrolysis processes, the biomass was reacted for a few seconds at approximately $550{ }^{\circ} \mathrm{C}$, and the reactions were quickly quenched to terminate unwanted byproduct formation. The product contained about $35 \%$ oxygen and had a higher heating value of about $22,800 \mathrm{~kJ} / \mathrm{kg}(9800 \mathrm{Btu} / \mathrm{lb})$. The differences between these two types of processes and the oils that are produced are discussed in detail in Section 3.3 of this report.

The BTC Program also studied two basic types of upgrading techniques for converting the intermediate products to hydrocarbon fuels. Zeolite catalysts were used with the fast pyrolysis products to convert them to an aromatic-rich mixture of hydrocarbons. Hydrotreating catalysts were used with both the high pressure and fast pyrolysis products to produce a somewhat different mixture of hydrocarbons. The research on these different pyrolysis and upgrading approaches is described in the following sections of this report.

\subsubsection{Basic Pyrolysis Research}

In addition to the research on individual process concepts, the BTC Program sponsored basic research on pyrolysis of biomass. In the late 1970's, the pyrolysis of biomass was incompletely understood. Through research sponsored by the BTC Program and others, the mechanisms and dynamics of biomass pyrolysis were described in detail. The improved understanding of biomass pyrolysis has had beneficial results on other thermochemical conversion systems, such as combustion or gasification systems. Pyrolysis occurs to a greater or lesser extent in all these systems, and an understanding of the mechanisms involved has helped drive process design. The basic work on biomass pyrolysis is described later in this chapter.

\subsubsection{Other Pyrolysis Research}

The BTC Program also sponsored research on the environmental issues surrounding the liquid products. This work consisted of the characterization of tar products both from pyrolysis and gasification projects. In addition, the program sponsored one project on production of char.

\subsection{PYROLYSIS/LIQUEFACTION RESEARCH EMPHASIS}

In the late 1970 's and early 1980 's, the perceived need to generate liquid fuels from biomass led to an emphasis on shorter term development projects which could potentially provide these fuels. The goal of the BTC Program at that time was to rapidly develop and commercialize processes which could produce liquid fuels from biomass. At that time, the main emphasis of the work was on the production of liquids using high pressure 
processes. A development-scale liquefaction facility had been built at Albany, Oregon. Research at the facility and at several support contractors focused on developing high pressure conversion processes. At the same time, work at a smaller scale showed that rapid pyrolysis also had potential as a means to generate liquid fuels. Development of these pyrolysis concepts also proceeded to the stage where research scale continuous process units were built and operated.

As this work continued, it became evident that the raw product from either process was not a high quality fuel, and research on product upgrading began. The work of the BTC Program allowed alternative upgrading approaches to be developed, and the results suggest that biomass can potentially be converted to hydrocarbon fuels at approximately the same cost as ethanol or methanol on an energy basis. Research on pyrolysis processes continued throughout the period to better understand the basics of biomass conversion.

By the late 1980's, the emphasis of DOE had shifted away from hydrocarbons toward oxygenated fuels, based primarily on clean-air considerations. The use of biomass pyrolysis technologies is presently seen as a means of producing higher value chemicals, fuels, and feedstocks for co-processing in refinery streams. Development work with industrial co-sponsors is underway.

The research on pressurized liquefaction and rapid pyrolysis processes is discussed in Section 3.3 of this report. Upgrading studies are discussed in Section 3.4, and basic pyrolysis research is described in Section 3.5. Other pyrolysis projects are discussed in Section 3.6.

\subsection{RESEARCH ON BIOMASS LIQUEFACTION PROCESSES}

Work on high pressure liquefaction of biomass began in the early 1970's at the Pittsburgh Energy Research Center (PERC). In the so-called PERC process, biomass was mixed at $7-15 \%$ wt\% with recycled product oil. Sodium carbonate catalyst was added as an aqueous solution, and the mixture was heated for $20-40$ minutes at about $350{ }^{\circ} \mathrm{C}$ at a pressure of about $200 \mathrm{~atm}$. Hydrogen and carbon monoxide reducing gases were also added. The process required extensive recycle of the product oil since only $10-20 \%$ of the material entering the reactor was fresh wood. In an effort to reduce the amount of product that had to be continually recycled, Lawrence Berkeley Laboratory (LBL) suggested a "once-through" process modification in which the biomass was fed to the reactor as an aqueous rather than an oil slurry. The process conditions in both cases were similar. In the early 1980's, these processes were the main focus of the BTC Program.

As the research on high pressure processes progressed, research at NREL and other places showed that rapid pyrolysis offered significant potential for producing liquids from biomass. The processes produced higher yields of liquid products and eliminated many of the operational problems encountered with the high pressure processes. By the mid1980 's, the emphasis of the program had changed to rapid pyrolysis with projects at 
NREL and Georgia Tech Research Institute. In these processes, biomass was rapidly heated at ambient pressure to temperatures of about $550^{\circ} \mathrm{C}$ and allowed to volatilize. The reactions were rapidly quenched by removing the volatile material from the reactive zone, and the residence time of the biomass was typically $0.5-5 \mathrm{sec}$.

The research sponsored by the BTC Program on high-pressure and rapid pyrolysis liquefaction processes is shown in Table 3.1. The individual projects in these areas are discussed below.

Table 3.1. Summary of High Pressure and Rapid Pyrolysis Liquefaction Projects Funded by the BTC Program.

\begin{tabular}{||l|l|}
\hline \hline TECHNOLOGY AREA & INSTITUTION \\
\hline Direct Liquefaction Processes & \\
\hline High Pressure Liquefaction Processes & \\
Albany, Oregon, Test Facility & Wheelabrator Cleanfuel Co. \\
Extruder Reactor System & University of Arizona \\
Aqueous Slurry Process System & Lawrence Berkeley \\
& Laboratory \\
Alternative Catalysts for Aqueous Systems & SRI International \\
Direct Liquefaction Studies & Pacific Northwest Laboratory \\
Rapid Pyrolysis Processes & \\
Ablative Reactor System & NREL \\
Entrained Reactor System & Georgia Tech Research \\
& Institute \\
\hline
\end{tabular}

\subsubsection{High Pressure Liquefaction Projects}

In the late 1970's and early 1980's, DOE focused primarily on high pressure liquefaction processes. This work included a large scale test facility, plus other support research and is decsribed below.

\subsubsection{Albany, Oregon, Liquefication Test Facility - Wheelabrator Cleanfuel Co.}

Principal Investigators: Walter Berry, Percy Thigpen 
Project Purpose: Work at the Pittsburgh Energy Technology Center (PERC) in the early 1970's showed that liquids could be produced from biomass using a high pressure process. This work was conducted primarily on MSW and also on biomass in small, batch autoclave reactors. Based on these preliminary results, the U.S. Bureau of Mines authorized the construction of a process research facility in Albany, Oregon, in the mid1970's, with the capability of feeding about 2 tpd of biomass on a continuous basis. The facility included a multi-story processing unit, a separate control room, laboratory facilities for analytical support, and office space.

The facility was constructed by Rust Engineering and was ready for operation in 1977. By this time, oversight of the project had been transferred to DOE. Initial shakedown operation of the facility was performed in 1977 by Bechtel Corporation, and in 1978 the operating contract was awarded to Wheelabrator Cleanfuel Company after several problems.

The objective of the research was to rapidly develop a process which could successfully liquefy biomass and to provide data which could be used to scale the concept to a commercial size. While it was recognized that the scale-up of the process based on limited data entailed considerable risk, the concern over crude oil availability at the time appeared to justify that risk.

\section{Summary of Research Project and Results:}

Description of Test Facility - The test facility was based on the best estimates of what would be required to convert the batch tests at PERC into a continuous process. The PERC process used wood blended with recycled oil to form a feed slurry. In the initial design, wood was dried and finely ground to -35 mesh. The wood powder was blended with recycled product oil to form a slurry which could be pumped to the pyrolysis reactor. Typical concentrations of wood in the slurry ranged from 7 to $10 \mathrm{wt} \%$. At higher wood concentrations the mixture could not be pumped. Since no biomass oil was available at the start of the project, the initial slurry was made with an anthracene oil from coal because it was believed to have similar characteristics to the biomass product. The anthracene oil was continually diluted as new product was produced from wood until only trace amounts of the anthracene oil remained.

A mixture of $2-5 \%$ sodium carbonate catalyst in aqueous solution was added to the slurry, and the mixture was pumped to the high pressure reaction zone at about $200 \mathrm{~atm}$ using a Moyno pump. The addition of the carbonate increased liquid yields somewhat, but it was never clear whether the effect was a catalytic one or merely an effect of adjusting the $\mathrm{pH}$. Initially, the slurry was pyrolyzed at about $350{ }^{\circ} \mathrm{C}$ in an electrically heated reactor with an internal stirrer consisting of scraper blades on a rotating shaft. The product from this reactor entered a second vessel where carbon monoxide and hydrogen reducing gases were introduced in concentrations of $60 \% \mathrm{CO}$ and $40 \% \mathrm{H}_{2}$. The reducing gas was added to lower the oxygen content of the product. The final product exited from the reactor and, following pressure letdown, was partially recycled back to the start of the process. The average residence time of the product is difficult to estimate since it was recycled many times, but residence time per pass was about 30- 
40 minutes. The initial reactor produced small amounts of oil, but the stirred vessel was subject to plugging.

To reduce plugging, the main pyrolysis vessel was redesigned. The stirred tank reactor was placed by a coil of high pressure tubing inside a gas-fired furnace. The mixture of reducing $\mathrm{CO}$ and $\mathrm{H}_{2}$ gases was added to the slurry at $200 \mathrm{~atm}$ prior to reaching the reactor, and the slurry was then pumped through the coiled tube. The residence time in the coiled reactor was about 35 seconds. The partially reacted slurry was then transferred to an upflow tubular reactor where it was held approximately 20 minutes longer at pressure and temperature. The redesigned reactor could be cleaned with steam if necessary and eliminated most plugging, even in extended tests lasting over 500 hours. The reactor configuration is shown in Figure 3.2.

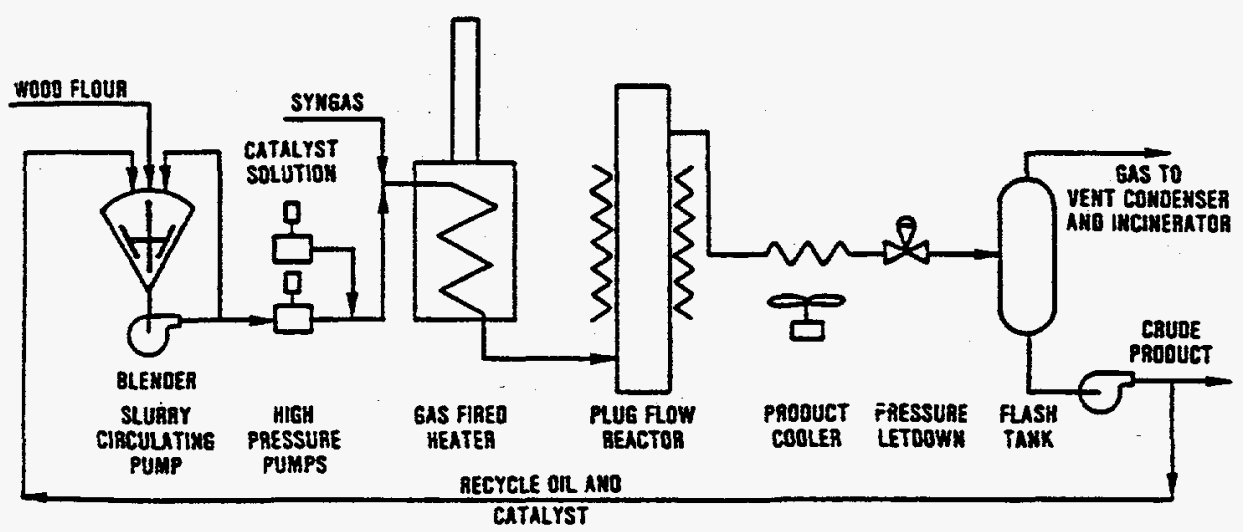

Figure 3.2. Schematic Diagram of Albany, Oregon, Liquefaction Test Facility (PERC Process).

In addition to the work with the oil slurry (PERC) process, the facility was also modified to test the water slurry process suggested by Lawrence Berkeley Laboratory (LBL), which is described in more detail below. In the LBL process, biomass was added to the pyrolyzer as an aqueous solution rather than an oil slurry. The primary changes to the Albany, Oregon, test facility involved the feedstock preparation system. Wood chips were pretreated in dilute sulfuric acid at $175^{\circ} \mathrm{C}$ for about 20 minutes, neutralized, and reduced in size using a conventional refiner. The resulting slurry with $10-15 \%$ solids was fed through the pressure pump, reducing gases of $\mathrm{CO}$ and $\mathrm{H}_{2}$ were added, and the mixture pumped through the coiled tube reactor at conditions similar to those of the PERC process. The higher water content of the LBL product also required additional water extraction at the end of the process.

Results - The Albany test facility successfully operated for extended periods of time and produced a total of about 35 barrels of oil. In one test run in early 1981, over $5000 \mathrm{~kg}$ of oil were produced during a test run extending 572 hours in duration. Wood feed rates during this test run averaged about $70 \mathrm{lb} / \mathrm{hr}$. Typical characteristics of the product and yields from the PERC and LBL processes are shown in Table 3.2. Pacific 
Northwest Laboratory provided most of the analyses of the oil, as described in section 3.3.1.5.

Table 3.2. Typical Yields and Characteristics of the Liquid

Products Produced at the Albany, Oregon, Test Facility.

\begin{tabular}{||c|c|c||}
\hline Characteristic & $\begin{array}{c}\text { PERC Oil Slurry } \\
\text { Process (Test Run } \\
\text { TR12) }\end{array}$ & $\begin{array}{c}\text { LBL Water Slurry } \\
\text { Process (Test Run } \\
\text { TR7) }\end{array}$ \\
\hline $\begin{array}{l}\text { Elemental Analysis \% (Dry } \\
\text { Basis) }\end{array}$ & & \\
\hline C & 78.9 & 79.2 \\
\hline H & 8.5 & 7.8 \\
\hline 0 & 12.3 & 14.4 \\
\hline S & 0.06 & NA \\
\hline $\begin{array}{l}\text { Viscosity of raw product, } \\
\text { cp @ 99 }{ }^{\circ} \text { C }\end{array}$ & 135 & 46 \\
\hline Specific Gravity & 1.11 & 1.09 \\
\hline Heating Value, dry basis & $34,520 \mathrm{~kJ} / \mathrm{kg}$ & $33,630 \mathrm{~kJ} / \mathrm{kg}$ \\
\hline $\begin{array}{l}\text { Yield, wt product/wt wood, } \\
\text { dry, ash free basis }\end{array}$ & 0.53 & 0.25 \\
\hline
\end{tabular}

The product from either process variation is typical of high pressure liquefaction processes. The oxygen content of the product is typically about $10-15 \%$ although the oxygen content was generally higher for the LBL processes. Detailed analyses of the constituents of the products were provided by Pacific Northwest Laboratory and by LBL, and that information is discussed later in this section. It is also interesting to note that the yields of product were consistently lower with the LBL process than the PERC approach. With the oil slurry PERC approach, the weight ratio of product yields to wood feed ranged from 0.33 to 0.53 . For the LBL process, the ratio ranged from 0.23 to 0.29. As will be explained later, this result was confirmed at LBL. A substantial amount of the biomass is converted to soluble organic acids in the water based process.

Combustion Tests - Wheelabrator Cleanfuel Corp also conducted combustion tests of the liquefaction products. Two barrels of product oil from each the PERC and LBL processes were shipped to what had become the Pittsburgh Energy Technology Center (PETC). The biomass products plus Number 2 and 6 fuel oils were burned in a $20 \mathrm{hp}$ fire tube boiler test unit. No major problems were encountered with the burn tests, although some modifications to the burner feeding system had to be made to adjust for 
the different flow properties of the biomass product. Although the biomass product has a lower heating value than petroleum-based fuel oil on a weight basis, the biomass product also has a higher specific gravity. As a result, the energy content of biomass oil on a volumetric basis was essentially the same as petroleum based fuel oils. The product oil contained sodium which had been added as a catalyst for the process, but the sodium did not cause problems in the short duration combustion tests.

Current Status: Work at the Albany facility was discontinued in 1981. The research had successfully shown that the high pressure liquefaction processes could be used to generate crude biomass oils, and it was felt that research to improve the processes could continue at lower cost in smaller research units elsewhere. The equipment was sold to private industry for use in an extractive metallurgical process in 1985.

The Albany facility must be viewed in relation to priorities at the time. The facility was successful in producing the first significant quantities of biomass oils, and it operated successfully for extended periods of time on two major process variations. It was successful in meeting its stated goal of developing a workable process for producing biomass liquids. However, with the perspective gained from a decade of low energy prices, the rush to scale up a concept based on very little research data was premature.

\section{Selected References:}

Rust International Corporation. 1983. An Investigation of Liquefaction of Wood: Final Report. PNL-5114, Pacific Northwest Laboratory, Richland, Washington.

Wheelabrator Cleanfuel Corporation. 1981. "Operation of the Biomass Liquefaction Facility, Albany, Oregon." In Proceedings of the 13th Biomass Thermochemical Conversion Contractor's Meeting, Arlington, Virginia, October 27-29, 1981, pp. 521550. CONF-8110115, Pacific Northwest Laboratory, Richland, Washington.

\subsubsection{Extruder Reactor System - University of Arizona}

\section{Principal Investigators: D. H. White and D. Wolf}

Project Objective: In the work with the PERC process at the Albany test facility, it had been difficult to feed biomass to the liquefaction reactor in oil slurries at concentrations above about $10 \mathrm{wt} \%$. As a result, the stream entering the reactor contained about $90 \%$ recycled oil, which increased process costs. The University of Arizona proposed using a modified polymer extruder to feed the biomass slurry to the liquefaction reactor. The extruder could successfully feed slurries up to about $60 \mathrm{wt} \%$ biomass, which reduced the ratio of recycled oil in the feed from about 9:1 to $0.7: 1$, an improvement of an order of magnitude. The goal of the research at the University of Arizona was to examine the feasibility of using the extruder as a feeder system and, if successful, to then demonstrate that the feeder system could be used to produce liquefaction products from biomass. 
Summary of Research Project and Results: The research at University of Arizona occurred in two phases. In the first phase, the university operated a single-screw extruder typical of those used in the polymer industry to pump very viscous fluids. The objective of this work was to examine the behavior of biomass slurries in this system and to determine if the extruder could be used as an effective feeder system.

An extruder consists of a helical screw which rotates in a cylinder and moves viscous liquids or solids through a channel around the screw. The university extruder had a 4.45 $\mathrm{cm}$ diameter and $1.1 \mathrm{~m}$ length. Heaters on the outside of the extruder allowed temperatures to be varied from ambient to about $200{ }^{\circ} \mathrm{C}$. Slurries entered the reactor at ambient pressure, and the extruder was capable of pumping material to an outlet where the pressure was $330 \mathrm{~atm}$ greater than the inlet. Since biomass oils were not available when this work started, synthetic fluids such as Dow low density polyethylene were initially used. As biomass oils were produced at the Albany test facility, they were also used in the extruder.

The research showed that the extruder could effectively be used as a feeder for concentrated slurries of biomass in the high pressure PERC-type process. Wood in slurries of either synthetic or biomass oils could be readily pumped against pressures up to $330 \mathrm{~atm}$ at concentrations ranging from 45 to $60 \mathrm{wt} \%$. Extensive data on the rheology of the wood slurries, the power consumption of the extruder under various conditions, and similar topics was also collected.

Based on the successful operation of the extruder as a feeder system, the university then designed and constructed a process research unit to convert up to $20 \mathrm{~kg} / \mathrm{hr}$ of biomass slurry, or approximately $11 \mathrm{~kg} / \mathrm{hr}$ based on the wood throughput alone. The unit is shown schematically in Figure 3.3.

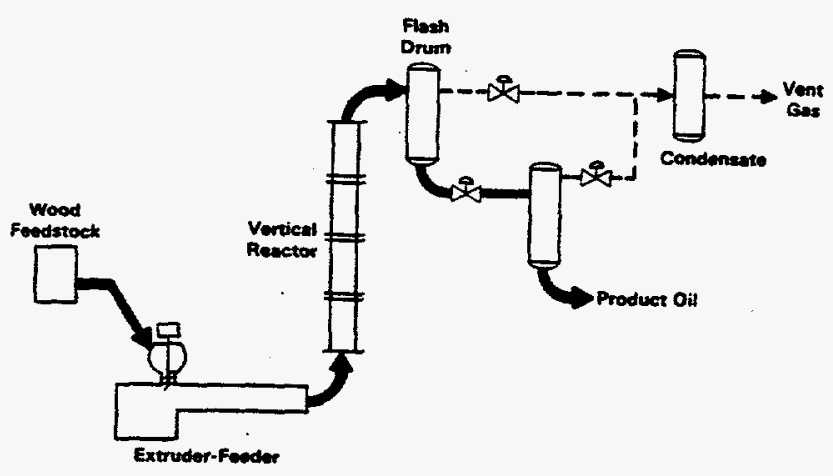

Figure 3.3 Schematic Diagram of the University of Arizona Extruder Liquefaction System. 
Wood slurries were prepared by mixing wood flour with the high molecular weight "bottoms" which remained after raw biomass oils had been partially distilled. The bottom material was a brittle solid at room temperature and could be readily ground and mixed as a solid with the wood flour. For the early experimental test runs, the bottoms from one of the Albany, Oregon, tests were used to slurry fresh wood. In later tests, the slurry oil contained almost entirely product produced at Arizona. The mixture was fed to the extruder using a crammer-feeder. The wood/oil mixture was heated by friction and by external heaters as it passed through the extruder, and the solids mixture became a viscous liquid at $150-250^{\circ} \mathrm{C}$. The mixture was pumped through an externally heated vertical reactor at a pressure of about 200 atm.

The vertical reactor was a high pressure tube with a $4.5 \mathrm{~cm}$ diameter capable of operation up to about $650 \mathrm{~atm}$. The vertical reactor consisted of up to four sections with a maximum length of about $2.3 \mathrm{~m}$. Carbon monoxide and steam could be added to the slurry as it entered the vertical reactor. Sodium carbonate catalyst was generally added ( $5 \mathrm{wt} \%$ ) by soaking the wood in a carbonate solution and drying prior to mixing. The sodium carbonate could also be added directly into the vertical reactor. The residence time of the material in the reactor ranged from about 35 to 50 minutes at temperatures of $310-350{ }^{\circ} \mathrm{C}$. The performance of the reactor was insensitive to presence or absence of an internal static mixer. Following pressure let down, the product was collected and analyzed. Typical properties of the crude product are shown in Table 3.3.

Table 3.3 Typical Characteristics of the Crude Product Oil from University of Arizona.

\begin{tabular}{||c|c|}
\hline Characteristic & Test Run \#H3 \\
\hline Elemental Analysis \% (Dry Basis) & \\
\hline C & 81.6 \\
\hline H & 8.5 \\
\hline O & 8.9 \\
\hline Heating Value, dry basis & $36,100 \mathrm{~kJ} / \mathrm{kg}$ \\
\hline
\end{tabular}

The reactor operated successfully under a variety of conditions, and nearly 60 experimental test runs were completed. Reaction temperatures were varied from 350 to $430{ }^{\circ} \mathrm{C}$, pressures from 5 to $200 \mathrm{~atm}$, and feed rates up to about $14 \mathrm{~kg} / \mathrm{hr}$ were achieved. More severe conditions such as longer residence times and higher temperatures resulted in a more viscous product with lower oxygen contents. These results are similar to those obtained elsewhere on the PERC-type process. The test program showed that the extruder concept could successfully be used as the design basis for the high pressure liquefaction process. It is interesting to note that the system could convert biomass at the rate of about $14 \mathrm{~kg} / \mathrm{hr}$, or about half the capacity of the much larger and more complex test facility at Albany. 
Current Status: By the late 1980's, national priorities had shifted away from high pressure biomass liquefaction. In addition, analyses of the PERC-type process, even with the improvements made possible by the University of Arizona, suggested that the PERC-type liquefaction process would not be commercially attractive for liquid fuels from biomass. These analyses will be discussed later in this report. The work at the university for the BTC Program was halted in 1988. Since that time, the university has continued the development of this technology as a means to dispose of wastes and has involved private industry.

\section{Selected References:}

Subcontractor Report. 1991. Development of an Extruder-Feeder Biomass Direct Liquefaction Process, Final Report, Volume 1: Parts 1-3. PNL-7830, Vol. 1, Pacific Northwest Laboratory, Richland, Washington.

Subcontractor Report. 1991. Development of an Extruder-Feeder Biomass Direct Liquefaction Process, Final Report, Volume 2: Parts 4-8. PNL-7830, Vol. 2, Pacific Northwest Laboratory, Richland, Washington.

White, D. 1988. "Production of Biocrude Oils in an Extruder Reactor." In Thermochemical Conversion Program Annual Meeting, June 21-22, 1988, pp. 57-66. SERI/CP-231-3355, National Renewable Energy Laboratory, Golden, Colorado.

\subsubsection{Aqueous Slurny Process - Lawrence Berkeley Laboratory (LBL)}

\section{Principal Investigators: Sabri Ergun, Hugh Davis}

Project Objective: LBL proposed an alternative high pressure biomass liquefaction process which involved an aqueous slurry rather than the oil slurry which had been used at PERC. The concept was a "once-through" process which would eliminate the need to recycle large quantities of the product oil and could potentially reduce process costs.

LBL conducted experiments in a laboratory research reactor to collect data on the steady state conversion of biomass. The reaction conditions closely matched those at the Albany test facility. The goal of the LBL work was to provide data on the process and to better characterize the products from the process.

Summary of Research Project and Results: LBL conducted most of its research in a laboratory-scale reactor system capable of operation in a continuous mode. The unit consisted of a 1 liter stirred autoclave reactor through which an aqueous slurry of biomass was pumped using a high pressure Moyno pump. The temperature of the reactor was maintained at about $350^{\circ} \mathrm{C}$, and the pressure maintained at about $200 \mathrm{~atm}$. Residence times of the slurry in the reactor were $10-30 \mathrm{~min}$. Sodium carbonate in concentrations of 2.5 to $5 \%$ were added, and most experimental tests were conducted with a reducing gas composed of $60 \% \mathrm{CO}$ and $40 \% \mathrm{H}_{2}$. 
In the LBL process, the preparation of the wood slurry was substantially different than in the PERC process. To break down the fibers in the wood so it could be reliably pumped, LBL subjected the wood to an acid hydrolysis step prior to the liquefaction step. Wood chips were heated to $180^{\circ} \mathrm{C}$ for about 45 minutes in an aqueous solution which had an initial pH of 1.9 (about $0.075 \%$ sulfuric acid). The treated wood was then homogenized with a refiner, neutralized, and then pumped to the liquefaction reactor. Slurries containing up to about $20 \%$ total solids were fed to the reactors. Although slurries with up to $35 \%$ solids were produced, they were too "dry" to be reliably pumped.

The reactor system allowed liquefaction to proceed under continuous, steady state conditions which closely matched those at the larger facility in Albany, Oregon. The ability to collect data under steady state conditions is particularly important in pyrolysis reactors because the reactions are very dependent on heating rates, temperatures, and others parameters. Research at LBL and other places showed that the slow heating rates which usually occur with batch reactors frequently resulted in data which was not representative of continuous operation.

The research at LBL showed that liquid products could be produced using this process. Oil phase products were produced at yields up to $35 \mathrm{wt} \%$ of the feedstock. While this yield was higher that at the Albany, Oregon facility, it was still less than the $53 \%$ yield obtained there for the PERC process. Typical oxygen contents of the LBL product were 12-17 wt\%, again higher than the PERC-type oils with 8-13\% oxygen. The oil-phase products consisted of a complex mixture of many chemical constituents. More than $70 \%$ of the total consisted of products with one or more phenolic groups, and the average molecular weight of the products were approximately 200-300 amu.

In the LBL process, the aqueous waste stream from the reactor contained about $25 \mathrm{wt} \%$ dissolved organics. The organics consisted of about $50 \%$ organic acids such as formic, acetic, glycolic, and others, and about $50 \%$ other organics such as ketones and phenolics. By comparison, the yields of aqueous phase organic material in the PERC process was about $8 \mathrm{wt} \%$. The high organic content of the aqueous phase in the LBL process is the primary cause of lower oil yields in this process. The partitioning of the products into the aqueous phase appeared to start with the pretreatment step, and additional partitioning occurs as the reaction proceeds. The material in the aqueous phase is difficult to recover or recycle.

LBL conducted extensive work on the identification of the oil and water phase products using a variety of techniques including chromatography/mass spectrometry (GC-MS), high pressure liquid chromatography (HPLC), high pressure size exclusion chromatography (HISEC), and others. As indicated above, the oil phase products are generally phenolic in nature while the aqueous phase material contains large amounts of organic acids. Detailed lists of many of the constituents of the oil and aqueous phase products were developed.

Current Status: The research at LBL showed that the aqueous slurry approach to high pressure liquefaction did not offer advantages over the oil slurry approach. The potential 
of reducing product oil recycle was more than offset by lower oil yields and high organic loadings of the aqueous effluent. In late 1983, the project was discontinued.

\section{Selected References:}

Davis, H.G. 1983. Direct Liquefaction of Biomass Final Report and Summary of Effort 1977-1983. LBL-16243, Lawrence Berkeley Laboratory, University of California, Berkely, California.

Ergun, S. 1981. Review of Biomass Liquefaction Efforts. LBL-13957, Lawrence Berkeley Laboratory, University of California, Berkely, California.

\subsubsection{Alternate Catalysts for High Pressure Liquefaction - SRI International}

\section{Principal Investigator: Donald Z. Rogers}

Project Objective: Sodium carbonate had been used as a catalyst in the PERC and LBL liquefaction processes, but its effectiveness was questionable. Total oil yields and the amounts of lighter molecular weigh constituents increased slightly when the carbonate was present, but the effect was minimal. In addition, the crude oil product also contained sodium, which could potentially cause problems when the oil was used or refined. The BTC Program sponsored research at SRI International to examine a range of water soluble catalysts which might be more effective for high pressure liquefaction than sodium carbonate. The objective of this work was to survey the activity of a variety of water soluble transition metal salts.

Summary of Research Project and Results: SRI International conducted the catalyst screening study using a $300 \mathrm{ml}$ batch autoclave with an internal stirrer. Biomass samples were mixed with water and catalyst, sealed in the autoclave, and carbon monoxide was added to bring the pressure of the cold vessel to $40 \mathrm{~atm}$. The autoclave was then heated to $350^{\circ} \mathrm{C}$ over about $30 \mathrm{~min}$ and remained at temperature for an additional $45 \mathrm{~min}$. Following the reaction, the product was removed, and a toluene extraction was performed to recover the lighter molecular weight components from the product.

SRI International screened fifteen soluble transition metal complexes for catalytic activity. The catalysts included copper, chromium, cesium, iron, magnesium, molybdenum, nickel, ruthenium, and rhenium with various ligands. The total yield of crude product ranged from 35 to $56 \mathrm{wt} \%$ of the original feed, and the products contained $11-17 \%$ oxygen. The amounts of toluene soluble product varied widely from 0 to $45 \mathrm{wt} \%$ of the dry feed. Two catalysts which produced the highest levels of toluene soluble product were investigated in more detail since the toluene soluble fraction had a lower average molecular weight and would potentially be easier to upgrade.

The two catalysts selected for additional study included potassium tetracyanonickelate and potassium octacyanomolybdate. Both catalysts produced toluene soluble yields of 42$45 \mathrm{wt} \%$ of the feed material. Since other catalysts containing cyanide ligands showed 
much less activity, the results indicated that the metal complex was involved in the reaction. Both nickel and molybdenum are hydrogenation catalysts, and they may be involved in this role in the liquefaction process.

Current Status; While the use of the homogeneous catalysts slightly improved product quality, the high cost of these metal complexes would necessitate their recovery from the oil product and their subsequent re-use. However, effective recovery of dissolved catalysts did not appear to be feasible, and the cost of their use would have been prohibitive. This research project was completed in 1981.

\section{Selected References:}

Tran, A.D. and D.Z. Rogers. 1985. Examination of Altermative Catalysts for Biomass Direct Liquefaction. PNL-5617, Pacific Northwest Laboratory, Richland, Washington.

SRI International. 1982. "Examination of Alternative Catalysts for Biomass Direct Liquefaction." In Proceedings of the 14th Biomass Thermochemical Contractor's Meeting, p. 627. CONF-820685, Pacific Northwest Laboratory, Richland, Washington.

\subsubsection{Direct Liquefaction Studies - Pacific Northwest Laboratory (PNL)}

\section{Principal Investigator: Douglas C. Elliott}

Project Objective: As the research on the high pressure liquefaction processes proceeded, consistent analysis of the liquefaction products was needed. PNL conducted extensive research to characterize the products from the various liquefaction processes. The analyses included determination of physical properties such as heating values, determination of elemental composition, and detailed identification of chemical constituents. In the later stages of the program, the analysis effort was expanded to a variety of liquids produced from not only liquefaction but also gasification processes. The results from the liquefaction work are described below, and the results from the more expanded effort are discussed in Section 3.6 of this report.

Summary of Research Project and Results: PNL used a variety of techniques to analyze the products from direct liquefaction processes. Analyses included characterization of the basic properties of the oils including heating value, moisture content, and elemental analysis (direct oxygen measurement). Research was also conducted on the distillation characteristics of the product, and detailed studies of the chemical composition of the biomass oil were performed using gas chromatography/mass spectrometry (GC/MS) techniques.

As shown previously in Table 3.2, the oils from the PERC and LBL processes are similar. They have carbon contents of about $80 \mathrm{wt} \%$ and the atomic hydrogen:carbon molecular ratios of about 1:2. Oxygen contents of the products were typically 10$15 \mathrm{wt} \%$, with the aqueous slurry product being a few percentage points higher. The raw 
product contained Heating values of the product were typically $32,500-35,000 \mathrm{~kJ} / \mathrm{kg}$ for the raw product and $36,000-38,400 \mathrm{~kJ} / \mathrm{kg}$ on a dry basis.

Moisture contents of the raw products ranged from 3 to $14 \mathrm{wt} \%$, and the moisture content affected the viscosity of the products. When products were dried to moisture contents below $3 \%$, the viscosity increased sharply as measured by pour point. The oil could contain $7-8 \%$ moisture without phase separation, but at higher moisture contents, a separate water phase would form over time. PNL used the ASTM D-95 xylene distillation method for moisture analysis. It should be noted that the water determination measurement is difficult to make and that results will vary significantly depending on the method of analysis used. The research was among the earliest to show that international collaboration to select appropriate analysis methods was important in producing reliable data. Collaboration through the International Energy Agency is discussed later in this chapter.

PNL conducted extensive research to identify the chemical constituents of the biomass oils using GC/MS techniques. In this approach, the components of the oil were separated in a gas chromatography column and then individually analyzed in as mass spectrometer. Over 100 individual chemical components were identified which included products from the following representative groups:

$\begin{array}{llll}\text { - } & \text { cyclic ketones, } \mathrm{C}_{6-9} & - & \text { guaiacols } \\ \text { - } & \text { cyclopentanones } & - & \text { cyclopentenones } \\ \text { - } & \text { phenols } & - & \text { unsaturated phenols } \\ \text { - } & \text { dihydroxybenzenes } & \text { - methyl napthols } \\ \text { - } & \text { high molecular weight guaiacols and oxygenates }\end{array}$

The chemical constituents were characterized by a very large number of oxygenated, cyclic molecules with a variety of molecular weights. Any single component was present in low concentrations, usually less than $1 \%$. The yields of products in various groups was affected by the severity of the reaction conditions. Guaiacols were the most prevalent product for the oils produced at less severe conditions, and the amounts of cyclic ketones and phenols increased when more severe conditions were used.

Further analysis of the oils was made with fractional distillation techniques to examine the higher molecular weight components that would not pass through gas chromatographs. The raw product was vacuum distilled into seven fractions plus the residual vacuum bottoms. The vacuum distillation was conducted at a pressure of $10 \mathrm{~mm}$ $\mathrm{Hg}$, and fractions were collected as the temperature of the material was increased from ambient to $370{ }^{\circ} \mathrm{C}$. Elemental analysis of the fractions showed that the $\mathrm{C}, \mathrm{H}$, and $\mathrm{O}$ compositions of all fractions were remarkably similar, and the heating values of the various fractions were also similar. The results suggested that the light and heavy oil fractions are chemically alike with the biggest difference being the molecular weigh ranges of the products in each fraction.

PNL also conducted studies to determine the stability of the oils over time. Samples were stored with air, light, and heat at $90{ }^{\circ} \mathrm{C}$ for periods of 6-12 months and compared 
to samples stored at about $5{ }^{\circ} \mathrm{C}$ in the dark with argon. The samples were stable over these periods with only minor changes in chemical composition.

Current Status: The research at PNL successfully developed expertise to analyze complex biomass tars and liquids, and a large library of data for identifying chemicals in GC/MS systems has been developed. This expertise was used to study a wider range of tars from biomass systems including gasifiers. That work is described in Section 3.6 of this report. PNL has continued its research on characterization of complex organic mixtures for both DOE and private clients.

Selected References:

Elliot, D.C. 1985. "Analysis and Comparison of Products from Wood Liquefaction." In Fundamentals of Thermochemical Biomass Conversion, eds. R.P. Overend, T.A. Milne, and L.K. Mudge, pp. 1003-1018. Elsevier Applied Science Publishers, London.

Beckman, D. and D.C. Elliot. 1985. "Comparisons of the Yields and Properties of the Oil Products from Direct Thermochemical Biomass Liquefaction Processes." Canadian Journal of Chemical Engineering, 64:99-104.

\subsubsection{RAPID PYROLYSIS PROCESSES}

The BTC Program also sponsored work on the production of biomass oils through the use of rapid pyrolysis techniques. With rapid pyrolysis, biomass is quickly heated to moderate temperatures of $400-550{ }^{\circ} \mathrm{C}$ where the biomass thermally depolymerizes and volatilizes. The products are then promptly removed from the reactive temperature zone to terminate further reactions. Typical residence times of the biomass in rapid pyrolysis reactors are a few seconds or less. Using this approach, yields of liquids up to about $65 \mathrm{wt} \%$ (dry basis) of the product feed can potentially be obtained. The product is different chemically than the product from high pressure liquefaction. While the high pressure product has undergone extensive reaction, the rapid pyrolysis product consists largely of the primary components that are formed as biomass first depolymerizes. The percentage of carbon, hydrogen, and oxygen in the product closely resemble that of unreacted wood, and the heating value of the raw product is also similar to wood on a weight basis.

The production of liquids from rapid pyrolysis offered several potential advantages. Any one of several types of reactors including entrained, fluidized bed, or the ablative reactor developed by NREL could potentially be used. The process operated at ambient pressure and did not require the addition of $\mathrm{CO} / \mathrm{H}_{2}$ reducing gas. These differences potentially lowered the cost of producing liquids from biomass. Since sodium carbonate was not added, the pyrolysis product also had a lower sodium content than the high pressure product. The BTC Program sponsored research on two rapid pyrolysis concepts including the ablative reactor at NREL and an entrained reactor at Georgia Tech Research Institute. It should also be noted that the Canadian national program has 
sponsored several projects on fast pyrolysis, and one of them is now being commercialized.

\subsubsection{Ablative Reactor System - NREL}

Principal Investigators: James Diebold, John Scahill

Project Objective: NREL developed a unique ablative reactor concept to rapidly pyrolyze biomass. The objective of the research sponsored by the BTC Program was to build and operate the reactor system and to collect data on rapid pyrolysis. The research on the operation of the system for producing pyrolysis products is described below. NREL also found that the pyrolysis products could be upgraded to aromatic hydrocarbons by contacting them with zeolite catalysts immediately downstream from the pyrolysis reactor. The upgrading work is described in Section 3.4 of this report.

Summary of Research Project and Results: The NREL rapid pyrolysis reactor was based on the observation that conductive heat transfer could be an efficient means to drive biomass reactions. When biomass particles are moved across a hot metal surface, the outer layer of the biomass begins to pyrolyze, and a thin film (10 microns) of liquid material is deposited on the metal surface. Heat transferred conductively from the metal rapidly volatilizes the liquid film. Although the surface of the metal is hot, typically $625^{\circ} \mathrm{C}$, the area surrounding the surface can be much cooler. By contacting solid biomass particles with a hot surface, the material can be rapidly pyrolyzed, and the resulting vapors can be quickly removed from the hot reaction zone to quench further reactions. The biomass particle itself remains at a low temperature and reacts only where it physically contacts the hot surface. The continuing vaporization of the thin layer of the biomass as it passes over the surface reduces the particle in size in an ablative manner, and little char is formed.

Vortex Reactor - NREL designed and built a vortex reactor system to test the ablative pyrolysis concept. The reactor consisted of an Incoloy tube $13 \mathrm{~cm}$ in diameter and $70 \mathrm{~cm}$ long. The tube was heated to temperatures as high as $1000{ }^{\circ} \mathrm{C}$ by external electrical heaters. Biomass was injected into the vessel at high centrifugal forces (up to $20,000 \mathrm{~g}$ 's) with steam or other entraining gases. The biomass entrained in the gas stream spiraled down the reactor vessel, and the biomass particles made repeated contact with the hot reactor walls. Typical residence times were $0.5-1$ second. The products exited the reactor, passed through a $5 \mathrm{~cm}$ ID by $6.4 \mathrm{~m}$ tube which could be used to thermally crack the products if desired, and then passed through a cyclone where unreacted biomass material was collected. In later modifications, a recycle loop was added so that partially ablated biomass particles could be reinjected to the reactor. The design capacity of the unit was approximately $50 \mathrm{~kg} / \mathrm{hr}$ of feedstock, which could be wood powder or small chips up to about $5 \mathrm{~mm}$. Modeling studies suggest that larger wood chips can be used in a commercial-sized unit. A schematic diagram of the NREL ablative pyrolysis reactor is shown in Figure 3.4. 


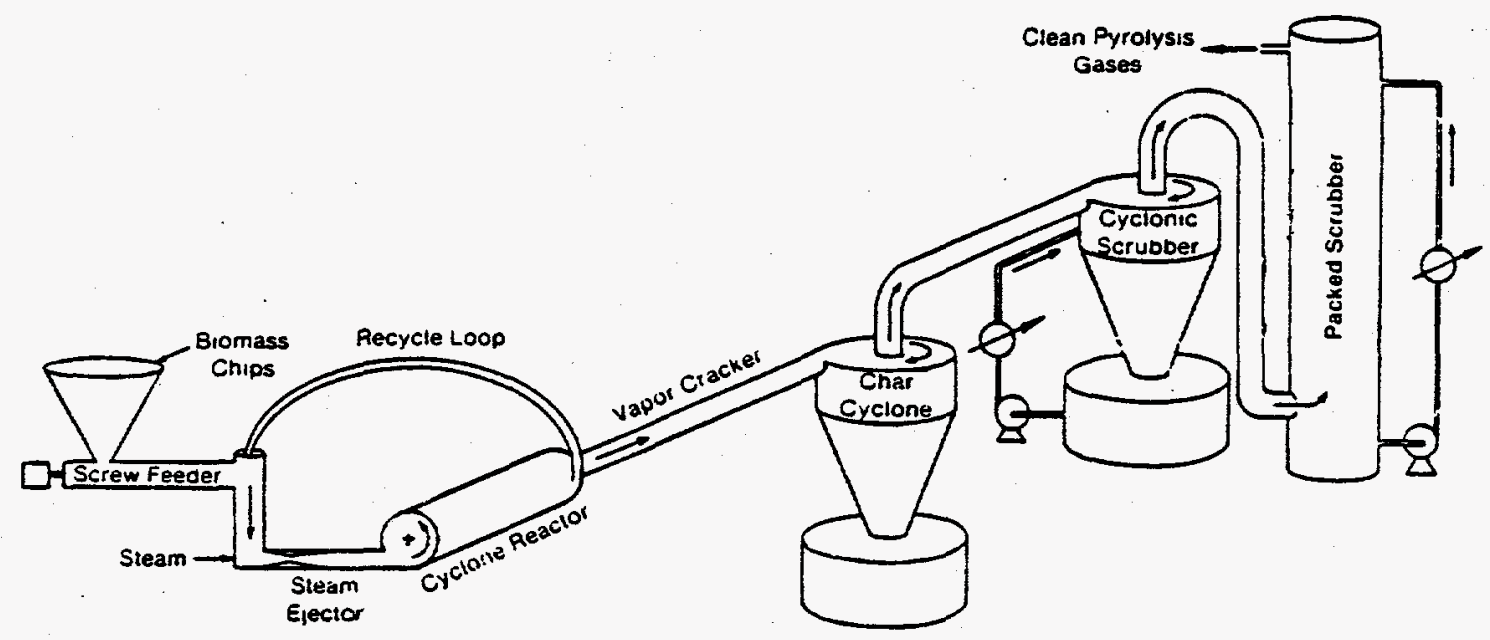

Figure 3.4 Schematic Diagram of the NREL Ablative Pyrolysis Reactor.

Over time, several significant changes were made to the reactor to improve system performance. Cold-model tests with a plexiglas tube showed that the entrained stream of biomass particles could be "directed" by the addition of small vanes $(3 \mathrm{~mm}$ high) arranged in a helical configuration which spiraled down the inside of the reaction vessel at pitch of about $2.5 \mathrm{~cm}$. The internal vanes successfully increased the number of spirals the gas stream made, which in turn increased the contact of biomass with the wall and increased product yields per pass. The Incoloy reactor was modified by attaching an internal spiral rib composed of a 0.25 -in. stainless steel tube. Later, the modified reactor was replaced with a 316 stainless steel tube with the spiral vanes machined inside. A section of $12.5 \mathrm{~cm}$ schedule 80 tube was machined to leave vanes $3.2 \mathrm{~mm}$ high with a pitch of $2.5 \mathrm{~cm}$. The machined reactor was successfully used in most of the experimental work at NREL.

NREL considered various methods of heating the tubular reactor. While electric heaters were very suitable for the test reactor, it was felt that conventional methods such as gas fired heaters might not be sufficient for a commercial unit. NREL considered the use of a sodium boiler surrounding the reaction vessel. This system would provide a very uniform temperature down the entire length of the reaction vessel and would provide excellent heat transfer. However, as more data became available, it was determined that the higher heat fluxes possible with the sodium boiler were not needed, and that lower cost conventional heating systems would be sufficient.

Results - At the start of the experimental test program at NREL, the vortex reactor was operated with the goal of maximizing the production of low molecular weight olefins such as ethylene, propylene, and others. These gaseous constituents could potentially be used to produce synthetic fuels. The reactor was heated to about $900{ }^{\circ} \mathrm{C}$, and the temperature in the vapor cracker immediately downstream was varied to test the effects of increasing the severity of reaction. The tests showed that biomass could be 
converted to about $90 \%$ gases in the system with yields of $\mathrm{C}_{2}+$ components exceeding $14 \%$. The yields of gases increased as the reaction severity increased, as did the wt\% yield of olefins. The research was useful in helping to better understand pyrolysis processes. The solid biomass depolymerized to form tars at $400-550{ }^{\circ} \mathrm{C}$. Depending on the temperature and residence time these intermediates experienced, they were cracked to gases and secondary tars. Cracking of the tars began about $650^{\circ} \mathrm{C}$ and proceeded more rapidly as temperature increased.

This understanding of the pyrolysis process allowed the reactor to be operated more efficiently. In most tests, the temperature of the wall of the vortex reactor was reduced to about $625^{\circ} \mathrm{C}$ and the resulting exit gas temperature was about $450^{\circ} \mathrm{C}$. The temperature of the cracking reactor downstream were varied as needed. With these changes, the production of primary tars in the vortex reactor could be separated from the cracking reactions which occurred in the cracking reactor downstream. It was therefore possible to adjust reaction conditions to produce a range of products. By operating the vapor cracker at high temperatures, the products were approximately $90 \%$ gases, while up to about 56\% liquid tars (dry basis) were produced with the vapor cracker at low temperatures. In either case, char yields were about $10-15 \%$.

By 1984, the emphasis of the work at NREL had changed to the production of liquids that could be upgraded to an aromatic hydrocarbon fuel. As indicated above, the reactor conditions could be varied to produce either liquid or gaseous products. The vortex reactor was used to produce primary oils at typical yields of about $55.3 \%$ (dry basis) of the feed. Characteristics of the product are summarized in Table 3.4

The liquid product, as indicated previously, contains many phenolic and sugar derivatives which are given off as biomass depolymerizes. Typical components include levoglucosan and other sugar derivatives from the cellulosic portion of the biomass and phenolic derivatives from the lignin in the feedstock. These products are primary pyrolysis products and are much different than the high pressure liquefaction products which have undergone extensive reaction. The significant difference in oxygen content is one indicator of the differences in the chemical composition.

In the NREL concept, the oils were volatilized in the vortex reactor and would remain in the gas phase where they would pass directly to a catalytic reactor to be converted to transportation fuels. Since the primary oil products would not be collected as liquids, NREL collected only relatively small samples of the primary oils for analysis. The NREL research on zeolite catalysts for upgrading the primary liquids is described in Section 3.4 of this report. 
Table 3.4. Typical Characteristics of the Liquid Products from the NREL Vortex Reactor.

\begin{tabular}{||c|c||}
\hline \hline Characteristic & $\begin{array}{c}\text { NREL Ablative } \\
\text { Reactor }\end{array}$ \\
\hline Elemental Analysis \% (Dry Basis) & 53.5 \\
$\mathrm{C}$ & 6.2 \\
$\mathrm{H}$ & 39.6 \\
0 & 1.38 \\
Molecular H:C ratio & $1300 @ 30 \mathrm{C}$ \\
\hline Viscosity of raw product, cp & 1.28 \\
\hline Specific Gravity & 16.1 \\
\hline Raw Product Moisture Content, wt\% & 22,300 \\
\hline Heating Value, dry basis, kJ/kg & 0.55 \\
\hline Yield, wt product/wt wood, dry basis & \\
\hline
\end{tabular}

Current Status: The rapid pyrolysis oils contain significant amount of phenolics which could potentially replace petroleum based materials in processes such as the production of phenolic resins. NREL has developed proprietary processes to extract the phenolics from the biomass crude oil. In the late 1980's, NREL formed the Pyrolysis Materials Research Consortium with five industrial partners to conduct R\&D activities which would promote the use of biomass based phenolics. In 1993, one of the members of the consortium, Interchem, began constructing a scaled-up vortex reactor to produce biocrude oils and other products such as char. The reactor was based on the concept developed at NREL but the detailed design was proprietary. Construction of the 36 tpd facility was begun in Kansas, but the project was put on an indefinite hold due to financial constraints in mid-1994.

\section{Selected References:}

Diebold, J.P. and J.W. Scahill. 1988. "Production of Primary Pyrolysis Oils in a Vortex Reactor." In Pyrolysis Oils From Biomass, Producing, Analyzing, and Upgrading, eds. E. Soltes and T. Milne, pp. 31-40. ACS Symposium Series 376.

Diebold, J.P. and J. Scahill. 1985. "Ablative Pyrolysis of Biomass in Solid-Convective Heat Transfer Environments." In Fundamentals of Thermochemical Biomass Conversion, eds. Overend, R.P., T.A. Milne, and L.K. Mudge, pp. 539-556. Elsevier Applied Science Publishers, London. 
Diebold, J.P. 1985. The Cracking Kinetics of Depolymerized Biomass Vapors in a Continuous Tubular Reactor. MS Thesis T-3007, Colorado School of Mines, Golden, Colorado.

\subsubsection{Entrained Rapid Pyrolysis Reactor System - Georgia Tech Research Institute (GTRI)}

Principal Investigator: James Knight, Raymond Kovac

Project Objective: The BTC Program sponsored research at GTRI to test the concept of using an entrained bed reactor to generate liquids from biomass. Biomass would enter the entrained bed and be rapidly heated. The resulting pyrolysis products would be rapidly swept from the reactive zone to quench additional reactions, and the products would then be collected. Entrained reactors are well characterized, readily scalable, and could potentially produce low cost liquids. The work at GTRI included the design, construction, and operation of research reactor system capable of converting about 45 $\mathrm{kg} / \mathrm{hr}$ of biomass.

Summary of Research Project and Results: In the GTRI research facility, finely ground biomass was injected into a stream of hot gases moving upward through a cylindrical reactor. A schematic diagram of the GTRI concept is shown in Figure 3.5.

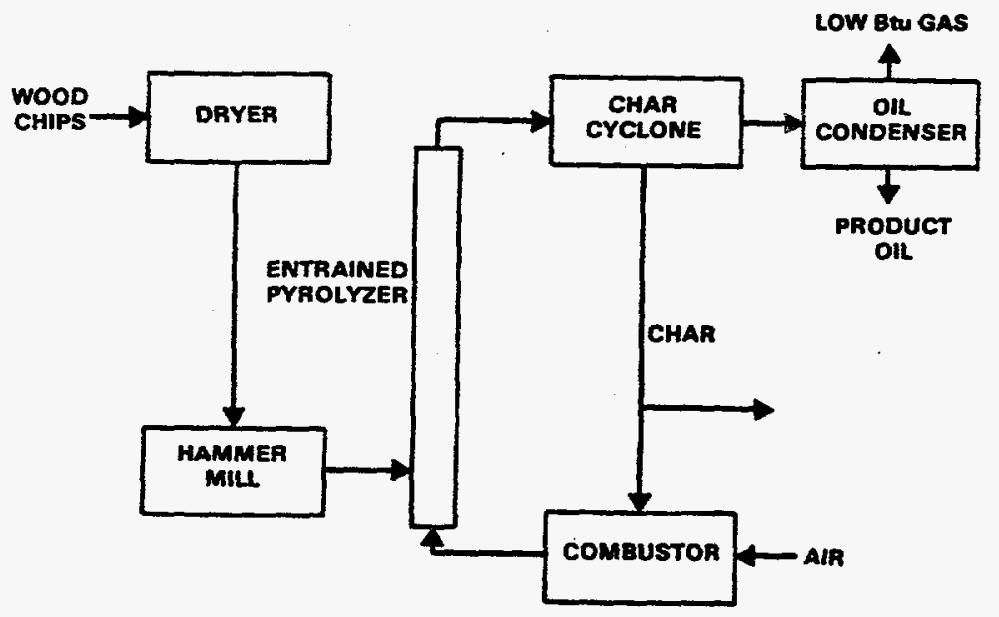

Figure 3.5. Simplified Schematic of GTRI

Entrained Rapid Pyrolysis Reactor.

The temperature of the entrained stream of biomass plus gas was varied between 400 and $550{ }^{\circ} \mathrm{C}$. Pyrolysis occurred as the biomass moved through the reactor. Char was then removed in a cyclone separator, and the biomass oils were collected in an air-cooled condenser with several sumps which allowed various oil fractions to be collected. The 
gas phase then passed through a demister and was vented. The hot gases which formed the entrainment stream were produced by burning propane with air, and then adding cooler steam to adjust the gas temperature. In a commercial reactor, the char, the lowenergy off-gas, or part of the biomass liquids would be used for this purpose, but the use of propane simplified operation of the test facility.

The GTRI entrained system successfully produced several hundred $\mathrm{kg}$ of oil. The yields of oil ranged from 31 to $53 \mathrm{wt} \%$ (dry basis) depending on the reaction conditions. The highest yields were produced with the feed introduced into the $475^{\circ} \mathrm{C}$ gas stream at a port near the middle of the entrained reactor. Increasing the residence time by injecting wood at the bottom of the reactor decreased liquid yields due to additional product cracking. Likewise, reducing the residence time too much by moving the feed port nearer the exit of the reactor lowered liquid yields due to incomplete reaction of the biomass. These results emphasize the importance of reaction severity on determining product yields. In these tests, a high 9:1 ratio of entrainment gas to wood feed was required to supply sufficient heat for the reaction. Typical characteristics of the GTRI oil product are shown in Table 3.5.

Table 3.5. Typical Yields and Characteristics of the Liquid Products Produced at GTRI.

\begin{tabular}{||c|c|}
\hline Characteristic & $\begin{array}{c}\text { GTRI Entrained } \\
\text { Reactor }\end{array}$ \\
\hline Elemental Analysis \% (Dry Basis) & 52.1 \\
$\mathrm{C}$ & 6.2 \\
$\mathrm{H}$ & 41.4 \\
0 & 1.42 \\
Molecular H:C ratio & $220 @ 40 \mathrm{C}$ \\
\hline Viscosity of raw product, cp & 1.27 \\
\hline Specific Gravity & 16.6 \\
\hline Raw Product Moisture Content, wt\% & 22,100 \\
\hline Heating Value, dry basis, kJ/kg & 0.53 \\
\hline Yield, wt product/wt wood, dry basis & \\
\hline
\end{tabular}

Comparison of Tables 3.4 and 3.5 show that the GTRI and NREL products are very similar in relation to their elemental analysis, heating value, and other characteristics. Closer examination of the chemical constituents of the two suggest that the GTRI product had undergone more secondary reactions than the NREL product. This was consistent with the lower yields in the GTRI reactor. The longer residence times (1-5 seconds) in 
the GTRI reactor appear to result in lower total yields due to additional cracking of the primary pyrolysis products.

GTRI also performed very limited research on using zeolite catalysts to upgrade the product oil. Approximately a dozen zeolites were tested with model compounds to determine their suitability with the biomass oil product. The results of the tests were inconclusive, and the data from the tests was not reported.

Current Status: In 1987, the project was discontinued due to shrinking program budgets and the retirement or moves of key staff. GTRI has not conducted additional process development work with the test facility. While it is not clear whether higher yields could be obtained at GTRI, it is clear that several fast pyrolysis reactor designs can successfully be used to produce high yields of biomass liquids.

\section{Selected References:}

Georgia Tech Research Institute. 1991. Research on the Pyrolysis of Hardwood in an Entrained Bed Process Development Unit. PNL-7788, Pacific Northwest Laboratory, Richland, Washington.

Kovac, R. 1988. "Production and Upgrading of Biomass Pyrolysis Oils." In Thermochemical Conversion Program Annual Meeting, June 21-22, 1988, pp. 5-20. SERI/CP-231-3355, National Renewable Energy Laboratory, Golden, Colorado.

\subsection{RESEARCH TO UPGRADE BIOMASS CRUDE OILS}

In the mid-1980's, one of the goals of the BTC program was to produce transportation fuels from biomass by upgrading the biocrude oils. The significant chemical differences between petroleum and the crude products from biomass required that different techniques be used to upgrade the biomass products into transportation fuels. Upgrading processes must accomplish several goals. The average molecular weight of the product must be reduced, the levels of oxygen reduced, and the $\mathrm{C}: \mathrm{H}$ molecular ratio must be adjusted. Biocrude oils are rich in carbon but deficient in hydrogen as compared to transportation fuels. In addition, such factors as volatility, boiling range, and octane number must ultimately be addressed.

The BTC Program funded research on two basic approaches to upgrading the crude products to fuels. These include the use of zeolite upgrading catalysts and the use of hydrotreating techniques. Zeolites are shape selective catalysts which promote the removal of oxygen from the biocrude oil primarily through the formation of $\mathrm{CO}$ and $\mathrm{CO}_{2}$, and to a lesser extent through formation of $\mathrm{H}_{2} \mathrm{O}$. The catalysts are effective at ambient pressures and convert the biocrude to a mixture rich in aromatics such as toluene and xylene. Zeolite catalysts had been used commercially in converting methanol to hydrocarbons in New Zealand. In hydrotreating processes, biocrude is reacted at pressures of about $135 \mathrm{~atm}$ in the presence of metal catalysts. Oxygen is removed from the biocrude oil through the formation of $\mathrm{H}_{2} \mathrm{O}$, and the product consists of a variety of 
hydrocarbon products. Hydrotreating of biocrudes is similar to hydrotreating of petroleum. The products from either biocrude upgrading process could be blended with petroleum gasoline or further refined to produce a biomass-derived gasoline. The projects on the upgrading of biocrude are summarized in Table 3.6.

Table 3.6. Research Projects to Upgrade Biomass Crude Oils.

\begin{tabular}{||l|l|}
\hline \hline TECHNOLOGY AREA & INSTITUTION \\
\hline Upgrading Biomass Crude Oils & \\
\hline $\begin{array}{l}\text { Upgrading Using Zeolite Catalysts } \\
\text { Zeolite Upgrading of Biocrude to High } \\
\text { Octane Gasoline }\end{array}$ & NREL \\
\hline $\begin{array}{l}\text { Upgrading Using Hydrotreating Catalysts } \\
\text { Catalytic Hydrotreating of Biocrude }\end{array}$ & PNL \\
\hline
\end{tabular}

\subsubsection{Upgrading of Biocrude Using Zeolite Catalysts}

The BTC Program funded research at NREL consisting of detailed studies to use commercially available zeolites to convert the biocrude vapors from its ablative reactor. That work is described below. In addition, Georgia Tech Research Institute performed extremely limited tests to screen potential zeolite catalysts, but data from that work inconclusive and was not published, as described in Section 3.3.2.2.

\subsubsection{Zeolite Upgrading of Biocrude to High Octane Hydrocarbons - NREL}

Principal Investigators: James Diebold, John Scahill, Robert Evans, Tom Milne

Project Objective: NREL conducted extensive research to upgrade the fast pyrolysis oils from its ablative reactor into transportation fuels. In this system, the primary pyrolysis vapors produced in the reactor were passed over zeolite catalysts to convert them into a mixture of products rich in aromatics such as toluene and xylene. The zeolite catalysts are reactive with the primary vapors which exit from the ablative reactor, but are less reactive with the secondary products which are formed when the vapors are condensed to a liquid phase. By using the primary products as they exited the ablative reactor in the vapor phase, high conversions to hydrocarbon product could potentially be achieved. The zeolite catalysts were also compatible with the ablative reactor system because they were effective at at atmospheric pressure and at similar temperatures. The zeolite catalysts did not require hydrogen for the upgrading process. 
The upgrading process required close coupling with the NREL ablative pyrolysis reactor since the vapors had to be reacted in the gas phase, but the zeolite process offered a simple and potentially economic method to upgrade biomass pyrolysis products. The purpose of the work at NREL was to conduct upgrading studies with the products from its ablative reactor and to develop a better understanding of the upgrading process.

Summary of Research Project and Results: The work at NREL was conducted both with the NREL ablative vortex pyrolysis reactor and with a molecular-beam mass spectrometer (MBMS) system. Much of the zeolite upgrading research used a system where a slipstream of primary oil vapors from the vortex reactor passed over a fixed bed of zeolite catalyst. The catalytic reactor consisted of a $30-\mathrm{cm}$ long cylinder containing $100 \mathrm{~g}$ of ZSM-5 catalyst from Mobil Research and Development Corporation. The catalyst was in the form of a $1.4 \mathrm{~mm}$ extrudate, and the residence time of the vapors in the reactor was approximately 1 second. Following reaction, the products were collected and analyzed. A schematic diagram of the system is shown in Figure 3.6.

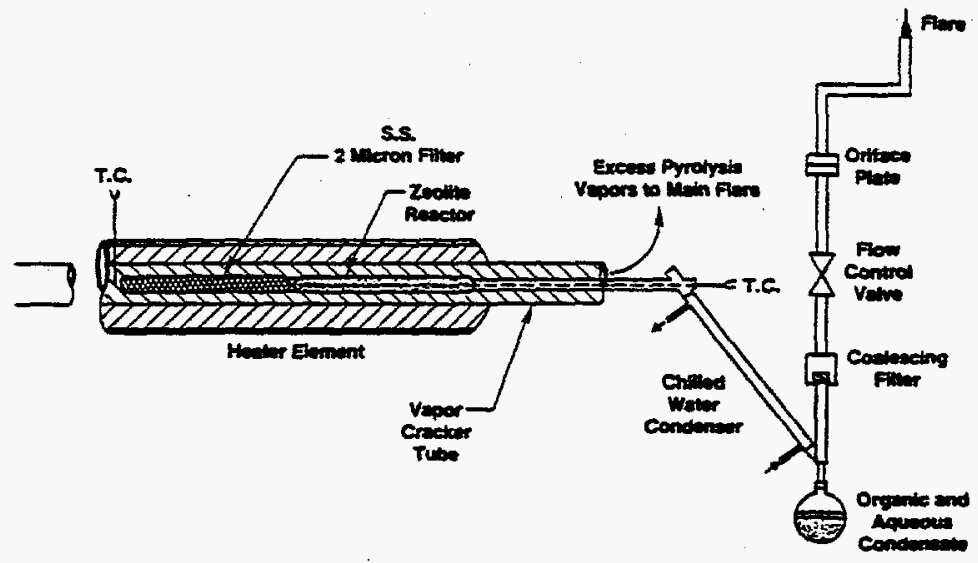

Figure 3.6. Schematic of NREL Zeolite Catalytic Reactor System.

In addition to the work with the ablative reactor, NREL conducted basic studies on the zeolite catalysts using an MBMS system, described in more detail in Section 3.5. The MBMS system not only allowed basic reaction mechanisms to be examined, but also allowed characterization of the resulting products.

The zeolites have active sites which foster the thermal removal of oxygen from biomass through the formation of $\mathrm{CO}, \mathrm{CO}_{2}$, and $\mathrm{H}_{2} \mathrm{O}$. The catalytic reactions generate a mix of products which can be collected as liquids including aromatic and substituted aromatic products, olefins and alkanes, as well as coke and pyrolysis gases. Typical yields from the process are shown in Table 3.7. It is important to note that the NREL process converts the pyrolysis vapors directly without first condensing them into an intermediate liquid. The reported yields are therefore based on the weight of wood feedstock rather than an intermediate oil. 
Table 3.7. Yields of Products From the NREL Ablative Reactor/ Zeolite Upgrading System. (Run 95-B, Reaction Zone Temp 502-522 ${ }^{\circ} \mathrm{C}$ ).

\begin{tabular}{|l|c|}
\hline Product & $\begin{array}{c}\text { Yield, g/g Wood } \\
\text { Fed }\end{array}$ \\
\hline Char & .120 \\
\hline Pyrolysis Gas & .11 \\
\hline Coke & .070 \\
\hline Catalyst Off Gas & .43 \\
\hline $\mathrm{C}_{2}$-C 4 In Off Gas & .056 \\
\hline $\mathrm{C}_{5}+$ In Off Gas & .082 \\
\hline Liquid Condensate & .078 \\
\hline $\begin{array}{l}\text { Total } \mathrm{C}_{2}+\text { Hydrocarbons (including } \\
\text { phenols) }\end{array}$ & .22 \\
\hline
\end{tabular}

With the zeolite catalysts, NREL successfully produced a mix of aromatic compounds including toluene, xylene, ethyl toluene, tri- and tetra-methyl benzenes, naphthalene, and many others. Total hydrocarbon yields $\left(\mathrm{C}_{2}+\right.$ and partially reacted phenols) were approximately $22 \mathrm{wt} \%$ of the wood feed. The overall efficiency of conversion is estimated to be 0.54-0.58 (LHV gasoline product/LHV wood) for a "self-sufficient" system where biomass is used to provide process heat and primary chemical feedstocks. The range of efficiencies is based on whether excess steam from a mature technology could be sold.

Analysis of the individual components of the product suggests that the blending octane number of the hydrocarbon would be over 100 . Because of the highly aromatic nature of the product, it would likely be blended with gasoline to improve the octane rating, or components such as xylene could be recovered for chemical use.

The temperatures at the reactor inlet were varied from about 390 to $500^{\circ} \mathrm{C}$, and heat given off by the catalytic upgrading reaction increased temperature to $420-550{ }^{\circ} \mathrm{C}$. The yields of liquids and their characteristics were dependent on the temperature of reaction. The total yields of hydrocarbons were highest at reactions temperatures near $500{ }^{\circ} \mathrm{C}$, and the yields of de-alkylated products such as benzene were also higher at these temperatures. Lower temperatures reduced total hydrocarbon yields, and the products contained more alkylated products such as tri-methyl benzenes. At higher temperatures. the amount of biomass which could be fed per load of catalyst was about 10 times higher than at low temperatures. 
Coke was produced at about $12 \mathrm{wt} \%$ in most cases. Coke formed rapidly on the surface of new or freshly regenerated catalyst, and then coke formation rates would slow. The carbon deposition reduced but did not eliminate catalyst activity. Particularly at the higher reaction temperatures, the deactivation of the catalyst by coke was very slow, and steam in the reacting gases may have contributed to the removal of char at the higher temperatures. The catalyst could be regenerated oxidatively after each test run.

NREL also studied methods to more effectively retrieve the low molecular weight olefinic gases from the catalyst off gases. These products can contribute to hydrocarbon yield but are difficult to trap with the higher molecular weight products. Absorbers including activated carbon and activated zeolite catalysts were introduced into the gas stream to retrieve the low molecular weight products. The activated carbon removed the products effectively, but the adsorption was only partially reversible. Although the use of zeolite catalyst was less efficient, the products could be recovered, but additional catalyst attrition could be expected due to thermal cycling. The results suggest that additional work in the recovery of these products may be necessary.

Studies showed that the zeolite catalysts eliminate significant amounts of $\mathrm{CO}$ and $\mathrm{CO}_{2}$ from the biomass vapors, reported above as part of the catalyst off gases. It would intuitively seem that eliminating carbon would reduce process efficiency. However, the overall efficiency (0.54-0.58 LHV gasoline/LHV wood) of this process is about the same or slightly higher than a hydrotreating process when "self-sufficient" systems are compared. Self-sufficient systems would use biomass to provide process heat, plus primary chemical inputs such as hydrogen would be generated from biomass or waste product streams. While the use of the self-sufficient systems is very important in comparing efficiencies, it should be noted that commercial systems would probably incorporate external energy or chemical sources if they provided cost advantages. The cost of producing gasoline from wood using the zeolite upgrading process (mature technology) is estimated to be about $\$ 0.65 / \mathrm{gal}$, or about the same as producing ethanol or methanol from biomass on an energy basis.

Current Status: Since the BTC Program ended in 1989, research on the use of zeolites for upgrading the biomass oils has continued at NREL. The research has focused on achieving higher yields of gasoline hydrocarbons which would be blended with petroleum gasoline.

\section{Selected References:}

Diebold, J.P., J.W. Scahill, and A.J. Power. 1988. "Engineering Aspects of Upgrading Pyrolysis Oil Using Zeolites." In Research in Thermochemical Conversion, eds. A.V. Bridgwater and J.L. Kuester, pp. 927-940. Elsevier Applied Science.

Diebold, J.P., J.W. Scahill, and A.J. Power. 1988. "Conversion of Wood to Aromatic Gasoline with Zeolite Catalysts." In Energy Progress, Vol. 8, No. 1, pp. 59-66.

Diebold, J. P. and J. W. Scahill. 1987. "Upgrading Pyrolysis Vapors to Aromatic Gasoline with Zeolite Catalysts at Atmospheric Pressure." In Proceedings of the 1987 
Biomass Thermochemical Conversion Contractors Meeting, pp. 61-80, CONF-8705212, National Technical Information Service, Springfield, Virginia.

\subsubsection{Upgrading Using Hydrotreating Catalysts}

In addition to the work on zeolite catalysts, the BTC Program sponsored research on catalytic hydrotreating of biocrude oils. While hydrotreating was used widely in the petroleum industry, the biocrude products had much higher oxygen contents and were different from petroleum chemically. The program sponsored research at Pacific Northwest Laboratory to specifically examine the process of hydrotreating biomass derived products.

\subsubsection{Catalytic Hydrotreating of Biocrude Oil - Pacific Northwest Laboratory (PNL)}

\section{Principal Investigator: Douglas C. Elliott}

Project Objective: The BTC Program funded research at PNL to develop methods for using hydrotreating catalysts to upgrade a range of biocrude oils. Hydrotreating was accomplished by heating the biocrude liquids at $250-400{ }^{\circ} \mathrm{C}$ with metal catalysts in the presence of hydrogen at pressures of about $135 \mathrm{~atm}$. The hydrotreating catalysts and techniques were similar to those used by the petroleum industry, but special procedures had to be developed to deal with the more highly oxygenated biomass product. The use of hydrotreating techniques gave BTC Program the flexibility to treat products from any of a number of high pressure or rapid pyrolysis processes.

Summary of Research Project and Results: The initial work at PNL focused on upgrading the liquid products from high pressure processes. Research was conducted primarily in a stirred autoclave system through which the biomass oils could be continuously pumped. Catalysts for the reaction were held in a basket inside the reactor, and hydrogen was added on a continuous basis. The products were removed from the system and analyzed.

Research with model compounds (phenols) was conducted first to develop a better understanding of the reaction mechanisms and to identify appropriate catalysts. To upgrade the phenolic components of the crude product, two types of reactions were necessary. The oxygen content of the oil was reduced through hydrodeoxygenation reactions, and the average molecular weight of the crude product were reduced through hydrocracking reactions. Hydrotreating of phenol and phenol derivatives was studied at temperatures from 300 to $400{ }^{\circ} \mathrm{C}$ with a variety of catalysts including the following:

Hydrotreating:

- NiMo

- NiW

- CoMo
- CoMo- $\mathrm{H}_{2} \mathrm{~S}$

- $\mathrm{CoMo-H}$ 
Hydrocracking:

$\begin{array}{ll}\text { - } \mathrm{Ni} & \text { - } \mathrm{Pd} \\ \text { - } \mathrm{Ni}-\mathrm{H}_{2} \mathrm{~S} & \text { - } \mathrm{Co}\end{array}$

The studies showed that the phenolics could be converted to products such as benzene or cyclohexane under moderate conditions. Nickel and cobalt were better hydrogenation catalysts, and the cobalt/molybdenum catalysts, particularly in sulfided form, were good deoxygenation catalysts.

Based on the results from the model compound studies, upgrading tests were performed on both distillate fractions of the crude oils produced in the Albany, Oregon liquefaction facility. The distillate fractions were flowable products which contained the lower molecular weight components of the whole oil. Tests were performed primarily with $\mathrm{Ni}$ and with sulfided CoMo catalysts. Reaction temperatures were in the range of 285$315^{\circ} \mathrm{C}$ at pressures of about $135 \mathrm{~atm}$. The tests showed that the distillate fractions could readily be hydrotreated to form a mixture of true hydrocarbons. When nickel catalyst was used, oxygen was removed from the biomass product, and saturated hydrocarbons such methyl- and propyl-cyclohexanes, other substituted cyclohexanes were formed as the major components. Minor components included various naphthalenes and phenanthracenes. The sulfided CoMo catalyst also removed oxygen efficiently, but hydrogen consumption was reduced since the products were less saturated. The major products included not only cyclohexanes, but substituted benzenes as well.

Upgrading tests with the whole oils produced at the Albany, Oregon, liquefaction facility were also performed. The whole oils were hydrotreated with NiMo or sulfided CoMo catalysts at temperatures of $340-435{ }^{\circ} \mathrm{C}$ and at pressures of about $135 \mathrm{~atm}$. Depending on the severity of conditions and the residence time in the reactor, the oils could be converted directly to a hydrocarbon product. Total yields of hydrocarbons were up to $80 \%$ by volume of the oil feed, giving total wood-to-hydrocarbon yields of about $40 \mathrm{wt} \%$. More than $60 \%$ of the hydrocarbon was in the distillation range of gasoline, and an additional $27 \%$ was in the diesel range. A comparison the properties of the crude and final product are shown in Table 3.8.

Additional research showed that both the hydrogen requirements and the residence time of the material could be reduced by removing hydrotreated products from the system after treatment under moderate conditions and then recycling the partially reacted material to complete the hydrotreating. Under these conditions, the total residence time was reduced by a multiple of 4 to about $5 \mathrm{~min}$, and the hydrogen demand was reduced from about 575 to $500 \mathrm{l} / 1$ oil.

The high aromatic content of the product suggested it would have a high octane. Actual measurement of the hydrocarbon product showed the $R+M / 2$ octane number of the hydrocarbon product was about 75 , the same as straight run gasoline. This figure was lower than expected and may suggest that less severe hydrotreating would be acceptable. 
Table 3.8. Comparison of Properties of Biocrude Oils and Hydrotreated Product.

\begin{tabular}{|l|c|c||}
\hline Characteristic & $\begin{array}{c}\text { Biocrude Oil } \\
\text { (Albany TR-7) }\end{array}$ & $\begin{array}{c}\text { Refined } \\
\text { Hydrocarbon } \\
\text { Product }\end{array}$ \\
\hline Hydrogen to Carbon Ratio & 1.21 & 1.61 \\
\hline Oxygen Content, wt\% (Dry Basis) & 11 & 0.3 \\
\hline Density, g/cm & 1.19 & 0.83 \\
\hline Viscosity cPs @ 35 ${ }^{\circ} \mathrm{C}$ & 100,000 & 1.1 \\
\hline Heating Value, kJ/kg dry basis & 36,800 & 44,000 \\
\hline $\begin{array}{l}\text { Vol \% of product distilled over the } \\
\text { following temperature ranges: }\end{array}$ & & \\
\hline $\begin{array}{l}\text { Under } 225{ }^{\circ} \mathrm{C} \text { (Petroleum } \\
\text { gasoline range) }\end{array}$ & 19 & 63 \\
\hline $\begin{array}{l}225-300{ }^{\circ} \mathrm{C} \text { (Petroleum } \\
\text { diesel range) }\end{array}$ & 35 & 27 \\
\hline $\begin{array}{l}300-384{ }^{\circ} \mathrm{C} \text { (Petroleum } \\
\text { Gasoil range) }\end{array}$ & 24 & 10 \\
\hline Residual above 384 ${ }^{\circ} \mathrm{C}$ & 25 & 0 \\
\hline
\end{tabular}

PNL also conducted research on the hydrotreating of the liquid products from rapid pyrolysis reactors such as those at NREL, GTRI, or others. Because of the high reactivity of these oils and their high oxygen contents, they were thermally unstable at normal hydrotreating temperatures. To upgrade the products, PNL first subjected the oils to a low temperature treatment which converted them to a product similar to the high pressure oils. The pyrolysis oils were heated to about $270{ }^{\circ} \mathrm{C}$ for about $30 \mathrm{~min}$. in the presence of a CoMo catalyst and hydrogen at $135 \mathrm{~atm}$. Although hydrogen consumption was minimal, about $40 \mathrm{l} / \mathrm{l}$ oil, the presence of it and the catalyst was crucial to prevent excess coke formation. In this initial step, much of the oxygen content of the pyrolysis oil was removed in the form of $\mathrm{CO}$ and $\mathrm{CO}_{2}$. Analysis showed that the treated product was chemically very similar to that from the high pressure processes. Following the low temperature treatment, the oils could be upgraded using the same techniques used with the high pressure products.

To simplify the process of upgrading the pyrolysis oils, PNL developed a non-isothermal hydrotreating concept which would allow hydrotreating to be accomplished in a single step. Oils were introduced at the inlet (bottom) of the reactor at $250-280{ }^{\circ} \mathrm{C}$. The oil was heated as it passed through the reactor, reaching a temperature of $350-400{ }^{\circ} \mathrm{C}$ at the reactor exit (top). The products formed in the non-isothermal reactor were essentially 
the same as from the two-stage process, and yields were higher, about $0.50-0.551 / 1$ of oil fed, or about $0.25-0.30 \mathrm{~g} / \mathrm{g}$ wood fed including the initial oil production.

The results from this research show that hydrotreating can be used successfully to upgrade a variety of biomass liquid products into hydrocarbons which closely matches straight-run gasoline. The overall process efficiency for converting wood into a straightrun gasoline was calculated to be about 0.40 (LHV fuel/LHV wood) for hydrotreated high pressure oils and about $0.50-0.52$ for hydrotreated rapid pyrolysis oils. These calculations were based on "self-sufficient" systems where biomass provided all major energy inputs, and biomass was used to generate hydrogen, carbon monoxide, and other primary products used in the process. This significant difference comes primarily from differences in the liquefaction step rather than the upgrading. The actual hydrotreating steps for the rapid pyrolysis and high temperature processes are about equal in overall efficiency since the pyrolysis product is produced in greater quantity but requires additional treatment. The main difference between the two systems is the fact that part of the biomass has to be gasified to form $\mathrm{CO}$ and $\mathrm{H}_{2}$ which is injected in the high pressure liquefaction reactor. This is not required in the rapid pyrolysis system and has significant process cost implications.

The efficiency of hydrotreating the rapid pyrolysis oils ( 0.52 based on LHV) is slightly less than using zeolite upgrading (0.54-0.58 depending on steam use). Various technoeconomic analyses have been performed on the two systems with mixed results. However, it appears that in either case, gasoline at approximately $\$ 0.65 /$ gal could potentially be produced. In either case, the cost of producing hydrocarbon fuels is approximately equivalent to that of producing ethanol or methanol from biomass.

Current Status: As a result of concerns over air quality, the DOE's emphasis has shifted from the production of hydrocarbons to the production of oxygenates, particularly ethanol, from biomass. PNL has applied for patents relating to its upgrading work, but research has stopped.

\section{Selected References:}

Elliot, D.C. and E.G. Baker. 1986. Catalytic Hydrotreating of Biomass Liquefaction Products to Produce Hydrocarbon Fuels, Interim Report. PNL-5844, Pacific Northwest Laboratory, Richland, Washington.

Elliot, D.C. and E.G. Baker. 1987. "Hydrotreating Biomass Liquids to Produce Hydrocarbon Fuels." In Proceedings of Energy from Biomass and Waste $X$, ed. D.L. Klass, pp. 765-784. Institute of Gas Technology, Chicago, Illinois.

\subsection{BASIC PYROLYSIS RESEARCH}

The BTC Program sponsored research to gain a better understanding of the biomass pyrolysis processes. In the 1970's, the role of pyrolytic reactions in a variety of thermal conversion processes was poorly understood. Through the work of this program and 
others such as National Science Foundation, the mechanisms of biomass pyrolysis have been examined in detail. From this research it has been determined that pyrolytic reactions occur in essentially all thermal conversion systems. As biomass heats, it depolymerized and volatilizes into primary oils. By controlling the severity of subsequent reactions, a variety of gaseous or liquid products can be formed. The improved understanding of biomass devolatilization has helped improve biomass combustion, gasification, and liquefaction systems. Based on the extensive information gathered over the past 15 years, pyrolytic reactions are now viewed as an integral part of biomass thermal conversion systems rather than simply a means to produce charcoal. The research sponsored by the BTC Program is summarized in Table 3.9 and is described below.

Table 3.9. Basic Pyrolysis Research Projects.

\begin{tabular}{|c|c|}
\hline TECHNOLOGY AREA & INSTITUTION \\
\hline \multicolumn{2}{|l|}{ Basic Pyrolysis Research } \\
\hline \multicolumn{2}{|c|}{ Use of a Molecular Beam/Mass Spectrometer System } \\
\hline Fundamental Pyrolysis Studies & NREL \\
\hline Rapid Characterization of Biomass Oils & NREL \\
\hline \multicolumn{2}{|l|}{ Other Basic Pyrolysis Studies } \\
\hline $\begin{array}{l}\text { Pyrolysis in Hydrogen and Methane } \\
\text { Atmospheres }\end{array}$ & Brookhaven National Lab \\
\hline Affects of Pressure on Pyrolysis & $\begin{array}{l}\text { Princeton University/ } \\
\text { University of Hawaii }\end{array}$ \\
\hline
\end{tabular}

\subsubsection{Use of a Molecular Beam/Mass Spectrometer (MBMS) System}

NREL used a molecular beam/mass spectrometer (MBMS) system to gather extensive data on biomass pyrolysis. The MBMS system allowed examination of detailed reaction pathways which occur as biomass heats. Mass spectrometric techniques can also be used to characterize volatile products, and NREL developed methods to rapidly characterize the oils and tars from various biomass gasification and liquefaction processes. This work is described below.

\subsubsection{Fundamental Pyrolysis Studies - NREL}

\section{Principal Investigators: Tom Milne, Robert Evans}

Project Objective: As indicated previously, the detailed reactions mechanisms which govern biomass pyrolysis were incompletely understood in the 1970's. The purpose of 
the work at NREL was to examine the detailed reactions which were taking place as biomass pyrolyzed and to develop a better understanding of pyrolytic reaction pathways in general. The research used a MBMS system as a tool examine the reaction pathways. The MBMS system was one of the few techniques which allowed the individual reaction products to be isolated and characterized in real time as the pyrolysis occurred. In addition to the fundamental studies, NREL also used the MBMS to develop methods to rapidly characterize biomass oils and liquids as described in Section 3.5.1.2.

Summary of Research Project and Results: The research at NREL used a small pyrolysis reactor closely coupled with a molecular beam/mass spectrometer. The goal of the work was to rapidly pyrolyze solid biomass, extract samples of the vapors, quench the reactions without allowing the products to condense or collide with the walls, and then to use the mass spectrometer to characterize the products. By generating the products under realistic conditions and then quickly quenching the reactions, the pyrolysis behavior could accurately be studied.

In the system, biomass was pyrolyzed by introducing small (typically $10-100 \mathrm{mg}$ ) amounts of biomass into a hot stream of inert gas. The pyrolysis residence time of about 0.5 to 3 seconds was representative of that encountered in larger rapid pyrolysis units, and residence times up to 150 seconds could also be studied. Several experimental reactor configurations were successfully used including a flame furnace and resistanceheated flow reactor. Initially, NREL used a furnace which burned a premixed combination of hydrogen and oxygen entrained in a stream of either helium or argon. Biomass samples were passed through the resulting hot gases consisting of steam and inert gas, and the pyrolysis vapors were swept into the mass spectrometer system. In later work, biomass was introduced into a hot stream of inert gas which had been preheated by the resistance heater, and the vapors were then introduced to the mass spectrometer. The flow reactor allowed better temperature control for studies at $800^{\circ} \mathrm{C}$ or less. A schematic diagram of the flow heater and the MBMS system are shown in Figure 3.7.

The MBMS system was used to quench the pyrolysis reactions and to analyze the reaction products. The products were swept from the reactor, and a plume of the product stream was pulled by vacuum through a sampling orifice into the first stage MBMS. The expansion of the gas stream in the vacuum rapidly cooled the pyrolysis products by reducing rotational and vibrational energies, thereby quenching further reactions. The product stream then passed through a chopper, which reduced the plume of gases into a very narrow, pulsed molecular beam, and a second stage vacuum pump removed excess gases. The beam then passed into a quadrupole mass spectrometer which allowed the molecular weights of the material in the molecular beam to be determined. The output from the mass spectrometer was a "fingerprint" which allowed the composition of the products to be determined and allowed the relative amounts of various products to be compared. 


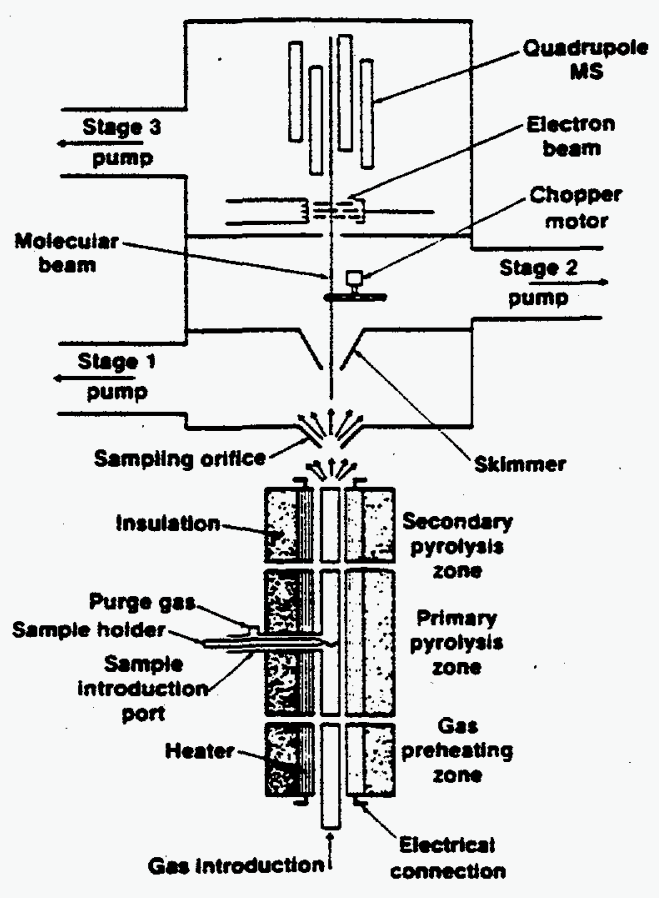

Figure 3.7. Schematic Diagram of the Pyrolysis MBMS System at NREL.

Since the pyrolysis reactions occurred under conditions very similar to larger reactors, the products were representative of those from much larger systems. By varying the sample size, the gas flow rate, and the placement of the reactor in relation to the sampling orifice, system could be used to selectively study a variety of pyrolysis reactions including both the primary devolatilization of the solid biomass and the secondary cracking of those products. This tool allowed a wide range of pyrolysis reactions to be examined.

At pyrolysis reactor temperatures below about $500{ }^{\circ} \mathrm{C}$, the primary pyrolysis reactions of biomass could be studied. As the biomass is heated, primary tars are given off as the cellulosic and lignin material initially depolymerize. The results from the MBMS system allowed detailed reaction mechanisms to be identified. For instance, the pyrolysis of cellulose in the wood is more complex than for pure cellulose. Additional fragmentation into products such as hydroxyacetaldehyde occurs with wood, while wood yielded less levoglucosan than pure cellulose. The lignin from the wood also undergoes primary depolymerization to form a wide variety of products such as coniferyl alcohol. It was noted that most prepared lignins did not behave as lignin from wood, probably because the processing to extract lignin had significantly changed its structure.

When the pyrolysis reactor was operated with exit temperatures above $550{ }^{\circ} \mathrm{C}$, secondary pyrolysis reactions could be studied. Secondary reactions involve the cracking of the primary tars and can be difficult to study since the tars are thermally unstable. The MBMS system allowed detailed studies of the secondary cracking reactions using both model compounds and biomass samples. At temperatures above about $700^{\circ} \mathrm{C}$, tertiary 
processes occur which convert the volatile materials to permanent gases such as $\mathrm{CO}$, $\mathrm{CO}_{2}$, and $\mathrm{H}_{2}$. While the individual mechanisms are very complex, the overall biomass reaction pathways can be shown in a simplified form, as shown in Figure 3.8.

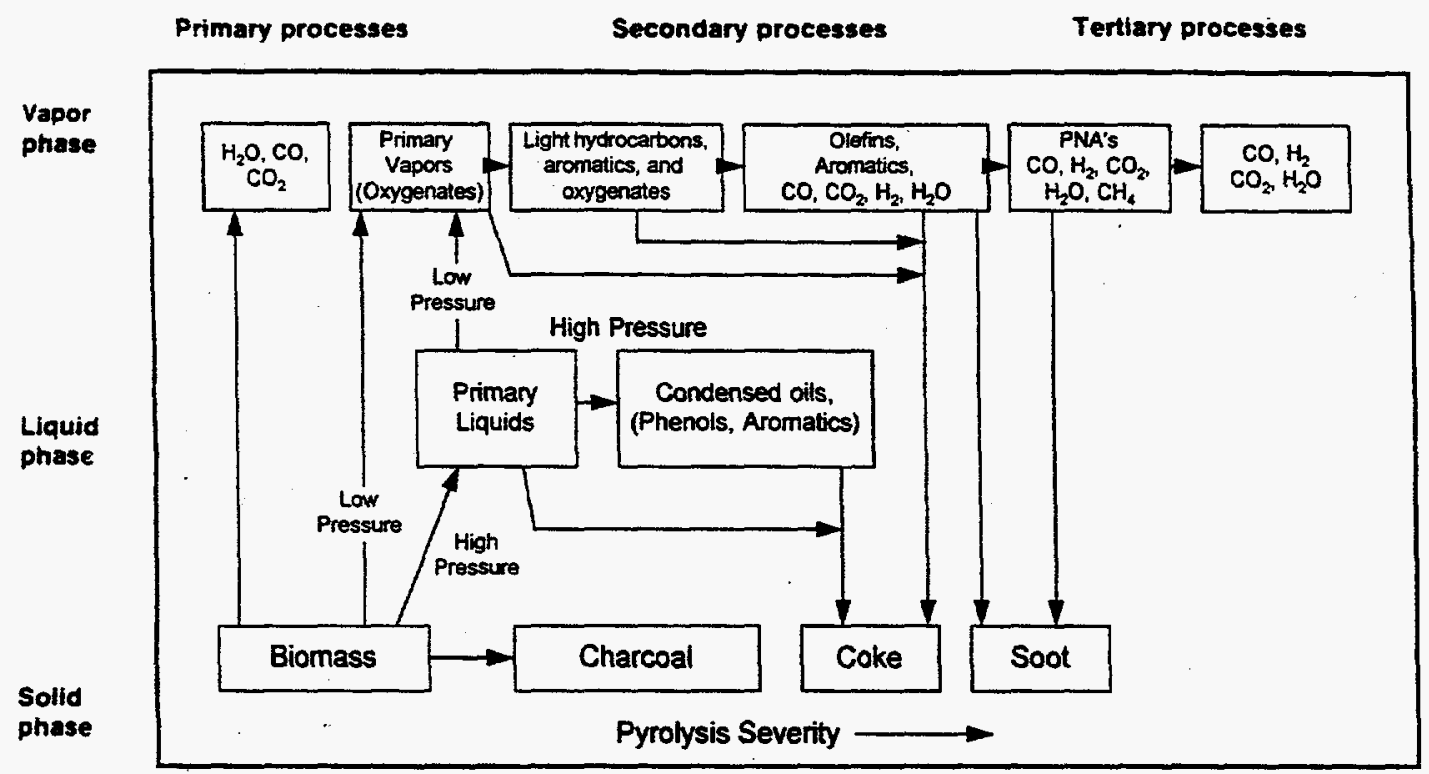

Figure 3.8. Representation of Typical Pyrolysis Reaction Pathways.

In addition to the work on biomass pyrolysis reactions, the MBMS system was used to provide basic data on the zeolite upgrading of pyrolysis vapors. For these studies, the primary vapors were passed through a zeolite catalyst bed prior to entering the MBMS. The research provided useful information on the mechanisms of the primary tar reaction on the zeolites and led to the identification of many of the upgraded products. NREL also used the analytical capabilities of the MBMS to develop rapid characterization methods for analyzing the liquid products from biomass. This work is described below in Section 3.5.1.2 of this report.

Current Status: The work with the MBMS system made a major contribution toward the development of a better understanding of pyrolysis processes and their importance in a variety of conversion systems. NREL is continuing to use this system to study biomass pyrolysis, to investigate catalytic upgrading, and to study the catalytic cracking of gasifier tars.

\section{Selected References:}

Evans, R.J. and T.A. Milne. 1987. "Molecular Characterization of the Pyrolysis of Biomass. I. Fundamentals." Energy and Fuels, 1:123-137. 
Evans, R. J., and T. A. Milne. 1987. "Molecular Characterization of the Pyrolysis of Biomass. II. Applications." Energy and Fuels, 1:311-319.

Evans, R.J., T.A. Milne, M.N. Soltys, and H.R. Schulten. 1984. "The Mass Spectrometric Behavior of Levoglucosan Under Different Ionization Conditions and Implications for Studies of Cellulose Pyrolysis." J. Anal. Appl. Pyrol., 6:273-283.

Evans, R.J. 1985. "Direct Mass-Spectrometric Studies of the Pyrolysis of Carbonaceous Fuels. IV. The Primary Pyrolysis of Carbohydrates." J. Anal. Appl. Pyrol. 8:99-104.

\subsubsection{Rapid Characterization of Biomass and Biomass Oils}

Principal Investigator: Tom Milne, Robert Evans

Project Objective: The chemical constituents of the liquids and tars from biomass pyrolyzers and gasifiers will depend on the temperature and reaction conditions under which they are formed. For instance oils produced at low temperatures contain large amounts of primary products, while oils formed at higher temperatures have constituents characteristic of secondary cracking reactions. Since the MBMS produces a representative "fingerprint" of the chemical constituents in the product, it can be used as an analytical tool to rapidly analyze biomass liquids and tars. NREL conducted research to use the MBMS to perform rapid qualitative analyses liquid biomass products.

Summary of Research Project and Results: NREL used the MBMS system described above to qualitatively characterize biomass liquids. Samples of biomass liquids were flash volatilized at $300-500{ }^{\circ} \mathrm{C}$ and were analyzed in the MBMS. About $90 \%$ of the liquid sample was typically volatilized in the process, and the gas phase material underwent little or no subsequent reaction.

As shown in Figure 3.9, the MBMS fingerprints for the high pressure liquefaction products and the primary rapid pyrolysis oils were very different. The method can be used to rapidly screen the liquids from various processes.

Current Status: The research to use the MBMS as a characterization tool has continued at NREL. In work started after the completion of the BTC Program, NREL also used the MBMS to provide for a semi-quantitative analysis of the contents of lignin, cellulose, and hemicellulose in whole biomass samples. Since the primary pyrolysis tars contain specific materials from the decomposition of each of these three constituents, it is possible to use the MBMS to measure the amounts of each component in the biomass sample. The method allows rapid semi-quantitative determination of the amount of each component in a biomass sample without the need for complex wet-chemical procedures. 

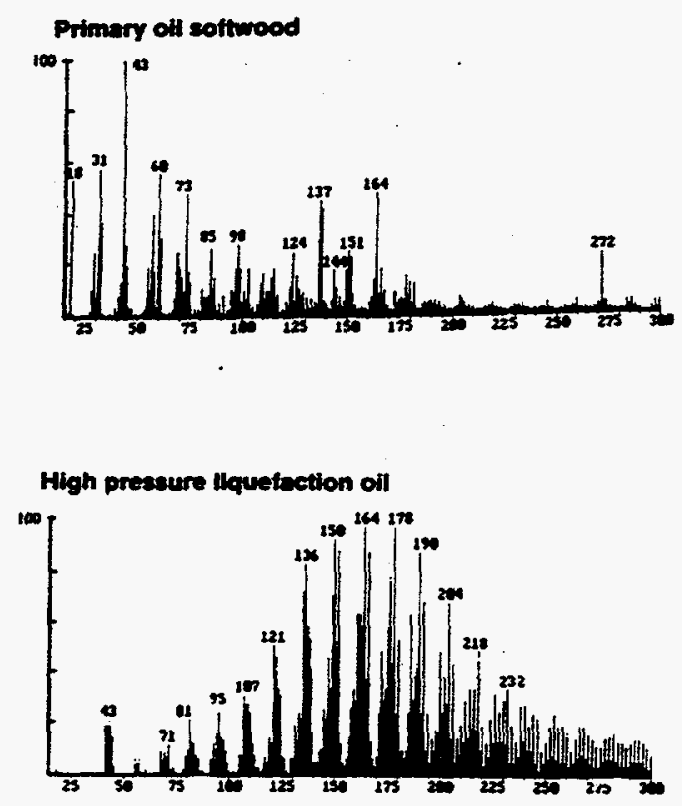

Figure 3.9. Comparison of Mass Spectra Rapid Pyrolysis and High Pressure Liquefaction Oils.

\section{Selected References:}

Evans, R.J. and T.A. Milne. 1987. "Molecular Characterization of the Pyrolysis of Biomass. II. Applications." Energy and Fuels, 1:311-319.

Evans, R.J., T.A. Milne, and M.N. Soltys. 1986. "Direct Mass-Spectrometric Studies of the Pyrolysis of Carbonaceous Fuels. III. Primary Pyrolysis of Lignins." J. Anal. Appl. Pyrol., 9:207-236.

\subsubsection{Other Basic Pyrolysis Studies}

The BTC Program also sponsored work to understand biomass pyrolysis behavior under different types of reactive conditions. Research at Brookhaven National Lab examined pyrolysis of biomass in the presence of hydrogen or methane to see if the product spectrum could be improved by the presence of these hydrogen-rich components. Other work was conducted at Princeton University/University of Hawaii to determine the effects of pressure on cellulose pyrolysis. These projects are described below. 


\subsubsection{Pyrolysis in Hydrogen and Methane Atmospheres - Brookhaven National Laboratory (BNL)}

\section{Principal Investigator: Meyer Steinberg}

Project Objective: As indicated previously, biomass is rich in carbon but deficient in hydrogen as compared to hydrocarbon transportation fuels. The BTC Program sponsored research on biomass pyrolysis in the presence of excess hydrogen or methane to determine reaction behavior and to determine if these gases could serve as hydrogen donors during the reaction. Pyrolysis of coal in the presence of hydrogen had increased yields of liquid products, but the influence of hydrogen with biomass was less clear. In later work, methane replaced hydrogen as a reactant. Brookhaven used an existing pyrolysis reactor to determine the effects of these reactive gases on the pyrolysis of biomass.

Summary of Research Project and Results: Brookhaven used a $2.5 \mathrm{~cm}$ entrained, downflow, rapid pyrolysis reactor capable of operating at pressures from atmospheric to about 35 atm. Biomass ground to a fine powder (300-1000 microns) was fed into a stream of preheated gas, and the entrained mixture flowed through a heated tubular reactor. In most experiments, a fine silica powder (Cab-O-Sil) was added to the wood to improve the flow characteristics of the finely ground biomass, but it did not affect the pyrolysis reactions. Temperatures in the reactor could be varied up to about $1000{ }^{\circ} \mathrm{C}$, and the average residence time of the biomass was approximately $1 \mathrm{sec}$. The products were swept from the reactor and rapidly quenched in a cooling section of the system. The product gases were then analyzed by gas chromatography.

Initial research at Brookhaven compared biomass pyrolysis in the presence of hydrogen gas with that of inert gases including helium and nitrogen. The research was conducted at high temperatures where hydrogen would react with the volatiles from biomass, and at these temperatures, the primary products were permanent gases. At reaction temperatures of about $1000^{\circ} \mathrm{C}$, the gas products were highly dependent on the pressure of the hydrogen entrainment gas. As pressures rose from 7 to $35 \mathrm{~atm}$, methane yields rose from about 10 to $40 \mathrm{wt} \%$. The amounts of $\mathrm{CO}$ were inversely related to the pressure, ranging from about 30 to $7 \mathrm{wt} \%$ over the same pressure range. In the hydrogen entrainment stream, the yields of $\mathrm{CO}_{2}$ and aromatics such as benzene, toluene, and xylene (BTX) were less than $2 \mathrm{wt} \%$ and did not vary significantly with pressure. By comparison, pyrolysis in a helium or nitrogen atmosphere under similar conditions resulted in much lower methane yields (approx. $7 \mathrm{wt} \%$ ), and the product distribution was only marginally influenced by pressure. The total yield of volatile material was highest at about $13 \mathrm{~atm}$ and decreased at higher pressures. The results showed that hydrogen was actively incorporated in the biomass products at these temperatures, and that the pressure of the hydrogen will have a significant influence on the products. While it was clear that the pyrolysis in hydrogen would be too expensive to be a commercial success, the research provided useful information on pyrolysis pathways.

Brookhaven also conducted research on the biomass pyrolysis in the presence of methane. Methane is also a potential hydrogen donor and is lower in cost than hydrogen. 
Biomass, primarily pine, was pyrolyzed in a methane gas stream at temperatures of 900 $1050{ }^{\circ} \mathrm{C}$ and pressures of about $4 \mathrm{~atm}$. Unlike the reactions in hydrogen or inert gases, the reaction in methane produced high yields of ethylene, BTX (primarily benzene), and similar hydrocarbons. As shown in Figure 3.10, the yields of these products were highest at about $1000{ }^{\circ} \mathrm{C}$.

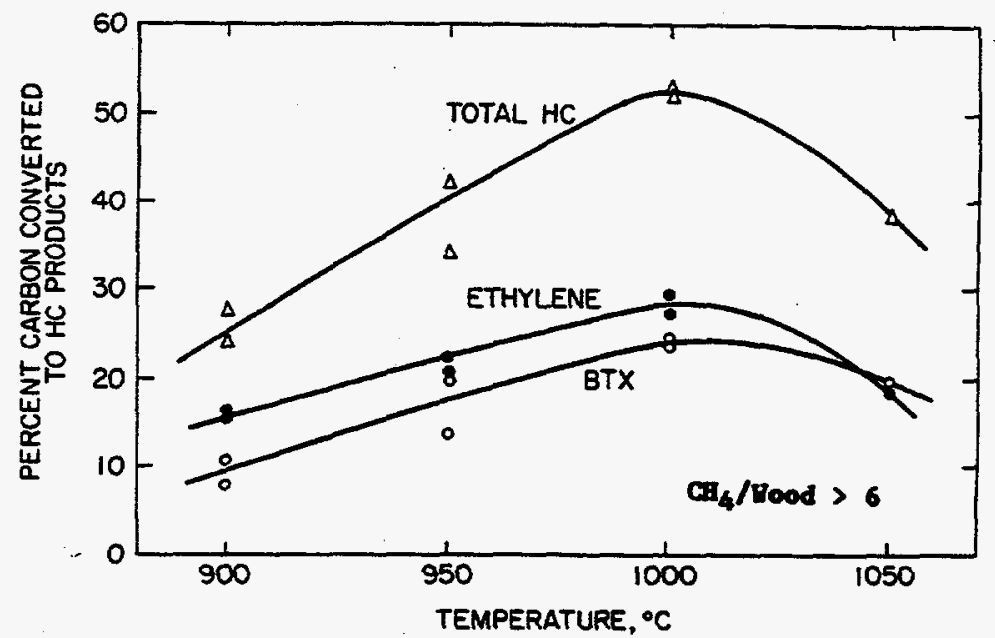

Figure 3.10. Yields From Wood Pyrolysis in the Presence of Methane Brookhaven National Lab.

The high yields of ethylene and BTX from pyrolysis of biomass in methane was unexpected, and the reaction mechanisms which govern these reactions are only partially understood. At the temperatures of $1000^{\circ} \mathrm{C}$, methane is generally unreactive, and in fact, methane was inactive in the reactor under identical conditions when wood was absent. The production of olefins appears to result from the interaction of volatile species from the wood, probably free radicals. The high yields and relative specificity of the reactions suggested that biomass pyrolysis may have commercial potential as a method to produce chemical species.

Current Status: As air quality regulations have been enacted, DOE's interest in aromatic fuels for transportation has declined, and the biomass pyrolysis work has been discontinued. BNL has applied for patents on a process to pyrolyze biomass in methane, and limited work to develop the process has been undertaken.

\section{Selected References:}

Steinberg, M., P.T. Fallon, and M.S. Sundaram. 1986. "Flash Pyrolysis of Biomass with Reactive and Non-Reactive Gas." Biomass, (9):293-315.

Steinberg, M., P.T. Fallon, and M.S. Sundaram. 1986. "Flash Methanolysis - The Flash Pyrolysis of Biomass with Methane Gas." In Proceedings of the 1985 Biomass 
Thermochemical Conversion Contractors' Meeting, pp. 15-29. CONF-8510167, Pacific Northwest Laboratory, Richland, Washington.

\subsubsection{Effects of Pressure on Pyrolysis - Princeton University/University of Hawaii}

\section{Principal Investigator: Michael Antal}

Project Objective: The BTC Program sponsored research to study the effects of pressure on cellulose pyrolysis. The objective of this work was to collect data on the heats of pyrolysis which could be used for engineering purposes and to help clarify the reaction pathways involved in the cellulose pyrolysis. The research was started when Dr. Antal was at Princeton University and completed after he moved to University of Hawaii in 1982.

Summary of Research Project and Results: The experimental research was conducted using a differential scanning calorimeter (DSC) modified for high pressure operation. The DSC was a type of calorimeter which measured heats of reaction as biomass reacted. The DSC consisted of two identical ceramic tubes inside a furnace which was surrounded by numerous opposing thermocouples. To accommodate high pressures, stainless steel tubes $(4.64 \mathrm{~mm})$ were placed inside the normal ceramic tubes. Cellulose samples were placed in one of the tubes, and the temperature of the furnace was increased to as high as $825^{\circ} \mathrm{C}$ at rates up to $20^{\circ} \mathrm{C} / \mathrm{min}$. Argon gas flowed through the two tubular vessels, and the pyrolysis products were trapped in an absorber column. The DSC compared the temperatures between the reference and pyrolysis vessels and provided data on the differential between the two. This information allowed the heats of pyrolysis of the cellulose to be determined.

The cellulose began pyrolyzing at about $330^{\circ} \mathrm{C}$ and reactions were complete by about $390{ }^{\circ} \mathrm{C}$. The heat of pyrolysis was inversely related to the pressure over the range of 1-25 atm. The pyrolysis reaction was endothermic to pressures of about 5-10 atm (depending on flow rates) and them became exothermic. Char formation, as expected, increased at higher pressures.

Additional studies were made to better understand the mechanism of cellulose pyrolysis. Two major competing reactions take place during cellulose pyrolysis including the depolymerization to levoglucosan and dehydration to anhydrocellulose. To study the depolymerization reaction, samples of levoglucosan were pyrolyzed at various pressures in the DSC. The levoglucosan appeared to react via two major pathways which included either evaporation or decomposition to a solid. The high pressures favored the decomposition mechanism. Results with heat-treated cellulose (to increase anhydrocellulose content) also suggested that there are similar competitive pathways with the dehydration reaction. Again, high pressures favor char formation. Based on these results, Antal proposed a detailed series of competing mechanisms which explained the reaction behavior. The research was among the first to systematically study the effects 
of pressure on pyrolysis, and the results have been helpful in developing a better understanding of biomass conversion processes.

Current Status: Although the research funded by the BTC Program at the University of Hawaii ended in 1982, Dr. Antal has continued to conduct research on biomass thermal reactions. His work has included studies of thermal conversion reactions occurring in aqueous solutions at or near the critical point of water. The concept for pyrolyzing biomass in aqueous solutions has led to the development of a proprietary concept for producing a hydrogen-rich gas product from biomass and a process which improves charcoal yields.

\section{Selected References:}

Antal, M. 1982. "Effects of Pressure on Biomass Pyrolysis." In Proceedings of the 14th Biomass Thermochemical Conversion Contractor's Meeting, Arlington, Virginia, June 23-24, 1982, pp. 403-451. CONF-820685, Pacific Northwest Laboratory, Richland, Washington.

Mok, W. 1982. Effects of Pressure on Biomass Pyrolysis. M.S.E. Thesis, Princeton University.

\subsection{OTHER BIOMASS PROJECTS}

The BTC Program has funded other research in the pyrolysis area, and also actively participated in the cooperative work on biomass liquefaction sponsored by the International Energy Agency's Bioenergy Agreement. These projects are discussed below.

\subsubsection{Other BTC Projects}

Research was conducted at PNL to characterize the liquid oil and tar products from a variety of biomass conversion units. Research at the University of Arkansas was conducted to attempt to increase the yields of char from biomass pyrolysis.

\subsubsection{Analysis and Comparison of Biomass Pyrolysis/Gasification Condensates - Pacific Northwest Laboratory (PNL)}

Principal Investigator: Douglas Elliott

Project Objective: As described previously in Section 3.3 of this report, PNL developed techniques to characterize the products from biomass liquefaction systems. The BTC Program expanded this work to examine a much wider range of liquid condensates from both biomass pyrolysis and gasification systems. Samples were selected which represented material formed under a wide range of temperatures and reaction severities. 
The samples were analyzed to determine general physical characteristics such as elemental composition, ash content and nature, and general chemical composition. In addition, the mutagenicity of the oils as measured by Ames assays was determined. The data allowed general conclusions to be drawn regarding the effects of reaction severity on the liquid products.

Summary of Research Project and Results: PNL used the techniques described in Section 3.4 of this report to characterize the physical and chemical characteristics of the products from the following gasifiers and pyrolysis units:

Gasifiers:

- $\quad$ Battelle Columbus - Hardwood

- $\quad$ Battelle Columbus - Pine

- $\quad$ Rome Georgia (air blown)

- $\quad$ Rocky Creek Gasogens (air-blown)
Pyrolyzers:

- $\quad$ Georgia Tech Research Institute

- NREL Vortex - Primary Tars

- NREL Vortex - Cracked Tars

The characteristics of the products were highly dependent on the severity of the conditions under which they were produced. Under the least severe conditions of short residence time and low temperature $\left(500^{\circ} \mathrm{C}\right)$, such as those produced in the NREL vortex reactor, the products were highly oxygenated primary tars which originated as the wood initially depolymerized. As temperature increased, the oxygen content of the product was reduced as additional cracking lead to the formation of complex polyaromatic hydrocarbons. Representative data showing this trend is listed in Table 3.10.

Table 3.10. Influence of Reaction Severity on Biomass Tar Composition.

\begin{tabular}{||l|c|c|c||}
\hline Source of Tar & $\begin{array}{c}\text { NREL } \\
\text { Vortex } \\
\text { Reactor }\end{array}$ & $\begin{array}{c}\text { Rocky } \\
\text { Creek } \\
\text { Gasifier }\end{array}$ & $\begin{array}{c}\text { BCL } \\
\text { Gasifier } \\
\text { (pine) }\end{array}$ \\
\hline $\begin{array}{l}\text { Comparative Severity of } \\
\text { Reaction }\end{array}$ & low & medium & high \\
\hline $\begin{array}{l}\text { Elemental Analysis (Dry } \\
\text { Basis) }\end{array}$ & & & \\
C & 53 & 67 & 84 \\
H & 6.2 & 5.8 & 5.7 \\
O & 40 & 25 & 8.7 \\
\hline H/C atomic ratio & 1.38 & 1.03 & 0.81 \\
\hline Density, g/ml & 1.28 & 1.16 & 1.14 \\
\hline HHV, kJ/kg (dry) & 22,300 & 28,600 & 32,300 \\
\hline
\end{tabular}


The analysis also showed that the chemical nature of the tars was highly affected by the severity of the reactive environment. Chemical analysis was performed with gas chromatography, liquid chromatography, NMR spectroscopy, and other techniques. PNL suggested the following general pathway to describe the decomposition of the wood tars:

mixed
phenolics $\rightarrow \begin{aligned} & \text { phenolic } \\ & \text { ethers }\end{aligned} \underset{\text { phenolics }}{\text { alkyl }} \rightarrow \begin{aligned} & \text { heterocyclic } \\ & \text { ethers }\end{aligned}$

Clearly, there are a great number of individual competing reactions involved, but the simplified pathway allows the overall result to be summarized.

In addition to the physical and chemical characterization, PNL conducted tests to determine the mutagenicity of the tar products. The mutagenicity was determined using standard Ames Assay procedures. Mutagenic activity was found only in the most highly reacted gasifier tars formed at the highest temperatures, and those samples also had the highest concentrations of PAH. The tars formed under conditions of low and moderate temperature were found not to show mutagenic activity. This suggests that tars from many processes will not require special handling techniques. For the higher temperature material, most gasifier developers are examining methods to convert the tars by recycling them in various ways or by catalytically destroying them in hot-gas cleanup systems. Limited testing of the low-temperature oils with mice also suggested that the carcinogenicity of the oil was minimal.

Current Status: PNL continues to provide support research to DOE through NREL.

\section{Selected Reference:}

Elliott, D.C. 1985. Analysis and Comparison of Biomass Pyrolysis/Gasification Condesnates - An Interim Report. PNL-5555, Pacific Northwest Laboratory, Richland, Washington.

\subsubsection{Pyrolysis for Char Production - University of Arkansas}

\section{Principal Investigator: James R. Kimzey, Henry H. Hicks}

Project Objective: Pyrolysis is used extensively throughout the world to produce charcoal. The process is typically inefficient, and typical charcoal yields are about $25 \%$ of the feedstock by weight. In an effort to improve charcoal production, DOE sponsored research at the University of Arkansas in the late 1970's on the use of a rotary kiln pyrolyzer. In the early 1980's, funding was provided by DOE to scale up the rotary kiln and to conduct tests on charcoal production.

Summary of Research Project and Results: Prior to the BTC Program, the University of Arkansas had conducted research on the use of small rotary kilns for making charcoal from biomass, primarily hardwoods. By 1980, DOE had appropriated funds to test the rotary kiln at a larger scale. The pyrolyzer consisted of a horizontal steel cylinder with 
a $2.1 \mathrm{~m}$ diameter and a length of $4.9 \mathrm{~m}$. The cylinder was refractory lined (total weight $13,500 \mathrm{~kg}$ ) and rotated on its horizontal axis. The cylindrical reactor was inclined at about 1 degree so that solids would slowly moved through the vessel as it rotated.

The pyrolysis reactor was heated by burning the pyrolysis gases with air, which flowed in a countercurrent direction to the char. The objective of the work was to limit the amount of air so that heat requirements could be met but that excess char gasification would not occur. Char formed in the reactor was removed in a pipe and cooled. The pyrolysis gases from the reactor passed through an afterburner to remove unreacted material.

Operation of the kiln proved to be difficult, and very limited amounts of char were produced in most tests. At feed rates of about $30 \mathrm{~kg} / \mathrm{hr}$ The highest char yields in any of the tests were about $25 \mathrm{wt} \%$, or about the same as commercial units. The seals at the ends of the rotating vessel allowed too much air into the system, and the unit behaved very much like an air-blown gasifier. In addition to the air leaks, there was extensive thermal stress on the vessel due to its heavy refractory lining, and a more adequate support system for the reactor would have been necessary. Final test runs on the pyrolyzer were made in early 1983 , and the project was discontinued.

\section{Selected Reference:}

Kimzey, J.R. and H.H. Hicks, Jr. 1985. Continuous Pyrolysis of Biomass Feedstocks in Rotary Kiln Convertor. Final Reoprt. DOE-CS-84003-T1, National Technical Information Service, Springfield, Virginia.

\subsubsection{BTC Program Participation in Liquefaction/Pyrolysis Research Sponsored by the International Energy Agency (IEA).}

The BTC Program participated actively in the cooperative bioenergy projects sponsored by the International Energy Agency's Bioenergy Agreement (IEA/BA). While the IEA/BA program is described elsewhere, its work on liquefaction and pyrolysis was very closely linked with that of the BTC Program. This research is described in more detail below.

\subsubsection{IEA Biomass Liquefaction/Pyrolysis Project}

Principal Investigators (for USA): Douglas Elliott, PNL; James Diebold, NREL

Project Objective: The IEA/BA provides a legal mechanism where participating countries can share information and perform cooperative research and development activities on bioenergy. Approximately fifteen countries are participating in the agreement, including those from North America, Europe, and the Pacific Rim. Participating countries identify specific areas of joint interest, and then organize an Activity to pursue their goals. Activities can include a variety of projects ranging from 
simple information exchange to cooperation which produces original research. The IEA provides only small amounts of funding to administer the work, and the main part of the effort is provided by the individual countries through their own national research programs.

The earliest IEA/BA cooperative project on biomass conversion was one on biomass liquefaction. In the early 1980's, four countries (Canada, Finland, Sweden, and United States) were interested in producing liquid fuels from biomass. The countries had active programs on liquefaction and felt that they could each benefit by coordinating their research efforts with the others. As a result of this interest, an Activity on biomass liquefaction was initiated. The work on liquefaction and pyrolysis has continued through the present time, and additional participants such as the United Kingdom and the European Union have joined the work. The BTC program actively participated in the Activity.

The primary goal of the Liquefaction Activity was to provide a comprehensive technoeconomic analysis of the emerging liquefaction processes. The first comprehensive analysis was prepared in 1983, and additional analyses of other systems have been completed since. In addition to the analyses, the Activity provided a means to develop better analytical methods, to exchange product samples, and to improve the methods to analyze the products. This work is described below.

\section{Summary of Research Project and Results:}

Phase 1 - From 1981 through 1983, the participating countries had very active programs on biomass liquefaction, and many participants wanted to determine which types of several different classes of processes had greater economic potential. The main purpose of the liquefaction activity was to prepare a comprehensive technoeconomic analysis, based on results from processes in several countries, which would determine the economics of producing biocrude oils. As the work started, several needs were quickly identified. The available data was based on the use of a variety of different feedstocks, and the analysis of liquid products was inconsistent. Further, the participating countries generally were interested in transportation fuels, but the crude products from several processes had never been upgraded, and data was not available. Finally, there was not a good compliation of appropriate literature review on liquefaction.

As a result of these needs, the Liquefaction Activity began several projects. Initially, the activity conducted an extensive literature review of biomass liquefaction. In order to have more consistent data to use, the activity also distributed standard samples of a poplar hybrid and of peat to participating laboratories. The individual laboratories used the standard samples in their own reactors, and the results were reported on the basis of a common feedstock. The group was also active in analyzing the liquid products and determining superior analytical methods. Samples from various processes were sent to Pacific Northwest Laboratory for analysis using the techniques described in Section 3.3 of this report, and the results were compared with the results from other participating labs. In some cases, the work identified needs for standardized procedures. For instance, the moisture content of the biocrude oils varied by nearly a multiple of two, 
depending on what type of analysis was used. The work resulted in the informal adoption of a method described by ASTM as being the most accurate method of determining moisture content. PNL also conducted comparative hydrotreating on some of the high pressure products.

With the data from the various participating laboratories, the Activity performed a detailed technoeconomic analysis on the production of biocrude using several liquefaction concepts. Detailed process flowsheets were constructed, mass and energy balances calculated, capital costs were calculated, and operation and maintenance costs were determined. Various parameters such as feedstock costs and capital requirements were varied to provide for sensitivity analysis. Because the concepts were still being developed, there was substantial uncertainty about the potential of the processes for future improvement. To deal with the uncertainties, the activity calculated production costs for four cases ranging from very optimistic to very pessimistic. The optimistic cases incorporated assumptions of future process improvement through research, low feedstock costs, and low capital, while the pessimistic cases were based on only those yields which had actually been achieved in the early 1980's and on higher costs.

The analysis showed that the biocrude was more expensive than petroleum crude oils at the time and that the production costs therefore exceeded the commercial product value. There was a clear correlation between biocrude production costs and the type of process used. Rapid pyrolysis concepts had the lowest cost, and high pressure liquefaction approaches were consistently more costly. The production costs for the biocrude liquids was compared to the cost of fuel oil at the time, $\$ 6.90 \mathrm{US} / \mathrm{GJ}$. The ratio of the production cost to the product value for the rapid pyrolysis processes ranged from about 1.3 to 1.8 for the most optimistic to most pessimistic cases while that for the high pressure systems ranged from 1.9 to about 3.5. The differences arise from the higher capital costs and lower overall conversion efficiencies of the high pressure processes.

Phase 2 - In the second phase of work between 1984 and 1987, the liquefaction activity continued technoeconomic analysis work and focused its efforts on systems where the biomass would first be converted to biocrude and then upgraded to hydrocarbon fuels. The work from Phase 1 was updated and used as the basis for producing biocrude. The study examined both an atmospheric rapid pyrolysis process and a pressurized liquefaction process to produce biocrudes which were then hydrotreated to a gasoline product. The hydrotreating was based on the type of process suggested by PNL. Analyses were prepared for "present" cases using only actually obtained yield data and for "potential" cases using best estimates of yields and processes which would be available as a result of additional research. Calculated costs were compared to average wholesale costs of gasoline at the time, $\$ 8.60$ US/GJ. The ratio of the production cost to the market value of the gasoline for the "potential" case was found to be 1.5 for the rapid pyrolysis process with wood and 1.8 for the high pressure process. Again, the gasoline from biomass was more expensive than gasoline from petroleum, and that from the high pressure process was more costly than from rapid pyrolysis. In later work, the activity also analyzed the production of gasoline using rapid pyrolysis and zeolite upgrading, as proposed by NREL. Under similar economic assumptions as the hydrotreating case, the ratio of the cost of producing gasoline to its value was about 1.05 
for the "potential" case. Within the uncertainty of the analysis, this was the same as the then-current cost of gasoline.

The results suggest that gasoline could potentially be produced from biomass at approximately the same costs as producing gasoline from petroleum, using the rapid pyrolysis process coupled with zeolite upgrading. While the analyses were performed in detail and with an emphasis on consistency, the results must be interpreted carefully. The "potential" cases are based on the assumptions that process improvements will be made and that certain processing steps will work at large scale. The liquefaction activity critically examined these assumptions and included them only if the assumptions appeared to have a very good probability of being realized. However, some of the yields and processing steps for the potential cases have not been demonstrated in practice, and there is uncertainty in the results. Other analyses done on a slightly different basis, as described in Chapter 5 of this report, have suggested that the hydrotreating of rapid pyrolysis oils may be more cost effective that zeolite upgrading.

The participation in the IEA liquefaction activity yielded many benefits for the BTC Program. Because the costs were shared, the BTC Program paid only about $20 \%$ of the costs of preparing the technoeconomic analyses. The improved information exchange and the adoption of better analytical methods also had important, less quantifiable benefits.

Current Status: Beginning in 1992, the activity changed the focus of its work toward analysis of advanced power generation systems. The analyses of several systems will be published in early 1995.

\section{Selected References:}

Y. Solantuasta, et al. 1992. "Assessment of Liquefaction and Pyrolysis Systems." Biomass and Bioenergy, Vol. 2, Nos. 1-6, pp. 279-297. Great Britain.

Elliot, D.C., et al. 1990. "Technoeconomic Assessment of Direct Biomass Liquefaction to Transportation Fuels." In Forestry, Forest Biomass, and Biomass Conversion: The IEA Bioenergy Agreement (1986-1989) Summary Reports, p. 251, eds. C.P. Mitchell, L. Zsuffa, S. Anderson, and D.J. Stevens. Elsevier Applied Science, London.

Diebold, J.P., et al. 1990. "IEA Technoeconomic Analysis of the Thermochemical Conversion of Biomass to Gasoline by the NREL Process." Advances in Thermochemical Biomass Conversion, Vol. 2, Bridgwater, A.V., ed., pp. 1325-1342. Blackie Academic \& Professional Press, London.

Beckman, D., et al. 1990. Techno-Economic Assessment of Selected Biomass Liquefaction Processes. Research Rept. \#697, Technical Research Centre of Finland, Espoo, Finland.

Pacific Northwest Laboratory. 1988. IEA Co-Operative Project DI Biomass Liquefaction Test Facility Project, Vols. 1-5. DOE/NBM--1062, NTIS, Springfield, VA. 


\subsection{SUMMARY AND RECOMMENDATIONS - PYROLYSIS AND LIQUEFACTION}

\subsubsection{Summary of Pyrolysis/Liquefaction Accomplishments}

The BTC Program successfully developed concepts to produce hydrocarbon fuels from biomass and significantly helped improve the basic understanding of pyrolytic processes. A summary of major accomplishments is listed below:

- The BTC Program sponsored basic research which contributed significantly to the development of a better understanding of biomass pyrolysis processes.

As indicated throughout this chapter, biomass pyrolysis mechanisms were poorly understood in the 1970's. The influence of pyrolytic reactions in a variety of thermochemical conversion systems was not realized, and this lack of understanding sometimes resulted in use of inefficient processes. Throughout the early 1980 's, basic research led to a much clearer understanding of the detailed reactions which occur when biomass pyrolyzes. Many programs such as NSF were involved in this effort, but the BTC Program was a major developer of basic information on biomass pyrolysis.

The basic research has shown that biomass first depolymerizes at moderate temperatures to form primary oils. These oils can be collected as liquids or, depending on the severity of reaction, be further reacted. Under certain conditions, the oils can be cracked to permanent gases, while under other conditions, the intermediates condense to form char. This allows thermal conversion processes to be optimized for the production of a variety of liquid, gaseous, or solid fuels from biomass by selection of appropriate reaction conditions.

The information from the basic research has had substantial practical impact on the thermal conversion technologies, and has allowed actual systems to be designed for improved operation. For instance, the reactions which sometimes lead to tar formation and plugging in biomass feeders can be avoided by designing systems which rapidly inject biomass into the reactors. The improved understanding of biomass pyrolysis and its role in a variety of thermal conversion processes is a major accomplishment of the BTC Program.

- The BTC Program successfully developed processes which are capable of producing hydrocarbon fuels from biomass which are essentially the same as gasoline from petroleum. The hydrocarbon fuels can be produced at costs competitive with other liquid fuels from biomass.

The program developed rapid pyrolysis and high pressure processes for producing a biocrude oils from biomass. These products are chemically quite different from 
petroleum crude oils, and the methods to upgrade them to hydrocarbon fuels are also different. The program developed hydrotreating and zeolite catalysts, which can be used to convert the crude product to a gasoline transportation fuel.

The rapid pyrolysis processes generate the highest yields of liquid products and are the most efficient based on the energy in the liquid product. In addition, these systems are the simplest, a variety of reactor types can be used to produce the product, and the cost of producing the biocrude is low. High pressure systems are more costly, and the overall efficiency of conversion is less. The high pressure product can be upgraded by hydrotreating techniques, but the cost of the product exceeds its value by a multiple of about 1.8. The rapid pyrolysis oils can be upgraded using either zeolite catalysts or hydrotreating techniques. Analyses provided by the IEA suggest that the zeolite process is more cost effective, while analyses by SAIC, as described in Chapter 5 , suggest the opposite. It appears to the author that the zeolite has the potential for lower costs if sufficient research progress can be made.

In either case, production costs for the biomass gasoline product are estimated to be about the same as producing gasoline from petroleum at $\$ 20 \mathrm{US} / \mathrm{bbl}$, based on feedstock costs of $\$ 42 /$ ton. This cost is roughly the same as producing oxygenates such as ethanol or methanol from biomass. The hydrocarbon fuels represent an alternative to oxygenates if the emphasis of DOE once again changes in the future.

- The technology developed by the BTC Program is being commercialized by industry for use in making chemical and other high value products.

Interchem with technical support form NREL is currently scaling up a rapid pyrolysis reactor based on the NREL design. The project will generate products including mixed phenolics for chemical use and char. The test facility will convert about 36 tpd of wood.

It is interesting to note that commercial implementation of rapid pyrolysis technology is also underway in Canada based on a design sponsored by that county's national program. It appears that the technology will initially be used for producing higher value products from biomass, and that fuel production will be a much longer-term objective.

- The BTC Program developed unique methods to analyze the liquid product from biomass thermochemical conversion processes and provided a comprehensive characterization of the liquid products.

The BTC Program provided a comprehensive characterization of the liquid products from various pyrolysis and gasification processes. The analyses were performed by specially adapting conventional analytical methods to biomass products and by developing new techniques. PNL, for instance, has developed a large library of gas chromatography/mass spectrometric traces for identifying 
the chemicals in biomass liquids. NREL developed mass spectrometric methods to rapidly characterize the products. The work by the BTC Program provided the first and, to date, the most complete characterization of these products.

The characterization efforts contributed significantly to the general understanding of biomass pyrolysis mechanisms, and there have been practical applications of this knowledge. For instance, the severity. of the reaction conditions will determine the mix of chemical constituents in the product. This information can be used to predict the type of products which will be produced in a reactor. Likewise, the characterization of products can be used to confirm whether a reactor is indeed working at design temperatures.

The BTC program also completed the first comprehensive tests on the biological mutagenicity of the liquids from biomass reactors. The results showed that the highly condensed PAH-containing tars produced under the most severe reactions have some mutagenic activity above background, but that the products from lower temperature reactors are not mutagenic. The PAH production is maximized at temperatures between $800-900{ }^{\circ} \mathrm{C}$, and application of processes operating at or above those ranges should consider including techniques to reduce or eliminate unwanted tar streams.

- The BTC Program benefitted significantly from its active participation in the IEA liquefaction activity.

The IEA liquefaction activity provided many benefits to the BTC Program. Effective information exchange made it possible to maximize the productivity of DOE funds by pursuing only the most promising research ideas. The establishment of standardized analytical protocols improved the quality of data and facilitated comparisons of the results from the BTC Program with results of other researchers. The detailed technoeconomic analyses produced by this group were consistent and were objective due to the widespread international scrutiny of the work before it was published. Since the cost of preparing the analyses was spread among several countries, the USA paid only about $20 \%$ of the costs it would have borne to complete the analyses by itself. DOE participated actively in this activity, and this active participation was crucial in realizing the significant benefits from the cooperation.

\subsubsection{Recommendations}

- Additional research on the use of biocrude pyrolysis oils as fuels for gas turbine systems is needed. Gas turbine systems can be used to efficiently generate power. The use of liquid fuels offers several potential advantages. The liquid fuels have high energy densities, and they can be stored for reasonable periods of time. These characteristics allow the liquid product to be produced at sites near the source of biomass and then be transported to the end-use facility. The ability to store the liquid product is particularly important if short-rotation 
forestry is used to produce the biomass. In this case, harvesting may be limited to a several months per year, and the ability to store fuel as a liquid will be important.

There are several technical considerations which must be addressed if rapid pyrolysis liquids are to be used as turbine fuels. The combustion must be sufficiently complete to avoid soot formation and to meet air quality requirements. Since biomass oils are more reactive than petroleum products, special combustors may be necessary. More importantly, the pyrolysis oils contain ash which may vaporize during combustion. Gas turbines require the combustion products to be very clean, so hot-gas cleanup issues must be addressed. The hot gas cleanup issues for liquid fuels will be closely related to those for gasifier/gas turbine systems, and the research on both types of systems should be pursued.

- Through the BTC Program, a much better understanding of the mechanisms of biomass pyrolysis has been developed, and this information is available to the research community. The wider implications of the role of biomass pyrolysis in other thermal conversion processes, particularly gasification, are now much better understood, but that information has not been pulled together into a single comprehensive analysis. As indicated in Chapter 2, it would be useful to collect and summarize basic data in one reference volume which would include the role of pyrolysis mechanisms in gasification.

- The petroleum industry has chosen to reformulate gasoline rather than go entirely to oxygenated fuels. The process to upgrade liquid fuels from biomass can potentially be altered to produce a wide variety of hydrocarbon and partially oxygenated products which would resemble reformulated gasoline. Research should examine whether a product resembling reformulated gasoline can be produced from rapid pyrolysis oils and what its cost would be. The product would likely contain some oxygenates from the biomass which were not converted all the way to hydrocarbons. Preliminary indications suggest costs would be less than upgrading all the way to a conventional gasoline product. Rapid pyrolysis is the most energy efficient way to generate liquid transportation fuels, and these high efficiencies should be exploited.

- It appears that the advanced biomass pyrolysis technologies will first be commercially used to produce higher value energy and chemical products. Industries in the USA and Canada are commercializing rapid pyrolysis technologies for these purposes. DOE should continue to be involved with these processes to benefit from advances that will be made.

- There is extensive ongoing international research and development of biomass pyrolysis technology and the use of biomass liquids for power generation. Some of this work is very sophisticated and may lead to state-of-the-art conversion technologies. DOE should continue to use various international agreements 
including IEA, bi-lateral and tri-lateral agreements, and other means to gain as much benefit as possible from the international efforts.

- Pyrolysis processes to generate charcoal have been commercially available for many decades, and additional research in this area is not needed. 


\subsection{COMBUSTION RESEARCH}

Although the major emphasis of the BTC Program was on biomass gasification and pyrolysis/liquefaction, the program also conducted limited research on innovative combustion concepts. Biomass combustion technologies are commercially available for a variety of uses. More than $99 \%$ of the $3.5 \mathrm{EJ}$ of biomass energy generated annually in the United States is from combustion. In most situations, the heat from biomass combustion is used to meet processing needs, and in some cases, the heat is used to generate electricity. The biomass-based electrical generation capacity in the United States is currently about $8000 \mathrm{MW}$. The research funded by the BTC Program was focused on unique innovative combustion applications where improvements in the technology could lead to new opportunities for biomass use.

\subsection{COMBUSTION RESEARCH EMPHASIS}

The major focus of the BTC Program combustion research was to expand the use of biomass fuels into applications where they had not previously been used. Most of this work centered on the use of biomass to power a gas turbine system for electricity generation. Typically, gas turbine systems are powered with natural gas or liquid fuels from petroleum. The ability to use solid biomass fuels in these systems offered the potential for efficient, low cost power generation from biomass. The largest amount of effort in the combustion area was directed toward research to determine the feasibility of operating direct combustion/gas turbine systems. This effort was headed by Aerospace Research Corporation.

In addition to the work with gas turbines, the program sponsored research to determine the feasibility of using biomass to power Stirling heat engines. The Stirling engines are very efficient and can potentially be used for small-scale power generation. Other work funded by the program included a basic study of combustion behavior. The combustion research sponsored by the BTC Program is summarized in Table 4.1 below.

\subsection{BIOMASS FUELED GAS TURBINE RESEARCH}

At present, most electricity is generated by combustion/steam turbine processes. Combustion provides heat to generate steam, and the steam is then used as a working fluid in a steam turbine to power an electrical generator. The necessity to generate a steam intermediate reduces process efficiency. 
Table 4.1 Biomass Combustion Research Projects

\begin{tabular}{||l|l|}
\hline TECHNOLOGY AREA & INSTITUTION \\
\hline Biomass Combustion & \\
\hline Biomass Fueled Gas Turbine Research & \\
Direct Combustion/Gas Turbine System & Aerospace Research Corp. \\
Pyrolysis Oil Testing for Gas Turbines & Teledyne Corp. \\
Other Combustion Projects & \\
Biomass Fueled Stirling Engine & United Stirling, AB \\
Basic Studies of Biomass Combustion & Jet Propulsion Laboratory \\
\hline
\end{tabular}

By comparison, gas turbine systems use the hot combustion gases themselves as a working fluid to drive the turbine, eliminating the need for the steam intermediate. This allows gas turbine systems to have high operating efficiencies. Gas turbine engines are commonly used in aircraft, and in some power generation facilities. Since the combustion gases must be very clean to be used with turbines, these systems are presently operated using natural gas or clean petroleum distillate fuels. The ability to use biomass to fuel these high efficiency turbines could reduce the cost of producing electricity from biomass.

The primary combustion research sponsored by the BTC Program was to test the feasibility of using solid biomass to power a gas turbine for electricity generation. Biomass was burned, and the hot gases were passed through a turbine which drove a generator. In addition, the program funded very limited research to test the feasibility of using biomass pyrolysis oils to fuel gas turbines. The work with the pyrolysis oils was conducted in a test facility rather than an actual turbine. These projects are discussed below.

\subsubsection{Direct Combustion/Gas Turbine System - Aerospace Research Corp.}

\section{Principal Investigator: J. T. Hamrick}

Project Objective: The objective of this project was to determine the feasibility of using solid biomass fuels to generate electricity using a gas turbine system. Aerospace Research Corp. conducted the work in phases. Initially, a research system using a biomass combustor coupled with $300 \mathrm{~kW}$ turbine was designed and operated in Roanoke, Virginia. The facility successfully produced electricity and provided critical engineering data on the process. Later, a larger $3 \mathrm{MW}$ system was constructed, tested in Roanoke, then transported to Red Boiling Springs, Tennessee for operation. The larger unit was connected to the electrical grid and provided data on a commercial scale facility. 
Wood feedstocks were used in both turbine systems, and a few tests with manure as a feedstock were performed with the smaller $300 \mathrm{~kW}$ system. Support research to characterize the combustion gases and the ash content of ash deposits in the turbine was provided by Battelle Columbus Laboratory.

Summary of Research Project and Results: The basic combustion/gas turbine concept proposed by Aerospace Research Corp. is shown in Figure 4.1. Biomass was fed to a pressurized combustor where it was burned with air, and the hot combustion gases passed through cleanup cyclones which removed particulates. The combustion gases were then fed directly to the turbine which converted the energy of the hot, pressurized gas stream to rotational shaft energy. Part of the energy from the turbine was used to drive an electrical generator, while part was used to compress additional combustion air.

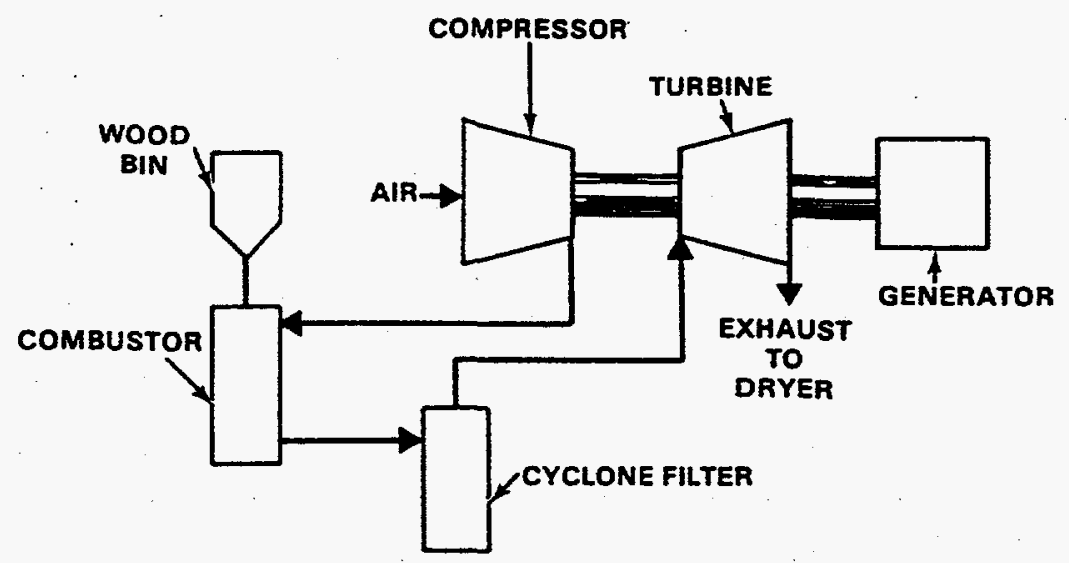

Figure 4.1 Schematic Diagram of the Aerospace Combustion/Gas Turbine Concept.

Aerospace Research Corp. conducted research with two different systems rated at about $300 \mathrm{~kW}$ and $3 \mathrm{MW}$ as described below.

Phase 1: $300 \mathrm{~kW}$ Combustor/Gas Turbine System. Work began in 1980 on a $3 \mathrm{~kW}$ research system which could be used to obtain engineering and operational data on the turbine concept. In this system, wood sawdust up to $1 \mathrm{~cm}$ was fed through a rotary valve system to a vertical combustor. The combustor was approximately $6.4 \mathrm{~m}$ in length, and used turbulent flow to achieve complete combustion of the biomass. The gases passed through cyclone filters to remove particulates. At first, three cyclones in series were used, but one was later found to be unnecessary and was removed. The combustor design limited turbine inlet temperatures to about $785^{\circ} \mathrm{C}$.

The hot combustion gases from the cyclones passed to a modified Garrett IE831-200 gas turbine which had been donated to the project by the U.S. Air Force. The turbine was rated at approximately $300 \mathrm{~kW}$ in this system. The original oil-fired combustor in the turbine was removed and replaced with steel ducting to transfer hot gases from the combustor. Ducting was also added to transfer fresh compressed air to the combustor. Safety vents were installed to protect the turbine from excessively high speeds in the event of loss of load. 
At the time, many experts involved with gas turbines predicted that the particulate material in the gas stream would be excessive and cause extensive erosion of the turbine blades. Measurements of the particulates entering the $300 \mathrm{~kW}$ turbine were made by Battelle Columbus Laboratory. Particulate loadings were in the range of 0.004 to $0.006 \mathrm{gr} / \mathrm{dscf}$ with $80-90 \%$ of the material less than 0.5 microns in diameter. These particulate loadings met the requirements for turbine operation and suggested that particulates from the biomass would not be a major problem in the system, at least at the inlet temperatures used in the tests.

The $300 \mathrm{~kW}$ system operated successfully with wood sawdust for more than 570 hours at speeds of 14,500 to $35,000 \mathrm{rpm}$. After the first $210 \mathrm{hr}$, the turbine was disassembled, and the turbine blades were examined. A light powdery deposit was found on the stators and turbine blades which could easily be removed. No detectable erosion or corrosion was found. A second turbine was also successfully operated with wood for an additional $365 \mathrm{hr}$. The much-feared problem of turbine erosion was, in fact, not an issue.

It must be strongly noted that the successful operation of the $300 \mathrm{~kW}$ system occurred with turbine inlet temperatures ranging from $650-785^{\circ} \mathrm{C}$. The design of the system feeder and combustor limited the temperature of the gas entering the turbine to $785{ }^{\circ} \mathrm{C}$. While it was recognized that commercial turbines would operate at inlet temperatures of $925-980{ }^{\circ} \mathrm{C}$, it was assumed at the time that the main difference between the operation at high and low temperature would be a corresponding loss of efficiency. The efficiency loss was felt to be acceptable in order to gather the necessary engineering data, including information on turbine blade erosion.

As the work with the larger $3 \mathrm{MW}$ unit showed, however, there were much more critical differences between high and low temperature operation. At temperatures above $815^{\circ} \mathrm{C}$, problems with ash vaporization and deposition caused major operational problems in the larger system, and would have caused similar problems in the $300 \mathrm{~kW}$ turbine if the inlet temperatures had been higher. Thus, the relatively successful operation of the $300 \mathrm{~kW}$ unit must be considered relative to the temperature limitations.

Limited testing of the $300 \mathrm{~kW}$ system with manure as feedstock were also conducted. In these tests, the ash from manure rapidly slagged in the combustor section and coated the combustor walls. In addition, the particulates entering the turbine exceeded that specifications for the unit. The turbine operated a total of about 20 hours using this feedstock, and the results showed that the problems with ash were greatly compounded when manure rather than wood was used.

Phase 2: $3 \mathrm{MW}$ Combustor/Gas Turbine System. Following the operation of the smaller unit, Aerospace Research designed and built a $3 \mathrm{MW}$ system based on a General Motors-Allison T-56 gas turbine. Funds for this work were provided by both the BTC Program and private investors, and Allison donated the use of a $3 \mathrm{MW}$ turbine to the project. The unit was assembled and tested at the Aerospace Research facility in Roanoke, Virginia, and them moved to Red Boiling Springs, Tennessee for operational testing. Contracts with Tennessee Valley Authority were obtained with the intent to sell electricity to the regional electricity grid. 
The design of the $3 \mathrm{MW}$ system was conceptually similar to the smaller one. Coarse sawdust was fed through a pair of rotary feeders to a combustor. The larger combustor consisted of two sections to allow for more complete combustion of the wood, Water could be added in the secondary combustor to increase the volume of gas entering the turbine and therefore increase its efficiency. The hot combustion gases then passed through two cyclone filters to remove particulates.

The $3 \mathrm{MW}$ system used a modified T-56 gas turbine. As with the smaller system, the original turbine combustion chambers were removed and replaced with ducting to both bring hot gases to the turbine and to provide compressed air for the combustor. The ducting for the $3 \mathrm{MW}$ system used a more efficient design where the compressed air and the combustion gases passed through concentric pipes. The turbine was started with an automotive engine adapted for the purpose. The turbine powered an electrical generator which provided electricity to the TVA grid.

The system operated for total of 760 hours and generated power to the TVA electrical grid for over 100 hours, thus becoming the first biomass-based gas turbine system to produce significant amounts of electricity. Measurements of emissions from the turbine were made by Battelle Columbus Laboratory. Particulate loadings at the turbine inlet were typically $0.017 \mathrm{gr} / \mathrm{dscf}$, with $77 \%$ of the material less than 1.2 microns in diameter and $100 \%$ less that 2.6 microns. Based on rule-of-thumb guidelines of less that $5 \mathrm{ppm}$ particles greater than 5 microns in diameter, the particulate loadings met turbine specifications. The gaseous emissions of nitrogen oxides and sulfur dioxide from the system were lower than EPA standards, while carbon monoxide emissions exceeded the guidelines. The high $\mathrm{CO}$ levels may have been the result of a leak in the system which was later fixed.

Despite this progress, numerous operational and technical problems were encountered with the $3 \mathrm{MW}$ system. The operational problems arose in part because this was a firstof-a-kind unit and in part because the project had limited funding. For instance, limited funding led to the use of an automotive engine to start the turbine rather than a more sophisticated starter system specifically designed for gas turbines.

Far more serious were problems with ash deposition which imposed significant temperature limitations on the system. The T-56 turbine was designed for operation with a maximum $925^{\circ} \mathrm{C}$ inlet temperature, and would normally operate near this limit to achieve high efficiency. In the $3 \mathrm{MW}$ system, however, operation was limited to inlet temperatures of about $800^{\circ} \mathrm{C}$. Above $815^{\circ} \mathrm{C}$, a glassy ash material rapidly deposited on the turbine blades, preventing further operation. At temperatures below about $800^{\circ} \mathrm{C}$, the turbine operated successfully for periods of about 26 hours before deposits on the turbine blades lowered efficiencies. The deposits could be cleaned by either passing a stream of milled walnut shells or a high pressure water spray through the turbine. It was estimated that a thorough disassembly and cleaning of the turbine would be required after about 180 hours. Thus, despite the fact that total particulate loadings met turbine requirements, the ash deposition imposed very serious temperature limitations. 
It must be noted that many turbine experts and a turbine manufacturer were involved in the project. Allison, for example, donated the use of a $3 \mathrm{MW}$ turbine to the project. While experts at the time predicted possible turbine blade erosion from particulates and corrosion from alkali, no one forsaw the ash deposition problem. Identification of this problem has resulted in extensive research on ash deposition mechanisms by the current DOE program.

At the time, it was not clear whether the small particles of ash simply softened and stuck to the blades or whether the ash actually vaporized in the combustor and then condensed on the blades as it cooled in the expanding gas stream. Battelle Columbus performed limited tests with a bench scale combustion simulator and performed elemental analysis on the deposited ash. This research gave preliminary indications that ash vaporization was involved. Since the end of the BTC Program in 1989, other research has shown that certain eutectic mixtures of alkali salts vaporize at temperatures of about $815^{\circ} \mathrm{C}$ and will condense in cool areas of combustion systems.

The ash deposition problem has significant implications for the direct combustion/gas turbine system, as well as broader implications for biomass thermochemical conversion. The combustion/turbine systems will either have to be operated at lower temperatures than desired $\left(785^{\circ} \mathrm{C}\right)$, or other means to reduce the vaporization must be developed. Work at Battelle Columbus suggested that additives such as lime could eliminate the ash deposition, and some other combustion systems use additives to control ash behavior. This approach may offer potential to solving the ash problem. The use of gasification/ turbine systems rather than combustion/turbines is also being currently considered. The fuel gas product can potentially be cleaned prior to use in the turbine. However, the problem of ash deposition in advanced thermal conversion systems must be considered carefully. The problem is particularly crucial when feedstocks such as straw or other agricultural wastes are used, and additional research on ash deposition is needed.

Current Status: The research with the gas turbine system not only produced the first electricity from biomass in this type of system, but also helped identify a major problem with ash deposition in advanced systems. As a result of this effort, the current DOE program at NREL is conducting additional research on ash deposition and on ways to used biomass gasifiers with gas turbines.

The main effort with the $3 \mathrm{MW}$ system at Red Boiling Springs, Tennessee ended in 1989 , and limited work has continued with private funds.

\section{Selected References:}

Aerospace Research Corporation. 1991. Development of Biomass as an Altermative Fuel for Gas Turbines. PNL-7673, Pacific Northwest Laboratory, Richland, Washington.

Hamrick, J.T. 1988. Evaluation of Manure as a Feedstock for Gas Turbines. PNL-6565, Pacific Northwest Laboratory, Richland, Washington. 


\subsubsection{Pyrolysis Oil Testing for Gas Turbines - Teledyne CAE}

\section{Principal Investigator: Teledyne CAE}

Project Objective: In the late 1970's, DOE funded Teledyne to determine the feasibility of using pyrolysis oil or mixtures of pyrolysis oil and char to power gas turbine engines. Teledyne evaluated the behavior of the oil and oil/char fuels in a test rig which closely simulated the conditions in an actual turbine. The fuels were burned in combustors similar to those in a turbine, and the hot gases impinged upon blades from a turbine which were mounted in a stationary position. The test rig allowed the combustion efficiencies of the fuels to be determined and allowed the effects of erosion and deposition on the blades to be studied. In 1982, the project was transferred to the BTC Program just as the project was being completed.

Summary of Research Project and Results: The Teledyne turbine test rig had been developed to simulate conditions which would be found in the Teledyne model J69-T-29 aircraft engine. The test rig consisted of a highly instrumented combustor system similar in concept to that from the aircraft engine. In the test rig, the compressor and turbine sections had been removed, and the product gases were ducted so they would impinge upon turbine blades mounted in a stationary frame.

Pyrolysis oils were obtained from several sources, including the Energy Resources Company of Cambridge Massachusetts, the Engineering and Experiment Station at Georgia Institute of Technology, the State of California, and Midland-Ross Corp. of Toledo, Ohio. Typical elemental analysis of the pyrolysis oils showed they contained $62 \%$ carbon, $6.7 \%$ hydrogen, and $29 \%$ oxygen. The oils were somewhat similar to the products from the GTRI entrained rapid pyrolysis unit discussed in Chapter 3.0 of this report, but more detailed analysis was not performed.

The tests showed that pyrolysis oils could be burned for several hour periods in the test rig with combustion efficiencies of about $99 \%$. The oils could be used either by themselves or as a supplement to petroleum fuels. The fuel injection device in the system, however, was unable to handle mixtures of pyrolysis oil and chars. The use of the mixed fuel resulted in an unstable flame which would "blow out" within a few minutes. Teledyne recommended that additional work on the fuel system components would be required to deal with the acidic nature of the pyrolysis product which was used.

Teledyne did not find evidence of erosion on the stationary turbine blades mounted downstream from the combustor, but solid deposits formed on the leading edge of all samples. Detailed analysis of the deposits were not made, but Teledyne described them as "slag buildup."

Current Status: While the combustor itself appeared to work well with the pyrolysis oils, it is evident that there was sufficient ash in the oil to cause potential problems. In the early 1980's, the possibility of turbine blade erosion was considered to be a major issue, but the issue of ash deposition was not understood or even generally recognized. In fact, erosion does not appear to be significant, but ash deposition is a major problem. If 
pyrolysis oils are to be used successfully in future gas turbines, the issue of ash deposition must be addressed in detail.

The research at Teledyne ended in 1982. World-wide interest in using pyrolysis oils for gas turbine fuels has continued for more than a decade and seems to be increasing at present. To date, however, the issue of potential ash deposition from the use of these fuels has not been addressed, nor has the problem been solved.

\section{Selected References:}

Jasas, G., J. Kasper, and R. Trauth. 1983. Gas Turbine Demonstration of PyrolysisDerived Fuels Final Technical Report for the Period September 1978 Through June 1982. Contract DE-AC03-78ET13333, U.S. Department of Energy, Washington, D.C.

Teledyne CAE. 1982. "Gas Turbine Demonstration of Pyrolysis-Derived Fuels." In Proceedings of the 14th Biomass Thermochemical Conversion Contractor's Meeting, Arlington, Virginia, June 23-24, 1982, pp. 487-545. CONF-820685, Pacific Northwest Laboratory, Richland, Washington.

\subsection{OTHER COMBUSTION PROJECTS}

The BTC Program also sponsored two additional combustion research projects. These included work to fuel Stirling heat engines with biomass, and basic research on biomass combustion. These projects are discussed below.

\subsubsection{Biomass Fueled Stirling Engine - United Stirling, Inc.}

\section{Principal Investigator: Worth Percival}

Project Objective: The objective of this research was to determine the feasibility of using biomass as a fuel for Stirling engines. Stirling engines are external, rather than internal, combustion engines. Instead of burning fuel inside the engine to drive pistons, the Stirling engines transfer heat from external sources to inert gases inside the engine. The inert gases serve as working fluids, and the expansion and contraction of the inert gases as they are heated and cooled drives pistons inside the Stirling engine. The engines have the potential for higher operating efficiencies than conventional internal combustion engines.

In 1982 when the work started, the development of the Stirling engine concept had reached the near-commercial stage. The use of biomass as a fuel appeared to offer advantages since the engine needed only a source of heat. Biomass could be burned, and the hot gases could be used to drive the engine. Stirling engines could be produced in several sizes (with outputs similar to smaller automotive engines) and would be appropriate for small scale power generation and similar applications. 
Summary of Research Project and Results: United Stirling, Inc., built and tested a biomass combustor coupled to a $20-\mathrm{kW}$ engine manufactured by its parent organization, United Stirling, AB, of Sweden. A two-stage combustor design was chosen for the system. Biomass was gasified with air in the first stage of the combustor, and the gases were burned in the closely coupled second stage. By gasifying at relatively low temperatures in the first stage, the problems of solid ash handling could be minimized, and the product gases could be burned completely in the second stage. The two stage system also allowed better regulation of the temperature of the combustion gases, which had to be a maximum of $700-750{ }^{\circ} \mathrm{C}$ in order to meet engine specifications.

Two different concepts were considered for the first stage of the combustor, including a cyclone and a stoker type gasifier. Preliminary tests of a cyclone gasifier built by United Stirling were made, and while the system showed promise, additional development work would have been necessary. As a result, an updraft, air-blown rotating grate stoker type gasifier was used for the tests with the engine. Wood was fed onto a rotating grate where it was gasified. Ash was removed from the bottom of the gasifier. The product gases flowed upward to a closely coupled second stage combustor where they were burned with excess air. The hot combustion gases then passed through the heat exchanger of the Stirling engine, which was mounted directly above the second stage combustor. The heat exchanger consisted of a series of small tubes separated by distances of about $2 \mathrm{~mm}$. The temperature of the hot gases entering the heat exchanger were maintained at about $750{ }^{\circ} \mathrm{C}$ by controlling the amount of air which passed through the stoker grate.

In total, the combustor/engine system operated for approximately $100 \mathrm{hr}$ on biomass fuel. For some of the tests, the engine was connected to an alternator to produce electricity. Conversion efficiencies for wood-to-shaft and wood-to-electricity outputs were measured to be about $16 \%$ and $20 \%$ respectively, although there was not sufficient time to optimize the system performance.

The system experienced operational problems such as air leaks which were mostly solved during the course of the tests. However, technical problems with ash deposition on the heat exchanger were far more serious. As the tests proceeded, a layer of glassy material was deposited on the heat exchanger tubes. The material not only reduced the efficiency of heat transfer but also tended to cause plugging in the $2 \mathrm{~mm}$ space between the exchanger tubes. The material was glass-like in nature and could not be cleaned from the surfaces. Apparently, the same type of ash deposition mechanisms which occurred in the Aerospace gas turbine also occurred in this system, even though the temperatures at the Stirling heat exchanger were lower. It may be possible to use other types combustors with Stirling engines, but in any case the hot combustion gases would have to be thoroughly cleaned.

Current Status: The work at United Stirling ended in 1983. The development of Stirling engine technology for conventional fuels has continued for more than a decade, but there has not been significant use of the engines in commercial situations. Interest in biomasspowered Stirling engines for small-scale electricity generation systems has recently been 
expressed in Europe, but the technical problems of ash deposition in these systems have not been resolved.

Selected References:

Percival, W.H., S. Gummesson, and B. Hansson. 1983. "Biomass Fueled Stirling Engine Combustor Research." In Proceedings of the 15th Biomass Thermochemical Conversion Contractors' Meeting, pp. 284-299. CONF-830323, Pacific Northwest Laboratory, Richland, Washington.

Percival, W.H. and B. Hansson. 1982. "Biomass Fueled Stirling Engine System Research and Development." In Proceedings of the 14th Biomass Thermochemical Conversion Contractors' Meeting, pp. 546-568. CONF-820685, Pacific Northwest Laboratory, Richland, Washington.

\subsubsection{Basic Studies of Biomass Combustion - Jet Propulsion Laboratory (JPL)}

\section{Principal Investigator: Kumar Ramohalli}

Project Objective: Jet Propulsion Laboratory conducted basic research with the intent of developing more efficient, cleaner ways to burn biomass. Initially, four phases of investigation were proposed. These included the development of a theoretical model to describe combustion behavior, validation of the model with experimental tests, investigation of the effects of inorganic additives on biomass combustion, and the testing of concepts in a research combustor. Due to funding constraints, however, the work was terminated much earlier than originally planned and was limited primarily to the development of a theoretical model.

Summary of Research Project and Results: In combustion models of the time, biomass was frequently considered as a homogeneous solid, and the models were based on the pyrolysis and combustion processes which would occur with that type of substrate. JPL developed a model based on the assumption that, as it burned, biomass was a heterogeneous solid consisting of fresh wood and char. The heterogeneity of the wood arose from differential rates of combustion of the cellulose and lignin. The cellulosic fractions of the biomass fiber volatilized most rapidly, leaving a lignin framework which led to char formation. The JPL model attempted to predict reaction behavior based on a substrate which contained both cellulosic and char (from lignin).

A preliminary mathematical model was developed that could, in part, account for the heterogeneous nature of wood. The model allowed burning rates to be calculated as a function of reaction temperature. Comparisons of calculated and actual combustion data showed that the model was reasonably accurate in situations where wood was partially burned, but the model was less predictive of the behavior of either fresh wood or char combustion. Reductions in program funding at the time prevented a more comprehensive model from being developed. 
In addition to the modeling work, JPL conducted a limited amount of experimental research to determine the effects of inorganic additives on combustion behavior. The intent of this work was to develop methods which allow inorganic materials to be added to biomass to reduce biomass combustion emissions. Experimental tests were performed to compare the combustion behavior of wood treated with calcium acetate to that of untreated wood. Wood dowels with a $2.5 \mathrm{~cm}$ diameter and $5 \mathrm{~cm}$ length were prepared and some were soaked for a 30-day period in 0.5 mole\% solution of calcium acetate. The samples were dried, six $0.005 \mathrm{~cm}$ diameter wire thermocouples were inserted in the dowels at approximate $1 \mathrm{~mm}$ intervals from the surface, and the samples were then mounted in the furnace system. The furnace was heated to as high as $1000^{\circ} \mathrm{C}$ and then lowered rapidly so that it surrounded the ambient temperature sample. The time required to heat the sample to its ignition point was measured, the reaction was terminated by removing the furnace, and the partially reacted samples were examined using an electron microscope. The ignition times were nearly identical for the untreated samples and those treated with calcium acetate. Electron micrographs showed there were qualitative differences in the char formation of the two materials, but the detailed nature of the effects of calcium acetate were not determined. The work was stopped in 1986 due to decreases in BTC Program funding.

Current Status: Although JPL is no longer conducting biomass combustion research, it should be noted that the effects of biomass additives on combustion behavior can be significant. For instance, biomass products are frequently treated with chemicals such as borax to make them more fire retardant. While the role of additives in this application is well understood, the potential influence of additives in other situations is largely undetermined. In the work at Battelle Columbus Laboratory related to the combustion gas turbine, for example, additives reduced ash vaporization and deposition in laboratory tests. It is possible that additives could play a more significant role in biomass combustion that they do at present.

Selected References:

Miller, C.A., J.S. Palmer, and K.N.R. Ramohalli. 1986. "Basic Research in Biomass Combustion." In Proceedings of the 1985 Biomass Thermochemical Conversion Contractors' Meeting, pp. 146-166. CONF-8510167, Pacific Northwest Laboratory, Richland, Washington.

Ramohalli, K.N.R. 1984. "Basic Research in Biomass Combustion." In Proceedings of the 16th Thermochemical Conversion Contractors' Meeting, pp. 269-286. CONF-8405157, Pacific Northwest Laboratory, Richland, Washington. 


\subsection{SUMMARY AND RECOMMENDATIONS - COMBUSTION}

\subsubsection{Summary of Combustion Accomplishments}

- The BTC Program research on biomass-fired gas turbine systems produced valuable information which has helped guide DOE's present program on gas turbines.

The research on the biomass powered gas turbine, while not successful, yielded important information. While experts at the time had predicted that erosion or corrosion of the turbine blades might be a problem, the research showed that these considerations were minor in comparison to ash vaporization and subsequent deposition in the system. The ash vaporization caused the formation of glassy deposits on the turbine blades when operating temperatures were above about $800^{\circ} \mathrm{C}$. The temperature limitations reduced turbine efficiency, although in some situations these limitations might be acceptable.

The project, while not successful in commercial implementation, was very helpful in providing the necessary background for the current development of biomass powered gas turbine technology. As a result of this this project, DOE has performed more extensive work on ash deposition mechanisms and their influence on advanced conversion systems. The work at Aerospace Research emphasized the need for a clean gas in the turbine, and developers of turbine systems which use gasifiers instead of direct combustion systems must not lose sight of this very crucial fact. The direct combustion turbines still offer the potential for high conversion efficiencies, and this potential for high operating efficiencies may merit longer term research.

- The combustion research sponsored by the BTC Program identified that ash deposition is a serious problem in systems using advanced technologies and that the problem must be carefully addressed in commercial scale units.

Ash deposition has long been recognized as a potential problem in many biomass combustion systems. In conventional systems such as boilers, the ash deposits can be periodically cleaned. While the cleaning increases production costs, the deposits generally do not threaten the viability of the technology.

For advanced technologies such as gas turbines or Stirling engines, even relatively small amounts of ash deposition can prevent systems from operating. In the more advanced technologies, the ash problems are not just a nuisance but make the technology unworkable. Future work on these types of systems must recognize and address the ash problem. This applies to both not only to combustion systems but also to those where biomass fuel gases or pyrolysis liquids are used. The work both at Teledyne on pyrolysis oils for turbines and the work at United Stirling with the two-stage gasifier/combustor showed that the ash deposition is a problem in those systems. 
Clearly, these systems had not been designed to address the ash problem, and better methods to reduce ash are being developed. Gas clean-up research, for instance, is currently being conducted to improve the fuel gases from biomass, and methods to reduce the ash in pyrolysis oils may be possible. It is critical, however, for system developers to note that ash deposition is potentially a significant problem in all advanced-technology applications of biomass thermal conversion processes. The problems must be addressed, or specific technologies will likely be unsuccessful.

\subsubsection{Recommendations}

- Additional research on a variety of topics related to ash deposition is needed. DOE should continue and expand work to study ash deposition mechanisms and to find methods to clean and condition fuel and combustion gases from biomass. This research is crucial to the implementation of advanced thermal conversion systems which are more sensitive to ash-related problems.

- Additional research on the use of additives to modify ash vaporization behavior is needed. Very preliminary results from the BTC Program suggest that inorganic additives can eliminate the eutectic salts which vaporize at low temperatures. 


\subsection{TECHNOECONOMIC ANALYSIS/SYSTEM STUDIES}

The BTC Program conducted ongoing technoeconomic and system analyses to help guide the development of the thermal conversion technologies. These types of analyses allowed the program to compare various process options and to identify areas where research could have the most beneficial impact in reducing conversion costs.

It must be remembered that technoeconomic analyses are simply mathematical models which predict the costs of products based on a set of assumptions for factors such as product yields, capital requirements, feedstock and operation costs, and others. The accuracy of the predicted costs are therefore only as good as the assumptions which have been made. For mature technologies with few unknowns, technoeconomic analyses can predict costs to within a few percent. However, for technologies which are being developed, the technoeconomic modeling is much less precise. Analyses based on only those results which have been actually demonstrated will not reflect the potential for future research advancements. Likewise, those which are based on anticipated results depend on research progress which may or may not be made. It is therefore important to deal with the analyses in context. The analyses can be very useful in identifying the areas where research progress can have greatest impact. However, direct comparison of figures between analyses done by different people or at different times must be made with extreme care.

\subsection{RESEARCH EMPHASIS}

At the start of the BTC Program in the early 1980's, the national concern over energy availability led to an emphasis on the rapid development of biomass technologies. Many of the researchers at the time individually prepared technoeconomic analyses of their gasification and liquefaction processes. These were prepared on inconsistent bases, frequently used the most optimistic assumptions available, and could not generally be directly compared. To provide more consistent analyses, the BTC Program funded SAIC International to perform a series of analyses on biomass gasification, liquefaction, and power generation technologies. The SAIC research provided a consistent set of financial and costing methodologies for the work, and the use of an outside, independent corporation reduced bias. Initially, analyses were prepared based on results which were available at the time ("present" cases), and later the analysis work was expanded to include process advancements which would be made in the future ("future" cases).

The BTC Program also funded Pyros, Inc. to produce a comprehensive analysis of the availability of wood for medium-scale conversion facilities. This work examined 
conventional forestry resources in the northeast and southeast United States. The study also examined possible infrastructural constraints on feedstock supply.

Prior to the start of the BTC Program, DOE had funded several comprehensive system studies to compare various biomass conversion technologies. These studies included work by SRI International to compare a range of thermal and biological technologies, work by Catalytica Corporation to examine catalytic processes in biomass and coal systems, and research by Gilbert/Commonwealth Corporation to study the feasibility of biomass gasification. These studies were essentially complete by 1980 when the BTC Program started, but are summarized briefly since they impacted on the program. A summary of these projects is shown in Table 5.1.

Table 5.1 Technoeconomic Analysis and Systems Studies Projects.

\begin{tabular}{|l|l|}
\hline TECHNOLOGY AREA & INSTITUTION \\
\hline Technoeconomic Analysis and Systems Studies & \\
\hline Technoeconomic Analyses & \\
$\begin{array}{l}\text { Technoeconomic Analysis of Advanced } \\
\text { Biomass Technologies Including } \\
\text { Gasification, Liquefaction, and Power }\end{array}$ & SAIC International \\
Production & \\
Systems Studies & \\
Assessment of Feedstock Availability & Pyros, Inc. \\
Solar Cost Data Bank & SRI International \\
Evaluation of Catalysis in Biomass and & Catalytica Associates, Inc. \\
Coal Conversion & \\
Research and Evaluation of Biomass & Gilbert/Commonwealth \\
Resources/Conversion/Utilization Systems & Associates, Inc. \\
\hline
\end{tabular}

\subsection{TECHNOECONOMIC ANALYSES}

The BTC program funded SAIC International to perform consistent technoeconomic analyses of various technologies. This work is described below.

\subsubsection{Technoeconomic Analysis of Advanced Biomass Technologies including Gasification, Liquefaction, and Power Generation - SAIC International}

Principal Investigator: Edward Wan 
Project Objective: The BTC Program funded SAIC International to perform a series of technoeconomic analyses on various topics. The purpose of the work was to provide consistent analyses to help guide the development of these technologies.

Summary of Research Project and Results: Between 1981 and 1988, SAIC performed a series of analyses on biomass gasification, power generation, and liquefaction technologies. In each case, SAIC prepared detailed process flowsheets and calculated detailed mass and energy balances. Capital estimates were then made for the systems based upon the costs of individual components required by the flowsheets. Operating and financing costs were also calculated, and the figures were then combined to give production costs. Sensitivity analysis for factors such as the influence of biomass feedstock cost was also performed. The first analysis dealt with gasification since that was the major area of program interest in the early 1980's.

Biomass Gasification for Methanol Production - The initial analysis by SAIC compared the costs of producing methanol from six gasification concepts which were being developed in the early 1980's. These six included technologies being developed by Battelle Columbus Laboratory, Wright-Malta Corporation, Pacific Northwest Laboratory, Institute of Gas Technology, Texas Tech University, and National Renewable Energy Laboratory. These gasification concepts are described in more detail in Chapter 2.0 of this report. In the SAIC analysis, the products from the gasifiers were cleaned and conditioned, and then converted to methanol using conventional technology.

The six gasification technologies were at different stages of development in the early 1980 's, and care had to be used in making process assumptions. SAIC based its flowsheets on processes which would be possible in a relatively short time, approximately five years. Where data from the biomass gasifiers was available, it was used directly, and assumptions were made where data was missing. The analysis was therefore based on technologies which were assumed to be ready for commercialization by the mid1980 's. As a result, the analysis was based on technologies which incorporated some improvements over the research gasifiers, but which were not necessarily the best that could be obtained if additional research were successful. To deal with the uncertainties, SAIC analyzed a total of eighteen individual process concepts based upon the six gasification technologies.

The analysis was based on the production of $500 \mathrm{tpd}$ of methanol, and feedstock requirements varied depending on the process. An analysis of a 100-tpd facility was also performed to determine the sensitivity of the system to plant size. Capital costs were based on mid-1982 estimates, and plant life was assumed to be 20 years. Costs were calculated for both utility and private financing scenarios. Sensitivities of varying feedstock costs between $\$ 25$ and $\$ 42 /$ ton were also calculated.

The cost of the gasification components of the systems varied widely depending on the process concept selected, but the costs of the overall systems varied much less. The costs of a gasifier similar to the unit at BCL were about $\$ 742,000$, while the costs for a system based on the Texas Tech technology were more than $\$ 2,000,000$. However, the total capital requirements for the complete system including components for feedstock 
preparation, gasification, and conversion to methanol were more closely grouped. Total capital costs ranged from \$82-124 million in the extreme, with typical values of \$95-105 million.

For biomass feedstock costs at $\$ 25 /$ ton, the methanol production costs ranged from $\$ 0.65-0.77 /$ gal for utility financing and from about $\$ 0.77-0.95 / \mathrm{gal}$ for private financing. The lowest costs were from pressurized gasifier systems, which reduced the cost of compressing the synthesis gas from the gasifier. Changing the size of the methanol plant from 500 to 100 tpd capacity increased methanol costs to the range $\$ 1.10-1.34 / \mathrm{gal}$ for utility financing. Increasing feedstock costs from $\$ 25 /$ ton to $\$ 42 /$ ton typically increased methanol production costs by $15-20 \%$ depending on the specific process.

The results showed that methanol production economics were sensitive to biomass gasifier design and that processes specifically designed for synthesis gas production offered economic advantages over those which were not. Pressurized systems, for example, may lower methanol costs. The results showed that methanol from biomass facilities would be competitive with methanol from coal in much larger scale facilities. The effect of scale is an important consideration in all biomass conversion systems, but the advantages of scale must be balanced with other factors such as the limitations on biomass availability. In recent years, analyses of systems up to about 10,000 tpd of biomass have been conducted by DOE on thermal and biological conversion systems, and these large systems have raised significant questions about biomass availability.

Pyrolysis for Liquid Hydrocarbon Fuels - SAIC also examined the economics of producing hydrocarbon fuels from biomass. Analyses were prepared for two cases, including one based on the NREL vortex pyrolyzer with zeolite upgrading and a second based upon the Georgia Tech pyrolyzer with upgrading through catalytic hydrotreating. In the NREL case, the vapors from the vortex reactor were upgraded directly to gasolinelike products. In the Georgia Tech case, the pyrolysis products were collected as liquids and then upgraded in a two-stage process similar to the concept used by PNL. SAIC produced analyses based both on presently available data (present case) and on systems thought to be possible with additional research (future case).

The analysis was performed for facilities using 1000 tpd of dry wood, and capital costs were estimated in terms of December, 1987 dollars. Capital costs for the Georgia Tech process ranged from about $\$ 95$ million for the present case to about $\$ 75$ million for the future case. This cost included the production of hydrogen for the hydrotreating step. The capital requirements for the NREL system were about $\$ 47$ million for each case. In the NREL process, the equipment would not change significantly from the present to the future, but yields of products would increase as a result of additional research.

SAIC calculated production costs of gasoline to be about $\$ 2.05 /$ gal for the 1987 case and about $\$ 0.96 /$ gal for the future case using the Georgia Tech/hydrotreating approach (utility financing). The costs for the gasoline from the NREL process were calculated to be $\$ 2.46 /$ gal for the 1987 case and $\$ 1.05 /$ gal using the same basis. Although the capital requirements for the NREL process would be significantly less, the lower yields assumed in the analysis for the NREL process resulted in higher product costs. 
As indicated in Chapter 3.0, this result contrasts with that of an analysis prepared by the IEA's liquefaction activity. Clearly, the yields from the processes have a major impact on process economics. The IEA analysis of the future NREL technology was performed after the SAIC analysis and assumes higher yields of hydrocarbon products. If the assumed product yields can be achieved through additional research, then the relative costs of the two concepts would change. Since the two analyses were performed with different assumptions and different methodologies, it is important not to place to much emphasis on the actual calculated costs. However, the two analyses provide interesting qualitative information about the two different types of upgrading approaches.

Combustion/Gas Turbine Power Generation - SAIC also provided the BTC Program with an analysis of the costs of producing electricity using direct combustion/gas turbine systems similar to that tested by Aerospace Research Corporation. As described in Chapter 4.0, the hot gases from a biomass combustor were used to power a gas turbine engine, which in turn provided shaft power to turn an electrical generator. SAIC assumed that turbine inlet temperatures were about $980^{\circ} \mathrm{C}$, which were not attained in the work at Aerospace. The analysis is therefore a "future" based on the expectation of research advances.

SAIC examined four combustor/turbine configurations in its analysis, including the following:

- A single $3 \mathrm{MWe}$ wood-fired modular gas turbine

- A 12 MWe facility consisting of four modular units

- A 13 MWe facility consisting of four modular $3 \mathrm{MWe}$ units, each equipped with exhaust gas recuperators

- An $18 \mathrm{MWe}$ combined cycle facility consisting of four $3 \mathrm{MWe}$ modular units plus one steam turbine.

Capital cost estimates were based on 1983 dollars, and the analysis allowed the influence of financing assumptions appropriate for public and private utilities, as well as private industry, to be examined. Calculations were based on wood feedstock costs which could be obtained at that time in the southeast USA, ranging from $\$ 5-18 /$ ton. While costs are lower than those used in many other analyses, they were representative of actual costs at the time. In any case, the influence of higher feedstock costs can easily be derived through simple calculations. The capital cost estimates and the resulting electricity costs for the four systems above are summarized in Table 5.2 below, assuming feedstock costs of $\$ 10 /$ ton. 
Table 5.2 Summary of Capital and Electricity Production Costs.

\begin{tabular}{|l|c|c|}
\hline Technology & $\begin{array}{c}\text { Capital } \\
\text { Requirements } \\
\text { (\$ million) }\end{array}$ & $\begin{array}{c}\text { Electricity Cost, } \\
\text { cents/kWhr } \\
\text { (Utility) }\end{array}$ \\
\hline $\begin{array}{l}\text { 3 MWe combustor/ } \\
\text { turbine }\end{array}$ & 1.8 & 3.6 \\
\hline $\begin{array}{l}\text { 12 MWe facility (four 3 } \\
\text { MWe modular units) }\end{array}$ & 5.9 & 2.5 \\
\hline $\begin{array}{l}\text { 13 MWe facility (four 3 } \\
\text { MWe units plus four } \\
\text { recuperators) }\end{array}$ & 7.0 & 2.4 \\
\hline $\begin{array}{l}\text { 18 MWe facility (four 3 } \\
\text { MWe units plus one } \\
\text { steam turbine) }\end{array}$ & 8.8 & 1.9 \\
\hline
\end{tabular}

In these systems, the cost of biomass is a significant factor, and doubling the feedstock cost from $\$ 10$ to $\$ 20 /$ ton will increase electricity costs from the range shown to a range of 2.9-5.2 cents/kWhr. Even at higher feedstock costs, the systems have significant potential. It must be remembered, however, that technology will only be successful if progress is made in the problems of ash deposition in the combustion/turbine systems.

Current Status: The analysis work at SAIC was completed in 1988 as the BTC Program ended, but analysis of various biomass processes is continuing at other locations, particularly NREL. It must be remembered that the analysis of emerging technologies is subject to a great deal of uncertainty. In particular, the costs calculated for "future" cases are only qualitatively accurate at best. The final yields and capital requirements of developing technologies are not well defined, and in some cases, the research progress needed to reduce costs may never be made. For example, the SAIC analysis showed that the PNL gasifier with catalysts in a fluidized bed had good economic potential. Research, however, showed that the catalysts were subject to attrition in the bed, and the original concept was not feasible. Likewise, the economics of direct combustion/gas turbine processes are promising, but major technical problems still exist. The analyses provide useful information, but that information must be used with care.

\section{Selected References:}

Wan, E.I., M.D. Fraser, and I.K. Kwareng. 1987. "Technical and Economic Evaluation of Emerging Biomass Pyrolysis Processes for Gasoline Production." In Proceedings of the 1987 Biomass Thermochemical Conversion Contractors' Review Meeting, pp. 115-139. CONF-8705212, Pacific Northwest Laboratory, Richland, Washington. 
Wan, E.I. 1987. "Economic Evaluation of Emerging Biomass Thermochemical Technologies." In Proceedings of Energy from Biomass and Wastes X, ed. D.L. Klass, pp. 1379-1394. Institute of Gas Technology, Chicago, Illinois.

Wan. E.I. 1986. "Technical and Economic Evaluation of Biomass-Based Fuel Processes." In Proceedings of the 1985 Biomass Thermochemical Conversion Contractors' Meeting, pp. 167-192. CONF-8510167, Pacific Northwest Laboratory, Richland, Washington.

Wan, E.I. and J.D. Price. 1984. "Technical and Economic Assessment of Emerging Advanced Biomass Thermochemical Conversion Technologies." In Proceedings of the 16th Biomass Thermochemical Conversion Contractors' Meeting, Portland, Oregon, May 8-9, 1984, pp. 423-451. CONF-8405157, Pacific Northwest Laboratory, Richland, Washington.

Wan, E.I. and J.D. Price. 1983. Technical and Economic Assessment of Liquid Fuel Production from Biomass, Final Research Report. DOE/NBM 1061, Vol. 1 \& 2, National Technical Information Service, Springfield, Virginia.

\section{$5.3 \quad$ SYSTEMS STUDIES}

The BTC Program funded limited work at Pyros, Inc., to assess feedstock availability in certain regions of the United States. In addition, DOE had funded several systems studies to help prioritize its research efforts prior to the start of the BTC Program. These were broad-based studies which examined many types of conversion technologies, sometimes including biological approaches. The systems studies were completed in 1980 and were not actually part of the BTC Program which started that year. However, the studies did impact on the program. Summaries of this work are provided below.

\subsubsection{Assessment Feedstock Availability - Pyros, Inc.}

Principal Investigator: Forest Orr

Project Objective: In 1984, the BTC Program funded Pyros to evaluate the availability of forestry and waste wood resources for energy facilities requiring 500-2000 tpd feedstock. At the time, the issue of feedstock availability for these types of facilities was strongly debated. While inexpensive wood and wood wastes were readily available in some areas, there were shortages in others. The DOE Biofuels research on biomass production was aimed primarily at short-rotation forestry, and was not conducting studies of conventional resources. As a result, the BTC Program funded Pyros to examine the overall availability of wood in two regions of the USA and to further examine infrastructural factors which might further limit wood usage.

Summary of Research Project and Results: Pyros conducted a detailed assessment of the wood supply in six of the states in the northeast region of the USA (Connecticut, Maine, 
Massachusetts, New Hampshire, New York, and Pennsylvania) plus four states in the southeast region (Alabama, Florida, Georgia, and South Carolina). The assessment included calculation of the total forestry resources available and an examination of factors such as terrain, land ownership, and transportation networks which might limit actual availability.

The assessment of total resources by state was made on the basis of USDA Forest Service data combined with input from state forestry and energy departments and other information where available. The assessment included estimates of the types of wood available such as logs or forestry wastes, and it provided information on the rates of biomass use by state.

The analysis showed that there was significant potential for medium-scale biomass facilities, but that the opportunities varied significantly by state. Small, urbanized states such as Connecticut held little opportunity for biomass facilities while larger, less urbanized states such as Maine offered more potential. The southeastern states tended to have greater resources than those in the northeast. While these conclusions are intuitively straightforward, the Pyros work provided actual data to support them.

The assessment also showed interesting infrastructural differences between regions. In the northeast states, the forest resources were typically on small parcels of land, and efforts to supply a conversion facility with feedstock would ultimately have to include many land owners. In the southeast states, the forest lands were typically owned in larger blocks by forest products companies. The two factors would have mixed implications for energy facilities. Dealing with numerous land owners presents potential problems, but it also may be difficult to compete for resources with the forest products industries. Factors such as transportation and terrain considerations were not found to cause significant problems in the states which were analyzed.

The analysis also showed that biomass supplies in several states were larger in the mid1980 's than they had been in the 1970's, and the amounts of unused biomass was also increasing. Sufficient supplies of wood from conventional sources appeared to be available for energy facilities. In the shorter term, medium scale bioenergy facilities will be able to obtain wood feedstocks from conventional forestry sources in many locations. In the longer term, however, the supplies of wood from conventional forestry will not be sufficient to support a greatly expanded bioenergy industry, and additional feedstocks such as short-rotation energy crops will be required.

Current Status: The research at Pyros, Inc., was completed in 1985.

\section{Selected References:}

Orr, F.E. 1983. "Assessment of Potential Wood Supply for Intermediate Scale Thermoconversion Facilities." In Proceedings of the 15th Biomass Thermochemical Conversion Contractors' Meeting, pp. 257-270. CONF-830323, National Technical Information Service, Springfield, Virginia. 
Pyros, Inc. 1985. Assessment of Potential Wood Supply for Intermediate Scale Thermoconversion Facilities. Tasks I, II, and III. PNL 5618, Pacific Northwest Labratory, Richland, Washington.

\subsubsection{Solar Cost Data Bank - SRI International}

\section{Principal Investigator: E. M. Kinderman}

Project Summary: Beginning in the mid-1970's, SRI International conducted a comparative analysis of various biomass conversion systems to help DOE focus its research efforts. These systems included 25 specific concepts dealing with combustion, thermal gasification, biological gasification, pyrolytic production of gasoline, extraction of rosin, and biological production of ethanol. The purpose of the study was to develop basic technoeconomic data on the processes and use that data to identify processes which entailed greater or lesser risk.

SRI prepared moderately detailed process flowsheets and developed capital costs for about 25 individual conversion technologies. The individual flowsheets did not contain the level of detail which later work by others included, but the detail was sufficient to give a first order approximation of costs. The analyses were prepared using data available from the research community, and, therefore, represented technologies which were available in the mid-1970's without consideration of the potential for future research to reduce costs.

SRI showed that the technologies which were the best developed and were closest to being commercial in the mid-1970's resulted in the lowest energy product cost, measured in terms of $\$ / M M B t u$. This is not surprising, since the analyses were based only on experimental data available at the time. Less developed processes with only preliminary data resulted in much higher costs. For instance, biomass combustion and low-energy gasification systems had low costs, as did anaerobic digestion. Processes such as pyrolysis gasoline and ethanol from wood were found to cost the most, with capital requirements per unit of energy more than eight times those of lower cost options.

At the time, DOE wanted to identify technologies which could be rapidly commercialized to address energy disruptions. The SRI work helped identify areas such as mediumenergy gasification where that goal could potentially be achieved. As time has passed, the limitations of the work have also become more evident. While the production of pyrolysis gasoline or ethanol from wood appeared to be extremely risky twenty years ago, the significant research progress which has made make these processes more economically promising now.

\section{Selected Reference:}

Kinderman, et al. 1982. Technical and Economic Evaluations of Biomass Utilization Processes: Solar Cost Data Bank - Final Report. National Technical Information Service, Springfield, Virginia. 


\subsubsection{Evaluation of Catalysis in Biomass and Coal Conversion - Catalytica Associates, Inc.}

Principal Investigator: R. L. Garten

Project Summary: Catalytica Associates conducted a study in 1979 to assess the role of catalysts in biomass thermal conversions systems. The study examined the potential role for catalysts in biomass gasification and liquefaction systems, and compared biomass systems with those for peat and coal. A major part of the Catalytica study consisted of a review of gasification and liquefaction processes which were proposed for biomass and coal in the late 1970's. The review provided an interesting summary of the process concepts which were being developed at the time.

Catalytica noted that biomass is a substantially different feedstock than coal, particularly with respect to its fibrous nature, its reactivity, and its ash composition. Catalytica suggested that the reactivity of biomass could be exploited, and recommended research on a molten salt gasification process. Catalytica also noted that the products from the PERC-type liquefaction processes would probably require upgrading and suggested the use of zeolite catalysts. While Catalytica provided useful insight into the potential to exploit the differences between biomass and coal, the processes they recommended have not been developed. Gasification using molten salt processes has not proven to offer advantages over more conventional systems. Zeolite catalysts have been used successfully with pyrolysis oils, but not the high pressure liquefaction products. However, Catalytica's recognition of the importance of biomass feedstock characteristics on process design was unusual in the late 1970's and turned out to be very important.

\section{Selected References:}

Garten, R.L., K.K. Ushiba, M. Cooper, and I. Mahawili. 1980. Catalytic Conversion of Biomass to Fuels, Final Report. Contract No. DE-AC03-78ET11013, U.S. Department of Energy, Washington, D.C.

Mahawili, I., K.K. Ushiba, M.C. Cooper, and R.L. Garten. 1979. "Catalytic Conversion of Biomass to Fuels." In Proceedings of the Eighth Biomass Thermochemical Conversion Contractors' Meeting, July 31-August 1, 1979, Seattle, Washington.

\subsubsection{Research and Evaluation of Biomass Resources/Conversion/Utilization Systems - Gilbert/Commonwealth Associates, Inc.}

Principal Investigator: Richard P. Stringer

Project Summary: Gilbert/Commonwealth developed a biomass allocation model which could potentially be used to show the most profitable combination of biomass feedstock, conversion technology, and fuel product for a specific regional market. As with the 
other system studies mentioned above, the work was completed in 1980 as the BTC Program started.

The development of the biomass allocation model included analysis of biomass availability and cost in four regions, the calculation of costs of producing a wide range of gaseous and liquid products using thermal conversion technologies, and the inclusion of the data in a model which could be used to select optimal systems. Gilbert/ Commonwealth also subcontracted with EEE, Inc. to conduct gasification tests which provided data for the analysis. The gasification research by EEE is discussed in chapter 2 of this report.

Gilbert/Commonwealth estimated biomass availability and costs using previous studies and data from the Department of Agriculture. The availability of woody and non-woody species for four regions was estimated. The regions consisted of two- and three-state groups in the northeast, central, southeast, and Pacific northwest areas of the USA. Detailed listings of more than 40 individual woody species and 17 non-woody crops were tabulated according to their individual contribution by region.

Technoeconomic analyses for ten different thermal conversion processes were then completed. The processes included conventional combustion for power generation, lowand medium-energy gasification, methanol production, and others. Process flowsheets for the analysis were fairly simple but contained enough detail to allow general comparisons for between the technologies.

The effects of feedstocks on the product costs of various energy products were then calculated. For woody crops, the production costs of gaseous and liquid fuels varied only slightly as a function of feedstock type, due primarily to small differences between the heating values of the different woods. Production costs, however, varied by a multiple of two or three between woody and non-woody crops. For instance, the costs of producing low-energy gas from hemlock wood were calculated to be about $\$ 2.70 / \mathrm{MMBtu}$ as compared to $\$ 5.98 / \mathrm{MMBtu}$ from sugar cane. The differences arose from the moisture contents of the feedstocks, overall conversion efficiencies, and the differences in the energy content of the feedstock. This and many other projects have shown that thermal conversion processes are generally insensitive to a wide variety of feedstocks, particularly woody ones. Moist, herbaceous crops tend to have more impact on product costs.

Gilbert/Commonwealth also used the data from these studies to begin development of a computer-based allocation model. The purpose of the allocation model was to sort through the numerous combinations of feedstock and conversion technologies by regions and to identify the best combinations. While a preliminary model was developed, the model was not used to any extent, and the model itself was not published. At the time, computer programs were very cumbersome, and the software could not easily be distributed. As a result, potential users were required to go to Gilbert/Commonwealth to obtain information, and that did not happen to any significant extent. In addition, the development of biomass conversion technologies will be market driven, and models of this type cannot accurately predict the market for biomass based energy. 


\section{Selected References:}

Ahn, Y.K., et al. 1980. "Research and Evaluation of Biomass Resources/Conversion/ Utilization Systems." In Proceedings of the 11th Biomass Thermochemical Conversion Contractors' Meeting, September 23-24, 1980, Richland, Washington.

Ahn, Y.K., et al. 1980. "Research and Evaluation of Biomass Resources/Conversion/ Utilization Systems (Market/Experimetnal Analysis for Development of a Data Base for a Fuels from Biomass Model)." In Proceedings of the 10th Biomass Thermochemical Conversion Contractors' Meeting, February 12-13, 1980, Berkely, California.

\subsection{RECOMMENDATIONS AND CONCLUSIONS}

\subsubsection{Summary of Accomplishments}

- The BTC Program sponsored continuing technoeconomic analyses to help guide the thermal conversion research.

The analyses produced by SAIC for the BTC Program gave an independent evaluation of the various processes under development. The work allowed the program to compare analyses prepared by individual investigators with those prepared by SAIC on a uniform basis. The information gave insight not only into the relative merits of individual processes, but also helped identify areas where additional research could have the most impact on improving conversion technologies. The use of peer reviewed analyses which could be critiqued by the process developers added objectivity to the conclusions of the studies.

- DOE completed several systems studies of biomass energy technologies.

The systems studies completed by DOE provided an overview of the various options available for converting biomass to energy. While each of these studies produced useful results, the overall analyses tended to lack focus, and the material rapidly became dated. If studies of this type are to have value, they need well defined goals, and the results need to be periodically updated.

\subsubsection{Recommendations}

- Technoeconomic analyses of emerging biomass conversion processes can be useful in determining research priorities and in tracking progress on individual concepts, and ongoing analysis of emerging technologies is useful. As indicated previously, the product costs derived from these studies will only be as accurate as the assumptions used to calculate them. As a result, it is crucial for the current DOE program to produce analyses with as little bias as possible. Where possible, DOE should have outside, independent organizations prepare the analyses. In the cases where the analyses are prepared either by the researchers 
involved in the technology or by the DOE program/support staff, the analyses should be subjected to rigorous outside peer review.

- Although numerous analyses have been produced by SAIC, individual researchers, the DOE program, and others, the results of the various work have not been brought together and analyzed in a consistent fashion. It would be useful to select particular technologies, to review the analyses which have been performed, and to track the predictions of the analyses as a function of time. With both thermal and biological conversion technologies, recent analyses predict lower "potential" costs in 1994 dollars than were predicted in early 1980's dollars more than a decade ago. It would be useful to compare previous analyses to determine whether the main source of this improvement has been research progress or other factors such as increased facility size.

- The analysis of emerging processes should be viewed qualitatively rather than quantitatively. There is a great deal of uncertainty in these analyses, and industry will perform detailed, site-specific calculations before they build processes. The analyses that are useful to DOE program planners will not be sufficiently specific for industrial use. 


\subsection{FEEDSTOCK CHARACTERIZATION AND OTHER BIOMASS RESEARCH PROJECTS}

In addition to the research described in previous chapters, the BTC Program sponsored or participated in other projects dealing with biomass thermochemical conversion. Two of these projects related to the characterization of biomass and the study of the effects that different types of biomass had on conversion processes. The program also sponsored limited work on the use of vegetable oils for transportation fuels. In addition, the BTC Program participated in other projects associated with the International Energy Agency's Bioenergy Agreement. These projects are summarized in Table 6.1 and are discussed below.

Table 6.1 Other Research Projects Sponsored by the BTC Program.

\begin{tabular}{|l|c|}
\hline TECHNOLOGY AREA & INSTITUTION \\
\hline Other Research Projects & \\
\hline Feedstock Characterization, and Influences of Feedstock on Conversion Processes \\
$\quad \begin{array}{l}\text { Biomass Characterization/IEA Standards } \\
\text { Activity }\end{array}$ \\
$\begin{array}{l}\text { The Effects of Biomass Properties on } \\
\text { Conversion Processes }\end{array}$ \\
$\begin{array}{l}\text { Research on the Use of Vegetable Oils for Fuels } \\
\text { Oil Seeds as an Alternative Fuel Source }\end{array}$ \\
$\begin{array}{l}\text { Other Participation in the International Energy Agency's Bioenergy Agreement } \\
\text { (IEA/BA) }\end{array}$ \\
IEA/BA Biomass Conversion Task & Pufts University \\
\hline
\end{tabular}

\subsection{FEEDSTOCK CHARACTERIZATION, AND INFLUENCES OF FEEDSTOCK ON CONVERSION}

The BTC Program funded two projects to deal with issues relating to biomass characterization. These included work at NREL to develop better methods to characterize biomass feedstocks. Part of this effort included leadership of an IEA 
activity on biomass standards which led to the establishment of biomass reference materials. The BTC Program also funded PNL to examine the effects of the physical and chemical properties of various biomass feedstocks on conversion processes. These projects are discussed below.

\subsubsection{Biomass Characterization/IEA Standards Activity - NREL}

Principal Investigators: Thomas Milne, Helena Chum

Project Objective: Comparison of technical data from different laboratories can be difficult. The data typically has been obtained using different analytical techniques and different biomass feedstocks. While the results obtained by any one research group are generally reproducible at that lab, the measurement of the same parameter by another lab can lead to significantly different results. The differences can arise from the use of different analytical techniques, the performance of different analyses, the use of different feedstocks, or all of these.

To improve the comparability of research data, the International Energy Agency's Bioenergy Agreement (IEA/BA) sponsored an activity between 1986 and 1991 to identify appropriate analytical techniques for a wide range of chemical analyses relating to biomass conversion. The purpose of this work was to allow laboratories to voluntarily select the best available methods, not to force the use of specific techniques. In addition, the IEA/BA activity made reference samples of selected biomass feedstocks available to the research community. The establishment of reference standards required extensive characterization of the biomass samples and led to improved analytical techniques. NREL led the activity, and the BTC Program actively participated in the work.

Summary of Research Project and Result: The IEA/BA activity on biomass standardized techniques was similar in structure to the IEA liquefaction activity described in Chapter 3.0. The IEA provided limited funds for administration of the cooperation, while most of the research effort was supported by the national programs of the participating countries. Canada, Finland, Italy, New Zealand, and the United States were the official participants in the activity, but laboratories from many other countries throughout the world also participated in the work. The activity was conducted in three main parts including interlaboratory comparisons of selected analytical techniques, the production of a reference volume on analytical methods appropriate for biomass processes, and the establishment of biomass reference standards. These three efforts are discussed below.

Interlaboratory Comparisons of Selected Analytical Techniques - The initial work of the activity was the performance of interlaboratory tests to compare results from selected analytical techniques. Workshops identified specific procedures in biological and thermal conversion processes where there were inconsistencies in the data and where more consistent analytical techniques were needed. In the biochemical conversion area, these included methods to judge the effectiveness of biomass hydrolysis and to determine protein concentrations in enzymes. 
Samples of enzymes and substrates were sent to participating labs along with a recommended analytical protocol. The laboratories conducted tests using both the recommended protocol and the method they had previously used. The results of the analyses were collected and compared. Similar tests to determine ultimate analyses and to evaluate moisture contents in pyrolysis oils from thermal conversion processes were also performed. The tests showed the need for common procedures and resulted in the publication of recommended protocols for the biomass hydrolysis and protein determination.

Reference Volume on Analytical Methods - In addition to the interlaboratory comparisons, NREL compiled a reference volume detailing recognized analytical methods appropriate for biomass conversion processes. The volume references standardized procedures recognized by 36 world-wide groups such as the American Society for Testing and Materials (ASTM), Technical Association of the Pulp and Paper Industry (TAPPI), or International Standards Organization (ISO). These included approximately 1500 analytical procedures in fourteen areas including:

- $\quad$ Feedstock sampling and preparation

- Elemental Analysis

- Special categories of biomass

- Waste product analysis

- $\quad$ Fire and Flammability

- Chromatography

- Conversion system performance and specifications
- Physical and thermal properties

- Chemical component and group analysis

- Fuel product analysis

- Enzymatic assays

- Temperature, pressure, and flow

- Spectrometry

- Measurements, units, quality assurance, and round-robin tests

The volume provides a short description of the purpose of each analysis and a reference where detailed information on specific procedures can be found. It will serve as a major, long-term reference sourcebook for analytical procedures related to biomass.

Standard Reference Materials: The work also led to the establishment of reference standards of four biomass materials which are now available to researchers through the National Institute of Science and Technology (NIST, formerly National Bureau of Standards) in the USA. Samples of biomass including pine, poplar, wheat straw, and bagasse were obtained by NREL and sent to NIST, where each species was homogenized. Samples $(10 \mathrm{~g})$ of each were packed in foil containers under nitrogen, and the samples were then distributed by NREL for round-robin testing by 19 laboratories in 12 countries around the world.

Initial tests confirmed that the samples were indeed homogeneous. From the round-robin testing, the chemical composition of the samples was determined. Quantitative analyses of polysaccarides such as arabinan, xylan, mannan, and others were made. Quantitative lignin determinations were made using a variety of techniques, and ash contents were also measured. As the result of the round-robin testing, well-characterized samples of biomass are available to researchers at a moderate cost through NIST. The availability of standard samples is very valuable to the research community. By using standard 
samples, the various laboratories can more readily compare their work with that of others. This improved the quality of data throughout the world.

As indicated in Chapter 3.0, the active participation of the USA in the international activities can have many benefits at low cost. The IEA standards activity led by NREL developed valuable reference source books and led to the establishment of wellcharacterized biomass reference standards. Because the costs of the efforts were shared by several countries and many individual labs, the cost to the BTC Program was roughly $15 \%$ of the total.

Current Status: The IEA/BA activity on biomass standards ended in 1991. Additional research at NREL and other labs has continued in an effort to expand the number of biomass species available through NIST. Additional work has also taken place with the goal of having the samples be reclassified as certified reference samples, a NIST category requiring more rigorous determination of chemical content.

\section{Selected References:}

Milne, T.A., H.L. Chum, F. Agblevor, and D.K. Johnson. 1992. "Standardized Analytical Methods." Biomass and Bioenergy, Vol. 2, Nos. 1-6, pp. 341-36.

Milne, T.A. 1990. "Voluntary Standards for Biomass for Fuels and Chemicals." In Forestry, Forest Biomass and Biomass Conversion, the IEA Bioenergy Agreement (19861989) Summary Reports, eds. C.P. Mitchell, L. Zsuffa, S. Andersson, and D.J. Stevens, pp. 343-351. Elsevier Applied Science.

Chum, H.L., et al. 1994. "Status of the IEA Voluntary Standards Activity - Round Robins on Whole Wood and Lignins." Advances in Thermochemical Biomass Conversion, ed. A.V. Bridgwater, p. 1701. Blackie Academic \& Professional Press, London.

Milne, T.A., A.H. Brennan, and B.H. Glenn. 1990. Sourcebook of Methods of Analysis for Biomass and Biomass-Conversion Processes. Elsevier Applied Science, New York.

\subsubsection{The Effects of Biomass Properties on Conversion Processes -Pacific Northwest Laboratory (PNL)}

\section{Principal Investigator: R. Scott Butner}

Project Objective: The chemical and physical properties of biomass feedstocks influence energy conversion processes. In thermal conversion systems, for example, the moisture and ash content of the feedstock impacts on system design and efficiency. In biological systems, properties such as lignin and cellulose contents affect product yields. By matching feedstock qualities and conversion processes, it may be possible to improve overall conversion efficiencies. In 1987, PNL began what was intended to be a longerterm effort to systematically examine the influence of feedstock qualities on a variety of 
conversion processes and to identify potential improvements in both feedstocks and conversion processes.

Summary of Research Project and Results: The first phase of this work consisted of a review to determine the types of feedstock effects which had previously been reported. PNL qualitatively examined feedstock effects on thermal and biological processes including combustion, gasification, rapid pyrolysis, high pressure liquefaction, digestion, and fermentation technologies. Feedstock effects as they related to mechanical pretreatment and handling of the feedstocks were also examined.

PNL noted that all of the conversion processes were sensitive in varying degrees to feedstock differences, and that the sensitivities were related to the overall severity of the conversion process. For instance, higher temperature combustion and gasification processes are generally insensitive to chemical differences between feedstocks but are influenced by the moisture content of the feedstock. Pyrolysis processes which occur at lower temperatures exhibit a small dependence on the chemical composition of the feedstock, and biological processes are highly dependent on the nature of the feedstock. Feedstock properties which affect front-end processing and handling impact on many different types of technologies.

Current Status: It had been planned that the initial qualitative conclusions from this work would be used to direct an experimental program which would produce more quantitative feedstock/conversion relationships. Due to changes in the BTC Program management in 1988, however, the work on feedstock effects was transferred to NREL where a joint effort with Oak Ridge National Laboratory was instituted.

\section{Selected References:}

Butner, R.S., D.C. Elliott, L.J. Sealock, Jr., and J.W. Payne. 1988. Effect of Biomass Feedstock Chemical and Physical Properties on Energy Conversion Processes, Volume 1 - Overview. PNL-6765, Vol. 1, Pacific Northwest Laboratory, Richland, Washington.

Butner, R.S., D.C. Elliott, L.J. Sealock, Jr., and J.W. Payne. 1988. Effect of Biomass Feedstock Chemical and Physical Properties on Energy Conversion Processes, Volume 2 - Appendices. PNL-6765, Vol. 2, Pacific Northwest Laboratory, Richland, Washington.

\subsection{RESEARCH ON THE USE OF VEGETABLE OILS FOR FUELS}

In the early 1980 's, DOE requested that the BTC Program fund an evaluation of the use of vegetable oils as transportation fuels. The U.S. Department of Agriculture had an active vegetable oil program at the time, and DOE was interested in determining how this technology might fit into an integrated strategy for increasing the use of bioenergy. DOE's interest was primarily in the fuel and its utilization rather than in crop production, so this work was funded through the BTC Program. 


\subsubsection{Oil Seeds as an Alternative Fuel Source - Tufts University}

\section{Principal Investigator: William Lockeretz}

Project Objective: The national concern about potential petroleum shortages in the early 1980's led DOE to investigate the possibility of using oil seed crops to produce alternative liquid fuels. At the time, the USA was the world's largest producer of soybean oil (over 8 million metric tons per year), and the USA accounted for about $25 \%$ of the total world production of edible oils. The oils could potentially be upgraded through a simple esterification process and used as diesel substitutes in internal combustion engines. Some short-duration engine tests with the oils had been performed, and engine performance was generally satisfactory, although the oils were 1.5-2 times the cost of petroleum fuels. The vegetable oils offered a short-term source of emergency fuels, and there was longer term potential for greater use if vegetable oil costs could be reduced.

In 1981, DOE provided funding to the BTC Program to analyze the potential of using vegetable oils as transportation fuels. Tufts University produced a general analysis of the potential of this type of fuel based primarily on farm-related issues. Technical issues such as oil performance in engines were not addressed, although such studies have been supported by U. S. Department of Agriculture.

Summary of Research Project and Results: The analysis by Tufts University provided a brief review of previous work on fuels from oil crops, provided an overview of the production and economics of oil seed crops in the USA in the early 1980's, and then examined ways to meet the potential upturn in vegetable oil demand. The university then looked qualitatively at the supply and demand relationships which would occur if vegetable oil use for transportation fuels was significantly expanded.

The analysis produced by Tufts University was pessimistic about the long-term potential of producing fuels from oil seed crops. The total production of oil from seed crops at the time was equivalent to about $1 \%$ of the national petroleum usage, and it was unlikely that significant amounts of the vegetable oils would be diverted from food to energy uses. Tufts also suggested that there was little opportunity to greatly expand oil seed production. Because oil crop planting practices were mature, the university believed there was little room for production cost improvements. In addition, the oil seed fuel price depended heavily on the sale of the seed meal as a livestock food. Additional oil seed production would increase the amount of this byproduct and lower its market price, further discouraging oil seed production. At some point, the market would become flooded with excess seed meal. The cost of the oil product was estimated to be more expensive than petroleum by a multiple of 1.5 to 2 , and the university foresaw little expectation that the relationship would change unless transportation fuel costs increased greatly. The university concluded that the oils had limited potential, primarily for use as an emergency fuel, in the early 1980's or beyond. The analysis was completed in 1982. 
Current Status: It is important to note that in the early 1990's, there has been a significant, world-wide resurgence of interest in vegetable oil fuels. Groups such as the National Biodiesel Development Board in the USA and the Italian Bioenergy Association are actively promoting the use of vegetable oil fuels. The so-called "biodiesel" product is oxygenated and free of aromatics, thus offering a potential method to meet air-quality requirements with diesel engines. The use of vegetable oils also potentially allows the energy and agricultural policies of various nations to be coordinated. Numerous engine tests have now been performed which show the oils can be used as diesel substitutes for extended periods. While the production costs of vegetable oils still exceed the production costs of petroleum diesel, the costs at the pump can potentially be similar, depending on tax considerations. In Europe particularly, the cost of petroleum diesel with taxes is about the same as biodiesel without taxes. It may therefore be possible to use tax and clean air policies to address agricultural and energy concerns simultaneously.

\section{Selected Reference:}

Lockeretz, W. 1982. Growing Oilseeds as an Alternative Fuel Source. Final Report submitted under PNL subcontract B-96221-A-Q. Tufts University, Medford, Massachusetts.

\subsection{OTHER PARTICIPATION IN THE INTERNATIONAL ENERGY AGENCY'S BIOENERGY AGREEMENT (IEA/BA)}

In addition to IEA's activities on standards and liquefaction, which are described previously, the BTC Program also participated actively in other IEA projects. These are discussed below.

\subsubsection{IEA/BA Biomass Conversion Task - PNL}

\section{Operating Agent: Don J. Stevens}

Project Objective: As indicated in Chapter 3.0, the IEA Bioenergy agreement provided a legal mechanism for countries to exchange information and coordinate their research on a variety of biomass topics. These included projects in the areas of biomass production, harvesting, conversion, and the utilization of municipal wastes. Beginning in the early 1980's, PNL provided leadership for the cooperative program in the biomass conversion area. Individual activities were established to deal with research topics in thermal and biological conversion processes, and several conversion activities had direct influence on the BTC Program. Two of these, including the standards and liquefaction activities, have been discussed previously in this report. In addition, the IEA/BA sponsored projects on gasification and combustion of biomass and produced a comprehensive data base of thermal conversion projects in the late 1980's. The IEA also organized a series of major international technical conferences on thermal conversion. These projects are summarized briefly below.

Summary of other IEA Projects: 
Gasification Activity - In 1987, a cooperative project on biomass gasification started. Led by Suresh Babu at the Institute of Gas Technology, the activity has created a successful information exchange network that follows the progress of various research and development projects throughout the world. The activity also conducts projects on specific topics, such as preparing reviews of research on hot gas cleanup research applicable for biomass systems.

Pyrolysis Activity - The Liquefaction Activity described previously was the focus of most work on biomass pyrolysis and direct liquefaction. As interest in these types of fuels waned in the late 1980's, the Activity focused its effort on the technoeconomic analysis of biomass power systems. Future offort on biomass pyrolysis is expected in the period between 1995 and 1997.

Combustion Activity - Led by Otto Sonju at the University of Trondheim in Norway, the combustion activity has also established an effective information exchange network. In addition, the activity has organized round-robin testing of the emissions from small boiler systems and from wood burning stoves. The testing has shown that the emissions test procedures in different countries are quite different, and that data produced in different countries must be compared cautiously. The USA participated in only part of this work.

Thermochemical Conversion Data Base - Between 1983 and 1989, Tony Bridgwater at Aston University in the United Kingdom led an effort to compile a database of thermal conversion research worldwide. The effort resulted in a listing of more than 600 projects at more than 400 institutions. The database was published as a reference book and was also maintained on a computer to allow for statistical analysis of the data.

International Thermochemical Conversion Conferences - The IEA/BA has been a primary sponsor and organizer of a series of three international conferences on biomass thermochemical conversion. The first of these was held in Estes Park, Colorado, in 1982 and dealt with fundamental research. The second was held in Phoenix, Arizona, in 1988 and dealt with basic and applied research on thermal conversion processes. The third conference was held in Interlaken, Switzerland, in 1992 and highlighted recent advances in the technology. In all three cases, peer-reviewed proceedings have been published which document research progress over the past decade. A fourth conference is tentatively planned for Canada in 1996. The proceedings of these meetings provide an excellent source of information on world-wide thermochemical conversion research over the past decade.

Current Status: In 1994, the IEA Bioenergy Agreement was extended for three additional years through 1997 . Research on biomass gasification, pyrolysis, and combustion will continue, was will various technoeconomic assessment studies and research on biochemical conversion. Additional information is available through $\mathrm{Carl}$ Wallace at NREL. 


\section{Selected References:}

Bridgwater, A.V., ed. 1994. Advances in Thermochemical Biomass Conversion, Volumes 1 and 2. Blackie Academic \& Professional Press, London.

Mitchell, C.P., L. Zsuffa, and D.J. Stevens, Guest Eds. 1992. Biomass \& Bioenergy

- International Energy Agency Bioenergy Agreement, Progress and Achievements 19891991. Pergamon Press, Oxford.

Nutek. 1994. IEA Bioenergy Annual Report 1993. Nutek, Stockholm, Sweden.

Nutek. 1993. IEA Bioenergy Annual Report 1992. Nutek, Stockholm, Sweden.

Mitchell, C.P., L. Zsuffa, S. Andersson, and D.J. Stevens, eds. 1990. Forestry, Forest Biomass and Biomass Conversion, the IEA Bioenergy Agreement (1986-1989) Summary Reports. Elsevier Applied Science, London.

Bridgwater, A.V. and J.L. Kuester, eds. 1988. Research in Thermochemical Biomass Conversion. Elsevier Applied Science, London.

Overend, R.P., T.A. Milne, and L.K. Mudge, eds. 1985. Fundamentals of Thermochemical Conversion. Elsevier Applied Science Publishers, London.

\subsection{SUMMARY AND RECOMMENDATIONS - OTHER BIOMASS RESEARCH}

\subsubsection{Summary of Accomplishments}

- Through the work of NREL and the IEA. well-characterized biomass samples are now available to the research community through NIST.

The establishment of well-characterized biomass reference standards is important to the biomass research community. The samples allow individual researchers to conduct tests with common feedstock and to more reliably compare research data.

\subsubsection{Recommendations}

- As indicated in Chapter 3, DOE should continue to take advantage of international collaboration on bioenergy. The collaboration can help provide guidance to the DOE program and can reduce the cost of DOE research by helping to identify the best research opportunities.

- Due to the strong international resurgence of interest in vegetable oils as transportation fuels, DOE should reevaluate the applicability of this concept. Significant changes in clean air legislation and farm policy have occurred since the early 1980's, and the opportunity for these types of fuels may have changed. 
DOE should have an independent evaluation performed which includes inputs from advocate and farm groups as well as opponents. The evaluation should provide objective conclusions about the potential of vegetable oils in the United States, the research which may be needed in this area, and the role, if any, of DOE in further developing the technology. 


\subsection{OVERALL SUMMARY}

The BTC Program sponsored a balanced research effort, which led to the successful development of new energy technologies and helped improve the basic understanding of thermal conversion processes. Some of the technologies funded by the program are being implemented by industry at present. The accomplishments and recommendations for each technology area have been summarized in the previous chapters of this report. The overall progress made by the program is discussed below and its importance is discussed in context with program considerations at the time and at present.

\subsection{TECHNICAL ACCOMPLISHMENTS}

The BTC Program conducted a balanced program that included both technology development and basic research. Progress in both areas was substantial.

\subsubsection{Development of New Technologies}

The BTC Program successfully developed new energy technologies in the areas of gasification and liquefaction. In the area of gasification, the Program was instrumental in developing technologies for producing medium-energy gases from biomass. While some work had been done previously on oxygen-blown gasifiers, very little had been done with indirectly heated gasification processes. The program examined several different types of gasifier concepts, and selected the best concepts through an ongoing process of review and evaluation. As a result, several types of gasifiers are available to meet the needs of industry.

In the area of liquefaction, the Program developed high pressure and rapid pyrolysis processes to convert biomass to a biocrude oil. The biocrude oil is substantially different than crude oil, but can be upgraded to gasoline hydrocarbon fuels either by using zeolite or hydrotreating catalysts. This technology gives the potential to generate fuels from biomass that are essentially the same as fuels from petroleum. In the shorter term, it appears the technology will be used to generate higher value chemical products such as phenolics from biomass or possibly fuel oils for vasious combustion applications.

The effort to use biomass as a fuel for a direct-fired gas turbine system was not successful, but did identify a major problem with ash deposition which must be solved before advanced technologies can successfully be used. This work has served as a basis for widespread current research and development of biomass gasifier/gas turbine systems. 
Providing relatively low levels of funding for the gas turbine work in the 1980's was a cost-effective way to identify the larger problems that must be addressed for this technology to be successful.

\subsubsection{Development of an Improved Basic Understanding of Biomass Processes}

A long-term legacy of the BTC Program is a much better understanding of the reaction mechanisms and pathways which affect biomass thermal processes. The role of pyrolysis in a variety of gasification, liquefaction, and combustion reactions is much better understood. By controlling reaction conditions, biomass can be converted to a variety of gaseous, liquid, or solid products.

This very significant contribution to the knowledge base has many practical uses. Knowledge of biomass pyrolysis, for example, has not only led to improved processes for generating biocrude but also to improved feeder systems which eliminate plugging as wood enters gasifiers or combustors. The knowledge which is available now permits detailed modeling of gasifier performance in a wide variety of gasification concepts, allowing engineers to design more effective systems. The pyrolysis information has been presented in summarized form in technical papers where more detailed information can readily be referenced. The information on gasification modeling, however, is contained in a variety of references, and it would be more useful if it were brought together in a single reference volume.

The knowledge of biomass reactions also has clearly shown that biomass is a very different resource than coal and that reaction temperatures, mechanisms, and pathways are also different. While it can sometimes be useful to examine coal conversion technologies, it must be clearly remembered that technologies which fail to exploit the unique characteristics of biomass will not be economically competitive with those which do.

From the basic research sponsored by the BTC Program, better, more standardized analytical methods were identified, and reference sample of biomass are now available to the research community. These types of efforts have improved the quality of biomass research, which improved the cost-effectiveness of the DOE efforts.

\subsection{INDUSTRIAL ACCEPTANCE OF BIOMASS THERMAL CONVERSION TECHNOLOGIES}

The technologies developed by the BTC Program are beginning to be commercialized by private industry. In the area of gasification, MTCI is building a medium-energy gasifier to destroy wood wastes for a major wood products company. The IGT gasifier is being scaled up in Hawaii, and BCL is planning a commercial gasifier unit in Vermont. Each of these gasifiers will convert 100-200 tpd of biomass to product gas. In the liquefaction area, the vortex reactor at NREL is being scaled by Interchem, Inc., to a size of about 
35 tpd. The unit will produce higher value products, such as a mixed phenolic stream and char.

In looking at the technologies which the BTC Program developed, it is useful to also look at the relative economic potential of some of the options. In gasification, it might intuitively seem that the indirect gasifiers should have lower production costs than oxygen-blown ones because they do not require oxygen. However, the data to either support or refute this assumption does not exist. In fact, the economics will depend on a host of site-specific factors which must be determined by the industry that will use the technology. In the liquid fuels area, the rapid pyrolysis processes appear to offer better economic potential than high pressure processes for either biocrude or upgraded hydrocarbon fuels. As described earlier, the relative advantages of zeolite or hydrotreating catalysts to upgrade the rapid pyrolysis products is less clear. Again, site specific factors will likely determine the type of process which is eventually used. It is important to have several options so that industry can select the most appropriate technology for its use.

The technologies developed by the BTC Program are closer to commercial acceptance than those funded by any other part of DOE's Biomass Energy Technology Program in the 1980's. However, the fact that acceptance is so slow merits comment. Biomass technologies must be cost-competitive with those using other fuels. With low current petroleum and natural gas costs, the biomass technologies will generally be most competitive where they simultaneously take care of waste disposal and generate a useful energy product. Biomass combustion systems, for example, typically use waste from one process step in a wood or paper processing plant to provide heat or electricity for another. In cases where biomass is used to produce electricity for the commercial grid, there are frequently regional incentives which increase the value of the product. California, in an attempt to reduce emissions from open burning, requires that some electricity be generated from farm wastes. Tax incentives are also used to support the present ethanol fuel industry.

It is not surprising, then, that gasification and thermal liquefaction processes have been slower in development. In the absence of market or regulatory incentives, the development of these technologies will initially be limited to waste disposal and production of higher value chemicals. This is an effective way to establish the infrastructure for bioenergy, but it may be slow. The federal government should examine whether further implementation of biomass thermal and biological conversion technologies can best be accomplished by ongoing outlays of research funds or through the establishment of various incentives.

\subsection{PROGRESS IN THE CONTEXT OF CHANGING PROGRAM GOALS IN THE 1980'S}

The balance between basic research and technology development allowed the BTC Program to be successful despite widely varying national goals through the 1980's. In the early 1980's, the nation reacted to disruptions in the energy supply and initiated 
efforts to rapidly develop technologies for producing gaseous and liquid products. DOE and its programs were given relatively large amounts of funding with the goal of shortterm technology development. This led to the funding of very risky concepts such as the high pressure liquefaction process at Albany, Oregon. By the mid-1980's, the disruptions in the international petroleum supply had subsided, and the emphasis of DOE shifted abruptly from short term technology development to long term research.

The substantial fluctuations in program goals and funding levels during these times made continuity difficult. DOE should examine methods to give its research programs smoother continuity. The adoption of 3-4 year plans, for example, might allow the programs to proceed with reasonable guidance, and then be reviewed and revaluated on a periodic basis. Rapid fluctuations in program direction and funding, however, are cost ineffective.

\subsection{ISSUES RELATING TO PUBLISHING DATA}

In preparing this document, it has been necessary to retrieve and review an extensive amount of information. As a result of many factors, there are problems with the documentation of the research which was performed. At the start of the BTC Program, DOE funded most of the research through its field offices. These included several of the larger gasifier projects such as Wright/Malta, much of the work on high pressure liquefaction, and many of the systems studies which were performed. As research contracts were completed, reports were filed with the field offices. At the time, many of the field offices were under tight security measures relating to weapons technology development, and information dissemination was not a high priority. Unfortunately, some of these reports were apparently never filed with the National Technical Information Service or similar public repositories. Copies of these reports may exist in contract files or elsewhere, but they have not been cleared for publication and cannot be considered "public documents."

Later, the subcontracting functions were transferred from DOE to Pacific Northwest Laboratory. PNL published many documents, including the final reports of most of the projects it funded. In some cases, however, proprietary rights or copyright considerations prevented the reports from being published in a publicly available format.

Throughout the program, periodic contractors review meetings were held, and proceedings of those meetings were produced. These proceedings contain a significant amount of valuable technical information and program history. PNL began formally publishing the proceedings in 1981, shortly after it became the field management lab for the BTC Program. However, the proceedings of the first twelve meetings, held in the late 1970's and into 1980 , were never formally published. While very limited numbers of copies of these early proceedings still exist, they have not been through formal publication procedures and also cannot be considered "public documents". These early proceedings are the major repository for much of the early DOE research on thermal conversion technologies, but the information cannot readily be referenced. 
The current DOE program should seriously consider archiving the early meeting proceedings with NTIS. The documents are rapidly disappearing and may no longer be available in a few years. In addition, the current program may want to consider attempting to trace and publish various final reports relating to early work done by the BTC program. Unless these documents are archived soon, they will be effectively lost to future researchers and developers of biomass technology.

The DOE Program should also review its procedures to ensure that projects it is currently funding will be adequately documented. At a minimum, detailed annual technical progress reports should be produced by each research project, whether it is performed by a DOE/National laboratory or by a subcontractor, and these reports should be published by the managing program office. It should be possible to combine the annual reports with contractors meetings so that the overall progress of the program can be reviewed in one document.

In addition, it is crucial to publish topical reports as project areas are completed. While annual reports present a good snapshot of progress, they do not serve well in reviewing overall technical progress over several years. It is crucial to summarize particular research areas on a periodic basis, typically 3-5 years. Good examples of topical summary reports are the peer reviewed papers NREL published on pyrolysis mechanisms or various reports PNL published on the characterization of biomass liquids and tars.

The need for DOE to review its publication procedures is also important because more of its current projects have proprietary aspects. There are many ways to simultaneously document technical progress and avoid disclosing proprietary data. DOE should ensure that reports on all projects are regularly published as retrievable documents. Without documentation, the research which is performed is rapidly forgotten and the effort becomes largely a waste of time and funds. 


\section{REVIEW AND ANALYSIS OF THE 1980-1989 BIOMASS THERMOCHEMICAL CONVERSION PROGRAM}

Volume II: Bibliography

Dr. Don Jay Stevens

September, 1994

Prepared Under NREL Subcontract AAE-3-13029-01 By:

Cascade Research, Inc.

2952 George Washington Way

Richland, WA 99352 


\title{
REVIEW AND ANALYSIS OF THE 1980-1989 BIOMASS THERMOCHEMICAL CONVERSION PROGRAM
}

VOLUME II: BIBLIOGRAPHY

\author{
Dr. Don Jay Stevens \\ Prepared Under NREL Subcontract AAE-3-13029-01 By: \\ Cascade Research, Inc. \\ 2952 George Washington Way \\ Richland, WA 99352
}

September, 1994 


\section{REVIEW AND ANALYSIS OF THE 1980-1989 BIOMASS THERMOCHEMICAL CONVERSION PROGRAM}

\section{Volume II: Bibliography}

In the period between 1980 and 1989, the U.S. Department of Energy sponsored research and development projects through its Biomass Thermochemical Conversion (BTC) Program. These projects included work on the gasification and liquefaction of biomass as well research on innovative combustion technologies. In addition, systems studies and technoeconomic analyses were prepared to support the program. This document presents a summary of the research which was performed during that period.

Volume I consists of a summary of individual projects, a listing of selected literature references, summaries of overall progress in various areas, and a discussion of future research needs. Volume II consists of a bibliography of reference documents which were published by the BTC Program and its subcontractors. In Volume II, the bibliography is arranged in the same order in which the projects are discussed in the first volume. 


\section{VOLUME II: BIBLIOGRAPHY}

\section{CONTENTS}

\subsection{INTRODUCTION}

1.1 PROCEEDINGS OF PERIODIC CONTRACTOR REVIEW MEETINGS . . 1

1.2 ANNUAL PROGRAM REPORTS $\ldots \ldots \ldots \ldots \ldots \ldots \ldots \ldots$

1.3 OTHER BTC PROGRAM DOCUMENTS $\ldots \ldots \ldots \ldots \ldots$

\subsection{GASIFICATION RESEARCH}

2.1 GASIFICATION APPROACHES

2.2 GASIFICATION RESEARCH EMPHASIS

2.3 MEDIUM-ENERGY GASIFICATION RESEARCH . . . . . . . . . 5

2.3.1 Larger Scale Medium Energy Biomass Gasifier Projects ... . . . 5

2.3.1.1 Circulating, Fluidized Bed Gasifier - Battelle Columbus Laboratory (BCL) . . . . . . . . . . . . . 5

2.3.1.2 Fluidized Bed Gasifier with Internal Heat Exchangers University of Missouri-Rolla . . . . . . . . 8

2.3.1.3 Pressurized Fluidized-Bed, Oxygen-Blown Gasifier Institute of Gas Technology (IGT) . . . . . . . . . 10

2.3.1.4 Down-Draft Oxygen-Blown Gasifier - National

Renewable Energy Laboratory and SynGas Inc. . . . . . 12

2.3.2 Additional Indirectly-Heated, Medium-Energy

Gasification Projects . . . . . . . . . . . . . . . . 13

2.3.2.1 Pulsed, Fluidized Bed Gasification-MTCI, Inc. . . . . 13

2.3.2.2 Ceramic Fire Tubes for Fluidized-Bed Gasifiers -

University of Nebraska . . . . . . . . . . . . . . 13

2.3.2.3 Pressurized Rotary Kiln Gasifier - Wright-Malta Corporation . . . . . . . . . . . . . . . 15

2.3.2.4 Pyrolytic Gasification of Wastes - Garrett Energy Research and Engineering Co. (GERE) . . . . . . 16

2.3.3 Additional Oxygen-Blown, Medium-Energy Gasification

Projects . . . . . . . . . . . . . . . . 17

2.3.3.1 Oxygen-Blown Gasification Research - Texas

Tech University . . . . . . . . . . . . . . . 17

2.3.3.2 Pressurized, Fixed-Bed Oxygen-Blown

Gasification - NREL . . . . . . . . . . . . 19

2.3.4 Alternative Medium-Energy Gasification Approaches . . . . . . . 21

2.3.4.1 Gasification of High-Moisture Biomass

Feedstocks - Pacific Northwest Laboratory (PNL). . . . . 21

2.3.5 Biomass Research Related to Coal Gasification . . . . . . . . 23

2.3.5.1 Gasifying Wood with Coal and Sewage Sludge Dynecology, Inc. 
2.3.5.2 Survey of Coal Gasification Technologies -

Gorham International . . . . . . . . . . . . 23

2.4 LOW-ENERGY AIR-BLOWN BIOMASS GASIFICATION

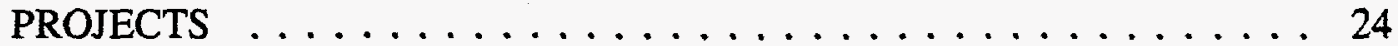

2.4.1 Data Collection with Low-Energy Gasifiers . . . . . . . . . 24

2.4.1.1 Coors Gasifier - University of Missouri Rolla . . . . . . 24

2.4.1.2 Data Collection on Gasifier Configurations -

Environmental Energy Engineering (EEE), Inc. . . . . 25

2.4.2 Use of Low-Energy Gases in Engines . . . . . . . . . . . 26

2.4.2.1 Research on Gasifier/Engine Systems -

Cal Recovery Systems . . . . . . . . . . . . . . . . 26

2.4.2.2 Enhancement of Engine Performance -

University of Florida . . . . . . . . . . . . 26

2.4.2.3 Field Testing of Small Gasifier Filter Systems -

Rocky Creek Gasogens, Inc. . . . . . . . . . . . 26

2.5 ENVIRONMENTAL/END-USE ASPECTS OF

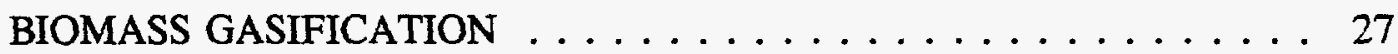

2.5.1 End-Use Applications . . . . . . . . . . . . . . . . 27

2.5.1.1 Catalysts for Synthesis Gas in an Indirectly

Heated Fluidized-Bed Gasifier - Pacific Northwest

Laboratory (PNL) . . . . . . . . . . . . 27

2.5.1.2 Improved Catalysts for Mixed Alcohol

Production-Lehigh University . . . . . . . . . 31

2.5.2 Environmental Aspects of Gasification . . . . . . . . 32

2.5.2.1 Treatment of Wastewaters from Biomass

Gasification - Pacific Northwest Laboratory . . . . . . 32

2.5.2.2 Waste Disposal via Gasification - Georgia Tech

Research Institute $(G T R I) \ldots \ldots \ldots \ldots$

\subsection{PYROLYSIS AND LIQUEFACTION RESEARCH}

3.1 LIQUEFACTION APPROACHES

3.2 PYROLYSIS/LIQUEFACTION RESEARCH EMPHASIS

3.3 RESEARCH ON BIOMASS LIQUEFACTION PROCESSES . . . . . 35

3.3.1 High Pressure Liquefaction Projects . . . . . . . . . 35

3.3.1.1 Albany, Oregon, Liquefication Test Facility -

Wheelabrator Cleanfuel Co. . . . . . . . . . . 35

3.3.1.2 Extruder Reactor System - University of Arizona . . . . 37

3.3.1.3 Aqueous Slurry Process - Lawrence Berkeley Laboratory (LBL) . . . . . . . . . . . . . . . 39

3.3.1.4 Alternate Catalysts for High Pressure

Liquefaction - SRI International . . . . . . . . . . 41

3.3.1.5 Direct Liquefaction Studies - Pacific Northwest

Laboratory $(P N L) \ldots \ldots \ldots \ldots \ldots \ldots$. . . . . 42 
3.3.2 Rapid Pyrolysis Processes . . . . . . . . . . . . . . 44

3.3.2.1 Ablative Reactor System - NREL . . . . . . . . . . . 44

3.3.2.2 Entrained Rapid Pyrolysis Reactor System -

Georgia Tech Research Institute (GTRI) . . . . . . . . 48

3.4 RESEARCH TO UPGRADE BIOMASS CRUDE OILS . . . . . . . . 50

3.4.1 Upgrading of Biocrude Using Zeolite Catalysts . . . . . . . 50

3.4.1.1 Zeolite Upgrading of Biocrude to High Octane

Gasoline - NREL . . . . . . . . . . . . 50

3.4.2 Upgrading Using Hydrotreating Catalysts . . . . . . . . . 51

3.4.2.1. Catalytic Hydrotreating of Biocrude Oil -

Pacific Northwest Laboratory (PNL) . . . . . . . . 51

3.5 BASIC PYROLYSIS RESEARCH $\ldots \ldots \ldots \ldots \ldots \ldots \ldots \ldots$

3.5.1 Use of a Molecular Beam/Mass Spectrometer

(MBMS) System . . . . . . . . . . . . . . . 53

3.5.1.1 Fundamental Pyrolysis Studies - NREL . . . . . . . 53

3.5.1.2 Rapid Characterization of Biomass and Biomass Tars . . . . . . . . . . . . 56

3.5.2 Other Basic Pyrolysis Studies . . . . . . . . . . . 57

3.5.2.1 Pyrolysis in Hydrogen and Methane Atmospheres Brookhaven National Laboratory (BNL) . . . . . . . 57

3.5.2.2 Affects of Pressure on Pyrolysis - Princeton Univ./ University of Hawaii . . . . . . . . . . . . . 59

3.6 OTHER BIOMASS PYROLYSIS PROJECTS $\ldots \ldots \ldots \ldots \ldots$

3.6.1 Other BTC Projects . . . . . . . . . . . . . . . 61

3.6.1.1 Analysis and Comparison of Biomass

Pyrolysis/Gasification Condensates - Pacific

Northwest Laboratory $(P N L)$. . . . . . . . . . . 61

3.6.1.2 Pyrolysis for Char Production - U. of Arkansas . . . . 63

3.6.2 BTC Program Participation in Liquefaction/Pyrolysis

Research Sponsored by the International Energy

Agency (IEA). . . . . . . . . . . . . . . . . . . 64

3.6.2.1 IEA Biomass Liquefaction/Pyrolysis Project . . . . . . . 64

\subsection{COMBUSTION RESEARCH}

4.1 COMBUSTION RESEARCH EMPHASIS

4.2.1 Direct Combustion/Gas Turbine System - Aerospace

Research Corp. . . . . . . . . . . . . . . . . . 65

4.2.2 Pyrolysis Oil Testing for Gas Turbines - Teledyne CAE . . . . 67

4.3 OTHER COMBUSTION PROJECTS . . . . . . . . . . 68

4.3.1 Biomass Fueled Stirling Engine - United Stirling, Inc. . . . . . 68

4.3.2 Basic Studies of Biomass Combustion - Jet Propulsion

Laboratory (JPL) . . . . . . . . . . . . . . . 68 
5.0 TECHNOECONOMIC ANALYSIS/SYSTEM STUDIES

5.1 RESEARCH EMPHASIS

5.2 TECHNOECONOMIC ANALYSES

5.2.1 Technoeconomic Analysis of Advanced Biomass

Technologies including Gasification, Liquefaction,

and Power Generation - SAIC International . . . . . . . . . . 69

5.3 SYSTEMS STUDIES . . . . . . . . . . . . . . . 71

5.3.1 Assessment Feedstock Availability - Pyros, Inc. . . . . . . 71

5.3.2 Solar Cost Data Bank - SRI International . . . . . . . . . 72

5.3.3 Evaluation of Catalysis in Biomass and Coal Conversion -

Catalytica Associates, Inc. . . . . . . . . . . . . . . 73

5.3.4 Research and Evaluation of Biomass Resources/

Conversion/Utilization Systems - Gilbert/Commonwealth

Associates, Inc.

6.0 FEEDSTOCK CHARACTERIZATION AND OTHER BIOMASS RESEARCH PROJECTS

6.1 FEEDSTOCK CHARACTERIZATION, AND INFLUENCES OF FEEDSTOCK ON CONVERSION

6.1.1 Biomass Characterization/IEA Standards Activity - NREL . . . . 75

6.1.2 The Effects of Biomass Properties on Conversion

Processes -Pacific Northwest Laboratory (PNL) . . . . . . . 76

6.2 RESEARCH ON THE USE OF VEGETABLE OILS FOR

FUELS

6.2.1 Oil Seeds as an Alternative Fuel Source - Tufts

University . . . . . . . . . . . . . . . . . . 76

6.3 OTHER PARTICIPATION IN THE INTERNATIONAL ENERGY

AGENCY'S BIOENERGY AGREEMENT (IEA/BA) . . . . . . . . 77

6.3.1 IEA/BA Biomass Conversion Task - PNL . . . . . . . . 77 


\section{THERMOCHEMICAL CONVERSION PROGRAM BIBLIOGRAPHY}

\subsection{GENERAL PROGRAM DOCUMENTS}

\subsection{Proceedings of Periodic Contractor Review Meetings}

National Renewable Energy Laboratory. 1988. Proceedings of the Thermochemcial Conversion Program Annual Meeting, June 21-22, 1988. SERI/CP-231-3355, National Renewable Energy Laboratory, Golden, Colorado.

Pacific Northwest Laboratory. 1987. Proceedings of the 1987 Biomass Thermochemical Conversion Contractors' Review Meeting, Atlanta, Georgia, May 20-21, 1987. CONF-8705212, Pacific Northwest Laboratory, Richland, Washington.

Pacific Northwest Laboratory. 1986. Proceedings of the 1985 Biomass Thermochemical Conversion Contractors' Meeting, Minneapolis, Minnesota, October 15-16, 1985. CONF-8510167, Pacific Northwest Laboratory, Richland, Washington.

Pacific Northwest Laboratory. 1984. Proceedings of the 16th Biomass Thermochemical Conversion Contractors' Meeting, Portland, Oregon, May 8-9, 1984. CONF-8405157, Pacific Northwest Laboratory, Richland, Washington.

Pacific Northwest Laboratory. 1983. Proceedings of the 15th Biomass Thermochemical Conversion Contractor's Meeting, Atlanta, Georgia, March 16-17, 1983. CONF-830323, Pacific Northwest Laboratory, Richland, Washington.

Pacific Northwest Laboratory. 1982. Proceedings of the 14th Biomass Thermochemical Conversion Contractor's Meeting, Arlington, Virginia, June 23-24, 1982. CONF-820685, Pacific Northwest Laboratory, Richland, Washington.

Pacific Northwest Laboratory. 1981. Proceedings of the 13th Biomass Thermochemical Conversion Contractor's Meeting, Arlington, Virginia, October 27-29, 1981. CONF-8110115, Pacific Northwest Laboratory, Richland, Washington.

Contractor's Review Meetings were also held between 1978 and 1980. Proceedings of these meetings were prepared but were not archived. In 1994, NREL started an effort to archive these these documents. Copies may be available from NTIS at a later date.

\subsection{Annual Program Reports}

Schiefelbein, G.F., D.J. Stevens, and M.A. Gerber. 1988. Biomass Thermochemical Conversion Program 1987 Annual Report. PNL-6614, Pacific Northwest Laboratory, Richland, Washington. 
Schiefelbein, G.F., D.J. Stevens, and M.A. Gerber. 1987. Biomass Thermochemical Conversion Program 1986 Annual Report. PNL-6282, Pacific Northwest Laboratory, Richland, Washington.

Schiefelbein, G.F., D.J. Stevens, and M.A. Gerber. 1986. Biomass Thermochemical Conversion Program 1985 Annual Report. PNL-5801, Pacific Northwest Laboratory, Richland, Washington.

Schiefelbein, G.F., D.J. Stevens, and M.A. Gerber. 1985. Biomass Thermochemical Conversion Program 1984 Annual Report. PNL-5442, Pacific Northwest Laboratory, Richland, Washington.

Schiefelbein, G.F., D.J. Stevens, and M.A. Gerber. 1984. Biomass Thermochemical Conversion Program 1983 Annual Report. PNL-5096, Pacific Northwest Laboratory, Richland, Washington.

Schiefelbein, G.F., D.J. Stevens, and M.A. Gerber. 1983. Biomass Thermochemical Conversion Program 1982 Annual Report. PNL-4779, Pacific Northwest Laboratory, Richland, Washington.

\subsection{Other Program Documents}

Schiefelbein, G.F. 1989. "Biomass Thermal Gasification Research: Recent Results from the United States DOE's Research Program." Biomass 19, 145-159.

Gerber, M. A. 1989. "Potential Energy Contribution from Medium-Btu Gas Produced from Biomass." Biomass 19:61-74

Schiefelbein, G. F. 1989. "Biomass Thermal Gasification Research: Recent Results from the United States DOE's Research Program." Biomass 19:145-149

Stevens, D. J. 1987. "Hydrocarbon Transportation Fuels from Biomass: An Overview of Thermal Conversion Research." In Proceedings of the 22nd Intersociety Energy Conversion Engineering Conference, pp. 936-94, American Institute of Aeronautics and Astronautics, New York.

Stevens, D. J. 1986. "Overview of Biomass Thermochemical Liquefaction Research Sponsored by the US Department of Energy." In Proceedings of the Intersociety Energy Conversion Engineering Conference, pp. 213-216, American Chemical Society, Washington D.C.

Stevens, D. J.and G. F. Schiefelbein. 1985. "Direct Conversion of Biomass to Liquids by Thermal Processes." Presented at the American Society of Agricultural Engineers Meeting, East Lansing, MI, 8 Jul 1985. PNL-SA-13281, CONF-8507731, Pacific Northwest Laboratory, Richland, Washington. 
Stevens, D. J. 1985. "Overview of the US Department of Energy's Biomass Thermochemical Conversion Program." Presented at the Solar and Biomass Energy Symposium, Atlanta, GA, 23 Apr 1985. PNL-SA-13008, Pacific Northwest Laboratory, Richland, Washington.

Schiefelbein, G. F. 1985. "Thermochemical Breakthroughs." Presented at the Renewable Energy Technologies Symposium and International Exposition, Anaheim, CA, 3 Jun 1985. PNL-SA-13214, Pacific Northwest Laboratory, Richland, Washington. 


\section{THERMOCHEMICAL CONVERSION PROGRAM BIBLIOGRAPHY}

\subsection{GASIFICATION}

\subsection{MEDIUM-ENERGY GASIFICATION RESEARCH}

\subsubsection{Larger Scale Medium Energy Gasification Projects}

\subsubsection{Circulating Fluidized Bed Gasifier - Battelle Columbus Laboratories}

Paisley, M. A., K. S. Creamer and T. L. Tewksbury. 1989. "Gasification of Refuse Derived Fuel in the Battelle High Throughput Gasification System." PNL-6998, Pacific Northwest Laboratory, Richland, Washington.

Feldmann, H. F., M. A. Paisley, H. R. Appelbaum and D. R. Taylor. 1988. "Conversion of Forest Residues to a Methane-Rich gas in a High-Throughput Gasifier." PNL-6570, Pacific Northwest Laboratory, Richland, Washington.

Feldman, M. F., and M. A. Paisley. 1988. "Conversion of RDF to Medium0BTU Gas." In Proceedings of the Thermochemical Conversion Program Annual Meeting, pp. 101-111, SERI/CP-231-3355, National Renewable Energy Laboratory, Golden, Colorado.

Feldmann, H. G., M. A. Paisley and H. R. Appelbaum. 1986. "Conversion of Forest Residues to a Methane-Rich Gas." PNL-5798, Pacific Northwest Laboratory, Richland, Washington.

Feldmann, H. F., M. A. Paisley, and H. R. Appelbaum. 1986. "Conversion of Forest Residues to a Methane-Rich Gas in a High Throughput Gasifier." In Proceedings of the 1985 Biomass Thermochemical Conversion Contractors' Meeting, pp. 339-360 CONF-8510167, National Technical Information Service, Springfield, Virginia.

Appelbaum, H. R., M. A. Paisley, and H. F. Feldmann. 1984. "Computer Modeling of the Battelle High Throughput Biomass Gasification System." 7th Energy Sources Technology Conference, February 12-16, 1984, New Orleans, Louisiana.

Feldmann, H. F., M. A. Paisley, and H. R. Appelbaum. 1984. "Scale-Up of a High Throughput Fluidized-Bed Gasifier to Produce Medium-Btu Gas (500 Btu/scf) from Wood." National Meeting on Biomass R\&D for Energy Applications, October 1-3, 1984.

Feldmann, H. F., M. A. Paisley, and H. R. Appelbaum. 1984. "Conversion of Forest Residues to a Methane-Rich Gas in a High Throughput Gasifier." In Proceedings of the 16th Biomass Thermochemical Conversion Contractors' Meeting, pp. 13-38 CONF-8405157, National Technical Information Service, Springfield, Virginia. 
Paisley, M. A., H. F. Feldmann, and H. R. Appelbaum. 1984. "Scale-Up of a High Throughput Gasifier to Produce Medium-Btu Gas (500 Btu/SCF) from Wood." In Proceedings of Energy from Biomass \& Wastes VIII, Institute of Gas Technology, Chicago, Illinois.

Chang, H., R. C. Nieman, K. E. Wilzbach and M. A. Paisley . 1983. "Environmental Characterization Studies of a High-Throughput Wood Gasifier." In Proceedings of Energy from Biomass \& Wastes VII, pp. 539-544. Institute of Gas Technology, Chicago, Illinois.

Feldmann, H. F., M. A. Paisley, and H. R. Appelbaum. 1983. "Gasification of Forest Residues in a High-Throughput Gasifier." In Proceedings of the 15th Biomass Thermochemical Conversion Contractors' Meeting, pp. 31-90, CONF-830323, National Technical Information Service, Springfield, Virginia.

Paisley, M. A., K. E. Wilzback, and H. Chang. 1983. "Environmental Characterization Studies of a High-Throughput Wood Gasifier." In Proceedings of Energy from Biomass \& Wastes VII, Institute of Gas Technology, Chicago, Illinois.

Feldmann, H. F., M. A. Paisley, and H. R. Appelbaum. 1982. "Gasification of Forest Residues in a High-Throughput Gasifier." In Proceedings of the 14th Biomass Thermochemical Conversion Contractors' Meeting, pp. 46-70, CONF-820685, National Technical Information Service, Springfield, Virginia.

Feldmann, H. F., P. S. Choi, H. NB. Conkle, and S. P. Chauhan. 1981. "Gasification of Forest Residues." In Biomass As A Nonfossil Fuel Source, ACS Symp. Ser., No. 144.

Battelle Columbus Laboratories. 1981. "Summary Report on Conversion of Forest Residues to a Methane-Rich Gas in a High-Throughput Gasifier." October 1981. Battelle Columbus Laboratory, Columbus, Ohio.

Feldmann, H. F., et al. 1981. "Gasification of Forest Residues to Produce a Methane-Rich Gas." In Proceedings of the 13th Biomass Thermochemical Conversion Contractors' Meeting, pp. 1-26, CONF-8110115, National Technical Information Service, Springfield, Virginia.

Battelle Columbus Laboratories. 1981. "Conversion of Forest Residues to a Methane-Rich Gas." In Proceedings of the 12th Biomass Thermochemical Conversion Contractors' Meeting, March 18-19, 1981, Washington, DC.

Feldmann, H. F., P. S. Choi, M. A. Paisley, S. P. Chauhan, C. J. Robb, D. W. Folsom, and B. C. Kim. 1981. "Steam Gasification of Wood in a Multi-Solid Fluidized-Bed (MSFB) Gasifier." In Energy From Biomass \& Wastes V, Institute of Gas Technology, Chicago, Illinois.

Feldmann, H. F., M. A. Paisley, D. W. Folsom, C. J. Robb, and B. C. Kim. 1981. "Gasification of Forest Residues to Produce a Methane-Rich Gas." Paper presented at the 1981 International Gas Research Conference, Los Angeles, California, September 28 - October 1. 
Feldmann, H. 1980. "Conversion of Forest Residues to a Methane-Rich Gas." In Proceedings of the 11th Biomass Thermochemical Conversion Contractors' Meeting, September 23-24, 1980, Richland, Washington.

Feldmann, H. 1980. "Conversion of Forest Residues to a Methane-Rich Gas." In Proceedings of the 10th Biomass Thermochemical Conversion Contractors' Meeting, February 12-13, 1980 , Berkeley, California.

Feldmann, H. 1979. "Conversion of Forest Residues to a Methane-Rich Gas." In Proceedings of the 9th Biomass Thermochemical Conversion Contractors' Meeting, November 7-8, 1979, Rolla, Missouri.

Feldmann, H. 1979. "Conversion of Forest Residues to a Methane-Rich Gas." In Proceedings of the Eighth Biomass Thermochemical Conversion Contractors' Meeting. July 31 - August 1, 1979, Seattle, Washington.

Feldmann, H. 1979. "Conversion of Forest Residues to a Methane-Rich Gas." In Proceedings of the Seventh Biomass Thermochemical Conversion Contractors' Meeting, April 24-25, 1979, Roanoke, Virginia.

Feldmann, H. F., P. S. Choi, and K. T. Liu. 1979. "Conversion of Forest Residues to a Methane-Rich Gas." In Proceedings of the Sixth Biomass Thermochemical Conversion Contractors' Meeting, January 16-17, 1979, Tucson, Arizona.

Feldmann, H. F. 1978. "Conversion of Forest Residues to a Methane-Rich Gas." In Proceedings of the Fifth Biomass Thermochemical Conversion Coordination Meeting: Fuels From Biomass Program, September 19-20, 1978, Fresno and Hanford, California.

Liu, K. T., and H. F. Feldmann. 1977. "Conversion of Forest Residues to a Methane-Rich Gas." In Proceedings of the Thermochemical Conversion of Biomass Third Contractors' Meeting, October 26, 1977, Ballston Spa, New York. 


\subsubsection{Fluidized Bed Gasifier With Internal Heat Exchangers - University of Missouri- Rolla}

Flanigan, V. J., O. C. Sitton and W. E. Huang. 1988. "The Development of a 20-Inch Indirect Fired Fluidized Bed Gasifier." PNL-6520, Pacific Northwest Laboratory, Richland, Washington.

Flanigan, V. J., W. E. Huang, E. Clancy, and O. C. Sitton. 1986. "Commercial Design of an Indirect Fired Fluid Bed Gasifier System." In Proceedings of the 1985 Biomass Thermochemical Conversion Contractors' Meeting, pp. 319-338, CONF-8510167, National Technical Information Service, Springfield, Virginia.

Flanigan, V. J., and W. O'Neill. 1984. "Development of a Low-Cost Fluidized Bed Gasifier Gas Engine System for Use in Remote Areas." In Energy from Biomass and Wastes VIII, Institute of Gas Technology, Chicago, Illinois.

Flanigan, V. J., A. Punyakumleard, H. H. Sineath, and O. C. Sitton. 1984. "20' Fire Tube Gasification System." In Proceedings of the 16th Biomass Thermochemical Conversion Contractors' Meeting, pp. 83-102, CONF-8405157, National Technical Information Service, Springfield, Virginia.

Flanigan, V. J., A. Punyakumleard, and O. C. Sitton. 1984. "Steam Gasification of Wood by Indirect Fired Internal Heating." In Proceedings of the 6th Symposium of Biotechnology for Fuels and Chemicals, C. D. Scott, ed., Symposium No. 14, pp. 3-14, John Wiley \& Sons, New York, New York.

Flanigan, V. J., and J. Chereau. 1983. "Effect of Operating Conditions on Gas Quality and Conversion Efficiency of a Fluidized-Bed Gasifier for Wood, Manure, and Peat." In Proceedings of Energy from Biomass and Wastes VII, Institute of Gas Technology, Chicago, Illinois.

Flanigan, V. J., M. E. Findley, and H. Sineath. 1983. "Steam Gasification of Wood in a Fluidized Bed Using Indirect Heating Fire Tubes." In Proceedings of the 15th Biomass Thermochemical Conversion Contractors' Meeting, pp. 14-30, CONF-830323, National Technical Information Service, Springfield, Virginia.

Lin, T. J. 1983. "Fixed Bed Wood Gasification with Recirculation." Master's Thesis, University of Missouri-Rolla, Rolla, Missouri.

O'Neill, W. 1983. "Fluidized Bed Char Gasifier." Master's Thesis, University of Missouri, Rolla, Missouri.

O'Reilly, C. 1983. "An Internally Heated Steam Fluidized-Bed Wood Gasifier." Master's Thesis, University of Missouri-Rolla, Rolla, Missouri. 
Sineath, H. H. 1983. "Steam Gasification of Wood in a Fluidized Bed Using Indirect Heating Fire Tubes." In Proceedings of the 15th Biomass Thermochemical Conversion Contractors' Meeting, pp. 14-30, CONF-830323, National Technical Information Service, Springfield, Virginia. 


\subsubsection{Pressurized Fluidized-Bed, Oxygen-Blown Gasifier - Institute of Gas Technology}

Evans, R. J., R. A. Knight, M. Onischak and S. P. Babu. 1988. "Development of Biomass Gasification to Produce Substitute Fuels." PNL-6518, Pacific Northwest Laboratory, Richland, Washington.

Evans, R. J., et al. 1987. "Process Performance and Environmental Assessment of Renugas Process." In Proceedings of Energy From Biomass and Waste X, pp. 677-696. Institute of Gas Technology, Chicago, Illinois.

Evans, R. J., M. Onischak, R. A. Knight and S. P. Babu. 1986. "Gasification of Wood Wastes in the Renugas Process." In Proceedings of the 1986 Distribution/Transmission Conference, CONF-86042184, American Gas Association, Chicago, Mlinois.

Evans, R. J., R. A. Knight, M. Onischak, and S. P. Babu. 1986. "Development of Biomass Gasification to Produce Substitute Fuels." In Proceedings of the 1985 Biomass Thermochemical Conversion Contractors' Meeting, pp. 271-294, CONF-8510167, National Technical Information Service, Springfield, Virginia.

Evans, R. J., et al. 1986. "Process Performance and Environmental Assessment of Renugas Process." In the Energy From Biomass and Wastes X, Institute of Gas Technology, Chicago, Illinois.

Nandi, S. P., and M. Onischak. 1985. "Gasification of Chars Obtained From Maple and Jack Pine Woods," Fundamentals of Thermochemical Biomass Conversion, pp. 567-588, eds. R. Overend, T. A. Milne, and L. K. Mudge, Elsevier Applied Science Publishers, London.

Evans, R. J., R. A. Knight, and G. M. Kosowski. 1985. "Operating Results From a Pressurized Fluidized Bed Biomass Gasification Process." In Proceedings of Energy from Biomass and Wastes IX, Institute of Gas Technology, Chicago, Illinois.

Onischak, M., S. P. Babu and W. G. Bair. 1985. "Development of the IGT (Institute of Gas Technology) Renugas Process." Presented at the 12th Annual Energy Technology Conference and Exposition, Washington, DC, 25 Mar 1985. CONF-8503018, National Technical Information Service, Springfield, Virginia.

Kosowski, G. M., M. Onischak, and S. P. Babu. 1984. "Development of Biomass Gasification to Produce Substitute Fuels." In Proceedings of the 16th Biomass Thermochemical Conversion Contractors' Meeting, pp. 39-59, CONF-8405157, National Technical Information Service, Springfield, Virginia.

Kosowski, G. M., M. Onischak, and S. P. Babu. 1984. "Development of Pressurized Fluidized-Bed Gasification of Biomass." In Energy From Biomass and Wastes VIII, Institute of Gas Technology, Chicago, Illinois. 
Kosowski, G. M., M. Onischak, and S. P. Babu. 1983. "Development of Biomass Gasification to Produce Substitute Fuels." In Proceedings of the 15th Biomass Thermochemical Conversion Contractors' Meeting, pp. 130-183, CONF-830323, National Technical Information Service, Springfield, Virginia.

Babu, S. P., M. Onischak, and G. Kosowski. 1982. "Development of a Pressurized Fluidized Bed Biomass Gasifier to Produce Substitute Fuels." Presented at Biomass to Methanol Specialists' Workshop, March 3-5, 1982, Durango, Colorado.

Kosowski, G. M., G. R. Rose, S. P. Nandi, M. Onischak, R. F. Zabransky, and S. P. Babu. 1982. "Development of Biomass Gasification to Produce Substitute Fuels." In Proceedings of the 14th Biomass Thermochemical Conversion Contractors' Meeting, pp. 71-149, CONF820685, National Technical Information Service, Springfield, Virginia.

Kosowski, G. M., G. R. Rose, S. P Nandi, S. P. Singh, M. Onischak, R. F. Zabransky, and S. P. Babu. 1982. "Development of Biomass Gasification to Produce Substitute Fuels." Project 65058 Technical Progress Report for the period September 15 through December 15, 1981, Institute of Gas Technology, Chicago, Illinois.

Nandi, S. P. 1982. "Gasification of Chars Obtained from Maple and Jack Pine Woods." Fundamentals of Thermochemical Biomass Conversion. Elsevier Applied Science, New York.

Kosowski, G. M., G. R. Rose, S. P. Nandi, S. P. Singh, M. Onischak, R. F. Zabransky, and S. P. Babu. 1981. "Development of Biomass Gasification to Produce Substitute Fuels." In Proceedings of the 13th Biomass Thermochemical Conversion Contractors' Meeting, pp. 89-154, CONF-8110115, National Technical Information Service, Springfield, Virginia.

Kosowski, G. M., G. F. Rose, S. P. Nandi, S. P. Singh, M. Onischak, and S. P. Babu. 1981. "Development of Hydroconversion of Biomass to Synthetic Fuels." In Proceedings of the 12th Biomass Thermochemical Conversion Contractors' Meeting, March 18-19, 1981, Washington, DC.

Institute of Gas Technology. 1980. "Development of Hydroconversion of Biomass." In Proceedings of the 11th Biomass Thermochemical Conversion Contractors' Meeting, September 23-24, 1980, Richland, Washington. 


\subsubsection{Down-Draft Oxugen-Blown Gasifier - National Renewable Energy Laboratory and SynGas, Inc.}

Reed, T. B., B. Levie and M. S. Graboski. 1988. "Fundamentals, Development and Scaleup of the Air-Oxygen Stratified Downdraft Gasifier." PNL-6600, Pacific Northwest Laboratory, Richland, Washington.

Reed, T. B., B. Levie, J. Scahill, R. Evans, and T. Milne. 1986. "Moving-Bed Air and Oxygen Biomass Gasification." In Proceedings of the 1985 Biomass Thermochemical Conversion Contractors' Meeting, pp. 295-318, CONF-8510167, National Technical Information Service, Springfield, Virginia.

Reed, T. B., M. Markson, anM. Grabowski. 1982. "The SERI High Pressure Oxygen Gasifier." Biomass to Methanol Specialists Workshop, eds. T. B. Reed and M. Grabowski, SERI/CP-234-1590, National Renewable Energy Laboratory, Golden, Colorado.

Reed, T. B., M. Grabowski, and M. Markson. 1982. "Synthesis Gas from Biomass: Operating Data on a 1-Ton/Day Oxygen Gasifier." Biomass to Methanol Specialists Workshop, eds. T. B. Reed and M. Grabowski, SERI/CP-234-1590, National Renewable Energy Laboratory, Golden, Colorado.

Note: Additional references on other fixed-bed gasification research performed by Dr. Tom Reed at National Renewable Energy Lab are listed in section 2.3.3.2 of this report. 


\subsubsection{Additional Indirectly-Heated, Medium-Energy Gasification Projects}

\subsubsection{Pulsed, Fluidized-Bed Gasification - Manufacturing and Technology Conversion International (MTCI)}

Manufacturing and Technology Conversion International, Incorporated. 1990. "Testing of an Advanced Thermochemical Conversion Reactor System." PNL-7245, Pacific Northwest Laboratory, Richland, Washington.

Durai-Swamy, K., D. W. Warren, and S. C. Che. 1988. Pulse-Enhanced Biomass Gasifier for Production of Medium-BTU Gas." In Proceedings of the Thermochemical Conversion Program Annual Meeting, pp. 77-86, SERI/CP-231-3355, National Renewable Energy Laboratory, Golden, Colorado.

\subsubsection{Ceramic Fire Tubes for Fluidized-Bed Gasifiers - University of Nebraska}

Ahmed, S., and L. D. Clements. 1988. "Kinetics of Biomass Pyrolysis With Radiant Heating," Research in Thermochemical Biomass Conversion, pp. 294-311, eds. A. V. Bridgwater and J. L. Kuester, Elsevier Applied Science, London.

Clements, L. D., S. Ahmed, J. Carlberg, T. Dinh, and W. J. Ho. 1986. "Development of an Indirectly Heated Biomass Pyrolysis Reactor." In Proceedings of the 1985 Biomass Thermochemical Conversion Contractors' Meeting, pp. 211-233, CONF-8510167, National Technical Information Service, Springfield, Virginia.

Clements, L. D., C. H. Cho. H. Y. Fang, and L. L. Ginn. 1984. "Developmenmt of an Indirectly Heated Fire Tube Biomass Pyrolysis Reactor." In Proceedings of the 16th Biomass Thermochemical Conversion Contractor's Meeting, p. 129. CONF 8405157, National Technical Information Service, Springfield, Virginia.

Cho, C. H. 1984. "Effect of Degree of Fluidization on Wall-To-Bed High Temperature Heat Transfer with a Single, Vertical Heater." Ph.D Dissertation, Texas Tech University, Lubbock, Texas.

Fang, H. Y. 1984. "Development, Performance Measurement, and Modeling of a Packed-Bed, Fire-Tube Heater. Ph.D Dissertation, Texas Tech University, Lubbock, Texas.

Clements, L. D., et. al. 1983. "Development of an Indirectly Heated Biomass Pyrolysis Reactor, Final Report." Texas Tech University, Lubbock, Texas.

Clements, L. D., C. H. Cho, H. R. Fang, and L. L. Ginn. 1984. "Development of an Indirectly Heated Fire-Tube Biomass Pyrolysis Reactor." In Proceedings of the 16th Biomass Thermochemical Contractors' Meeting, pp. 129-160, CONF-8405157, National Technical Information Service, Springfield, Virginia. 
Clements, L. D., C. H. Cho, R. Moser, H. Y Fang, L. L. Ginn, and J. P. Jeffrey. 1983. "Development of an Indirectly heated Pyrolysis Reactor." In Proceedings of the 15th Biomass Thermochemical Conversion Contractors' Meeting, pp. 181-222, CONF-830323, National Technical Information Service, Springfield, Virginia.

Clements, L. D., et al. 1982. "Development of an Indirectly heated Biomass Pyrolysis Reactor." In Proceedings of the 14th Biomass Thermochemical Conversion Contractors' Meeting, pp. 202-229, CONF-820685, National Technical Information Service, Springfield, Virginia.

Clements, L. D., and S. M. Oliver. 1982. "Pyrolysis by Indirect Radiant Heating: A Unique Biomass Gasification Reactor." Alternative Energy Sources IV, ed., T. N. Veziroglu, pp. 351374, Ann Arbor Science Publishers, Ann Arbor, Michigan.

Jeffrey, J. P. 1982. "Pyrolysis of Cellulose by Radiant Heating." M.S. Thesis, Texas Tech University, Lubbock, Texas.

Clements, L. D., et al. 1981. "Development of an Indirectly Heated Biomass Pyrolysis Reactor." In Proceedings of the 13th Biomass Thermochemical Conversion Contractors' Meeting, pp. 27-70, CONF-8110115, National Technical Information Service, Springfield, Virginia.

Clements, L. D., C. H. Cho, and J. P. Jeffrey. 1981. "Development of an Indirectly Heated Biomass Pyrolysis Reactor." In Proceedings of the 12th Biomass Thermochemical Conversion Contractors' Meeting, March 18-19, 1981, Washington, D.C.

Ginn, L. L. 1984. "Effect of Internals on the Behavior of a Biomass Fluidized Bed." M.S. Thesis, Texas Tech University, Lubbock, Texas.

Clements, L. D., and S. Selim. 1980. "Development of an Indirectly heated Biomass Pyrolysis Reactor." In Proceedings of the 11th Biomass Thermochemical Conversion Contractors' Meeting, September 23-24, 1980, Richland, Washington. 


\subsubsection{Pressurized Rotary Kiln Gasifier - Wright-Malta Corporation}

Coffman, J. A. 1982. "Steam Gasification of Biomass." In Proceedings of the 14th Biomass Thermochemical Conversion Contractors' Meeting, pp. 32-45, CONF-820685, National Technical Information Service, Springfield, Virginia.

Coffman, J. A. 1981. "Steam Gasification of Biomass." In Proceedings of the 13th Biomass Thermochemical Conversion Contractors' Meeting, pp. 274-296, CONF-8110115, National Technical Information Service, Springfield, Virginia.

Coffman, J. A. 1980. "Steam Gasification of Biomass Semi-Annual Progress Report." In Proceedings of the 11th Biomass Thermochemical Conversion Contractors' Meeting, September 23-24, 1980, Richland, Washington.

Coffman, J. A. 1980. "Steam Gasification of Biomass Quarterly Progress Report. In Proceedings of the 10th Biomass Thermochemical Contractors' Meeting, February 12, 1980, Berkeley, California.

Coffman, J. A. 1979. "Steam Gasification of Biomass Quarterly Progress Report." In Proceedings of the 9th Biomass Thermochemical Conversion Contractors' Meeting, November 7-8. 1979, Rolla, Missouri.

Catalyzed Steam Gasification of Biomass Phase II. 1979. In Proceedings of the Sixth Biomass Thermochemical Conversion Contractors' Meeting, January 16-17, 1979, Tucson, Arizona.

Wright-Malta Corporation. 1979. Catalyzed Steam Gasification of Biomass: Phase II. Progress Report No. COO/4736-1, 2, 3. Wright-Malta Corporation, Ballston Spa, New York.

Wright Malta Corporation. 1978. Catalyzed Steam Gasification of Biomass Phase II. In Proceedings of the Fifth Biomass Thermochemical Conversion Coordination Meeting: Fuels From Biomass Program, September 19-20, 1978, Fresno and Hanford, California.

Coffman, J. 1977. "Steam Gasification of Biomass." In Proceedings of the Thermochemical Conversion of Biomass Third Contractors' Meeting, October 26, 1977, Ballston Spa, New York. 


\subsubsection{Pyrolytic Gasification of Wastes - Garrett Energy Research and Engineering Co. (GERE)}

Garrett, D. E. 1979. "Thermal Conversion of Biomass into Medium Btu Gas in a Multiple Hearth Type Furnace." In Proceedings of the Eighth Biomass Thermochemical Conversion Contractors' Meeting, July 31 - August 1, 1979, Seattle, Washington.

Garrett, D. E. 1979. "A Multiple Hearth Medium BTU Gasifier." In Proceedings of the Seventh Biomass Thermochemical Conversion Contractors' Meeting, April 24-25, 1979, Roanoke, Virginia.

Garrett, D. E. 1979. "Biomass Gasification Process Development Unit." In Proceedings of the Sixth Biomass Thermochemical Conversion Contractors' Meeting, January 16-17, 1979, Tucson, Arizona.

Mikesell, R.D., and D. C. Hoang. 1978. "Garrett Energy Research \& Engineering Co., Biomass Gasification Process Development Unit." In Proceedings of the Fifth Biomass Thermochemical Conversion Coordination Meeting: Fuels From Biomass Program, September 19-20, 1978, Fresno and Hanford, California.

Garrett, D. E. 1977. "Gas Production in a Multiple Hearth Reactor." In Proceedings of the Thermochemical Conversion of Biomass Third Contractors' Meeting, October 26, 1977, Ballston Spa, New York.

Garrett, D. E. 1977. "Conversion of Biomass Materials into Gaseous Products." In Proceedings of Fuels From Biomass Program Thermochemical Coordination Meeting, February 23 1977, Lubbock, Texas. 


\subsubsection{Additional Oxygen-Blown, Medium Energy Gasificaton Projects}

\subsubsection{Oxygen-Blown Gasification Research - Texas Tech University}

Beck, S. R., et al. 1982. "Application of SGFM Technology to Alternate Feedstocks - Phase III." In Proceedings of the 14th Biomass Thermochemical Conversion Contractors' Meeting, pp. 1-8, CONF-820685, National Technical Information Service, Springfield, Virginia.

Beck, S. R., et al. 1981. "Application of SGFM Technology to Alternate Feedstocks - Phase III." In Proceedings of the 13th Biomass Thermochemical Conversion Contractors' Meeting, pp. 199-244, CONF-8110115, National Technical Information Service, Springfield, Virginia.

Beck, S. R., U. Mann, R. A. Bartsch, J. Yr, R-C. Wang, and R. Ruggieri. 1981. "Application of SGFM Technology to Alternate Feedstocks - Phase III." In Proceedings of the 12th Biomass Thermochemical Conversion Contractors' Meeting, March 18-19, 1981, Washington, DC.

Beck, S. R., M. J. Wang, and J. A. Hightower. 1981. "Gasification of Oak Sawdust, Mesquite, Corn Stover, and Cotton Gin Trash in a Countercurrent Fluidized Bed Pilot Reactor." Biomass as a Nonfossil Fuel Source, ed., D. L. Klass, ACS Symp. Ser., \#144, p. 335.

Beck, S. R., and M. J. Wang. 1980. "Wood Gasification in a Fluidized Bed." Ind. Eng. Chem. Proc. Des. Dev., 19, pp. 312-317.

Beck, S. R., U. Mann, R. A. Bartsch, F. Thurner, J. Yu, D. Kao, and R. Ruggieri. 1980. "Application of SGFM Technology to Other Feedstocks - Phase III." In Proceedings of the 11th Biomass Thermochemical Conversion Contractors' Meeting, September 23-24, 1980, Richland, Washington.

Beck, S. R., R. A. Bartsch, and U. Mann. 1980. "Application of SGFM Technology to Alternate Feedstocks - Phase III." In Proceedings of the 10th Biomass Thermochemical Conversion Contractors' Meeting, February 12-13, 1980, Berkeley, California.

Kao, C. H. 1980. "Extraction of Waste Water from Biomass Gasification." M.S. Thesis, Texas Tech University, Lubbock, Texas.

Beck, S. R. 1979. "Application of SGFM Technology to Other Feedstocks." In Proceedings of the 3rd Annual Biomass Energy Systems Conference, U.S. DOE Report No. SERI/TP-33285, pp. 339-347, Solar Energy Research Institute, Golden, Colorado.

Beck, S. R., R. A. Bartsch, J. A. Hightower, U. Mann. 1979. "Application of SGFM Technology to Alternate Feedstocks - Phase III." In Proceedings of the 9th Biomass Thermochemical Conversion Contractors' Meeting, November 7-8, 1979, Rolla, Missouri. 
Beck, S. R., W. J. Huffman, B. C. Landeene, and J. E. Halligan. 1979. "Pilot Plant Results for Partial Oxidation of Cattle Feedlot Manure." Ind. Eng. Chem. Proc. Des. Dev., 18(2), p. 328.

Beck, S. R., M. J. Wang, and J. A. Hightower. "Application of SGFM Technology to Alternate Feedstocks." In Proceedings of the Eighth Biomass Thermochemical Conversion Contractors' Meeting, July 31 - August 1, 1979, Seattle, Washington.

Beck, S. R., M. J. Wang, J. A. Hightower, R. A. Bartsch, and R. J. Ruggieri. 1979. "Biomass Gasification in the SGFM Process." In Proceedings of the Seventh Biomass Thermochemical Conversion Contractors' Meeting, April 24-25, 1979, Roanoke, Virginia.

Beck, S. R., R. A. Bartsch, M. J. Wang, and D. Siller. 1979. "Application of SGFM Technology to Other Feedstocks, Phase II. In Proceedings of the Sixth Biomass Thermochemical Conversion Contractors' Meeting, January 16-17, 1979, Tucson, Arizona.

Siller, D. 1979. "Analysis of Waste Streams from the SGFM Reactor." M.S. Thesis, Texas Tech University, Lubbock, Texas.

Beck, S. R. 1978. "Fluidized Bed Gasification of Cattle Feedlot Manure." In Proceedings of the Second Annual Fuels From Biomass Symposium, ed., W. Shuster, pp. 269-285, RPI, Troy, New York.

Beck, S. R., W. J. Huffman, J. E. Halligan, B. C. Landeene, C. S. Lin, R. Ravi, R. A. Bartsch, and P. E. Hillman. 1978. "Partial Oxidation - Pyrolysis of Cattle Feedlot Manure in the SGFM Reactor." U.S. DOE Report No. AL0/3779-1.

Beck, S. R., U. Mann, H. D. Wong, M. J. Wang. 1978. "Application of SGFM Technology to Other Feedstocks, Phase II. In Proceedings of the Fifth Biomass Thermochemical Conversion Coordination Meeting: Fuels From Biomass Program, September 19-20, 1978, Fresno and Hanford, California.

Huffman, W. J., S. R. Beck, R. A. Bartsch, B. C. Landeene, C. S. Lin, and H. D. Wong. 1977. "Application of SGFM Technology to Other Feedstocks - A Review." In Proceedings of the Thermochemical Conversion of Biomass Third Contractors' Meeting, October 26, 1977, Ballston Spa, New York.

Huffman, W. J., J. E. Halligan, R. A. Bartsch, R. L. Peterson, E. de la Garza, B. C. Landeene, and P. E. Hillman. 1977. "Application of SGFM Technology to Other Feedstocks: Status Report." In Fuels from Biomass Program Thermochemical Coordination Meeting, February 23, 1977, Lubbock, Texas. 


\subsubsection{Pressurized, Fixed-Bed Oxygen-Blown Gasification - National Renewable Energy Laboratory (NREL)}

Reed, T.. B, and Markson, M. 1985. "Reaction Velocities in a Downdraft Gasifier." Fundamentals of Thermochemical Biomass Conversion, eds. R. Overend, T. A. Milne, and L. K. Mudge, Elsevier Applied Science Publishers, London.

Reed, T. B., B. Levie, and A. Das. 1985. "Understanding, Operating, and Testing Fixed-Bed Gasifiers." In Bioenergy '84, eds. H. Egneus and A. Ellegard, Elsevier, London.

Reed, T. B., B. Levie, J. Scahill, R. Evans, and T. Milne. 1986. "Moving Bed Air and Oxygen Gasification." Proceedings of the 1985 Biomass Thermochemical Conversion Contractor's Meeting, pp. 295-318, CONF 8510167, National Technical Information Service, Springfield, Virginia.

Reed, T. B. 1985. "Principles and Technology of Biomass Gasification." Advances in Solar Energy 2, eds. K. W. Boer and J. A. Duffie, Plenum Press, pp. 125-174.

Reed, T. B., and B. Levie. 1984. "A Simplified Model of the Stratified Downdraft Gasifier." The International Bio-Energy Directory and Handbook 1984. ed. P. Bente, Bio-Energy Council, Washington D.C.

Reed, T. B., B. Levie, M. L. Markson, and M. S. Grabowski. 1983. In Proceedings of the Symposium on Mathematical Modeling of Biomass Pyrolysis Phenomena, Am. Chem Soc. Division of Fuel Chemistry Vol. 28(5).

Reed, T. B., and M. Markson. 1983. "A Predictive Model for Stratified Downdraft Gasification of Biomass." In Progress in Biomass Conversion, Vol 4, eds. D. Tillman and E. Jahn. Academic Press, New York.

Reed, T. B., M. Markson, and M. Graboski. 1983. "The SERI High Pressure Oxygen Gasifier." In Proceedings of the Biomass-to-Methanol Specialists' Workshop, eds. T. Reed and M. Graboski, SERI/CP-234-1590, Solar Energy Research Institute, Golden, Colorado.

Reed, T. B., M. Graboski, and M. Markson. 1981. "Synthesis Gas From Biomass: Operating Data on a 1 Ton/Day Oxygen Gasifier." In Proceedings of the 13th Biomass Thermochemical Conversion Contractors' Meeting, pp. 175-198, CONF-8110115, National Technical Information Service, Springfield, Virginia.

Reed, T., ed. 1981. "A Survey of Biomass Gasification, Vols. I-III." SERI/TR-33-239, National Renewable Energy Laboratory, Golden, Colorado.

Reed, T., Ed. 1981. "Biomass Gasification: Principles and Technology." Energy Technology Review No. 67, Noyes Data Corp., Park Ridge, New Jersey. 
Reed, T. B., J. Diebold, and R. Desrosiers. 1981. "Heat Transfer Perspectives." Proceedings of the Specialists Conference on Fast Pyrolysis of Biomass, ed. J. Dioebold, SERI/CP-622-1096.

Desrosiers, R. 1981. "Fundamental Air-Gasification Engineering Parameters." In Proceedings of the 13th Biomass Thermochemical Conversion Contractors' Meeting, pp. 697-717, CONF8110115, National Technical Information Service, Springfield, Virginia.

Desrosiers, R., and G. Richey. 1981. "Gasification Engineering - Quarterly Report,, January March 1981." SERI/PR-622-1153, Solar Energy Research Institute, Golden, Colorado.

Desrosiers, R. 1981. "Gasification Engineering." In Proceedings of the 12th Biomass Thermochemical Conversion Contractors' Meeting, March 18-19, 1981, Washington, DC. 


\subsubsection{Alternative Medium-Energy Gasification approaches}

\subsubsection{Gasification of High-Moisture Biomass Feedstocks - Pacific Northwest Laboratory (PNL)}

Elliott, D.C., G. G. Neuenschwander, T. R. Hart, M. R. Phelps and L. J. Sealock. 1993. "Low-Temperature Catalytic Gasification of Wet Industrial Wastes. FY 1991-1992 Interim Report. Progress Report." PNL-8739, Pacific Northwest Laboratory, Richland, Washington.

Elliott, D. C. and T. H. Scheer. 1992. "Assessment of TEES(reg sign) Applications for Wet Industrial Wastes: Energy Benefit and Economic Analysis Report." PNL-7990, Pacific Northwest Laboratory, Richland, Washington.

Elliott, D. C., G. G. Neuenschwander, E. G. Baker, R. S. Butner and L. J. Sealock. 1990. "Bench-Scale Reactor Tests of Low-Temperature, Catalytic Gasification of Wet, Industrial Wastes." Presented at the Intersociety Energy Conversion Engineering Conference (25th), Reno, NV, 12-17 Aug 1990. PNL-SA-17707, CONF-90080136, Pacific Northwest Laboratory, Richland, Washington.

Sealock, L. J., D. C. Elliott, R. S. Butner and G. G. Neuenschwander. 1989. "Low-Temperature Conversion of High-Moisture Biomass: Continuous Reactor System Results." PNL-7126, Pacific Northwest Laboratory, Richland, Washington.

Sealock, L. J., D. C. Elliott, R. S. Butner and G. G. Neuenschwander. 1988. "Low-Temperature Conversion of High-Moisture Biomass: Topical Report, January 1984-January 1988." PNL-6726, Pacific Northwest Laboratory, Richland, Washington.

Elliott, D. C., R. S. Butner and L. J. Sealock. 1988. "Low-temperature Gasification of High-Moisture Biomass," Research on Thermochemical Biomass Conversion, pp. 696-710, eds. A. V. Bridgwater, and J. L. Kuester, Elsevier Applied Science, New York.

Butner, R. S., L. J. Sealock, D. C. Elliott and G. G. Neuenschwander. 1988. " Thermochemical Conversion of High-Moisture Biomass Feedstocks." In Proceedings of the Thermochemical Conversion Program Review Meeting, SERI/CP-231-3355, National Renewable Energy Laboratory Golden, Colorado.

Butner, R. S., D. C. Elliott, L. J. Sealock and G. G. Neuenschwander. 1988. "Thermochemical Gasification of Wet Biomass and Wastes." In Proceedings of the American Institute of Chemical Engineers Spring National Meeting, New Orleans, LA. PNL-SA-15703, CONF-8803484, National Technical Information Service, Springfield, Virginia.

Butner, R. S., D. C. Elliott, and L. J. Sealock, Jr. 1987. "Low-Temperature Thermochemical Conversion of High Moisture Biomass Feedstocks." In Proceedings of the 1987 Biomass Thermochemical Conversion Contractors' Review Meeting, pp. 99-113, CONF-8705212, National Technical Information Service, Springfield, Virginia. 
Butner, R. S., D. C. Elliott, and L. J. Sealock, Jr. 1987. "Energy Recovery from Aquatic Biomass in a Thermochemical Gasifier." In Aquatic Plants for Water Treatment and Resource Recovery, eds. K. R. Reddy and W. H. Smith, pp. 739-745. Magnolia Publishing, Inc., Orlando, Florida.

Butner, R. S., D. C. Elliott, and L. J. Sealock, Jr. 1987. "The Effects of Catalyst Type and Concentration on Thermal Gasification of High-Moisture Biomass Feedstocks." Biotechnology and Bioengineering. 17:169-177.

Butner, R. S., D. C. Elliott, and L. J. Sealock, Jr. 1987. " Thermochemical Conversion of High Moisture Biomass Feedstocks to Methane-Rich Gas Products." In Energy from Biomass and Wastes X, ed. D. L. Klass, pp. 1645-1646. Institute of Gas Technology, Chicago, Illinois.

Elliott, D. C., L. J. Sealock, Jr., and R. S. Butner. 1987. "Product Analysis from Direct Liquefaction of Several High-Moisture Biomass Feedstocks." Amer. Chem. Soc. Div. Fuel Chem. Preprts. 32(2):186-194.

Butner, R. S., D. C. Elliott, L.J. Sealock and D. P. Chynoweth. 1987. "Process Study of the Biothermal Conversion of Water Hyacinths to Methane." Presented at the Symposium on Biotechnology for Fuels and Chemicals, Boulder, CO, 5 May 1987. PNL-SA-14552, CONF8705235, Pacific Northwest Laboratory, Richland, Washington.

Butner, R. S., D. C. Elliott, and L. J. Sealock, Jr. 1986. "Development of Water Slurry Gasification Systems for High-Moisture Biomass." Biotechnology and Bioengineering. Symposium No. 15. John Wiley \& Sons, New York, New York.

Butner, R. S., D. C. Elliott, and L. J. Sealock, Jr. 1986. "Low-Temperature Thermochemical Conversion of High-Moisture Biomass Feedstocks." In Proceedings of the 1985 Biomass Thermochemical Conversion Contractors' Meeting, pp. 193-209 CONF-8510167, National Technical Information Service, Springfield, Virginia.

Hallen, R. T., L. J. Sealock, and R. Cuello, "Influence of Alkali Carbonates on Biomass Volatilization," Fundamentals of Thermochemical Biomass Conversion, pp. 157-166, eds. R. Overend, T. A. Milne, and L. K. Mudge, Elsevier Applied Science Publishers, London.

Elliott, D. C., and L. J. Sealock, Jr. 1985. "Low-Temperature Gasification of Biomass Under Pressure." In Fundamentals of Thermochemical Biomass Conversion, pp. 937-950, eds. R. Overend, T.A. Milne, and L. K. Mudge, Elsevier Applied Science Publishers, Ltd., London.

Elliott, D. C., R. T. Hallen, and L. J. Sealock, Jr. 1984. "Alkali Catalysts in Biomass Gasification." Journal of Analytical and Applied Pyrolysis, 6:299-316.

Sealock, L. J., Jr., and D. C. Elliott. 1984. "Thermochemical Gasification of High-Moisture Feedstocks." In Proceedings of the 16th Biomass Thermochemical Conversion Contractors' Meeting, pp. 161-176 CONF-8405157, National Technical Information Service, Springfield, Virginia. 
Sealock, L. J., Jr., D. C. Elliott, and R. T. Hallen. 1982. Kinetics and Catalysis of Producing Synthetic Gases from Biomass. Final Report, GRI-8210036, Gas Research Institute, Chicago, Illinois.

\subsubsection{Biomass Research Related to Coal Gasification}

\subsubsection{Gasifying Wood With Coal and Sewage Sludge - Dynecology, Inc.}

Arbo, J. C., and H. W. Schulz. 1984. "Clean Energy from Coal, Forest Pulp, and Sewage Sludge." In Proceedings of the 16th Biomass Thermochemical Conversion Contractors' Meeting, pp. 193-210, CONF-8405157, National Technical Information Service, Springfield, Virginia.

Arbo, J. C., R. O. Bonkowski, R. B. Schulz, and J. B. Vergona. 1984. Development of a Process for Producing Clean Energy from Coal. Forest Pulp and Sewage Sludge. Final Research Report under PNL Contract No. B-F0440-A-Q, Pacific Northwest Laboratory, Richland Washington.

Irwin, C. F., and R. B. Schulz. 1981. "Energy From Biomass: The Simplex Process for the Gasification of Coal and Forest Pulp." In Proceedings of the 13th Biomass Thermochemical Conversion Contractors' Meeting, pp. 155-174, CONF-8110115, National Technical Information Service, Springfield, Virginia.

\subsubsection{Survey of Coal Gasification Technologies - Gorham International}

Keene, A. G., and A. C. Nyce. 1979. "Coal Gasification Technology: Wood Feedstock Retrofit Potential." In Proceedings of the Eighth Biomass Thermochemical Conversion Contractors' Meeting, July 31 - August 1, 1979, Seattle, Washington.

Nyce, A., and A. Keene. 1979. "An Assessment of the Technical and Economic Feasibility of Converting Wood Residues to Liquid and Gaseous Fuel Products Using State-Of-The-Art and Advanced Coal Conversion Technology." In Proceedings of the Seventh Biomass Thermochemical Conversion Contractors' Meeting, April 24-25, 1979, Roanoke, Virginia.

Nyce, A. 1979. "An Assessment of the Technical and Economic Feasibility of Converting Wood Residues to Liquid and Gaseous Fuel Products Using State-Of-The-Art and Advanced Coal Conversion Technology." In Proceedings of the Sixth Biomass Thermochemical Conversion Contractors' Meeting, January 16-17, 1979, Tucson, Arizona.

Keene, A. G. 1978. "An Assessment of the Technical and Economic Feasibility of Converting Wood Residues to Liquid and Gaseous Fuel Products Using State-Of-The-Art and Advanced Coal Conversion Technology." In Proceedings of the Fifth Biomass Thermochemical Conversion Coordination Meeting: Fuels From Biomass Program, September 19-20, 1978, Fresno and Hanford, California. 


\subsection{LOW-ENERGY AIR-BLOWN GASIFICATION PROJECTS}

\subsubsection{Data Collection With Low-Energy Gasifiers}

\subsubsection{Coors Gasifier - University of Missouri-Rolla}

Flanigan, V. J., et al. 1981. "Gasification Research on Wood, Low Energy Gas ProductionPhase I." DOE Report No., DOE/ET/23029-T6., National Technical Information Service, Springfield, Virginia.

Flanigan, V. J., et al. 1981. "Phase II Grow Project." In Proceedings of the 13th Biomass Thermochemical Conversion Contractors' Meeting, pp. 71-88, CONF-8110115, National Technical Information Service, Springfield, Virginia.

Flanigan, V. J., M. E. Findley, and H. H. Sineath. 1981. "Wood Gasification at the University of Missouri-Rolla." In Proceedings of the 12th Biomass Thermochemical Conversion Contractors' Meeting, March 18-19, 1981, Washington, DC.

Flanigan, V. J., et al. 1980. "Gasification Research on Wood." In Proceedings of the 11th Biomass Thermochemical Conversion Contractors' Meeting, Volume I, September 23-24, 1980, Richland, Washington.

Shimon, J. E. 1980. "Low Btu Gas From a Small Scale Fluidized Bed Reactor." Masters Thesis, University of Missouri-Rolla, Rolla, Missouri.

Welch, N. E., V. J. Flanigan, M. E. Findley, and Y. Omurtag. "Low Energy Gas Production Phase I Preliminary Results." In Proceedings of the 10th Biomass Thermochemical Conversion Contractors' Meeting, February 12-13, 1980, Berkeley, California.

Flanigan, V. J., Y. Omurtag, and N. E. Welch. 1979. "The Preliminary Results from the Phase I Test on the GROW Facility." In Proceedings of the 9th Biomass Thermochemical Conversion Contractors' Meeting, November 7-8, 1979, Rolla, Missouri.

Flanigan, V. J., Y. Omurtag, J. E. Halligan, and N. E. Welch. "GROW (Gasification Research on Wood)." In Proceedings of the Eighth Biomass Thermochemical Conversion Contractors' Meeting, July 31 - August 1, 1979, Seattle, Washington.

Flanigan, V. J., Y. Omurtag, J. Halligan, and N. E. Welch. 1979. "GROW for Energy." In Proceedings of the Seventh Biomass Thermochemical Conversion Contractors' Meeting, April 24-25, 1979, Roanoke, Virginia.

Flanigan, V., Y. Omurtag, and J. Halligan. 1979. "Gasification Research of Wood Project." In Proceedings of the Sixth Biomass Thermochemical Conversion Contractors' Meeting, January 16-17, 1979, Tucson, Arizona. 


\subsubsection{Data Collection on Gasifier Configurations - Environmental Energy Engineering (EEE), Inc.}

Bailie, R. C. 1982. "A Feasibility Study for Early Commercialization of a Modular-UNT Dual Fluidized-Bed System for Converting Terrestrial Biomass into Alternate Fuels." In Proceedings of the 14th Biomass Thermochemical Conversion Contractors' Meeting, pp. 646-686, CONF820685, National Technical Information Service, Springfield, Virginia.

Environmental Engineering, Inc. 1980. "Biomass PDU Gasification Studies, Volume IV, Research and Evaluation of Biomass Resources/Conversion/Utilization Systems. Final Report to Gilbert Commonwealth under DOE contract DE-AC02-78ET20611.

Stiller, A. H., and R. C. Bailie. 1980. "Biomass Characterization." In Proceedings of the 11th Biomass Thermochemical Conversion Contractor's Meeting, September 23-24, 1980, Richland, Washington.

Balie, R. 1979. "Pyrolysis Gas Chromatography of Biomass Fuels and Related Subjects." In Proceedings of the 9th Biomass Thermochemical Conversion Contractor's Meeting, November 7-8, 1979, Rolla, Missouri. 


\subsubsection{Use of Low-Energy Gases in Engines}

\subsubsection{Research on Gasifier/Engine Systems - Cal Recovery Systems, Inc.}

Savage, G. M. 1984. "Research and Development on Biomass Gasifier/Engine Systems." In Proceedings of the 16th Biomass Thermochemical Conversion Contractors' Meeting, pp. 231243, CONF-8405157; National Technical Information Service, Springfield, Virginia.

\subsubsection{Enhancement of Engine Performance - University of Florida}

Shaw, L. N., and D. M. Post. 1984. "Performance Enhancement of Engines Fueled with producer Gas." In Proceedings of the 16th Biomass Thermochemical Conversion Contractors' Meeting, pp. 211-222, CONF-8405157, National Technical Information Service, Springfield, Virginia.

Shaw, L. N. 1986. "Performance Enhancement of Engines Fueled with Producer Gas, Final Report." Submitted under subcontract B-F0462-A-Q, Pacific Northwest Laboratory, Richland Washington.

\subsubsection{Field Testing of Small Gasifier Filter Systems - Rocky Creek Farm Gasogens, Inc.}

Hargrave, R. H. 1984. "Field Testing Small Gasifier Filter Systems, Final Report." Submitted under subcontract B-F0463-A-Q, Pacific Northwest Laboratory, Richland, Washington.

Hargrave, R. H. 1984. "Field Testing Small Gasifier Systems." In Proceedings of the 16th Biomass Thermochemical Conversion Contractors' Meeting, pp. 223-229, CONF-8405157, National Technical Information Service, Springfield, Virginia. 


\subsection{ENVIRONMENTAL/END-USE ASPECTS OF BIOMASS GASIFICATION}

\subsubsection{End-Use Applications}

\subsubsection{Catalysts for Synthesis Gas in an Indirectly Heated Fluidized-Bed Gasifier - Pacific Northwest Laboratory (PNL)}

Mudge, L.K., M. D. Brown and W. A. Wilcox. 1988. "Bench-Scale Studies on Fluid-Bed Pyrolysis of Wood." PNL-6114, Pacific Northwest Laboratory, Richland, Washington.

Mudge, L. K., E. G. Baker, M. D. Brown and W. A. Wilcox. 1988. "Catalytic Destruction of Tars in Biomass-Derived Gases." Research in Thermochemical Biomass Conversion, pp.11411155, A. V. Bridgwater, ed., Elsevier Applied Science, London.

Mudge, L. K., M. A. Gerber and W. A. Wilcox. 1988. "Improved Gasification by Catalytic Destruction of Tars in Biomass-Derived Gases." In Proceedings of the Thermochemical Conversion Program Review Meeting, pp. 87-100, SERI/CP-231-3355, National Renewable Energy Laboratory, Golden, Colorado.

Mudge, L. K., E. G. Baker, M. D. Brown and W. A. Wilcox. 1987. Bench-Scale Studies on Gasification of Biomass in the Presence of Catalysts. PNL-5699, Pacific Northwest Laboratory, Richland, Washington.

Mudge, L. K., M. D. Brown, and W. A. Wilcox. 1987. "Bench-Scale Studies on Fluid-Bed Pyrolysis of Wood Using Different Contact Gases." In Proceedings of the 1987 Biomass Thermochemical Conversion Contractors' Review Meeting, pp. 141-150, CONF-8705212, National Technical Information Service, Springfield, Virginia.

Brown, M. D., E. G. Baker, and L. K. Mudge. 1987. "Evaluation of Processes for Removal of Particulates, Tars and Oils from Biomass Gasifier Product Gases." In Energy from Biomass and Waste X, ed. D. L. Klass, pp. 655-676. Institute of Gas Technology, Chicago, Illinois.

Baker, E. G., and L. K. Mudge. 1986. Tar Removal in a Hot Gas Desulfurization Process. DOE/MC/21290-2007 (DE86001054), pp. 48.

Brown, M. D., E. G. Baker, and L. K. Mudge. 1986. "Environmental Design Considerations for Thermochemical Biomass Energy." Biomass 11:255-270.

Mudge, L. K., E. G. Baker, M. D. Brown, and W. A. Wilcox. 1986. "Bench-Scale Studies on Catalytic Gasification of Biomass." In Proceedings of the 1985 Biomass Thermochemical Conversion Contractors' Meeting, pp. 235-255, CONF-8510167, National Technical Information Service, Springfield, Virginia. 
Baker, E. G., M. D. Brown, R. H. Moore, L. K. Mudge and D. C. Elliott. 1986. Engineering Analysis of Biomass Gasifier Product Gas Cleaning Technology. PNL-5534, Pacific Northwest Laboratory, Richland, Washington.

Baker, E. G., L. K. Mudge, and W. A. Wilcox. 1985. "Catalysts of Gas-Phase Reactions in Steam Gasification of Biomass." Fundamentals of Thermochemical Biomass Conversion, eds. R. Overend, T. A. Milne, and L. K. Mudge, pp. 863-874, Elsevier Applied Science, London.

Baker, E. G., M. D. Brown and R. J. Robertus. 1985. Catalytic Gasification of Bagasse for the Production of Methanol. PNL 5100, Pacific Northwest Laboratory, Richland, Washington.

Mudge, L. K., E. G. Baker, M. D. Brown and W. A. Wilcox. 1985. "Bench Scale Studies on Catalytic Gasification of Biomass." In Proceedings of the 1985 Biomass Thermochemical Conversion Contractors' Meeting, CONF-85101672, National Technical Information Service, Springfield, Virginia.

Baker, E. G., and M. D. Brown. 1984. "Catalytic Steam Gasification of Bagasse for the Production of Methanol." In Energy from Biomass and Wastes VIII, Institute of Gas Technology, Chicago, Illinois.

Baker, E. G., and L. K. Mudge. 1984. "Mechanisms of Catalytic Biomass Gasification." J. of Analytical and Applied Pyrolysis 6:285-297.

Baker, E. G., and L. K. Mudge. 1984. Catalysis in Biomass Gasification. PNL-5030, Pacific Northwest Laboratory, Richland, Washington.

Baker, E. G., L. K. Mudge, and M. D. Brown. 1984. "Progress in Studies on Catalyzed Gasification of Biomass." In Proceedings of the 16th Biomass Thermochemical Conversion Contractors' Meeting, pp. 103-128, CONF-8405157, National Technical Information Service, Springfield, Virginia.

Baker, E. G., L. K. Mudge, and D. H. Mitchell. 1984. "Oxygen/Steam Gasification of Wood in a Fixed-Bed Gasifier." Industrial \& Engineering Chemistry Process Design and Development. 23(4).

Mudge, L. K., E. G. Baker, and M. D. Brown. 1984. "Economic Update on Catalytic Conversion of Biomass to Methanol." Process Economics International 5(1):30-33.

Baker E. G., D. H. Mitchell, L. K. Mudge, and M. D. Brown. 1983. "Methanol Synthesis Gas from Wood Gasification." Energy Progress 3(4):226-229.

Mudge, L. K., et al. 1983. Catalytic Gasification Studies in a Pressurized Fluid Bed Unit. PNL-4594, Pacific Northwest Laboratory, Richland, Washington. 
Mudge, L. K., E. G. Baker, D. H. Mitchell, M. D. Brown, and R. J. Robertus. 1983. "Catalytic Steam Gasification of Biomass for Methanol and Methane Production." In Energy From Biomass and Wastes VII, pp. 365-411, Institute of Gas Technology, Chicago, Illinois.

Mudge, L. K., E. G. Baker, R. J. Robertus, and M. D. Brown. 1983. "Progress in Studies on Catalyzed Gasification of Wood." In Proceedings of the 15th Biomass Thermochemical Contractors' Meeting, pp. 91-129, CONF-830323, National Technical Information Service, Springfield, Virginia.

Mudge, L. K., E. G. Baker, and D. H. Mitchell. 1982. "Catalytic Generation of Methanol Synthesis Gas from Wood." Presented at the Biomass-To-Methanol Specialists Workshop, March 3-5, 1982, Durango, Colorado.

Mudge, L. K., D. H. Mitchell, E. G. Baker, R. J. Robertus, and M. D. Brown. 1982. "Steam Gasification of Wood in the Presence of Catalysts." In Proceedings of the 14th Biomass Thermochemical Conversion Contractors' Meeting, pp. 9-31, CONF-820685, National Technical Information Service, Springfield, Virginia.

Mitchell, D. H., L. K. Mudge, and E. G. Baker. 1981. "Steam Gasification of Biomass in the Presence of Catalysts." In Proceedings of the 13th Biomass Thermochemical Conversion Contractors' Meeting, pp. 245-273, CONF-8110115, National Technical Information Service, Springfield, Virginia.

Mudge, L. K., S. L. Weber, D. H. Mitchell, L. J. Sealock, Jr., and R. J. Robertus. 1981. Investigations of Catalyzed Steam Gasification of Biomass. PNL-3695, Pacific Northwest Laboratory, Richland, Washington.

Mudge, L. K. 1981. "Progress on Catalyzed Steam Gasification of Biomass." PNL-SA-9350, Pacific Northwest Laboratory, Richland, Washington.

Mudge, L. K., S. L. Weber, L. J. Sealock, Jr, and R. J. Robertus. 1981. "Progress on Catalyzed Steam Gasification of Biomass." In Proceedings of the 12th Biomass Thermochemical Conversion Contractors' Meeting, March 18-19, 1981, Washington, DC.

Sealock, L. J., Jr., et al. 1981. Kinetics and Catalysis of Producing Synthetic Gases from Biomass. Annual Report. GRI-80/0116, Gas Research Institute, Chicago, Illinois.

Mitchell, D. H., et al. 1980. "Methane/Methanol by Catalytic Gasification of Biomass." Chem. Eng. Prog. 76(9):53-57.

Mudge, L. K., et al. 1980. "Catalytic Gasification of Biomass." 1980. In Proceedings of the 3rd Annual Biomass Energy Systems Conference, pp. 351-357, SERI/TP-33285, Solar Energy Research Institute, Golden, Colorado. 
Mudge, L. K., et al. 1980. "Investigation of Gasification of Biomass in the Presence of Catalysts." In Proceedings of the 11th Biomass Thermochemical Conversion Contractors' Meeting, September 23-24, 1980, Richland, Washington. PNL-SA-7939, Rev. 3, Pacific Northwest Laboratory, Richland, Washington.

Mudge, L. K., et al. 1980. "Investigation of Gasification of Biomass in the Presence of Catalysts." In Proceedings of the 10th Biomass Thermochemical Conversion Contractors' Meeting, February 12-13, 1980 Berkeley, California. PNL-SA-7939, Rev. 2, Pacific Northwest Laboratory, Richland, Washington.

Robertus, R. J., et al. 1980. "Use of Catalysts in Biomass Gasification." Presented at the 3rd Miami International Conference on Alternative Energy Sources, December 15-19, 1980, Miami, Florida. PNL-SA-8518, Pacific Northwest Laboratory, Richland, Washington.

Sealock, L. J., Jr., S. L. Weber, and L. K. Mudge. 1980. "Kinetics and Mechanisms of Steam Gasification of Biomass in the Presence of Alkali Carbonates." Biosources Digest (21):12-26.

Weber, S. L., et al. 1980. "Gasification of Biomass in the Presence of Multiple Catalysts for the Direct Production of Specific Products." In Energy from Biomass and Wastes IV, Institute of Gas Technology, Chicago, Illinois.

Mudge, L. K., et al. 1979. "Catalytic Gasification of Wood Residues for Methanol Generation." In Proceedings of Mid-American Wood Combustion Conference, MASEC-CF-80005, Traverse City, Michigan.

Mudge, L. K., et al. 1979. "Catalytic Gasification of Biomass." In Proceedings of the 3rd Annual Biomass Energy Systems Conference, pp. 351-357, SERI/TR-33285, Solar Energy Research Institute, Golden, Colorado. PNL-SA-7766, Pacific Northwest Laboratory, Richland, Washington.

Mudge, L. K., et al. 1979. "Investigation of Gasification of Biomass in the Presence of Catalysts." In Proceedings of the 9th Biomass Thermochemical Conversion Contractors' Meeting, November 7-8, 1979, Rolla, Missouri. PNL-SA-7939, Rev. 1, Pacific Northwest Laboratory, Richland, Washington.

Mudge, L. K., et al. 1979. "Investigation of Gasification of Biomass in the Presence of Catalysts." In Proceedings of the Eighth Biomass Thermochemical Conversion Contractors' Meeting, July 31 - August 1, 1979, Seattle, Washington. PNL-SA-7939, Pacific Northwest Laboratory, Richland, Washington.

Mudge, L. K., L. J. Sealock, Jr., and S. L. Weber. 1979. "Catalyzed Steam Gasification of Biomass." J. of Analytical and Applied Pyrolysis 1:165-175.

Mudge, L. K., J. J. Sealock, Jr., R. J. Robertus, D. H. Mitchell, S. L. Weber, E. G. Baker, and P. C. Walkup. 1979. "Investigation of Gasification of Biomass in the Presence of 
Catalysts." In Proceedings of the Sixth Biomass Thermoconversion Contractors' Meeting, January 16-17, 1979, Tucson, Arizona.

Robertus, R. J., L. K. Mudge, L. J. Sealock, Jr., D. H. Mitchell, and S. L. Weber. 1979. "Investigation of Gasification of Biomass in the Presence of Catalysts." In Proceedings of the Seventh Biomass Thermochemical Conversion Contractors' Meeting, April 24-25, 1979, Roanoke, Virginia.

Weber, S. L, et al. 1979. "Enhanced Gasification of Wood in the Presence of Mixed Catalysts." The 6th National Conference on Energy and the Environment, May 21-24, 1979, Pittsburgh, Pennsylvania. PNL-SA-7704, Pacific Northwest Laboratory, Richland, Washington.

Mudge, L. K., L. J. Sealock, Jr., R. J. Robertus, D. H. Mitchell, E. G. Baker, and P. C. Walkup. 1978. "Investigation of Gasification of Biomass in the Presence of Catalysts." In Proceedings of the Fifth Biomass Thermochemical Conversion Coordination Meeting: Fuels from Biomass, September 19-20, 1978, Fresno and Hanford, California.

Sealock, L. J., et al. 1978. "Catalyzed Gasification of Biomass." Paper presented at First World Conference on Future Sources of Organic Raw Materials, July 10-13, 1978, Toronto, Ontario, Canada. PNL-SA-6689, Pacific Northwest Laboratory, Richland, Washington.

Walkup, P. C., et al. 1978. "Investigation of Gasification of Biomass in the Presence of Multiple Catalysts." In Proceedings of the Second Annual Symposium on Fuels from Biomass, pp. 301-319, ed. W. W. Shuster, Rensselaer Polytechnic Institute, Troy, New York. CONF7805107-P1. PNL-SA-6990

\subsubsection{Improved Catalysts for Mixed Alcohol Production - Lehigh University}

Klier, K., and R. G. Herman. 1981. "Catalysts for Alcohols from Biomass." In Proceedings of the 12th Biomass Thermochemical Conversion Contractors' Meeting, March 18-19, 1981, Washington, DC.

Klier, K., R. G. Herman, G. W. Simmons, and C. S. Kraihanzel. 1980. "Catalysts for Alcohols from Biomass." In Proceedings of the 11th Biomass Thermochemical Conversion Contractors' Meeting, September 23-24, 1980, Richland, Washington.

Herman, R. G., K. Klier, G. W. Simmons, B. P. Finn, J. P. Bulko, and T. P. Kobylinski. 1979. J. Catal., 56, 407-429. 


\subsubsection{Environmental Aspects of Gasification}

\subsubsection{Treatment of Wastewaters from Biomass Gasification - Pacific Northwest Laboratory (PNL)}

Petty, S. E., N. E. Bell, and C. J. English, Jr. 1981. "Treatment of Biomass Gasification Wastewaters Using Wet Air Oxidation, Solvent Extraction, and Reverse Osmosis." In Proceedings of the 13th Biomass Thermochemical Conversion Contractors' Meeting, pp. 718747, CONF-8110115, National Technical Information Service, Springfield, Virginia.

Bell, N. E. 1981. 'Treatment of Biomass Gasification Wastewaters Using Liquid-Liquid Extraction." PNL-4016, Pacific Northwest Laboratory, Richland, Washington.

English, C. J., Jr. 1981. "Treatment of Biomass Gasification Wastewater by Wet Air Oxidation." PNL-4013, Pacific Northwest Laboratory, Richland, Washington.

Petty, S. E. 1981. 'Treatment of Biomass Gasification Wastewaters Using Reverse Osmosis." PNL-4018, Pacific Northwest Laboratory, Richland, Washington.

Maxham, J. V. 1981. "Treatment of Biomass Gasification Wastewaters Using Reverse Osmosis." In Proceedings of the 12th Biomass Thermochemical Conversion Contractor's Meeting, March 18-19, 1981, Washington, D. C.

Maxham, J. V., and N. E. Bell. 1980. "Treatment of Biomass Gasification Wastewaters." In Proceedings of the 11th Biomass Thermochemical Conversion Contractors Meeting, September 23-24, 1980, Richland, Washington.

Maxham, J. V., and W. Wakamiya. 1980. "Treatment of Biomass Gasification Wastewaters." In Proceedings of the 10th Biomass Thermochemical Conversion Contractors Meeting, February $12-13,1980$, Berkeley, California.

Wakamiya, W., J. V. Maxham, and S. E. Petty. 1979. Biomass Gasification Wastewater Treatment-Interim Report. PNL-SA-8165, National Technical Information Service, Springfield, Virginia. 


\subsubsection{Waste Water Disposal via Gasification - Georgia Tech Research Corporation}

McGowan, T. F., A. D. Jape, and J. L. Walsh. 1984. "Utilization of Tar and Aqueous Effluents from Biomass Gasification Systems." In Proceedings of the 16th Biomass Thermochemical Conversion Contractors' Meeting, pp. 177-191, CONF-8405157, National Technical Information Service, Springfield, Virginia.

McGowan, T. F., A. D. Jape, and J. L. Walsh. 1983. "Utilization of Waste Streams in Biomass Gasifiers." In Proceedings of the 15th Biomass Thermochemical Conversion Contractors' Meeting, pp. 223-235, CONF-830323, National Technical Information Service, Springfield, Virginia.

McGowan, T. F. 1981. "Wood Gasification Research for Textile Industry Applications." In Proceedings of the 13th Biomass Thermochemical Conversion Contractors' Meeting, pp. 685696, CONF-8110115, National Technical Information Service, Springfield, Virginia. 


\subsection{LIQUEFACTION AND PYROLYSIS}

\subsection{RESEARCH ON BIOMASS LIQUEFACTION PROCESSES}

\subsubsection{High Pressure Liquefaction Projects}

\subsubsection{Albany, Oregon, Liquefaction Test Facility - Wheelabrator Cleanfuel Co.}

Rust International Corporation. 1982. "An Investigation of Liquefaction of Wood: Final Report." PNL 5114, Pacific Northwest Laboratory, Richland, Washington.

Thigpen, P. L., and W. L. Berry. 1982. "Liquid Fuels from Wood by Continuous Operation of the Albany, Oregon Biomass Liquefaction Facility." In Energy from Biomass and Waste VI, ed. D. L. Klass, pp. 1057-1093, Institute of Gas Technology, Chicago, Illinois.

Berry, W. L., Jr., and P. L. Thigpen. 1981. "Operation of the Biomass Liquefaction Facility, Albany, Oregon." In Proceedings of the 13th Biomass Thermochemical Conversion Contractors' Meeting, pp. 521-550, CONF-8110115, National Technical Information Service, Springfield, Virginia.

Operation of the Biomass Liquefaction Facility, Albany, Oregon. 1981. In Proceedings of the 12 th Biomass Thermochemical Conversion Contractors' Meeting, March 18-19, 1981, Washington, DC.

Berry, W. L., Jr. 1980. "Operation of the Biomass Liquefaction Facility, Albany, Oregon. In Proceedings of the 11th Biomass Thermochemical Conversion Contractors' Meeting, September 23-24, 1980, Richland, Washington.

Berry, W. L., Jr. 1980. "Operation of the Biomass Liquefaction Facility, Albany, Oregon." In Proceedings of the 10th Biomass Thermochemical Conversion Contractors' Meeting, February 13, 1980, Berkeley, California.

Milligan, B. 1979. "Operation of the Biomass Liquefaction Facility, Albany, Oregon. In Proceedings of the 9th Biomass Thermochemical Conversion Contractors' Meeting, November 7-8, 1979, Rolla, Missouri.

Berry, W. L., Jr. 1979. "Operations of the Biomass Liquefaction Facility, Albany, Oregon." In Proceedings of the Eighth Biomass THermochemical Conversion Contractors' Meeting, July 31- August 1, 1979, Seattle, Washington. 
Hart, D. 1979. "Biomass Liquefaction Experimental Facility." In Proceedings of the Seventh Biomass Thermochemical Conversion Contractors' Meeting, April 24-25, 1979, Roanoke, Virginia.

Hart, D. R. 1979. "Liquefaction of Douglas Fir Wood Flour." In Proceedings of the Sixth Biomass Thermochemical Conversion Contractors' Meeting, January 16-17, 1979, Tucson, Arizona.

Allison, G. L. 1979. "The Utilization of Biomass as an Energy Source." In Proceedings of the Sixth Biomass Thermochemical Conversion Contractors' Meeting, January 16-17, 1979, Tucson, Arizona.

Hart, D. 1978. "Biomass Liquefaction Experimental Facility, Albany, Oregon." In Proceedings of the Fifth Biomass Thermochemical Conversion Coordination Meeting: Fuels From Biomass Program", September 19-20, 1978, Fresno and Hanford, California. 


\subsubsection{Extruder Reactor System - University of Arizona}

White, D. H. and D. Wolf. 1991. "Development of an Extruder-Feeder Biomass Direct Liquefaction Process." Volume 1: Parts 1-3. PNL-7830 Vol.1, Pacific Northwest Laboratory, Richland, Washington.

White, D. H. and D. Wolf. 1991. "Development of an Extruder-Feeder Biomass Direct Liquefaction Process." Volume 2: Parts 4-8. PNL-7830 Vol. 2, Pacific Northwest Laboratory, Richland, Washington.

White, D. H., D. Wolf, G. Davenport, S. Mathews, M. Porter, and Y. Zhao. 1987. "An Advanced Extruder-Feeder Biomass Liquefaction Reactor System." In Proceedings of the 1987 Biomass Thermochemical Conversion Contractors' Review Meeting, pp. 5-21 CONF-8705212, National Technical Information Service, Springfield, Virginia.

White, D. H., and D. Wolf. 1987. "A Continuous Extruder-Feeder for Reactor Systems for Biomass Fuels Processing." In Proceedings of Energy from Biomass and Waste X, ed. D. L. Klass, pp. 1685-1688. Institute of Gas Technology, Chicago, Illinois.

White, D. H., D. Wolf, N. W. Andrews, D. Joshi, J. Wong, and G. Davenport. 1986. "RealTime Microprocessor Control and Data Acquisition of Biomass Direct Liquefaction Systems." In Proceedings of the Second National Conference on Microcomputer Applications for Conservation and Renewable Energy, Donald E. Osborn, ed., University of Arizona, Tucson, Arizona,

White, D. H., and D. Wolf. 1986. "An Advanced Extruder-Feeder Biomass Liquefaction Reactor System." In Proceedings of the 1985 Biomass Thermochemical Conversion Contractors' Meeting, pp. 115-140 CONF-8510167, National Technical Information Service, Springfield, Virginia.

White, D. H., and D. Wolf. 1985. "An Extruder-Feeder for Reactor Systems for Biomass Fuels Processing." In Proceedings of the Fourth Technical Review Meeting. Energy from Biomass: Building on a Generic Technology Base, pp. 115-124 ANL/CNSV-TM-176, Argonne National Laboratory, Argonne, Illinois.

Homaidan, A. 1984. "Modeling of Extruder-Feeder for Biomass Concentrated Slurries." Master of Science Thesis, University of Arizona, May 1984.

Khan, M. B. 1984. "Gas Dispersion in Viscous Non-Newtonian Fluids Using an Extruder-Feeder." Master of Science Thesis, University of Arizona, August 1984.

Shlapak, N. A. 1984. "Microprocessor-Based Real-Time Process Control of Biomass Liquefaction." Master of Science Thesis, University of Arizona, August 1984. 
White, D. H. 1984. "Development of Extruder-Feeder Biomass Liquefaction System." In Proceedings of the 16th Biomass Thermochemical Conversion Contractors' Meeting, pp. 375397 CONF-8405157, National Technical Information Service, Springfield, Virginia.

White, D. H. 1983. "Advanced Laboratory-Scale Extruder Reactor Biomass Liquefaction Unit." In Proceedings of the 15th Biomass Thermochemical Conversion Contractors' Meeting, pp. 445-454, CONF-830323, National Technical Information Service, Springfield, Virginia.

White, D. H., et al. 1981. "Modified Extruder for Feeding Fine-Ground Cellulosic Slurries to Pressure Systems." In Proceedings of the 13th Biomass Thermochemical Conversion Contractors' Meeting, pp. 576-645, CONF-8110115, National Technical Information Service, Springfield, Virginia.

White, D. H. 1981. "Modified Extruder for Feeding Fine-Ground Cellulosic Slurries to Pressure Systems." In Proceedings of the 12th Biomass Thermochemical Conversion Contractors' Meeting, March 18-19, 1981, Washington, DC.

White, D. H. 1980. "Progress Report on Modified Extruder for Feeding Cellulosic Slurries to Pressure Systems." In Proceedings of the 11th Biomass Thermochemical Conversion Contractors' Meeting, September 23-24, 1980, Richland, Washington.

White, D. H. 1979. "Modified Extruder for Feeding Fine-Ground Cellulosic Slurries to Pressure Systems." In Proceedings of the 9th Biomass Thermochemical Conversion Contractors' Meeting, November 7-8, 1979, Rolla, Missouri.

White, D. H. 1979. "Modified Extruder for Feeding Cellulosic Slurries to Pressure Systems." In Proceedings of the Eighth Biomass Thermochemical Conversion Contractors' Meeting, July 31 - August 1, 1979, Seattle, Washington.

White, D. H. 1979. "Modified Extruder for Feeding Cellulosic Slurries to Pressure Systems." In Proceedings of the Seventh Biomass Thermochemical Conversion Contractors' Meeting, April 24-25, 1979, Roanoke, Virginia.

White, D. H. 1979. "Progress Report on Modified Extruder for Feeding Cellulosic Slurries to Pressure Systems." In Proceedings of the Sixth Biomass Thermochemical Conversion Contractors' Meeting, January 16-17, 1979, Tucson, Arizona.

White, D. H. 1978. "Modified Extruder for Feeding Fine-Ground Cellulosic Slurries to Pressure Systems." In Proceedings of the Fifth Biomass Thermochemical Conversion Coordination Meeting: Fuels From Biomass Program, September 19-20, 1978, Fresno and Hanford, California. 


\subsubsection{Aqueous Slurry Process - Lawrence Berkeley Laboratory (LBL)}

Davis, H.G., M. A. Eames, C. Figueroa, R. R. Gansley, L. L. Schaleger, and D. W. Watt. 1985. "The Products of Direct Liquefaction of Biomass," Fundamentals of Thermochemical Biomass Conversion, pp. 1027-1038, eds. R. Overend, T.A. Milne, and L. K. Mudge, Elsevier Applied Science Publishers, London.

Davis, H. G. 1983. "Direct Liquefaction of Biomass Final Report and Summary of Effort." LBL-16243, Lawrence Berkeley Laboratory, University of California, Berkeley, California.

Davis, H. G., and D. W. Watt. 1983. "Preliminary Experiments on Direct Liquefaction of Biomass By Solvolysis and Catalytic Hydrogenation." In Proceedings of the 15th Biomass Thermochemical Conversion Contractors' Meeting, pp. 467-483, CONF-830323, National Technical Information Service, Springfield, Virginia.

Figueroa, C., L. Schaleger, and H. Davis. 1982. "LBL Continuous Bench-Scale Liquefaction Unit, Operation and Results." In Energy from Biomass and Wastes VI, Institute of Gas Technology, Chicago, Illinois.

Davis, H. G. 1982. "Hydrogen or Carbon Monoxide in the Liquefaction of Biomass." Presented at the World Hydrogen Energy Conference IV, June 13-17, 1982, Pasadena, California. LBL-44018, Lawrence Berkeley Laboratory, Berkeley, California.

Davis, H. G., M. A. Eames, C. Figueroa, R. R. Gansley, L. L. Schaleger, and D. W. Watt. "The Products of Direct Liquefaction of Biomass." Fundamentals of Thermochemical Biomass Conversion, pp. 1027-1038, R. Overend, ed., Elsevier Applied Science, London.

Davis, H., C. Figueroa, and L. Schaleger. 1982. "Research and Development Activities on Direct Liquefaction Technology." In Proceedings of the 14th Biomass Thermochemical Conversion Contractors' Meeting, pp. 569-600, CONF-820685, National Technical Information Service, Springfield, Virginia.

Davis, H., C. Figueroa, and L. Schaleger. 1982. "Liquid Fuels by Direct Liquefaction of Biomass." Presented at the KTI Fifth Annual High Temperature Processing Technology Symposium, Napa Valley, California, May 9-12, 1982. LBL-14155, Lawrence Berkeley Laboratory, Berkeley, California.

Yu, S. -M. G. 1982. "Solvolytic Liquefaction of Wood Under Mild Conditions." Ph.D Thesis, April 1982. LBL-14096, Lawrence Berkeley Laboratory, Berkeley, California.

Davis, H. G. 1981. "Titration of Acids and Anions in Aqueous Product and Feed Slurries." Technical Report, March 1981, LBL-12331, Lawrence Berkeley Laboratory, Berkeley, California. 
Davis, H., et al. 1981. "Direct Liquefaction Process Development Activities at Lawrence Berkeley Laboratory." In Proceedings of the 12th Biomass Thermochemical Conversion Contractors' Meeting, March 18-19, 1981, Washington, DC.

Davis, H., C. Figueroa, C. Karatas, D. Kloden, L. Schaleger, N. Yaghoubzadeh. 1981. "Catalytic Liquefaction of Biomass." In Proceedings of the 13th Biomass Thermochemical Conversion Contractors' Meeting, pp. 493-520, CONF-8110115, National Technical Information Service, Springfield, Virginia.

Davis, H. G., D. J. Kloden, and L. L. Schaleger. 1981. "Chemistry and Stoichiometry of Wood Liquefaction." 3rd Symposium on Biotechnology in Energy Production and Conservation, Gatlinburg, Tennessee, May 13-15, 1981, Paper 13, Biotechnology and Bioengineering Symposium Series.

Ergun, S. 1981. Review of Biomass Liquefaction Efforts. LBL-13957, Lawrence Berkeley Laboratory, University of California, Berkeley, California.

Davis, H. G. 1980. "Stoichiometry of Wood Liquefaction." Technical Report, October, LBL11776, Lawrence Berkeley Laboratory, Berkeley, California.

Davis, H., et al. 1980. "Catalytic Biomass Liquefaction Quarterly Report." In Proceedings of the 11th Biomass Thermochemical Conversion Contractors' Meeting, September 23-24, 1980, Richland, Washington.

Ergun, S., C. Figueroa, and C. Karatas. 1980. "Monitoring the Biomass Liquefaction Process Development Unit at Albany, Oregon." LBL Energy and Environment Division Annual Report, FY 1979, pp. 4-24 to 4-26, LBL-10319, Lawrence Berkeley Laboratory, Berkeley, California.

Figueroa, C., C. Karatas, and J. Wrathall. 1980. "LBL Biomass Liquefaction Process Engineering Unit." In Proceedings of the 10th Biomass Thermochemical Conversion Contractors' Meeting, February 12-13, 1980, Berkeley, California.

Schaleger, L., N. Yaghoubzadeh, and S. Ergun. 1980. "Pretreatment of Biomass Prior to Liquefaction." LBL Energy and Environment Division Annual Report, FY 1979, pp. 4-19 to 4-20, LBL-10319, Lawrence Berkeley Laboratory, Berkeley, California. 


\subsubsection{Alternative Catalysts for High Pressure Liquefaction - SRI International}

Tran, A. D., and D. Z. Rodgers. 1985. "Examination of Alternative Catalysts for Biomass Direct Liquefaction. PNL-5617, Pacific Northwest Laboratory, Richland, Washington.

Rogers, D. Z., and T. D. An. 1982. "Examination of Alternative Catalysts For Direct Biomass Liquefaction." In Proceedings of the 14th Biomass Thermochemical Conversion Contractors' Meeting, pp. 627-645, CONF-820685, National Technical Information Service, Springfield, Virginia.

Rogers, D. Z., and T. D. An. 1981. "Examination of Alternative Catalysts For Direct Biomass Liquefaction." In Proceedings of the 13th Biomass Thermochemical Conversion Contractors' Meeting, pp. 646-656, CONF-8110115, National Technical Information Service, Springfield, Virginia.

Kinderman, E. M. 1981. "A Feasibility Study of New Processes for Fuel from Biomass: Economic Evaluations." In Proceedings of the 12th Biomass Thermochemical Conversion Contractors' Meeting, March 18-19, 1981, Washington, DC.

Rogers, D. Z, D. J. Wilhelm, and D. S. Ross. 1981. "Feasibility Study on New Processes for Fuel From Biomass." Summary Report, DOE Contract No. DE-AC03-79ET23023. U.S. Department of Energy, Washington, D.C.

Rogers, D. Z., D. J. Wilhelm, and E. Capener. 1981. "Feasibility Study on New Processes for Fuel from Biomass: Task III Economic Evaluation." In Proceedings of 12th Biomass Thermochemical Conversion Contractors' Meeting, March 18-19, 1981, Washington, DC.

Rogers, D. Z. $1980 . \quad$ "Feasibility Study on New Processes for Fuels from Biomass." In Proceedings of the 11 th Biomass Thermochemical Conversion Contractors' Meeting, September 23-24, 1980, Richland, Washington.

Rogers, D. Z, J. Blessing, and D. Ross. "Feasibility Study on New Processes for Fuels from Biomass." In Proceedings of the 10th Biomass Thermochemical Conversion Contractors' Meeting, February 12-13, 1980, Berkeley, California.

Rogers, D., J. Blessing, and D. Ross. 1979. "Feasibility Study on New Processes for Fuels from Biomass." In Proceedings of the 9th Biomass Thermochemical Conversion Contractors' Meeting, November 7-8, 1979, Rolla, Missouri.

Ross, D., D. Rogers, and J. Blessing. 1979. "Feasibility Study on New Processes for Fuels from Biomass." In Proceedings of the Eighth Biomass Thermochemical Conversion Contractors' Meeting, July 31 - August 1, 1979, Seattle, Washington. 


\subsubsection{Direct Liquefaction Studies - Pacific Northwest Laboratory (PNL)}

Elliott, D. C. 1983. "Basic Research in Biomass Direct Liquefaction." In Proceedings of the 15 th Biomass Thermochemical Conversion Contractors' Meeting, pp. 455-466, CONF-830323, National Technical Information Service, Springfield, Virginia.

Elliott, D. C. 1981. "Process Development for Direct Liquefaction of Biomass." In Fuels from Biomass and Wastes, eds. D. L. Klass and G. H. Emert, pp. 435-450. Ann Arbor Science Publishers, Inc., Ann Arbor, Michigan.

Elliott, D. C. 1982. "Bench Scale Research in Biomass Direct Liquefaction." In Proceedings of the 14th Biomass Thermochemical Conversion Contractors' Meeting, pp. 601-626, CONF820685, National Technical Information Service, Springfield, Virginia.

Elliott, D.C. 1981. "Bench Scale Research in Biomass Direct Liquefaction." In Proceedings of the 13th Biomass Thermochemical Conversion Contractors' Meeting, pp. 551-575, CONF8110115, National Technical Information Service, Springfield, Virginia.

Elliott, D. C. 1981. "Bench Scale Research in Biomass Liquefaction in Support of the Albany, Oregon, Experimental Facility." In Proceedings of the 12th Biomass Thermochemical Conversion Contractors' Meeting, Washington, DC, March 18-19, 1981.

Elliott, D. C. 1981. "Description and Utilization of Product from Direct Liquefaction of Biomass." Biotech. and Bioeng., Symp No. 11, 187-198.

Elliott, D. C. 1980. "Process Development for Direct Liquefaction of Biomass." Am. Chem. Soc. Div. Fuel Chem. Preprt., Vol. 25, No. 4, pp. 257-263, August 1980.

Elliott, D. C., M. J. McGee, G. M. Giacoletto, and D. A. Nelson. 1980. "Bench Scale Research in Biomass Liquefaction in Support of the Albany, Oregon, Experimental Facility." In Proceedings of the 11th Biomass Thermochemical Conversion Contractors' Meeting, September 23-24, 1980, Richland, Washington.

Elliott, D. C. 1980. "Bench Scale Research in Biomass Liquefaction in Support of the Albany, Oregon, Experimental Facility." In Proceedings of the 10th Biomass Thermochemical Conversion Contractors' Meeting, February 12-13, 1980, Berkeley, California.

Elliott, D. C. 1980. "Bench Scale Research in Biomass Liquefaction by the CO-Steam Process." Canadian. J. Chem. Eng. 58(6):730-734.

Elliott, D. C., and P.C. Walkup. 1979. "Bench Scale Research in Biomass Liquefaction in Support of the Albany, Oregon, Experimental Facility. In Proceedings of the 9th Biomass Thermochemical Conversion Contractors' Meeting, November 7-8, 1979, Rolla, Missouri. 
Elliott, D. C. 1979. "Bench Scale Research in Thermochemical Conversion of Biomass to Liquids in Support of the Albany, Oregon, Experimental Facility." In Proceedings of the Eighth Biomass Thermochemical Conversion Contractors' Meeting, July 31 - August 1, 1979, Seattle, Washington.

Elliott, D. C. 1979. "Bench Scale Research in Thermochemical Conversion of Biomass to Liquids in Support of the Albany, Oregon, Experimental Facility." In Proceedings of the Seventh Biomass Thermochemical Conversion Contractors' Meeting, April 24-25, 1979, Roanoke, Virginia.

Elliott, D. C. 1979. "Bench Scale Research in Thermochemical Conversion of Biomass to Liquids in Support of the Albany, Oregon, Experimental Facility." In Proceedings of the Sixth Biomass Thermochemical Conversion Contractors' Meeting, January 16-17, 1979, Tucson, Arizona.

Elliott, D. C., and G. M. Giacoletto. 1979. "Bench Scale Research in Biomass Liquefaction in Support of the Albany, Oregon Experimental Facility." SERI/TP-33-285, pp. 123-130.

Elliott, D. C. 1978. "Bench Scale Research in Thermochemical Conversion of Biomass to Liquids in Support of the Albany, Oregon, Experimental Facility." In Proceedings of the Fifth Biomass Thermochemical Conversion Coordination Meeting: Fuels from Biomass Program, September 19-20, 1978, Fresno and Hanford, California.

Elliott, D. C., and P. C. Walkup. 1977. "Bench Scale Research in Thermochemical Conversion of Biomass to Liquids in Support of the Albany, Oregon, Experimental Facility." In Proceedings of the Third Thermochemical Conversion of Biomass Contractors' Meeting, October 26, 1977, Ballston Spa, New York. 


\subsubsection{Rapid Pyrolysis Processes}

\subsubsection{Ablative Reactor System - National Renewable Energy Lab. (NREL)}

Diebold, J., and A. J. Power. 1988. "Engineering Aspects of the Vortex Pyrolysis Reactor to Produce Primary Pyrolysis Oils for Use in Resins and Adhesives, " Research in Thermochemical Biomass Conversion, pp. 609-628, eds. A. V. Bridgwater and J. L. Kuester, Elsevier Applied Science, London.

Scahill, J., and J. P. Diebold. 1988. "Adaptation of the SERI Vortex Reactor for RDF Pyrolysis. Proceedings of the Thermochemical Conversion Program Annual Meeting, pp. 237246, SERI/CP-231-3355, National Renewable Energy Laboratory, Golden, Colorado.

Levie, B., J. P. Diebold, and R. West. 1988. "Pyrolysis of Single Pellets of Refuse-Derived Fuel," Research in Thermochemical Biomass Conversion, pp. 312-326, eds. A. V. Bridgwater and J. L. Kuester, Elsevier Applied Science, London.

Diebold, J. P., and J. W. Scahill. 1987. "Production of Primary Pyrolysis Oils in a Vortex Reactor." Preprints of 193rd ACS Meeting, Div. Fuel Chemistry, Denver, Colorado, April 510, Vol. 32, No. 2, pp. 21-28.

Diebold, J. P., J. W. Scahill, and R. J. Evans. 1986. Entrained-Flow, Fast Ablative Pyrolysis of Biomass, Annual Report, 1 December 1984 - 31 December 1985. SERI/PR-234-3012, Solar Energy Research Institute, Golden, Colorado.

Diebold, J. P., J. W. Scahill, and R. J. Evans. 1986. "The Thermal and Catalytic Upgrading of Oxygenated, Primary Biomass Pyrolysis Oil Vapors." In Proceedings of the 1985 Biomass Thermochemical Conversion Contractors' Meeting, pp. 31-55, CONF-8510167, National Technical Information Service, Springfield, Virginia.

Diebold, J. P. 1985. The Cracking Kinetics of Depolymerized Biomass Vapors in a Continuous Tubular Reactor, MS Thesis T-3007, Colorado School of Mines, Golden, Colorado.

Diebold, J. P., and J. W. Scahill. 1985. Entrained-Flow, Fast Ablative Pyrolysis of Biomass, Annual Report. 1 October - 30 November 1984. SERI/PR-234-2665, Solar Energy Research Institute, Golden, Colorado.

Diebold, J. P., J. W. Scahill, and R. J. Evans. 1985. "The Thermal and Catalytic Upgrading of Oxygenated, Primary Biomass Pyrolysis Oil Vapors." In Proceedings of the 1985 Biomass Thermochemical Conversion Contractors' Meeting, pp. 31-56, CONF-8510167, National Technical Information Service, Springfield, Virginia.

Diebold, J., and J. Scahill. 1985. "Ablative Pyrolysis in Solid Convective Heat Transfer Environments." Fundamentals of Thermochemical Biomass Conversion, pp. 539-556, R. Overend, T. A. Milne, and L. K. Mudge, eds., Elsevier Applied Science, London. 
Diebold, J. P., and J. W. Scahill. 1984. "Ablative Entrained-Flow Fast Pyrolysis of Biomass." In Proceedings of the 16th Biomass Thermochemical Conversion Contractors' Meeting, pp. 319347, CONF-8405157, National Technical Information Service, Springfield, Virginia.

Diebold, J. P., and J. W. Scahill. 1984. "Formation of Biomass Vapors in a Vortex Reactor." In Abstracts of the National Meeting on Biomass R\&D for Energy Applications, Arlington, Virginia. SERI/CP-230, Solar Energy Research Institute, Golden, Colorado.

Diebold, J. P., and J. W. Scahill. 1984. Entrained-Flow. Fast Ablative Pyrolysis of Biomass. Annual Report, 1 December 1982 to 30 September 1983. SERI/PR-234-2144, Solar Energy Research Institute, Golden, Colorado.

Diebold, J., and J. Scahill. 1983. "Ablative Entrained-Flow Fast Pyrolysis Status." In Proceedings of the 15th Biomass Thermochemical Conversion Contractors' Meeting, pp. 300 357, CONF-830323, National Technical Information Service, Springfield, Virginia.

Diebold, J. P., and J. W. Scahill. 1983. Entrained-Flow, Fast Ablative Pyrolysis of Biomass, Annual Report, 1 December 1982 - 30 September 1983. SERI/PR-234-2144, Solar Energy Research Institute, Golden, Colorado.

Diebold, J. P., and J. W. Scahill. 1983. Ablative Pyrolysis of Biomass in the Entrained-Flow Cyclonic Reactor at SERI, Annual Report, 1 October 1981 to 30 November 1982. SERI/PR234-1883, Solar Energy Research Institute, Golden, Colorado.

Diebold, J. P., and J. W. Scahill. 1982. "Fluidizing Device for Solid Particulates." DOE Case No. S-58,351, SERI Disclosure IR-82-7.

Diebold, J., and J. Scahill. 1982. "Ablative Fast Pyrolysis of Biomass in the Entrained-Flow Cyclonic Reactor at SERI." In Proceedings of the 14th Biomass Thermochemical Contractors' Meeting, pp. 272-310, CONF-820685, National Technical Information Service, Springfield, Virginia.

Diebold, J. P., and J. W. Scahill. 1982. Progress in the Entrained-Flow, Fast Ablative Pyrolysis of Biomass. Annual Report. October 1980 to September 1981. SERI/PR-234-1456, Solar Energy Research Institute, Golden, Colorado.

Reed, T. B., and J. P. Diebold. 1982. "Heat Transfer Mechanisms for Analytical Pyrolysis." 5th International Symposium on Analytical and Applied Pyrolysis, Vail, Colorado, September 25-29, 1982.

Diebold, J. P., Workshop Chairman. 1981. Proceedings of the Specialists Workshop on the Fast Pyrolysis of Biomass. Copper Mountain, Colorado, 20-22 October 1980. SERI/CP-6221096. Solar Energy Research Institute, Golden, Colorado.

Diebold, J., and J. Scahill. 1981. "October 1981 Update on the Progress in the Entrained Flow, Fast Pyrolysis of Biomass." In Proceedings of the 13th Biomass Thermochemical 
Contractors' Meeting, pp. 332-365, CONF-8110115, National Technical Information Service, Springfield, Virginia.

Diebold, J., and J. Scahill. 1981. "Progress in the Entrained-Flow, Fast Ablative Pyrolysis of Biomass." In Proceedings of the 12th Biomass Thermochemical Conversion Contractors' Review Meeting, Washington, DC, March 18-19, 1981. SERI/PR-622-1151.

Diebold, J. P., 1980. "Gasoline from Solid Wastes by a Noncatalytic Thermal Process." Thermal Conversion of Solid Wastes and Biomass, ACS Symposium Series 130, pp. 209-226.

Diebold, J. 1980. "Research into the Pyrolysis of Pure Cellulose, Lignin, and Birchwood Flour in the China Lake Entrained-Flow Reactor." Report No. SERI/TR-332-586, Solar Energy Research Institute, Golden, Colorado.

Diebold, J. P. 1980. "Thermochemical Conversion of Biomass to Gasoline." In Proceedings of the 11th Biomass Thermochemical Conversion Contractors' Meeting, Battelle Pacific Northwest Laboratory, Richland, Washington.

Diebold, J. 1980. "Ablative Pyrolysis of Macroparticles of Biomass." In Proceedings of the Specialists Workshop on the Fast Pyrolysis of Biomass, October 19-22, SERI/CP-622-1096. National Renewable Energy Laboratory, Golden, Colorado.

Diebold, J. P., Workshop Chairman. 1980. Proceedings of Specialists Workshop on the Fast Pyrolysis of Biomass. SERI/CP-622-1096, Solar Energy Research Institute, Golden, Colorado.

Diebold, J. P. 1980. "Research into the Pyrolysis of Pure Cellulose, Lignin, and Birch Wood Flour in the China Lake Entrained-Flow Reactor." SERI/TR-332-586.

Diebold, J. P., and C. B. Benham. 1980. "Pyrolysis Experiments at China Lake Using a Tubular Entrained Flow Reactor." Proceedings Specialist Workshop on Fast Pyrolysis of Biomass. op cit. pp. 271-285.

Diebold, J., and G. Smith. 1980. "Commercialization Potential of the China Lake Trash-toGasoline Process." In Design and Management for Resource Recovery. Vol. 1 - Energy from Waste, ed. T. C. Frankiewicz, pp. 113-140, Science Publishers, Inc., Ann Arbor, Michigan.

Reed, T. B., J. Diebold, and R. Desrosiers. 1980. "Perspectives in Heat Transfer Requirements and Mechanisms for Fast Pyrolysis." In Brocedings of the Specialists Workshop on the Fast Pyrolysis of Biomass, Copper Mountain, Colorado; 20-22 October 1980. SERI/CP622-1096, Solar Energy Research Institute, Golden, Colorado.

Diebold, J. P., and G. D. Smith. 1979. "Noncatalytic Conversion of Biomass to Gasoline." ASME sponsored Solar Energy Conference, San Diego, California, March 12-15, 1979. ASME Paper No. 79-Sol-29. 
Diebold, J. P., G. D. Smith, and C. B. Benham. 1979. "Conversion of Organic Wastes to Unleaded, High Octane Gasoline." Final Report to the Environmental Protection Agency, Contract EPA-IAG-D6-0781, September 1979.

Milne, T. 1979. "Pyrolysis - The Thermal Behavior of Biomass Below $600^{\circ} \mathrm{C}$." In A Survey of Biomass Gasification: Volume II - Principles of Gasification. SERI/TR-33-239, pp. II-99. Solar Energy Research Institute, Golden, Colorado. 


\subsubsection{Entrained Rapid Pyrolysis Reactor System - Georgia Tech Research Institute}

Kovac, R. J., C. W. Gorton, J. A. Knight, C. W. Newman, and D. J. O'Neil. 1991. "Research on the Pyrolysis of Hardwood in an Entrained Bed Process Development Unit." PNL-7788, Pacific Northwest Laboratory, Richland, Washington.

Kovac, R. J., C. W. Gorton, D. J. O'Neil, and C. J. Newman. 1987. "Low Pressure Entrained Flow Pyrolysis of Biomass to Produce Liquid Fuels." In Proceedings of the 1987 Biomass Thermochemical Conversion Contractors' Review Meeting, pp. 23-39 CONF-8705212, National Technical Information Service, Springfield, Virginia.

Knight, J. A., C. W. Gorton, R. J. Kovac, and C. J. Newman. 1986. "Entrained Flow Pyrolysis of Biomass." In Proceedings of the 1985 Biomass Thermochemical Conversion Contractors' Meeting, pp. 99-113 CONF-8510167, National Technical Information Service, Springfield, Virginia.

Knight, J. A., C. W. Gorton, and R. J. Kovac. 1984. "Entrained Flow Pyrolysis of Biomass." In Proceedings of the 16th Biomass Thermochemical Conversion Contractors' Meeting, pp. 287-297, CONF-8405157, National Technical Information Service, Springfield, Virginia.

Gorton, C. W., and J. A. Knight. 1984. "Oil from Biomass by Entrained Flow Pyrolysis." In Proceedings of the Sixth Symposium on Biotechnology for Fuels and Chemicals, C. D. Scott, ed., Symposium No. 14, pp. 15-20. John Wiley \& Sons, New York, New York.

Knight, J. A., C. W. Gorton, and R. J. Kovac. 1983. "Entrained Flow Pyrolysis of Biomass." In Proceedings of the 15th Biomass Thermochemical Conversion Contractors' Meeting. pp. 409420, CONF-830323, National Technical Information Service, Springfield, Virginia.

Knight, J. A., and C. W. Gorton. 1983. "Oil Production by Entrained Flow Pyrolysis of Biomass." In Proceedings of the Third Canadian Biomass Liquefaction Experts Meeting, pp. 138-146, University of Sherbrooke, Sherbrooke, Quebec, Canada.

Knight, J. A., C. W. Gorton, R. J. Kovac, and L. W. Elston. 1982. "Entrained Flow Pyrolysis of Biomass." In Proceedings of the 14th Biomass Thermochemical Conversion Contractors' Meeting, pp. 250-271, CONF-820685, National Technical Information Service, Springfield, Virginia.

Knight, J. A., C. W. Gorton, R. J. Kovac, L. W. Elston, and D. R. Hurst. 1981. "Oil Production Via Entrained Flow Pyrolysis of Biomass." In Proceedings of the 13th Biomass Thermochemical Conversion Contractors' Meeting, pp. 475-492, CONF-8110115, National Technical Information Service, Springfield, Virginia.

Knight, J. A., C. W. Gorton, J. H. Murphy, L. W. Elston, R. J. Kovac, and D. R. Hurst. 1981. "Thermochemical Conversion of Biomass to Syngas Via the Georgia Tech Entrained Pyrolysis/ Gasification Process." In Proceedings of the 12th Biomass Thermochemical Conversion Contractors' Meeting, March 18-19, 1981, Washington, DC. 
Knight, J. A., C. W. Gorton, and J. H. Murphy. 1980. "Thermochemical Conversion of Biomass to Syngas Via the Georgia Tech Entrained Pyrolysis/Gasification Process." In Proceedings of the 11th Biomass Thermochemical Conversion Contractors' Meeting, September 23-24, 1980, Richland, WA.

Kosstrin, H. 1980. "Direct Formation of Pyrolysis Oil from Biomass." In Proceedings, Specialists' Workshop on Fast Pyrolysis of Biomass, pp. 105-121, SERI/CP-622-1096.

Knight, J. A., D. R. Hurst, and L. W. Elston. 1977. "Wood Oil from Pyrolysis of Pine BarkSawdust Mixtures." D. A. Tillman, et al., eds. Fuels and Energy from Renewable Sources, pp. 169-195. Academic Press, New York.

Coats, R. M., J. Benion, and W. Liston. 1976. "Entrained Flow Gasification." In Proceedings Mathematical Modeling of Coal Conversion Processes, Energy Research Development Administration, M. J. Biallas, ed., Washington, DC, pp. 126-138.

Knight, J. A. 1976. "Pyrolysis of Pine Sawdust." F. Shafizadeh, et al., eds. Thermal Uses and Properties of Carbohydrates and Lignins, pp. 159-173, Academic Press, New York.

Knight, J. A., C. W. Gorton, R. J. Kovac, et al. "Thermochemical Conversion of Biomass Via the Georgia Tech Entrained Pyrolysis/Gasification Process." Final Report, Contract No. DEAS05-80CS83007. 


\subsection{RESEARCH TO UPGRADE BIOMASS CRUDE OILS}

\subsubsection{Upgrading of Biocrude Using Zeolite Catalysts}

\subsubsection{Zeolite Upgrading of Biocrude to High Octane Gasoline}

Milne, T. A., R. J. Evans, and J. Filley. 1988. "Molecular Beam Mass Sspectrometric Studies of HZSM-5 Activity During Wood Pyrolysis Product Conversion, " Research in Thermochemical Biomass Conversion, pp. 910-926, eds. A. V. Bridgwater and J. L. Kuester, Elsevier Applied Science, London.

Diebold, J. P., and J. W. Scahill. 1987. "Upgrading Pyrolysis Vapors to Aromatic Gasoline with Zeolite Catalysis at Atmospheric Pressure." In Proceedings of the 1987 Biomass Thermochemical Conversion Contractors' Review Meeting, pp. 61-80, CONF-8705212, National Technical Information Service, Springfield, Virginia.

Diebold, J. P., and J. W. Scahill. 1987. "Biomass-to-Gasoline (BTG): Upgrading Pyrolysis Vapors to Aromatic Gasoline With Zeolite Catalysts at Atmospheric Pressure." Prepr. of 193rd ACS Meeting, Div Fuel Chem., Vol. 32, No. 2, pp. 297-307.

Diebold, J. P., H. L. Chum, R. J. Evans, T. A. Milne, T. B. Reed, and J. W. Scahill. 1987. "Low Pressure Upgrading of Primary Pyrolysis Oils from Biomass and Organic Wastes." In Proceedings of Energy from Biomass and Wastes X, ed. D. L. Klass, pp. 801-830, Institute of Gas Technology, Chicago, Illinois.

Evans, R. J., and T. A. Milne. 1987. "Molecular-Beam Mass Spectrometric Studies of Wood Vapor and Model Compounds Over HZSM-5 Catalyst." Preprints of 193rd ACS Meeting, Div. Fuel Chemistry, Vol. 32, No. 2, pp. 287-296.

Reed, T. B., J. P. Diebold, H. L. Chum, R. J. Evans, T. A. Milne, and J. W. Scahill. 1986. "Overview of Biomass Fast Pyrolysis and Catalytic Upgrading to Liquid Fuels." In Proceedings of the 1986 Annual Meeting. American Solar Energy Society. Inc., Boulder, Colorado. June $11-14,1986$.

Diebold, J. P., J. W. Scahill, and R. J. Evans. 1986. "The Thermal and Catalytic Upgrading of Oxygenated, Primary Biomass Pyrolysis Oil Vapors." In Proceedings of the 1985 Biomass Thermochemical Conversion Contractors' Meeting, pp. 31-55, CONF-8510167, National Technical Information Service, Springfield, Virginia.

Chum, H. L., et al. 1985. "Liquid Fuels from Lignins." In Biochemical Conversion Program, Semi-Annual Review Meeting, SERI/CP-231-2726. National Renewable Energy Laboratory, Golden, Colorado. 


\subsubsection{Upgrading Using Hydrotreating Catalysts}

\subsubsection{Catalytic Hydrotreating of Biocrude Oil - Pacific Northwest Laboratory (PNL)}

Elliott, D. C., E. G. Baker, A. Oestman, S. B. Gevert and D. Beckman. 1989. "Technical Economic Analysis of Direct Biomass Liquefaction." In Proceedings of Energy from Biomass and Waste XIII, ed. D. L. Klass, Institute of Gas Technology, Chicago, Illinois.

Elliott, D. C. and E. G. Baker. 1988. "Catalytic Hydrotreating Processes for Upgrading Biocrude Oils. In Proceedings of the Thermochemical Conversion Program Review Meeting, pp. 45-56, SERI/CP-231-3355, National Renewable Energy Lab, Golden, Colorado.

Baker, E. G., and D. C. Elliott. 1988. "Catalytic Upgrading of Biomass Pyrolysis Oils," Research in Thermochemical Biomass Conversion, pp. 883-895, eds. A. V. Bridgwater and J. L. Kuester, Elsevier Applied Science, London.

Baker, E. G., and D. C. Elliott. 1987. "Catalytic Hydrotreating of Biomass-Derived Oils." Amer. Chem. Soc. Div. Fuel Chem. Preprints, 32(2):257-263.

Elliott, D. C., and E. G. Baker. 1987. "Research on Hydrotreating Catalysts to Hydrodeoxygenate Biocrude Oils." In Proceedings of the 1987 Biomass Thermochemical Conversion Contractors' Review Meeting, pp. 81-97, CONF-8705212, National Technical Information Service, Springfield, Virginia.

Elliott, D. C., and E. G. Baker. 1987. "Hydrotreating Biomass Liquids to Produce Hydrocarbon Fuels." In Proceedings of Energy from Biomass and Waste X, ed. D. L. Klass, pp. 765-784. Institute of Gas Technology, Chicago, Illinois.

Elliott, D. C., and E. G. Baker. 1986. Catalytic Hydrotreating of Biomass Liquefaction Products to Produce Hydrocarbon Fuels, Interim Report. PNL-5844, Pacific Northwest Laboratory, Richland, Washington.

Elliott, D. C., and E. G. Baker. 1986. "Upgrading Biomass Liquid Fuels." In Proceedings of the 1985 Biomass Thermochemical Conversion Contractors' Meeting, pp. 81-97, CONF-8510167, National Technical Information Service, Springfield, Virginia.

Beckman, D., and D. C. Elliott. 1985. Can. J. Chem. Eng., 63:99-104.

Elliott, D. C., and E. G. Baker. 1985. "Hydrodeoxygenation of Wood-Derived Liquids to Produce Hydrocarbon Fuels." In Proceedings of the 20th Intersociety Energy Conversion Engineering Conference, pp. 1.586-1.592, \#SAE P-164, Society of Automotive Engineers.

Elliott, D. C. 1984. "Bench-Scale Research in Biomass Direct Liquefaction." In Proceedings of the 16th Biomass Thermochemical Conversion Contractors' Meeting, pp. 399-422, CONF-8405157, National Technical Information Service, Springfield, Virginia. 
Elliott, D. C., and E. G. Baker. 1984. "Biomass Liquefaction Product Analysis and Upgrading." In Comptes Rendus de L'Atelier de Travail Sur la Liquefactionde la Biomasse, University of Sherbrooke, Sherbrooke, Quebec, Canada.

Elliott, D. C., and E. G. Baker. 1984. "Upgrading Biomass Liquefaction Products Through Hydrodeoxygenation." In Biotechnology and Bioengineering Symposium, C. D. Scott, ed., Symposium No. 14, pp. 159-174. John Wiley \& Sons, New York, New York.

Elliott, D. C., and E. G. Baker. 1983. "Biomass Liquefaction Product Analysis and Upgrading." In Proceedings of the 3rd Meeting of Biomass Liquefaction Specialists, eds. E. Chomet and R. Overend, University of Sherbrooke, Sherbrooke, Quebec.

Elliott, D. C. 1983. "Hydrodeoxygenation of Phenolic Components of Wood-Derived Oil." Amer. Chem. Soc. Div. Petr. Chem. Preprts. 28(3):667-674. 


\subsection{BASIC PYROLYSIS RESEARCH}

\subsubsection{Use of a Molecular Beam/Mass Spectrometer (MBMS) System}

\subsubsection{Fundamental Pyrloysis Studies - National Renewable Energy Laboratory (NREL)}

Evans, R. J., J. Filley, and T. A. Milne. 1988. "Molecular Beam Mass Spectrometric Studies of HZSM-5 Activity During Wood Pyrolysis Product Conversion. Proceedings of the Thermochemical Conversion Program Annual Meeting, pp. 33-44, SERI/CP-231-3355, National Renewable Energy Laboratory, Golden, Colorado.

Evans, R. J., and T. A. Milne. 1988. "Mass Spectrometric Studies of the Relationship of Pyrolysis Oil Composition to Formation Mechanisms and Feedstock Composition, "Research in Thermochemical Biomass Conversion, pp. 264-279, eds. A. V. Bridgwater and J. L. Kuester, Elsevier Applied Science, London.

Evans, R. J., and T. A. Milne. 1987. "Molecular Characterization of the Pyrolysis of Biomass I. Fundamentals." Energy and Fuels, 1:123-137.

Evans, R. J., and T. A. Milne. 1987. "Molecular Characterization of the Pyrolysis of Biomass II. Applications." Energy and Fuels, 1:311-319.

Evans, R. J., and T. A. Milne. 1986. "Applied Mechanistic Studies of Biomass Pyrolysis." In Proceedings of the 1985 Biomass Thermochemical Conversion Contractors' Meeting, pp. 5779 CONF-8510167, National Technical Information Service, Springfield, Virginia.

Evans, R. J., and T. A. Milne. 1986. Fundamental Pyrolysis Studies, Final Report 1 October 1980 - 30 December 1985. SERI/PR-234-3026, Solar Energy Research Institute, Golden, Colorado.

Evans, R. J. 1986. "Direct Mass-Spectrometric Studies of the Pyrolysis of Carbonaceous Fuels. IV. The Primary Pyrolysis of Carbohydrates. J. Anal. Pyrol.

Evans, R. J., T. A. Milne, and M. N. Soltys. 1986. "Direct Mass-Spectrometic Studies of the Pyrolysis of Carbonaceous Fuels. III. Primary Pyrolysis of Lignins." J. Anal. Appl. Pyrol. 9:207-236.

Evans, R. J. 1985. "Direct Mass-Spectrometric Studies of the Pyrolysis of Carbonaceous Fuels. IV. The Primary Pyrolysis of Carbohydrates." J. Anal. Appl. Pyrol.

Evans, R. J., and T. A. Milne. 1985. Mechanisms of the Pyrolysis of Municipal Solid Waste: Annual Report. 1 August 1984 to 30 July 1985. SERI/PR-234-2852, Solar Energy Research Institute, Golden, Colorado. 
Evans, R. J., T. A. Milne, and M. N. Soltys. 1985. "Direct Mass-Spectrometric Studies of the Pyrolysis of Carbonaceous Fuels. III. Primary Pyrolysis of Lignin." J. Anal. Appl. Pyrol. 9:207-236.

Evans, R. J., M. N. Soltys, and T. A. Milne. 1985. Fundamental Pyrolysis Studies: Annual Report, 1 October 1983 to 30 December 1984. SERI/PR-234-2701, Solar Energy Research Institute, Golden, Colorado.

Milne, T. A., and M. N. Soltys. 1985. "The Direct, Mass-Spectrometric Study of the Primary and Secondary Pyrolysis Behavior of Biomass and Its Constituents." Fundamentals of Thermochemical Biomass Conversion, pp. 361-384, R. Overend, T. A. Milne, and L. K. Mudge, eds., Elsevier Applied Science, London.

Evans, R. J., M. N. Soltys, and T. A. Milne. 1984. Mechanisms of the Pyrolysis of Municipal Solid Waste: Annual Report, 5 July 1983 to 5 July 1984. SERI/PR-234-2596, Solar Energy Research Institute, Golden, Colorado.

Evans, R. J., T. A. Milne, M. N. Soltys, and H. R. Schulten. 1984. "The Mass Spectrometric Behavior of Levoglucosan Under Different Ionization Conditions and Implications for Studies of Cellulose Pyrolysis." J. Anal. Appl. Pyr. 6:273-283.

Milne, T. A., and M. N. Soltys. 1984. "Direct Mass-Spectrometric Studies of the Pyrolysis of Carbonaceous Fuels." J. Anal. Appl. Pyrol., 5:93-110.

Evans, R., T. Milne, and M. Soltys. 1984. Fundamental Pyrolysis Studies, Quarterly Report. 1 April - 30 June 1984. SERI/PR-234-2398, Solar Energy Research Institute, Golden, Colorado.

Evans, R. J., T. A. Milne, and M. N. Soltys. 1984. "Fundamental Pyrolysis Studies." In Proceedings of the 16th Biomass Thermochemical Contractors' Meeting, pp. 349-373, CONF-8405157, National Technical Information Service, Springfield, Virginia.

Himmel, M. E., K. K. Oh, D. W. Sopher, and H. L. Chum. 1983. "High-Performance Size Exclusion Chromatography of Low-Molecular Weight Lignins and Model Compounds." I. Chromatog. 267:249-265.

Milne, T. A., and M. N. Soltys. 1983. "Direct Mass-Spectrometric Studies of the Pyrolysis of Carbonaceous Fuels. I. A Flame-Pyrolysis, Molecular-Beam Sampling Technique." J. Anal. Appl Pyrol. 5:93-110.

Milne, T. A., and M. N. Soltys. 1983. "Direct Mass-Spectrometric Studies of the Pyrolysis of Carbonaceous Fuels. II. Qualitative Observations of Primary and Secondary Processes in Biomass." J. Anal. Appl. Pyrol. 5:111-131. 
Milne, T. A., M. N. Soltys, and R. J. Evans. 1983. "Fundamental Pyrolysis Studies." In Proceedings of the 15th Biomass Thermochemical Conversion Contractors' Meeting, pp. 358408, CONF-830323, National Technical Information Service, Springfield, Virginia.

Milne, T. A., R. J. Evans, and M. N. Soltys. 1983. Fundamental Pyrolysis Studies, Annual Report, 1 December 1982 - 30 September 1983. SERI/PR-234-2152. Solar Energy Research Institute, Golden, Colorado.

Milne, T. A., and M. N. Soltys. 1982. Fundamental Pyrolysis Studies. Quarterly Report, October-December 1981. SERI/PR-234-1537, Solar Energy Research Institute, Golden, Colorado.

Milne, T. A., and M. N. Soltys. 1982. "The Direct Observation of Pyrolysis Behavior of Carbonaceous Solids in a Hot-Steam Argon Environment." Paper presented at the Spring Meeting of the Western States Section of the Combustion Institute. SERI/TP-234-1524, Solar Energy Research Institute, Golden, Colorado.

Milne, T. A., and M. N. Soltys. 1982. Fundamental Pyrolysis Studies. Quarterly Report, January-March 1982. SERI/PR-234-1617, Solar Energy Research Institute, Golden, Colorado.

Milne, T. A., and M. N. Soltys. 1982. "Fundamental Pyrolysis Studies." In Proceedings of the 14th Biomass Thermochemical Conversion Contractors' Meeting, pp. 312-402, CONF820685, National Technical Information Service, Springfield, Virginia.

Milne, T. A., and M. N. Soltys. 1981. "Fundamental Pyrolysis Studies - Annual Report for Fiscal Year 1981." In Proceedings of the 13th Biomass Thermochemical Contractors' Meeting, pp. 366-398, CONF-8110115, National Technical Information Service, Springfield, Virginia.

Milne, T. A., and M. N. Soltys. 1981. Kinetics and Mechanisms of Fast Pyrolysis: Quarterly Report - January-March 1981. SERI/PR-622-1152, Solar Energy Research Institute, Golden, Colorado.

Milne, T. A., and M. N. Soltys. 1981. "Kinetics and Mechanisms of Fast Pyrolysis." In Proceedings of the 12th Biomass Thermochemical Conversion Contractors' Meeting, March 1891, 1981, Washington, DC.

Milne, T. A., and M. N. Soltys. 1981. Pyrolysis Mechanisms: Quarterly Report - April-June 1981. SERI/PR-622-1347, Solar Energy Research Institute, Golden, Colorado.

Soltys, M. N., and T. A. Milne. 1981. The SERI High-Pressure, Molecular Beam, Mass Spectrometric, Sampling System. SERI/TR-622-1172, Solar Energy Research Institute, Golden, Colorado.

Milne, T. A. 1979. "The Kinetics and Mechanism of Fast Pyrolysis." In Proceedings of the 9th Biomass Thermochemical Conversion Contractors' Meeting, November 7-8, 1979, Rolla, Missouri. 
3.5.1.2 Rapid Characterization of Biomass and Biomass Oils - National Renewable Energy Laboratory (NREL)

Evans, R. J., and T. A. Milne. 1987. "Molecular Characterization of the Pyrolysis of Biomass I. Fundamentals." Energy and Fuels, 1:123-137.

Evans, R. J., and T. A. Milne. 1987. "Molecular Characterization of the Pyrolysis of Biomass II. Applications." Energy and Fuels, 1:311-319.

Evans, R. J., and T. A. Milne. 1987. "Liquid Fuels From the Pyrolysis of Municipal Solid Waste and Its Components: Rapid Product Characterization and Process Parameter Screening by Molecular Beam, Mass Spectrometry." In Energy from Biomass and Wastes XI, D. L. Klass, ed., Institute of Gas Technology, Chicago, Illinois.

Evans, R. J., T. A. Milne, and M. N. Soltys, 1986. "Direct Spectrometric Studies of the Pyrolysis of Carbonaceous Fuels. III. Primary Pyrolysis of Lignins." J. Anal. Pyrol. 9:207236.

56 


\subsubsection{Other Basic Pyrolysis Studies}

\subsubsection{Pyrolysis in Hydrogen and Methane Atmospheres - Brookhaven National}

Laboratory (BNL)

Steinberg, M. 1987. "HYDROCARB Process: Conversion of Carbonaceous Materials to Clean Carbon and Gaseous Fuel." BNL-40731. In Energy from Biomass and Wastes XI, Institute of Gas Technology, Chicago, Illinois.

Steinberg, M., P. T. Fallon, and M. S. Sundaram. 1986. "Flash Pyrolysis of Biomass with Reactive and Non-Reactive Gas." Biomass (9):293-315.

Steinberg, M., P. T. Fallon, and M. S. Sundaram. 1986. "Flash Methanolysis - The Flash Pyrolysis of Biomass with Methane Gas." In Proceedings of the 1985 Biomass Thermochemical Conversion Contractors' Meeting, pp. 15-29, SERI/CP-231-3355, National Renewable Energy Laboratory, Golden, Colorado.

Steinberg, M., P. T. Fallon, and M. S. Sundaram. 1985. Flash Methanolysis - The Flash Pyrolysis of Biomass with Methane Gas - Summary Report for Period of October 1984 - October 1985. BNL- 37423, Brookhaven National Laboratory, Upton, New York.

Sundaram, M. S., M. Steinberg, and P. T. Fallon. 1985. "Flash Pyrolysis of Biomass with Reactive and Non-Reactive Gases." In Fundamentals of Thermochemical Biomass Conversion, pp. 167-182, eds.R. Overend, T. A. Milne, and L. K. Mudge, Elsevier Applied Science Publishers, London.

Steinberg, M. 1985. "Direct Use of Natural Gas (Methane) for Conversion of Carbonaceous Raw Materials to Fuels and Chemical Feedstocks." In Proceedings of the Miami International Conference on Alternative Energy Sources. Miami Beach. FL, USA, 9 Dec 1985. BNL-37383, CONF-85120112, National Technical Information Service, Springfield, Virginia.

Steinberg, M. 1985. "Direct Use of Natural Gas (Methane) for Conversion of Carbonaceous Raw Materials to Fuels and Chemical Feedstocks." In Proceedings of the Beijing International Symposium on Hydrogen Systems, Beijing, China, 7 May 1985. BNL-36368, CONF-8505123. National Technical Information Service, Springfield, Virginia.

Steinberg, M., P. T. Fallon, and M. S. Sundaram. 1984. "Flash Pyrolysis of Biomass with Reactive and Non-Reactive Gases." In Proceedings of the 16th Biomass Thermochemical Conversion Contractors' Meeting, pp. 299-317, CONF-8405157, National Technical Information Service, Springfield, Virginia. (BNL 34734).

Steinberg, M., P. T. Fallon, and M. S. Sundaram. 1983. "Flash Pyrolysis of Biomass with Reactive and Non-Reactive Gases." In Proceedings of the 15th Biomass Thermochemical Conversion Contractors' Meeting, pp. 421-444, CONF-830323, National Technical Information Service, Springfield, Virginia. 
Steinberg, M., and P. T. Fallon. 1982. "Flash Pyrolysis of Biomass with Reactive and NonReactive Gases." In Proceedings of the 14th Biomass Thermochemical Conversion Contractor's Meeting, pp. 452-471, CONF-820685, National Technical Information Service, Springfield, Virginia.

Sundaram, M. S., M. Steinberg, and P. T. Fallon. 1982. "Flash Pyrolysis of Biomass with Reactive and Non-Reactive Gases." Fundamentals of Thermochemical Biomass Conversion, pp.167-182, R. Overend, T. A. Milne, and L. K. Mudge, eds., Elsevier Applied Science, London.

Steinberg, M., and P. T. Fallon. 1981. "Flash Pyrolysis and Hydropyrolysis of Biomass, Progress Report No. 2." In Proceedings of the 13th Biomass Thermochemical Conversion Contractors' Meeting, pp. 445-474, CONF-8110115, National Technical Information Service, Springfield, Virginia.

Steinberg, M., and P. Fallon. 1981. "Flash Hydropyrolysis of Biomass." In Proceedings of the 12th Biomass Thermochemical Contractors'Meeting. BNL-30235, Brookhaven National Laboratory, Upton, New York.

Steinberg, M. 1980. "The Flash Hydrogenation of Biomass." In Proceedings of the 11th Biomass Thermochemical Conversion Contractors' Meeting, September 23-24, 1980, Richland, Washington.

Steinberg, M. 1980. "The Flash Hydrogenation of Biomass." BNL 28297, Brookhaven National Laboratory, Upton, New York.

Steinberg, M., and B. Bhatt. 1980. "Flash Pyrolysis and Hydropyrolysis of Coal." BNL 28577, Brookhaven National Laboratory, Upton, New York.

Steinberg, M., and P. Fallon. 1980. Flash Pyrolysis of Biomass with Reactive and NonReactive Gases. BNL 51560, Brookhaven National Laboratory, Upton, New York.

Fallon, P., and M. Steinberg. 1979. "Flash Hydropyrolysis of Coal." Progress Report No. 7, BNL 51010, Brookhaven National Laboratory, Upton, New York.

Steinberg, M., T. V. Sheehan, and Q. Lee. 1975. Flash Hydropyrolysis Process for Conversion of Lignite to Liquid and Gaseous Products. BNL 20915, Brookhaven National Laboratory, Upton, New York. 


\subsubsection{Effects of Pressure on Pyrolysis - Princeton University/University of Hawaii}

Antal, M. J., M. Carlsson, C. Habenicht, L. Kam, N. Bian, R. J. Cunningham, and M. Jones. 1994. Ind. Eng. Chem. Res. 33, pp. 1989-1996.

Antal, M. J., and X. Xu. 1994. "Kinetics and Mechanism of the Autocatalytic Dehydratipon of t-Butanol in Hot Liquid Water." AIChE Journal 40, pp. 1524-1534.

Antal, M. J., D. Yu, and M. Aihara. 1993. "Hydrogen Production by Steam Reforming Biomass in Supercritical Water." Ind. Eng. Chem Res. 30, pp. 1157-1161.

Antal, M. J., and W. S. L. Mok. 1992. "Uncatalyzed Solvolysis of Whole Biomass Hemicellulose by Hot Compressed Water." Energy and Fuels 7. pp. 574-577.

Antal, M. J., W. S. L. Mok, P. Szabo, G. Varhegyi, and B. Zelei. 1992. "Formation of Charcoal From Biomass in a Sealed Reactor." Ind. Eng. Chem. Res. 31, pp. 1162-1166.

Antal, M. J, and R. Narayan. 1990. "The Influence of Pressure on the Acid Catalyzed Rate Constant for 1-Propanol Dehydration in Supercritical Water." J. Am. Chem Soc. 112, pp. 1927-1931.

Antal, M. J., G. Varhegyi, T. Szekely, and P. Szabo. 1989. "Kinetics of the Thermal Decomposition of Cellulose, Hemicellulose, asnd Ssugar Cane Bagasse." Energy and Fuels 3. pp. 329-335.

Antal, M. J., and W. S. Mok. 1988. "A Study of the Acid-Catalyzed Dehydration of Fructose in Near-Critical Water," Research in Thermochemical Biomass Conversion, pp.464-472, eds. A. V. Bridgwater and J. L. Kuester, Elsevier Applied Science, London.

Antal, M. J. 1985. "A Review sof the Vapor Phase Pyrolysis of Biomass Derived Volatile Matter, " Fundamentals of Thermochemical Biomass Conversion, pp. 511-538, eds. R. Overend, T. A. Milne, and L. K. Mudge, Elsevier Applied Science Publishers, London.

Antal, M. J. 1985. "Biomass Pyrolysis. A Review of the Literature Part 2: Lignocellulose Pyrolysis." Advances in Solar Energy, pp. 175-255, eds. K. W. Boer and J. A. Duffie, Plenum Press, New York.

Antal, M. J., and W. S. L. Mok. 1983. "Effects of Pressure on Biomass Pyrolysis II. Heats of Reaction of Cellulose Pyrolysis.." Combustion Science and Technology 21, pp. 141-152.

Antal, M. J. 1982. "Biomass Pyrolysis. A Review of the Literature Part 1: Carbohydrate Pyrolysis." Advances in Solar Energy, pp. 165-186, eds. K. W. Boer and J. A. Duffie, American Soslar Energy Society, Boulder, Colorado. 
Mok, W. S. M. J. Antal. 1982. "Effects of Pressure on Biomass Pyrolysis." In Proceedings of the 14th Biomass Thermochemical Conversion Contractors' Meeting, pp. 403-451, CONF820685, National Technical Information Service, Springfield, Virginia.

Mok, W. 1982. "Effects of Pressure on Biomass Pyrolysis." M.S.E. Thesis, Princeton University.

Mok, W., and M. J. Antal 1981. "Effects of Pressure on Biomass Pyrolysis and Gasification." In Proceedings of the 13th Biomass Thermochemical Conversion Contractors' Meeting, pp. 399444, CONF-8110115, National Technical Information Service, Springfield, Virginia.

Antal, M. J., H. L. Friedman, and F. E. Rogers. 1980. "Kinetics of Cellulose Pyrolysis in Nitrogen and Steam." Combustion Science and Technology, Vol. 21, pp. 141-152. 


\subsection{OTHER BIOMASS PYROLYSIS/LIQUEFACTION PROJECTS}

\subsubsection{Other Biomass Thermochemical Conversion Program Projects}

\subsubsection{Analysis and Comparison of Biomass Pyrolysis/Gasification Condensates - Pacific Northwest Laboratory (PNL)}

Elliott, D. C., L. J. Sealock and R. S. Butner. 1987. "Product Analysis from Direct Liquefaction of Several High-Moisture Biomass Feedstocks." Presented at the 193rd National Meeting of the American Chemical Society, Denver, CO, 5 Apr 1987. PNL-SA-14315, CONF87041027, Pacific Northwest Laboratory, Richland, Washington.

Elliott, D. C. 1987. Analysis of Medium-BTU Gasification Condensates, June 1985-June 1986. PNL-5979, Pacific Northwest Laboratory, Richland, Washington.

Elliott, D. C. 1986. Analysis and Comparison of Biomass Pyrolysis/Gasification Condensates: Final Report. PNL-5943, Pacific Northwest Laboratory, Richland, Washington.

Beckman, D., and D. C. Elliott. 1985. "Comparisons of the Yields and Properties of the Oil Products from Direct Thermochemical Biomass Liquefaction Processes." Canadian Journal of Chemical Engineering. 63:99-104.

Elliott, D. C. 1985. "Analysis and Comparison of Biomass Pyrolysis/Gasification Condensates - An Interim Report." PNL-5555, Pacific Northwest Laboratory, Richland, Washington.

Elliott, D. C. 1985. "Analysis and Comparison of Products from Wood Liquefaction." In Fundamentals of Thermochemical Biomass Conversion, eds. R. P. Overend, T. A. Milne, and L. K. Mudge. pp. 1003-1018. Elsevier Applied Science Publishers, London.

Schirmer, R. E., T. R. Pahl, and D. C. Elliott. 1984. "Analysis of a Thermochemically-Derived Wood Oil." Fuel 63:368-372.

Elliott, D. C. 1985. "Comparative Analysis of Gasification/Pyrolysis Condensates." In Proceedings of the 1985 Biomass Thermochemical Conversion Contractors' Meeting, pp. 361381, CONF-8510167, National Technical Information Service, Springfield, Virginia.

Elliott, D. C. 1985. Analysis and Comparison of Biomass Pyrolysis/ Gasification Condensates - An Interim Report. PNL-5555, National Technical Information Service, Springfield, Virginia.

Elliott, D. C. 1985. "Analysis and Comparison of Products from Wood Liquefaction." In Fundamental of Thermochemical Biomass Conversion, eds. R. P. Overend, T. A. Milne, and L. K. Mudge, pp. 1003-1018, Elsevier Applied Science Publishers, London. 
Elliott, D. C. 1983. Analysis and Upgrading of Biomass Liquefaction Products. Final Report, Volume 4 of IEA Forestry Energy Cooperative Project D-1, Biomass Liquefaction Test Facility, National Energy Administration, Stockholm.

Elliott, D. C. 1981. "Description and Utilization of Product from Direct Liquefaction of Biomass." Biotech. and Bioeng., Symp. No. 11, 187-198. 


\subsubsection{Pyrolysis for Char Production - University of Arkansas}

Kimzey, J. R. and H. H. Hicks. 1985. "Continuous Pyrolysis of Biomass Feedstocks in Rotary Kiln Convertors. Technical Evaluation of a Cellulose Waste Converter at Jonesboro, Arkansas. Final Report." DOE-CS-84003-T1, National Technical Information Service, Springfield, Virginia.

"Engineering Optimization of a Large Rotary Kiln Pyrolysis System." 1981. In Proceedings of the 12th Biomass Thermochemical Conversion Contractors' Meeting, March 18-19, 1981, Washington, DC.

Hicks, H. H., Jr. 1980. "The Production and Utilization of Charcoal and Its By-Products in the Ozarks Region and Elsewhere in the United States." In Proceedings of the 11th Biomass Thermochemical Conversion Contractors' Meeting, September 23-24, 1980, Richland, Washington.

"Thermal Conversion of Biomass in a Rotary Kiln System." 1980. In Proceedings of the 11th Biomass Thermochemical Conversion Contractors' Meeting, September 23-24, 1980, Richland, Washington.

Hicks, H. 1980. "Evaluation and Optimization of a Rotary Kiln Biomass Convertor." In Proceedings of the 10th Biomass Thermochemical Conversion Contractors' Meeting, February 12-13, 1980, Berkeley, California.

Hicks, H. H., J. R. Kimzey, and J. L. Turpin. 1979. "Pyrolytic Charcoal Using Rotary Kiln Biomass Converter." In Proceedings of the Sixth Biomass Thermochemical Conversion Contractors' Meeting, January 16-17, 1979, Tucson, Arizona. 
3.6.2 BTC Program Participarion in Liquefaction/Pyrolysis Research Sponsored by the International Energy Agency

\subsubsection{IEA Biomass Liquefaction/Pyrolysis Project - International Energy Agency}

Beckman, D., D. C. Elliott, B. Gevert, C. Hörnell, B. Kjellstroem, A Östman, Y. Solantausta, and V. Tulenheimo. 1990. "Techno-Economic Assessment of Selected Biomass Liquefactiojn Processes." VTT-697, Technical Research Center of Finland, Espoo, Finland.

Kjellstroem, B., D. Beckman, D. C. Elliott, A. Kannel and P. McKeough. 1988. "IEA (International Energy Agency) Co-Operative Project D1, Biomass Liquefaction Test Facility Project: Volume 1, Summary, Conclusions and Recommendations." DOE-NBM-1062-Vol.1, National Technical Information Service, Springfield, Virginia.

Beckman, D., A. Bergh, D. C. Elliott and A. Kannel. 1988. "IEA (International Energy Agency) Co-Operative Project D1, Biomass Liquefaction Test Facility Project: Volume 2, State-of-the-Art Review." DOE-NBM-1062-Vol.2, National Technical Information Service, Springfield, Virginia.

Kjellstroem, B., D. Beckman, D. C. Elliott, A. Kannel and P. McKeough. 1988. "IEA (International Energy Agency) Co-Operative Project D1 Biomass Liquefaction Test Facility Project: Volume 3, Results from the Comparative Test Program." DOE-NBM-1062-Vol.3, National Technical Information Service, Springfield, Virginia.

Elliott, D. C. 1988. "IEA (International Energy Agency) Co-Operative Project D1 Biomass Liquefaction Test Facility Project: Volume 4, Analysis and Upgrading of Biomass Liquefaction Products." DOE-NBM-1062-Vol.4, National Technical Information Service, Springfield, Virginia.

McKeough, P., M. Nissilae, Y. Solantausta, D. Beckman and A. Ostman. 1988. "IEA (International Energy Agency) Co-Operative Project D1 Biomass Liquefaction Test Facility Project: Volume 5, Techno-Economic Assessment of Selected Biomass Liquefaction Processes." DOE-NBM-1062-Vol.5, National Technical Information Service, Springfield, Virginia. 


\section{BIOMASS THERMOCHEMICAL CONVERSION BIBLIOGRAPHY}

\subsection{COMBUSTION PROJECTS}

\subsection{Biomass Fueled Gas Turbine Research}

\subsubsection{Direct Combustion/Gas Turbine System - Aerospace Research Corporation}

Hamrick, J. T. 1991. "Development of Biomass as an Alternative Fuel for Gas Turbines." PNL-7673, Pacific Northwest Laboratory, Richland, Washington.

Hamrick, J. T. 1988. "Evaluation of Manure as a Feedstock for Gas Turbines." PNL-6565, Pacific Northwest Laboratory, Richland, Washington.

Hamrick, J. T. 1987. "3 MW Wood Fired Gas Turbine at Red Boiling Springs, Tennessee." In Proceedings of the 1987 Biomass Thermochemical Conversion Contractors' Review Meeting, pp. 171-182 CONF-8705212, National Technical Information Service, Springfield, Virginia.

Hamrick, J. T. 1987. "Start-Up and Operations of a 3-MW Wood Burning Gas Turbine at Red Boiling Springs, Tennessee." In Energy from Biomass and Wastes X, ed. D. L. Klass, pp. 517 528. Institute of Gas Technology, Chicago, Illinois.

Hamrick, J. T. 1986. "Development of Wood as an Alternative Fuel for Gas Turbines." In Proceedings of the 1985 Biomass Thermochemical Conversion Contractors' Meeting, pp. 263270 CONF-8510167, National Technical Information Service, Springfield, Virginia.

Hamrick, J. T. 1984. "Development of Wood-Burning Gas Turbine Systems." Modern Power Systems. 4(6) June 1984.

Hamrick, J. T., and N. H. Owen. 1984. "Gas Turbine Performance with High Moisture Content Biomass." Presented at Sixth Symposium on Biotechnology for Fuels and Chemicals, Gatlinburg, Tennessee.

Hamrick, J. T. 1984. "Installation of a Three Megawatt Wood Burning Gas Turbine at Red Boiling Springs, Tennessee." Presented at Institute of Gas Technology Symposium at Orlando, Florida, February 1984.

Hamrick, J. T. 1984. "Development of Wood as an Alternative Fuel for Gas Turbine Systems." In Proceedings of the 16th Biomass Thermochemical Conversion Contractors' Meeting, pp. 257-267 CONF-8405157, National Technical Information Service, Springfield, Virginia.

Hamrick, J. T. 1984. "The Design and Development of a Wood Burning Gas Turbine." High Temperature Technology. 2(1) February 1984. 
Layne, R. 1984. "This Gas Turbine Burns Sawdust." Popular Science, November 1984.

Makansi, J. 1984. "Developments to Watch." Power, August 1984.

Stambler, I. 1984. "Aerospace Working on 3-MW Wood-Fired Gas Turbine Plant." Cogeneration, May 1984.

"Wood Gasifier to Fuel 3-MW Gas Turbine Engine." Biomass Digest, 6(7) July 1984.

Hamrick, J. T. 1983. "Development of Wood as an Alternative Fuel for Gas Turbine Systems." In Proceedings of the 15th Biomass Thermochemical Conversion Contractors' Meeting, pp. 271-283, CONF-830323, National Technical Information Service, Springfield, Virginia.

Hamrick, J. T. 1982. "Development of Wood as an Alternative Fuel for Gas Turbine Systems." In Proceedings of the 14th Thermochemical Conversion Contractors' Meeting, pp. 472-486, CONF-820685, National Technical Information Service, Springfield, Virginia.

Hamrick, J. T. 1981. "Development of Wood as an Alternative Fuel for Gas Turbine Systems." In Proceedings of the 13th Thermochemical Conversion Contractors' Meeting, pp. 657-668, CONF-8110115, National Technical Information Service, Springfield, Virginia.

Hamrick, J. T. 1981. "Development of Wood as an Alternative Fuel for Large Power Generating Systems." In Proceedings of the 12th Biomass Thermochemical Conversion Contractors' Meeting, March 18-19, 1981, Washington, DC.

Hamrick, J. T., and T. M. Hamrick. 1981. Development of Wood as an Alternative Fuel for Large Power Generating Systems Part 1: Research on Wood Burning Gas Turbines. Aerospace Research Corporation Final Report (DOE/ET/20058-72(Pt1)(DE82002034).

Hamrick, J. T. 1981. Development of Wood as an Alternative Fuel for Large Power Generating Systems Part 2: Selection of an Oil or Gas Fired Boiler System for Retrofit. Aerospace Research Corporation Final Report DOE/ET/20058-T2(Pt.2)(DE82002033).

Hamrick, N. A. 1981. Development of Wood as an Alternative Fuel for Large Power Generating Systems Part 3: Computer Simulation of the Dynamic Response of an Industrial Gas Turbine with Large Volume Combustion and Filtering System. Aerospace Research Corporation Final Report, DOE/ET/20058-T2(Pt3)(DE82001992).

Hamrick, J. T. 1980. "Development of Wood as an Alternative Fuel for Large Power Generating Systems." In Proceedings of the 11th Biomass Thermochemical Conversion Contractors' Meeting, September 23-24, 1980, Richland, Washington.

Hamrick, J. T. 1980. "Development of Wood as an Alternative Fuel for Large Power Generating Systems." In Proceedings of the 10th Biomass Thermochemical Conversion Contractors' Meeting, February 12-13, 1980, Berkeley, California. 
Hamrick, J. T. 1979. "Development of Wood as an Alternative Fuel for Large Power Generating Systems." In Proceedings of the 9th Biomass Thermochemical Conversion Contractors' Meeting, November' 7-8, 1979, Rolla, Missouri.

Hamrick, J. T. 1979. "Development of Wood as an Alternative Fuel for Large Power Generating Systems." In Proceedings of the Eighth Biomass Thermochemical Conversion Contractors' Meeting, July 31 - August 1, 1979, Seattle, Washington.

Hamrick J. T. 1979. "Development of Wood as an Alternative Fuel for Large Power Generating Systems. In Proceedings of the Seventh Biomass Thermochemical Conversion Contractors' Meeting, April 24-25, 1979, Roanoke, Virginia.

Hamrick, J. T. 1979. "Development of Wood as an Alternative Fuel for Large Power Generating Systems." In Proceedings of the Sixth Biomass Thermochemical Conversion Contractors' Meeting, January 16-17, 1979, Tucson, Arizona.

Hamrick, J. T. 1978. "Development of Wood as an Alternative Fuel for Large Power Generating Systems." In Proceedings of the Fifth Biomass Thermochemical Conversion Coordination Meeting, September 19-20, 1978, Fresno and Hanford, California.

\subsubsection{Pyrolysis Oil Testing for Gas Turbines - Teledyne CAE}

Jasas, G., J. Kasper, and R. Trauth. 1983. "Gas Turbine Demonstration of Pyrolysis-Derived Fuels. Final Technical Report for the Period September 1987 Through June 1982." Produced under subcontract DE-ACO3-78ET13333 for U. S. Department of Energy, Washington, D.C.

Teledyne CAE. 1982. "Gas Turbine Demonstration of Pyrolysis-Derived Fuels." In Proceedings of the 14th Biomass Thermochemical Conversion Contractors' Meeting, pp. 487545, CONF-820685, National Technical Information Service, Springfield, Virginia. 


\subsection{Other Combustion Projects}

\subsubsection{Biomass Fueled Stirling Engine - United Stirling, Inc.}

Percival, W. H., S. Gummesson, and B. Hansson. 1983. "Biomass Fueled Stirling Engine Combustor Research." In Proceedings of the 15th Biomass Thermochemical Conversion Contractors' Meeting, pp. 284-299, CONF-830323, National Technical Information Service, Springfield, Virginia.

Percival, W. 1983. "Final Report of Biomass Fueled Stirling Engine System Research." Final Report prepared under subcontract B-C5803-A-Q, Pacific Northwest Laboratory, Richland, WA.

Percival, W. H., and B. Hansson. 1982. "Biomass Fueled Stirling Engine System Research and Development." In Proceedings of the 14th Biomass Thermochemical Conversion Contractors' Meeting, pp. 546-568, CONF-820685, National Technical Information Service, Springfield, Virginia.

Percival, W. H., S. Gummesson, and B. Hansson. 1981. "Biomass Fueled Stirling Engine Research and Development." In Proceedings of the 13th Biomass Thermochemical Conversion Contractors' Meeting, pp. 669-684, CONF-8110115, National Technical Information Service, Springfield, Virginia.

\subsubsection{Basic Studies of Biomass Combustion - Jet Propulsion Laboratory (JPL)}

Ramohalli, K., C.A. Miller, and J. Palmer. 1985. "Basic Research in Biomass Combustion, Final Report." NASA/JPL RE-152 A/395, Jet Propulsion Laboratory, Pasadena, California.

Miller, C. A., J. S. Palmer, and K. N. R. Ramohalli. 1986. "Basic Research in Biomass Combustion." In Proceedings of the 1985 Biomass Thermochemical Conversion Contractors' Meeting, pp. 146-166, CONF-8510167, National Technical Information Service, Springfield, Virginia.

Ramohalli, K. N. R. 1984. "Basic Research in Biomass Combustion." In Proceedings of the 16th Thermochemical Conversion Contractors' Meeting, pp. 269-286, CONF-8405157, National Technical Information Service, Springfield, Virginia. 


\section{THERMOCHEMICAL CONVERSION OF BIOMASS BIBLIOGRAPHY}

\subsection{TECHNOECONOMIC ANALYSIS/SYSTEM STUDIES}

\subsection{Technoeconomic Analyses}

5.2.1 Technoeconomic Analysis of Advanced Biomass Technologies Including Gasification, Liquefaction, and Power Generation - SAIC International Corporation

Wan, E. I., and M. D. Fraser. 1988. "Economic Potential of Producing Liquid Transportation Fuels from Biomass," Research in Thermochemical Biomass Conversion, pp. 61-76, eds. A. V. Bridgwater and J. L. Kuester, Elsevier Applied Science, London.

Wan, E. I., M. D. Fraser, and I. K. Kwarteng. 1987. "Technical and Economic Evaluation of Emerging Biomass Pyrolysis Processes for Gasoline Production." In Proceedings of the 1987 Biomass Thermochemical Conversion Contractors' Review Meeting, pp. 115-139 CONF8705212, National Technical Information Service, Springfield, Virginia.

Wan, E. I. 1987. "Economic Evaluation of Emerging Biomass Thermochemical Technologies." In Proceedings of Energy from Biomass and Wastes X, ed. D. L. Klass, pp. 1379-1394. Institute of Gas Technology, Chicago, Illinois.

Wan, E. I. 1986. "Technical and Economic Evaluation of Biomass-Based Fuel Processes." In Proceedings of the 1985 Biomass Thermochemical Conversion Contractors' Meeting, pp. 167192, CONF-8510167, National Technical Information Service, Springfield, Virginia.

Wan, E. I. 1985. Economics of a Wood-Fired Gas Turbine Power System. Technical Progress Report, Science Applications International Corporation, McLean, Virginia.

Wan, E. I. 1984. "Economics of Methanol Production from Indigenous Resources." In Proceedings of IGT's 8th Annual Meeting on Energy from Biomass and Wastes, Buena Vista, Florida.

Wan, E. I., and J. D. Price. 1984. "Technical and Economic Assessment of Emerging Advanced Biomass Thermochemical Conversion Technologies." In Proceedings of the 16th Biomass Thermochemical Conversion Contractors' Meeting, pp. 423-451, CONF-8405157, National Technical Information Service, Springfield, Virginia.

Wan, E. I., J. D. Price and J. A. Simmons. 1983. "Methanol Production from Indigenous Resources in New York State. Volume 1, 2 \& 3. Technical and Economic Evaluation of Conversion Process Plants." NYSERDA-8317, Vol 1,2 \& 3, New York State Energy Research and Development Authority, Albany, N.Y. 
Wan, E. I., and J. D. Price. 1983. Technical and Economic Assessment of Liquid Fuel Production from Biomass. Final Research Report. DOE/NBM 1061, Vol. 1 \& 2, National Technical Information Service, Springfield, Virginia.

Wan, E. I., and J. D. Price. 1983. "Technical and Economic Assessment of Emerging Advanced Biomass Thermochemical Conversion Techniques." In Proceedings of the 15th Biomass Thermochemical Conversion Contractors' Meeting, pp. 236-256, CONF-830323, National Technical Information Service, Springfield, Virginia.

Wan, E. I., and J. D. Price. 1982. "Technical and Economic Assessment of Liquid-Fuel Production from Biomass." In Proceedings of the 14th Biomass Thermochemical Conversion Contractors' Meeting, pp. 230-249, CONF-820685, National Technical Information Service, Springfield, Virginia.

Wan, E. I. and J. D. Price. 1982. Technical and Economic Assessment of Liquid Fuel Production from Biomass. Volume 1. Final Research Report. DOE/NBM-1061-V1, National Technical Information Service, Springfield, Virginia.

Wan, E. I. and J. D. Price. 1982. Technical and Economic Assessment of Liquid Fuel Production from Biomass. Volume 2. Appendices. Final Research Report. DOE/NBM-1061-V2, National Technical Information Service, Springfield, Virginia.

Wan, E. I., et al. 1981. "Technical and Economic Assessment of Liquid-Fuel Production from Biomass." In Proceedings of the 13th Biomass Thermochemical Conversion Contractors' Meeting, pp. 297-331, CONF-8110115, National Technical Information Service, Springfield, Virginia.

Wan, E. I., J. A. Simmons, and J. D. Price. 1981. "Biomass-Based Methanol Processes." In Proceedings of the 12th Biomass Thermochemical Conversion Contractors' Meeting, March 18-19, 1981, Washington, DC.

Wan, E. I., J. A. Simmons, and J. D. Price. 1980. "Biomass Based Methanol Processes." In Proceedings of the 11th Biomass Thermochemical Conversion Contractors' Meeting, September 23-24, 1980, Richland, Washington.

Wan, E. I., J. A. Simmons, J. D. Price, and T. D. Nguyen. 1980. "Technical-Economic Assessment of the Production of Methanol from Biomass." In Proceedings of the 10th Biomass Thermochemical Conversion Contractors' Meeting, February 12-13, 1980, Berkeley, California.

Wan, E. I., et al. 1979. Technical-Economic Assessment of the Production of Methanol from Biomass. Vols. I, II, III, Science Applications Incorporated, McLean, Virginia.

Wan, E. I., J. A. Simmons, J. D. Price, and T. D. Nguyen. 1979. "Technical-Economic Assessment of the Production of Methanol from Biomass." In Proceedings of the 9th Biomass Thermochemical Conversion Contractors' Meeting, November 7-8, 1979, Rolla, Missouri. 
Wan, E. I., J. A. Simmons, J. D. Price, and T. D. Nguyen. 1979. "Technical-Economic Assessment of the Production of Methanol from Biomass." In Proceedings of the Eighth Biomass Thermochemical Conversion Contractors' Meeting, July 31 - August 1, 1979, Seattle, Washington.

Wan, E. I., J. A. Simmons, J. D. Price, and T. D. Nguyen. 1979. "Biomass Based Methanol Processes." In Proceedings of the Seventh Biomass Thermochemical Conversion Contractors' Meeting, April 24-25, 1979, Roanoke, Virginia.

Wan, E. I. 1979. "Biomass Based Methanol Processes." In Proceedings of the Sixth Biomass Thermochemical Conversion Contractors' Meeting, January 16-17, 1979, Tucson, Arizona.

Wan, E. I. 1978. "Evaluation of Biomass Based Methanol Processes." In Proceedings of the Fifth Biomass Thermochemical Conversion Coordination Meeting: Fuels From Biomass Program, September 19-20, 1978, Fresno and Hanford, California.

\subsection{SYSTEMS STUDIES}

\subsubsection{Assessment of Feedstock Availability - Pyros, Inc.}

Pyros, Inc., Gaithersburg, MD. 1985. "Assessment of Potential Wood Supply for Intermediate Scale Thermoconversion Facilities, Tasks 1, 2, 3." PNL-5618, Pacific Northwest Laboratory, Richland, Washington.

Orr, F. E. 1983. "Assessment of Potential Wood Supply for Intermediate Scale Thermoconversion Facilities." In Proceedings of the 15th Biomass Thermochemical Conversion Contractors' Meeting, pp. 257-270, CONF-830323, National Technical Information Service, Springfield, Virginia. 


\subsubsection{Solar Cost Data Bank - SRI International}

Kinderman, E. M., P. Meagher, D. L. Olsen, W. J. Short, J. W. Stallings, N. Teater, and D. J. Wilhelm. 1982. "Technical and Economic Evaluations of Biomass Utilization Processes: Solar Cost Data Bank - Final Report." Published by National Technical Information Service, Springfield, Virginia.

Kinderman, E. M. 1981. "Solar (Biomass) Cost Data Bank - Technoeconomic and Market Analysis." In Proceedings of the 12th Biomass Thermochemical Conversion Contractors' Meeting, March 18-19, 1981, Washington, DC.

Kam, A. Y. 1980. "Interim Status Report on the Preparation of a Cost Data Bank for DOE/Biomass Energy Systems Branch." In Proceedings of the 10th Biomass Thermochemical Conversion Contractors' Meeting, February 12-13, 1980, Berkeley, California.

Kam, A. Y., et al. 1979. "Preparation of a Cost Data Bank for DOE/Biomass Energy Systems Branch." In Proceedings of the 9th Biomass Thermochemical Conversion Contractors' Meeting, November 7-8, 1979, Rolla, Missouri.

Kam, A. Y., et al. 1979. "Preparation of a Cost Data Bank for DOE/Biomass Energy Systems Branch." In Proceedings of the Eighth Biomass Thermochemical Conversion Contractors' Meeting, July 31 - August 1 1979, Seattle, Washington.

Kam, A. Y., and R. L. Dickenson. 1979. "Preparation of a Cost Data Bank for DOE/Biomass Energy Systems Branch." In Proceedings of the Seventh Biomass Thermochemical Conversion Contractors' Meeting, April 24-25, 1970, Roanoke, Virginia.

Kohan, S. M., R. L. Dickenson, A. Y Kam. 1979. "Preparation of a Cost Data Bank for DOE/Fuels from Biomass Systems Branch." In Proceedings of the Sixth Biomass Thermochemical Conversion Contractors' Meeting, January 16-17, 1979, Tucson, Arizona.

SRI International. 1978. "Mission Analysis for the Federal Fuels from Biomass Program.. Vol. II: Mission Selection, Market Penetration, Modeling, and Economic Evaluation. Final Report," TID 29091, National Technical Information Service, Springfield, Virginia.

SRI International. 1979. "Mission Analysis for the Federal Fuels from Biomass Programn. Vol. III. Feedstock Availability, Final Report." SAN--0115-T1, National Technical Information Service, Springfield, Virginia. 


\subsubsection{Evaluation of Catalysts in Biomass and Coal Conversion - Catalytica Associates, Inc.}

Garten, R. L., K. K. Ushiba, M. Cooper, and I Mahawili. 1980. "Catalytic Conversion of Biomass to Fuels, Final Report." Prepared under contract DE-ACO3-78ET11013, U. S. Department of Energy, Washington, D.C.

Mahawili, I., K. K. Ushiba, M. C. Cooper, and R. L. Garten. 1979. "Catalytic Conversion of Biomass to Fuels." In Proceedings of the Eighth Biomass Thermochemical Conversion Contractors' Meeting, July 31- August 1, 1979, Seattle, Washington.

Ushiba, K. K., I. Mahawili, M. C. Cooper, and R. L. Garten. 1979. "Thermochemical Catalytic Conversion of Biomass." In Proceedings of the Seventh Biomass Thermochemical Conversion Contractors' Meeting, April 24-25, 1979, Roanoke, Virginia.

Garten, R. L. 1979. "Progress Report on a Study of the Catalytic Conversion of Biomass to Fuels." In Proceedings of the Sixth Biomass Thermochemical Conversion Contractors' Meeting, January 16-17, 1979, Tucson, Arizona. 


\subsubsection{Research and Evaluation of Biomass Resources/Conversion/Utilization Systems - Gilbert Commonwealth Associates, Inc.}

Ahn, Y. K., H. T. Chen, E. Nelson, K. Shields, and R. P. Stringer. 1980. "Research and Evaluation of Biomass Resources/Conversion/ Utilization Systems." In Proceedings of the 11th Biomass Thermochemical Conversion Contractors' Meeting, September 23-24, 1980, Richland, Washington.

Ahn, Y. K., H. T. Chen, Y. C. Chen., R. W. Helm, E. T. Nelson, K. J. Shields, R. P. Stringer, and R. C. Bailie (West Virginia University). 1980. "Research and Evaluation of Biomass Resources/Conversion/Utilization Systems (Market/Experimental Analysis for Development of a Data Base for a Fuels from Biomass Model.)" In Proceedings of the 10th Biomass Thermochemical Conversion Contractors' Meeting, February 12-13, 1980, Berkeley, California.

Ahn, Y. K., H. T. Chen, Y. C. Chen., R. W. Helm, E. T. Nelson, R. P. Stringer, and R. C. Bailie (West Virginia University). 1979. "Research and Evaluation of Biomass Resources/Conversion/ Utilization Systems. Market/Experimental Analysis for Development of a Data Base for a Fuels from Biomass Model." In Proceedings of the 9th Biomass Thermochemical Conversion Contractors' Meeting, November 7-8, 1979, Rolla, Missouri.

Ahn, Y. K., R. J. Brumberg, H. T. Chen, E. T. Nelson, R. P. Stringer, and R. C. Bailie (West Virginia University). 1979. "Research and Evaluation of Biomass Resources/Conversion/ Utilization Systems (Market/Experimental Analysis for Development of a Data Base for a Fuels from Biomass Model.)" In Proceedings of the Eighth Biomass Thermochemical Conversion Contractors' Meeting, July 31 - August 1, 1979, Seattle, Washington.

Ahn, Y. K., R. J. Brumberg, E. T. Nelson, R. P. Stringer, and R. C. Bailie (West Virginia University). 1979. "Research and Evaluation of Biomass Resources/Conversion/Utilization Systems (Market/Experimental Analysis for Development of a Data Base for a Fuels from Biomass Model.)" In Proceedings of the Seventh Biomass Thermochemical Conversion Contractors' Meeting, January 16-17, 1979, Tucson, Arizona.

Stringer, R., Y. K. Ahn, and E. Nelson. 1979. "Resources/Conversion Utilization System." In Proceedings of the Seventh Biomass Thermochemical Conversion Contractors' Meeting, April 24-25, 1979, Roanoke, Virginia. 


\section{THERMOCHEMICAL CONVERSION PROGRAM BIBLIOGRAPHY}

\subsection{FEEDSTOCK CHARACTERIZATION AND OTHER BIOMASS RESEARCH PROJECTS}

\subsection{Feedstock Characterization and Influences of Feedstock on Conversion Characterization}

\subsubsection{Biomass Characterization/IEA Standards Activity - National Renewable Energy Laboratory (NREL)}

Chum, H.L., et al. 1994. "Status of the IEA Voluntary Standards Activity - Round Robins on Whole Wood and Lignins." Advances in Thermochemical Biomass Conversion, ed. A.V. Bridgwater, p. 1701. Blackie Academic \& Professional Press, London.

Milne, T.A., H.L. Chum, F. Agblevor, and D.K. Johnson. 1992. "Standardized Analytical Methods." Biomass and Bioenergy, Vol. 2, Nos. 1-6, pp. 341-36.

Milne, T.A. 1990. "Voluntary Standards for Biomass for Fuels and Chemicals." In Forestry, Forest Biomass and Biomass Conversion, the IEA Bioenergy Agreement (1986-1989) Summary Reports, eds. C.P. Mitchell, L. Zsuffa, S. Andersson, and D.J. Stevens, pp. 343-351. Elsevier Applied Science, London.

Milne, T.A., A.H. Brennan, and B.H. Glenn. 1990. Sourcebook of Methods of Analysis for Biomass and Biomass-Conversion Processes. Elsevier Applied Science, New York.

Evans, R. J., and T. A. Milne. 1988. "Mass Spectrometric Studies of the Relationship of Pyrolysis Oil Composition to Formation Mechanisms and Feedstock Composition, "Research in Thermochemical Biomass Conversion, pp. 264-279, eds. A. V. Bridgwater and J. L. Kuester, Elsevier Applied Science, London.

Milne, T., ed. 1987. Proceedings of a Workshop on Standards in Biomass for Energy and Chemicals, SERI/CP-234-2506, National Renewable Energy Laboratory, Golden, Colorado. 
6.1.2 The Effects of Biomass Properties on Conversion Processes - Pacific Northwest Laboratory (PNL)

Butner, R.S., D.C. Elliott, L.J. Sealock, Jr., and J.W. Payne. 1988. Effect of Biomass Feedstock Chemical and Physical Properties on Energy Conversion Processes, Volume 1 - Overview. PNL-6765, Vol. 1, Pacific Northwest Laboratory, Richland, Washington.

Butner, R.S., D.C. Elliott, L.J. Sealock, Jr., and J.W. Payne. 1988. Effect of Biomass Feedstock Chemical and Physical Properties on Energy Conversion Processes. Volume 2 - Appendices. PNL-6765, Vol. 2, Pacific Northwest Laboratory, Richland, Washington.

6.2 Research on the Use of Vegetable Oils for Fuels

\subsubsection{Oil Seeds as an Alternative Fuel Source - Tufts University}

Lockeretz, W. 1982. "Growing Oilseeds as an Alternative Fuel Source." Final Report submitted under PNL subcontract B-96221-A-Q. Tufts University, Medford, Massachusetts. 
6.3 Other Participation in the International Energy Agency's Bioenergy Agreement

\subsubsection{IEA/BA Biomass Conversion Task - Pacific Northwest Laboratory (PNL)}

Mitchell, C.P., L. Zsuffa, and D.J. Stevens, Guest Eds. 1992. Biomass \& Bioenergy International Energy Agency Bioenergy Agreement. Progress and Achievements 1989-1991. Pergamon Press, Oxford.

Mitchell, C.P., L. Zsuffa, S. Andersson, and D.J. Stevens, eds. 1990 . Forestry. Forest Biomass and Biomass Conversion, the IEA Bioenergy Agreement (1986-1989) Summary Reports. Elsevier Applied Science, London.

Bridgwater, A.V., ed. 1994. Advances in Thermochemical Biomass Conversion, Volumes 1 and 2. Blackie Academic \& Professional Press, London.

Bridgwater, A.V. and J.L. Kuester, eds. 1988. Research in Thermochemical Biomass Conversion. Elsevier Applied Science, London.

Overend, R.P., T.A. Milne, and L.K. Mudge, eds. 1985. Fundamentals of Thermochemical Conversion. Elsevier Applied Science Publishers, London.

Nutek. 1994. IEA Bioenergy Annual Report 1993. Nutek, Stockholm, Sweden.

Nutek. 1993. IEA Bioenergy Annual Report 1992. Nutek, Stockholm, Sweden.

Nutek. 1992. IEA Bioenergy Annual Report 1991. Nutek, Stockholm, Sweden.

Mitchell, C. P., ed. 1991. Bioenergy and the Greenhouse Effect. Nutek, Stockholm, Sweden.

National Energy Administration. 1991. IEA Bioenergy Annual Report 1990. National Energy Administration, Stockholm, Sweden.

National Energy Administration. 1990. IEA Bioenergy Annual Report 1989. National Energy Administration, Stockholm, Sweden.

National Energy Administration. 1989. IEA Bioenergy Annual Report 1988. National Energy Administration, Stockholm, Sweden.

National Energy Administration. 1988. IEA Bioenergy Annual Report 1987. National Energy Administration, Stockholm, Sweden.

National Energy Administration. 1987. IEA Forestry Energy Summary Report 1978-1986. National Energy Administration, Stockholm. 


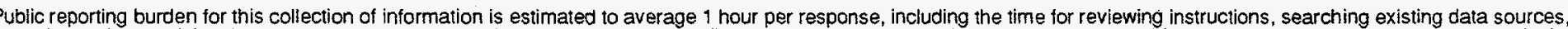

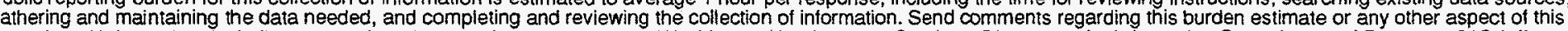

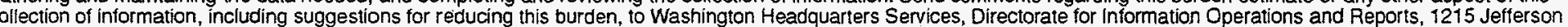

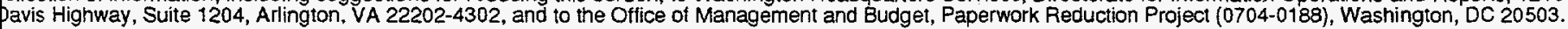

\begin{tabular}{|l|l|l}
\hline AGENCY USE ONLY (Leave blank) & $\begin{array}{c}\text { 2. REPORT DATE } \\
\text { September 1994 }\end{array}$ & $\begin{array}{l}\text { 3. REPORT TYPE AND DATES COVERED } \\
\text { Subcontract Report }\end{array}$ \\
\hline
\end{tabular}

\section{TITLE AND SUBTITLE}

Review and Analysis of the 1980-1989 Biomass Thermochemical Conversion Program

\section{FUNDING NUMBERS}

(C) AAE-3-13029-01

(TA) BF524012

\section{AUTHOR(S)}

Don J. Stevens

PERFORMING ORGANIZATION NAME(S) AND ADDRESS(ES)

8. PERFORMING ORGANIZATION REPORT NUMBER

NA

\section{SPONSORINGMONITORING} AGENCY REPORT NUMBER

NRELTP-421-7501

lational Renewable Energy Laboratory

617 Cole Boulevard

Solden, CO 80401-3393

\section{SUPPLEMENTARY NOTES}

\section{2a. DISTRIBUTION/AVAILABILITY STATEMENT}

Jational Technical Information Service

I.S. Department of Commerce

285 Port Royal Road

pringfield, VA 22161

\section{ABSTRACT (Maximum 200 words)}

his document summarizes the research performed under the Biomass Thermochemical Conversion (BTC) Program between 1980 and 1989 . It consists of an analysis it the research projects funded by the BTC Program and a bibliography of published documents. The BTC Program included a wide range of biomass conversion rojects in the areas of gasification, pyrolysis, liquefaction, and combustion. This work formed the basis of the present DOE R\&D efforts on advanced liquid fuel and ower generation systems.

\section{SUBJECT TERMS}

iomass, combustion, thermochemical, pyrolysis, liquefaction, gasification, liquid fuels

7. SECURITY CLASSIFICATION

OF REPORT

\section{SECURITY CLASSIFICATION} OF THIS PAGE
19. SECURITY CLASSIFICATION OF ABSTRACT
15. NUMBER OF PAGES

252

16. PRICE CODE

20. LIMITATION OF ABSTRACT

Standard Form 298 (Rev. 2-89) Prescribed by ANSi Std. 239-18 298-102 
